Department für Nutztierwissenschaften Abteilung Tierernährungsphysiologie der

Georg-August-Universität Göttingen

\title{
Studien zur Aminosäurenwirksamkeit beim Mastgeflügel unter spezifischer Betrachtung der schwefelhaltigen Aminosäuren
}

\author{
Dissertation \\ zur Erlangung des Doktorgrades \\ der Fakultät für Agrarwissenschaften \\ der Georg-August-Universität Göttingen
}

vorgelegt von

Jaqueline Farke

geboren in Leinefelde

Göttingen, im März 2011 
D7

Referent:

Prof. Dr. F. Liebert

Korreferent:

Prof. Dr. E. Pawelzik

Tag der mündlichen Prüfung: 12. Mai 2011 



\section{Inhaltsverzeichnis}

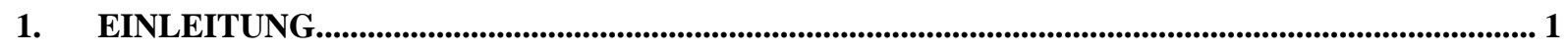

2. LITERATURÜBERBLICK ........................................................................................................ 3

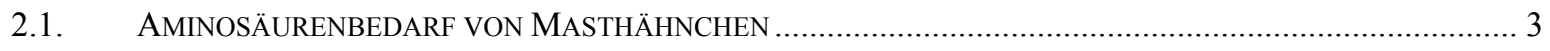

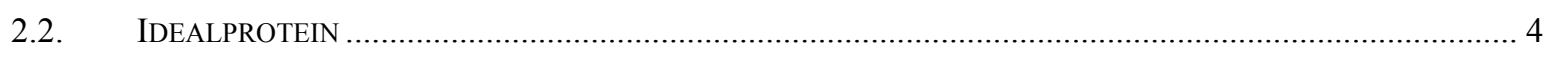

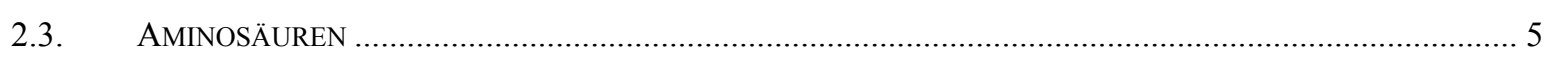

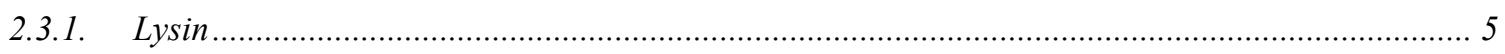

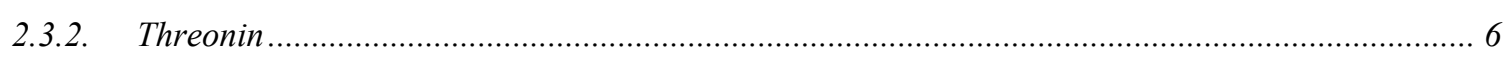

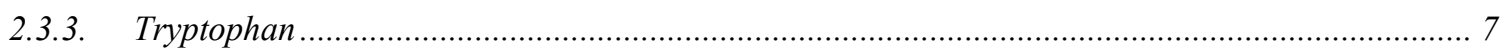

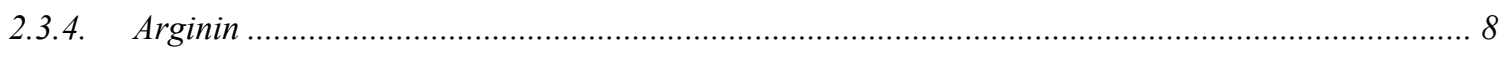

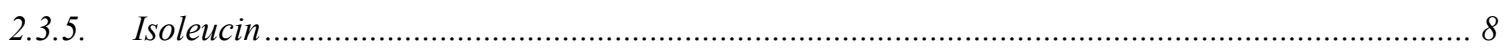

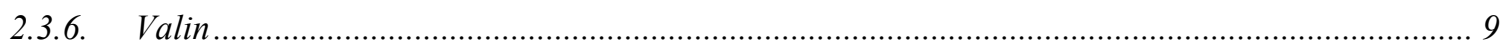

2.3.7. Schwefelhaltige Aminosäuren und deren relevante Vorstufe .................................................... 9

2.4. BESTIMMUNG DES AMINOSÄURENBEDARFES.............................................................................. 13

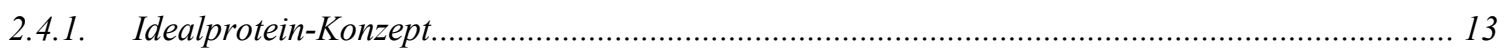

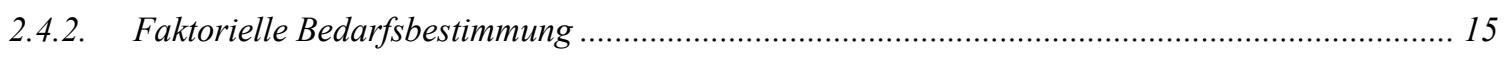

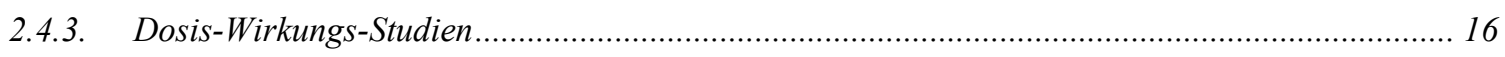

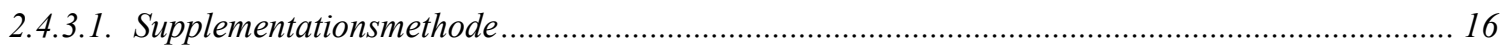

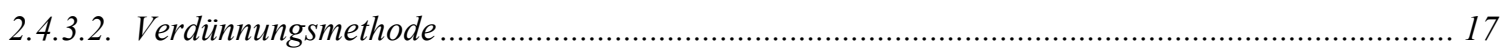

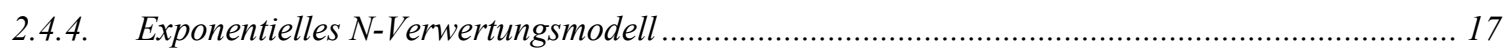

3. VERSUCHSZIELSTELLUNG .......................................................................................................... 21

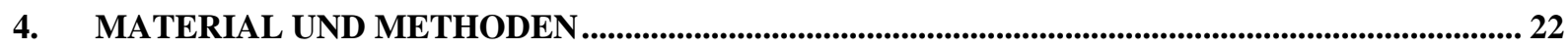

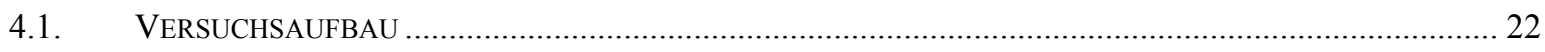

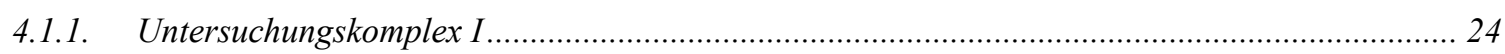

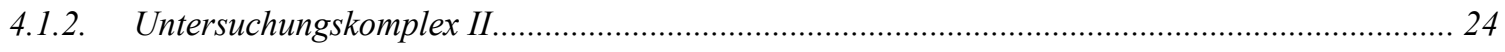

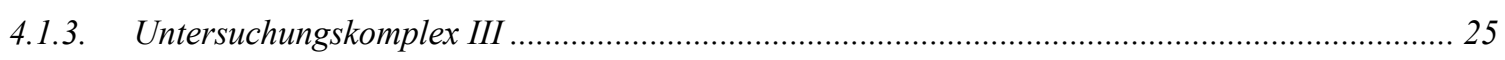

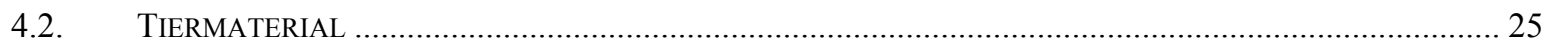

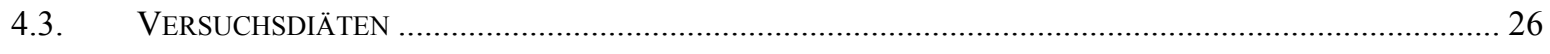

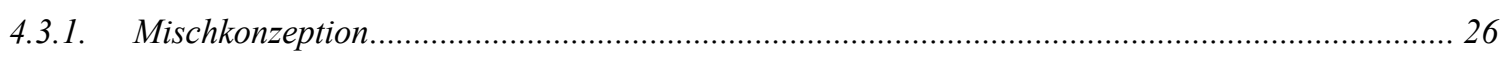

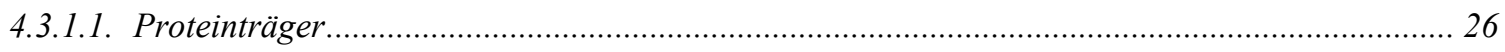

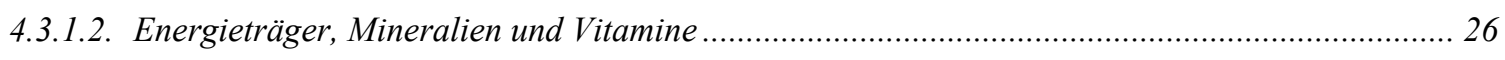

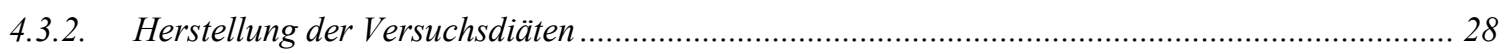

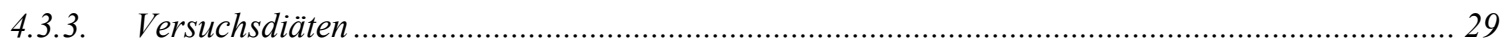

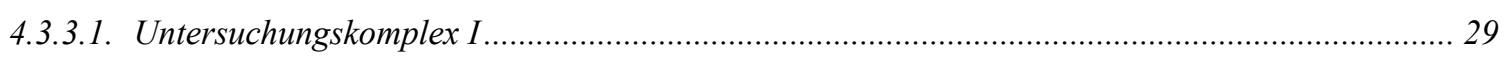

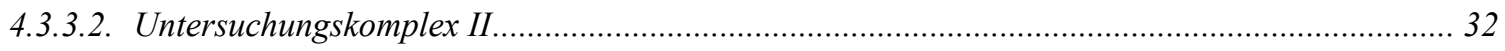

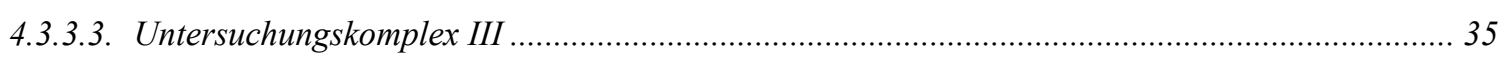

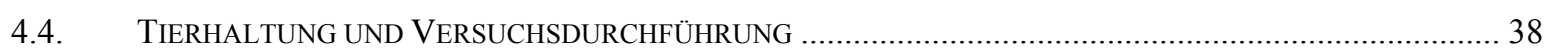




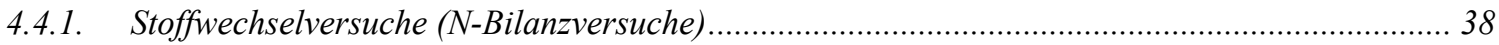

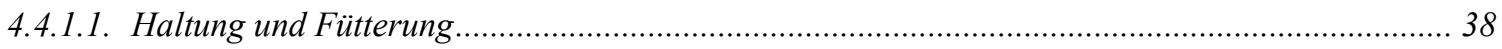

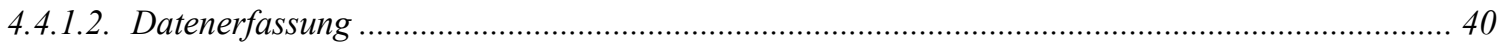

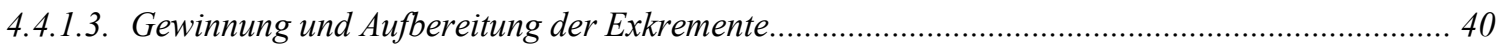

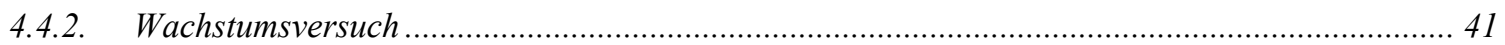

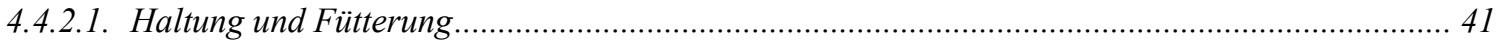

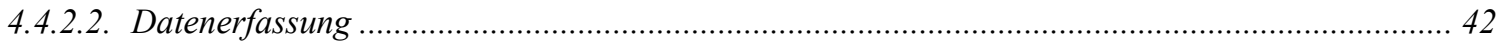

4.4.2.3. Schlachtung und Aufbereitung der Ganzkörperproben ....................................................... 42

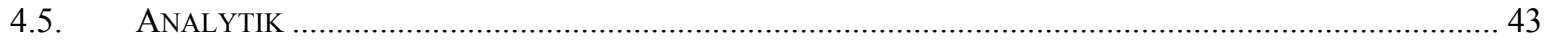

4.5.1. Analytische Aufarbeitung der Einzelkomponenten und der Futtermischungen........................... 43

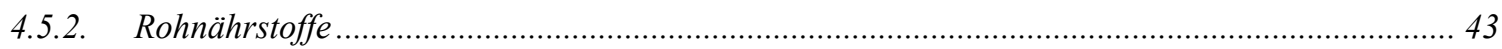

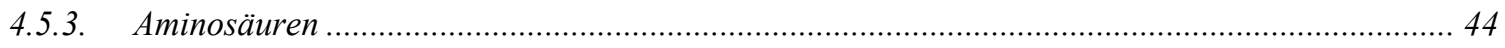

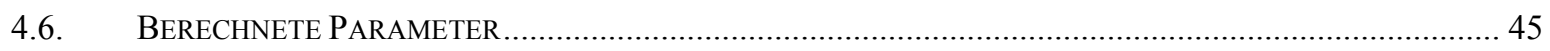

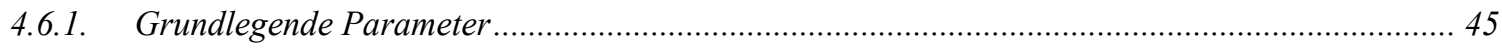

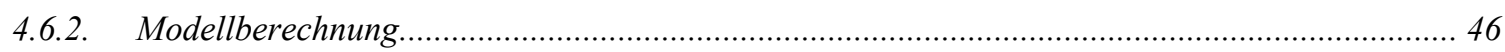

4.6.3. Berechnung der relativen Wirksamkeit von MHA zu DLM .................................................... 48

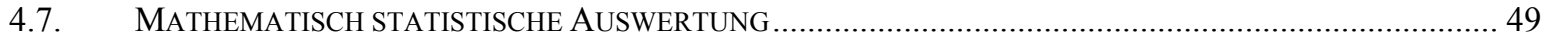

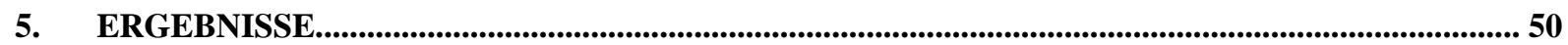

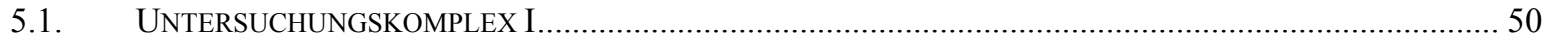

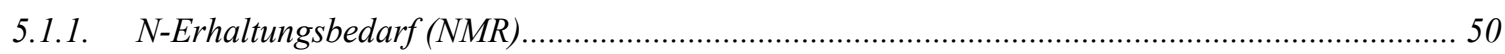

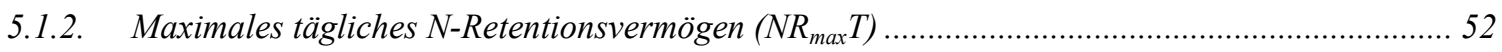

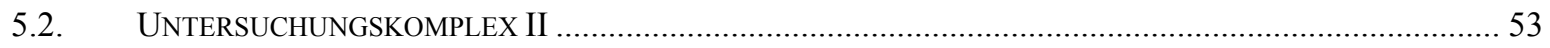

5.2.1. Ermittlung der Methioninwirksamkeit von MHA relativ zu DLM ........................................... 53

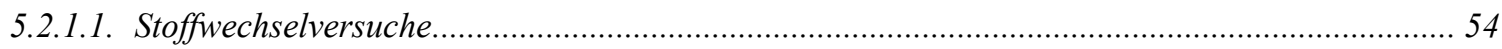

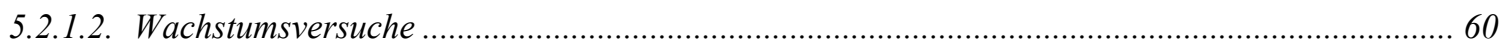

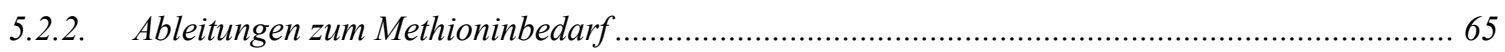

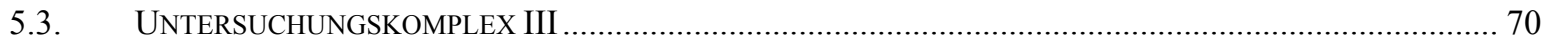

5.3.1. Ableitungen zum Idealprotein - Stoffwechselversuche …..................................................... 70

5.3.2. Ableitungen zum Idealprotein - Wachstumsversuche .............................................................. 78

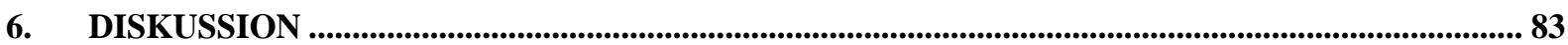

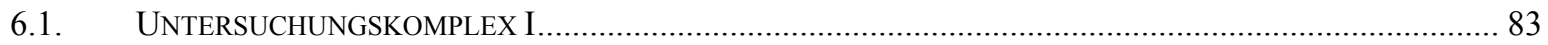

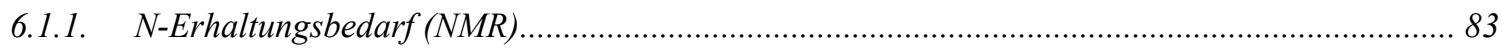

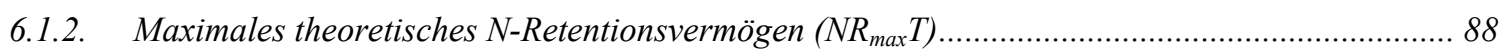

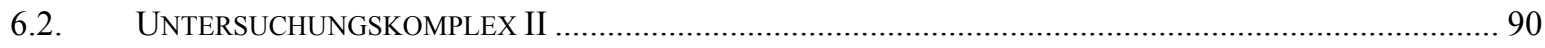

6.2.1. Ermittlung der Methioninwirksamkeit von $M H A$ relativ zu DLM ......................................... 90

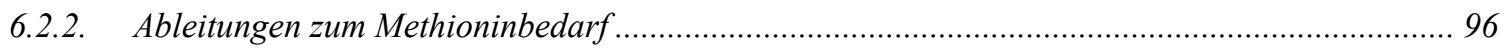

6.2.3. Ableitung zum Methionin/Cystein-Bedarf in Abhängigkeit vom Met:Cys-Verhältnis ................ 100

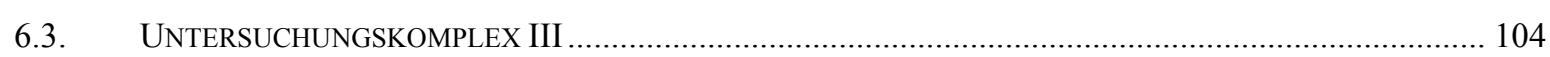

6.3.1. Einordnung und Bewertung des ermittelten idealen Aminosäurenverhältnisses (N-

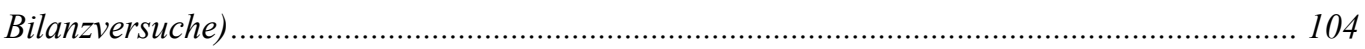


6.3.2. $\quad$ Einordnung des ermittelten idealen Aminosäurenverhältnisses (Wachstumsversuche)............. 113

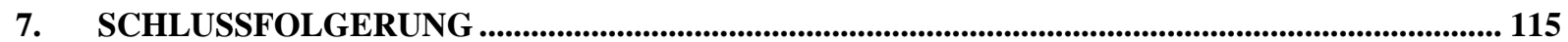

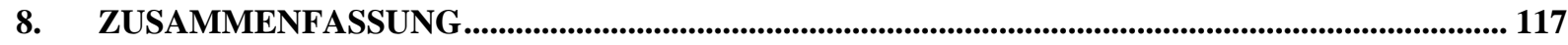

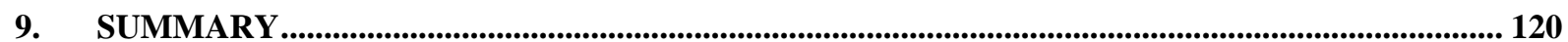

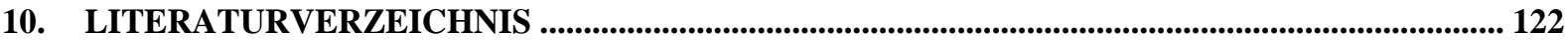

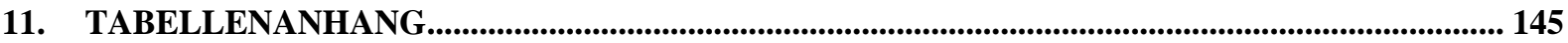




\section{Tabellenverzeichnis}

Tabelle 2.1: Angaben zum Aminosäurenbedarf von Broilern $(\mathrm{g} / \mathrm{kg})$......

Tabelle 2.2: Zusammenstellung ausgewählter ,,idealer Aminosäurenverhältnisse “ für Broiler

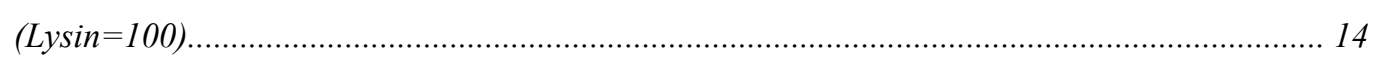

Tabelle $ґ .1:$ Ausgewählte Angaben zu den durchgeführten Versuchen (Komplex I und II)............................. 23

Tabelle 4 4.2: Ausgewählte Angaben zu den durchgeführten Versuchen (Komplex III).................................... 23

Tabelle 4.3: Zusammensetzung des Premixes: VM Broiler Vilomix (je kg Premix).......................................... 27

Tabelle 4 4.4: Zusammensetzung der Startermischungen $(\mathrm{g} / \mathrm{kg})$ im Versuch 1 ............................................. 30

Tabelle 4.5: Energie-, Rohnährstoff- \& Aminosäurengehalte der Startermischungen (\% FS) (Versuch

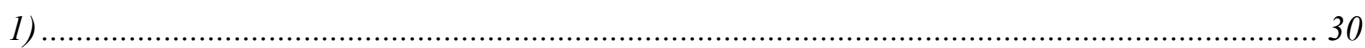

Tabelle 4 .6: Zusammensetzung der Growerfuttermischungen $(\mathrm{g} / \mathrm{kg})$ im Versuch 1...................................... 31

Tabelle 4.7: Energie-, Rohnährstoff- \& Aminosäurengehalte der Growermischungen (\% FS) (Versuch

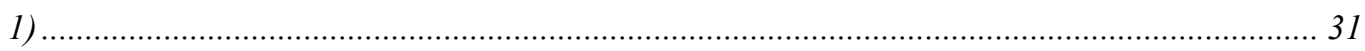

Tabelle 4 .8: Zusammensetzung der Starterfuttermischungen $(\mathrm{g} / \mathrm{kg})$ im Untersuchungskomplex II..................... 33

Tabelle 4.9: Energie-, Rohnährstoff- \& Aminosäurengehalte der Starterfuttermischungen (\% FS),

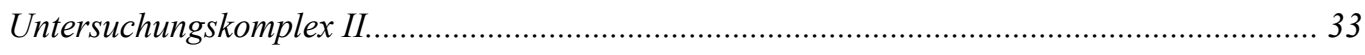

Tabelle ґ.10: Zusammensetzung der Growerfuttermischungen $(\mathrm{g} / \mathrm{kg})$ im Untersuchungskomplex II................... 34

Tabelle 14.11: Energie-, Rohnährstoff- \& Aminosäurengehalte der Growerfuttermischungen (\% FS),

Untersuchungskomplex II............................................................................................ 34

Tabelle 4.12: Zusammensetzung der Basalmischung des Untersuchungskomplexes III (g/kg) ............................ 36

Tabelle 4.13: Energie-, Rohnährstoff- \& Aminosäurengehalte der Basalmischungen (\% FS),

Untersuchungskomplex III ............................................................................................... 37

Tabelle ¡5.1: Ergebnisse des N-Bilanzversuchs differenziert nach Wachstumsperiode (Versuch 1) * ................ 50

Tabelle 5.2: Ergebnisse des Stoffwechselversuches mit DLM/MHA-Supplementation bei konstantem

Met:Cys-Verhältnis (Versuch 2) *

Tabelle 55.3: Ergebnisse des Stoffwechselversuchs mit DLM/MHA-Supplementation bei variierendem

Met:Cys-Verhältnis (Versuch 4)*

Tabelle 15.4: Ergebnisse des Wachstumsversuches mit DLM/MHA-Supplemetation bei konstantem

Met:Cys-Verhältnis (Versuch 3) *

Tabelle 5.5: Ergebnisse des Wachstumsversuchs mit DLM/MHA-Supplementation bei variierendem

Met:Cys-Verhältnis (Versuch 5) ${ }^{l}$.....

Tabelle 15.6: Kalkulierter Methioninbedarf in Abhängigkeit vom Proteinansatz, Methioninwirksamkeit und täglicher Futteraufnahme (Starterperiode, mittlere LM:500g).

Tabelle 55.7: Kalkulierter Methioninbedarf in Abhängigkeit vom Proteinansatz, Methioninwirksamkeit und täglichen Futteraufnahme (Growerperiode, mittlere LM:1800g)

Tabelle 5.8: Kalkulierter Met-Bedarf in Abhängigkeit vom täglichen XP-Ansatz und täglicher

Futteraufnahme bei variierendem Met:Cys-Verhältnis (Starterperiode, mittlere

LM:500g) 
Tabelle 55.9: Kalkulierter Met-Bedarf in Abhängigkeit vom täglichen XP-Ansatz und täglicher

Futteraufnahme bei variierendem Met:Cys-Verhältnis (Growerperiode, mittlere

LM:1800g)

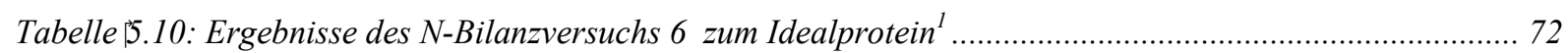

Tabelle 55.11: Ergebnisse des N-Bilanzversuchs 8 zum Idealprotein ${ }^{l}$.............................................................. 74

Tabelle 15.12: Ergebnisse des N-Bilanzversuchs 9 zum Idealprotein ${ }^{l}$.......................................................... 75

Tabelle 15.13: Geschlussfolgerte optimale Aminosäurenverhältnisse der N-Bilanzversuche differenziert

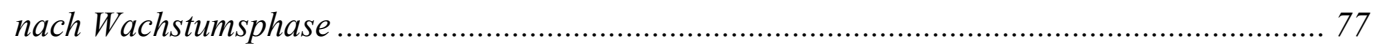

Tabelle 15.14: Ergebnisse des Wachstumsversuchs 7 zum Idealprotein ${ }^{1}$......................................................... 78

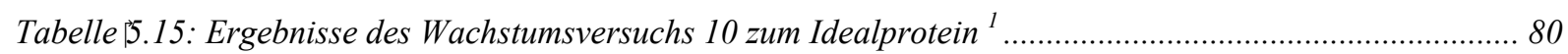

Tabelle 55.16: Geschlussfolgerte optimale Aminosäurenverhältnisse der Wachstumsversuche

differenziert nach Wachstumsphase ................................................................................. 82

Tabelle 6.1: Täglicher N-Erhaltungsbedarf (NMR) nach verschiedenen Literaturangaben ..............................86

Tabelle 16.2: Publizierte Aminosäurenverhältnisse für Broiler ............................................................ 110

Tabelle/6.3: Gegenüberstellung der abgeleiteten optimalen Aminosäurenverhältnisse (Starter und Grower) mit Literaturdaten. 


\section{Abbildungsverzeichnis}

Abbildung 2.1: Stoffwechsel des Methionins (nach FINKELSTEIN und MUDD 1966)

Abbildung 2.2: Umwandlung von D-Met und DL-MHA zu L-Methionin (nach SAUNDERSON 1991)

Abbildung 15.1: Ableitung des täglichen N-Erhaltungsbedarfes (NMR) männlicher Broilerküken der genetischen Herkunft Ross 308, differenziert nach Wachstumsphasen.

Abbildung 15.2: Ableitung von ND ${ }_{\max }$ T für männliche Broilerküken der genetischen Herkunft Ross 308, differenziert nach Wachstumsphase.....

Abbildung [5.3: Wirksamkeit von MHA relativ zu DLM (=100\%) (Versuch 2). 56

Abbildung 15.4: Wirksamkeit von MHA relativ zu DLM (=100\%) (Versuch 4) 59

Abbildung 15.5: Wirksamkeit von MHA im Vergleich zu DLM (=100\%) (Versuch 3)..... 62

Abbildung 15.6: Wirksamkeit von MHA im Vergleich zu DLM (=100\%) (Versuch 5) 64

Abbildung 15.7: Das optimale Aminosäurenverhältnis (N-Bilanzversuche, Starterperiode) 76

Abbildung 55.8: Das optimale Aminosäurenverhältnis (N-Bilanzversuche, Growerperiode). 76

Abbildung 15.9: Das optimale Aminosäurenverhältnis (Wachstumsversuche, Starterperiode) ..... 81

Abbildung 15.10: Das optimale Aminosäurenverhältnis (Wachstumsversuche, Growerperiode) 81 


\section{Tabellenverzeichnis des Anhangs}

Tabelle A 1: Aminosäurengehalte der Futtermischungen (\% FS), Versuch 1 (Starterperiode)....................... 145

Tabelle A 2: Aminosäurengehalte (\% FS), Versuch 1 (Growerperiode)........................................................... 145

Tabelle A 3: Aminosäurengehalte der Futtermischungen (\% FS), Versuch 2 - 5 (Starterperiode).................... 146

Tabelle A 4: Aminosäurengehalte der Futtermischungen (\% FS), Versuch 2 - 5 (Growerperiode) .................. 146

Tabelle A 5: Aminosäurengehalte der Basalmischung (\% FS), Versuch 6 - 10......................................... 146

Tabelle A 6: Aminosäurenmuster der Basalmischungen (Lys = 100), Untersuchungskomplex III................... 147

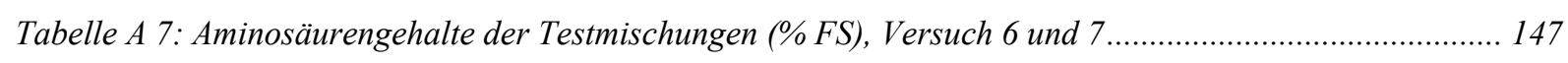

Tabelle A 8: Aminosäurengehalte der Testmischungen (\% FS), Versuch 8.................................................... 147

Tabelle A 9: Aminosäurengehalte der Testmischungen (\% FS), Versuch 9 und 10....................................... 148

Tabelle A 10: Mittlere Lebendmasse, TS-Aufnahme, N-Ausscheidung (NEX), N-Aufnahme und N-

Deposition (ND) im Versuchs 1, Starterperiode

Tabelle A 11: Mittlere Lebendmasse, TS-Aufnahme, N-Ausscheidung (NEX), N-Aufnahme und N-

Deposition (ND) im Versuchs 1, Growerperiode.

Tabelle A 12: Mittlere Lebendmasse, TS-Aufnahme, N-Aufnahme, N-Ausscheidung (NEX), N-

Deposition (ND) und Proteinqualität (b) im Versuchs 2, Starterperiode

Tabelle A 13: Mittlere Lebendmasse, TS-Aufnahme, N-Aufnahme, N-Ausscheidung (NEX), N-

Deposition (ND) und Proteinqualität (b) im Versuchs 2, Growerperiode ............................. 155

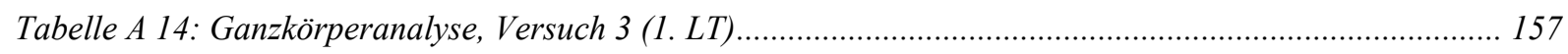

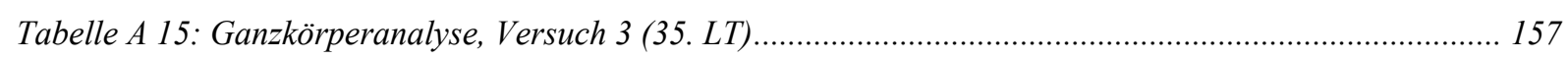

Tabelle A 16: Anfangs-, Endmasse, Futteraufnahme, Zuwachs und Futteraufwand, Versuch 3 ..................... 158

Tabelle A 17: Mittlere Lebendmasse, TS-Aufnahme, N-Aufnahme, N-Ausscheidung (NEX), N-

Deposition (ND) und Proteinqualität (b) im Versuchs 4, Starterperiode

Tabelle A 18: Mittlere Lebendmasse, TS-Aufnahme, N-Aufnahme, N-Ausscheidung (NEX), N-

Deposition (ND) und Proteinqualität (b) im Versuchs 4, Growerperiode ............................... 162

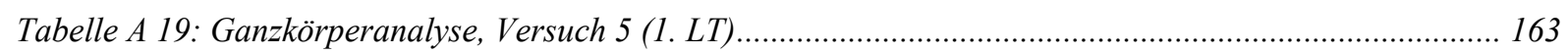

Tabelle A 20: Ganzkörperanalyse, Versuch 5 (35. LT) ............................................................................ 164

Tabelle A 21: Anfangs-, Endmasse, Futteraufnahme, Zuwachs und Futteraufwand, Versuch 5 ..................... 164

Tabelle A 22: Mittlere Lebendmasse, TS-Aufnahme, N-Aufnahme, N-Deposition (ND) und

Proteinqualität (b), Versuch 6, Starterperiode.

Tabelle A 23: Mittlere Lebendmasse, TS-Aufnahme, N-Aufnahme, N-Deposition (ND) und

Proteinqualität (b), Versuch 6, Growerperiode .................................................................. 168

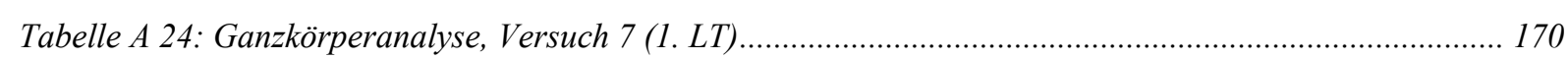

Tabelle A 25: Ganzkörperanalyse, Versuch 7 (21. LT) ............................................................................... 170

Tabelle A 26: Ganzkörperanalyse, Versuch 7 (Beginn Growerperiode, 21. LT) ........................................ 171

Tabelle A 27: Ganzkörperanalyse, Versuch 7 (35 LT).............................................................................. 171

Tabelle A 28: Anfangs- und Endmasse, Futteraufnahme, Lebendmassezunahme (LMZ) und

Futteraufwand, Versuch 7 ......................................................................................... 172 
Tabelle A 29: Mittlere Lebendmasse, TS-Aufnahme, N-Aufnahme, N-Deposition (ND) und Proteinqualität (b), Versuch 8, Starterperiode.

Tabelle A 30: Mittlere Lebendmasse, TS-Aufnahme, N-Aufnahme, N-Deposition (ND) und

Proteinqualität (b), Versuch 8, Growerperiode. 176

Tabelle A 31: Mittlere Lebendmasse, TS-Aufnahme, N-Aufnahme, N-Deposition (ND) und Proteinqualität (b) im Versuchs 9, Starterperiode. 178

Tabelle A 32: Mittlere Lebendmasse, TS-Aufnahme, N-Aufnahme, N-Deposition (ND) und Proteinqualität (b) im Versuchs 9, Growerperiode. 180

Tabelle A 33: Ganzkörperanalyse, Versuch 10 (1. LT) ............................................................................ 181

Tabelle A 34: Ganzkörperanalyse, Versuch 10 (Beginn Growerperiode, 21. LT) ........................................ 181

Tabelle A 35: Ganzkörperanalyse, Versuch 10 (21. LT) ........................................................................... 182

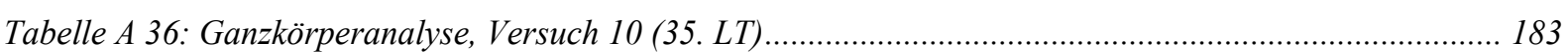

Tabelle A 37: Anfangs- und Endmasse, Futteraufnahme, Zuwachs und Futteraufwand, Versuch 10. 184 


\section{Abkürzungen / Abbreviations}

\begin{tabular}{|c|c|}
\hline $\mathrm{AA}$ & Aminosäuren \\
\hline Abb. & Abbildung \\
\hline Arg & Arginin \\
\hline $\mathrm{b}$ & Proteinqualitätsparameter im exponentiellen N-Verwertungsmodell \\
\hline $\mathrm{BC}$ & Basale Kontrollmischung \\
\hline \multirow[t]{2}{*}{$\mathrm{bc}^{-1}$} & Aminosäurenwirksamkeitsparameter im exponentiellen N- \\
\hline & Verwertungsmodell \\
\hline${ }^{\circ} \mathrm{C}$ & Grad Celsius \\
\hline $\mathrm{Ca}$ & Calcium \\
\hline $\mathrm{CaCO}_{3}$ & Calciumcarbonat \\
\hline Cys & Cystein \\
\hline $\mathrm{d}$ & Tag \\
\hline DCP & Dicalciumphosphat \\
\hline DLM & DL-Methionin \\
\hline FI & Futteraufnahme \\
\hline FS & Frischsubstanz \\
\hline g & Gramm \\
\hline His & Histidin \\
\hline I. E. & Internationale Einheiten \\
\hline Ile & Isoleucin \\
\hline $\mathrm{kg}$ & Kilogramm \\
\hline $\mathrm{kJ}$ & Kilojoule \\
\hline KMB & Alpha-Ketosäure, 2-Keto-(4-Methylthio) Butansäure \\
\hline LAA & Limitierende Aminosäure \\
\hline LAAI & LAA-Aufnahme \\
\hline Leu & Leucin \\
\hline L-Met & L-Methionin \\
\hline LT & Lebenstag \\
\hline L-Lys-HCl & L-Lysin-Monohydrochlorid \\
\hline LM & Lebendmasse \\
\hline $\mathrm{LM}_{\mathrm{kg}}{ }^{0,67}$ & Metabolische Lebendmasse \\
\hline LMZ & Lebendmassezunahme \\
\hline Lys & Lysin \\
\hline ME & Umsetzbare Energie \\
\hline
\end{tabular}




\begin{tabular}{|c|c|}
\hline Met & Methionin \\
\hline $\mathrm{MCP}$ & Monocalciumphosphat \\
\hline Met+Cys & Methionin + Cystein \\
\hline $\mathrm{mg}$ & Milligramm \\
\hline MHA & Methionin-Hydroxy-Analog, 2-Hydroxy-4-Methylthiobuttersäure \\
\hline MHA-Ca & Methionin-Hydroxy-Analoges Calciumsalz \\
\hline MJ & Megajoule \\
\hline MW & Mittelwert \\
\hline $\mathrm{N}$ & Stickstoff \\
\hline $\mathrm{NaCl}$ & Natriumchlorid \\
\hline $\mathrm{NC}$ & Negativkontrolle \\
\hline ND & Stickstoffdeposition, Stickstoffansatz \\
\hline NEX & Stickstoffausscheidung \\
\hline $\mathrm{NfE}$ & $\mathrm{N}$-freie Extraktstoffe \\
\hline NI & Stickstoffaufnahme \\
\hline NMR & Täglicher N-Erhaltungsbedarf \\
\hline $\mathrm{NR}_{\max } \mathrm{T}$ & Theoretischer Grenzwert für das maximale tägliche N- \\
\hline & Retentionsvermögen im exponentiellen N-Verwertungsmodell \\
\hline $\mathrm{P}$ & Irrtumswahrscheinlichkeit \\
\hline Phe & Phenylalanin \\
\hline $\mathrm{PNu}$ & Physiologischer Nutzwert \\
\hline PUFA & mehrfach ungesättigte Fettsäuren \\
\hline SAA & Schwefelhaltige Aminosäuren \\
\hline SD & Standardabweichung \\
\hline SP & Sammelperiode \\
\hline $\mathrm{SPC}$ & Sojaproteinkonzentrat \\
\hline Tab. & Tabelle \\
\hline Thr & Threonin \\
\hline TI & Trockensubstanzaufnahme \\
\hline $\operatorname{Trp}$ & Tryptophan \\
\hline TS & Trockensubstanz \\
\hline Val & Valin \\
\hline VDLUFA & $\begin{array}{l}\text { Verband Deutscher Landwirtschaftlicher Untersuchungs- } \\
\text { Forschungsanstalten }\end{array}$ \\
\hline XA & Rohasche \\
\hline $\mathrm{XF}$ & Rohfaser \\
\hline $\mathrm{XL}$ & Rohfett \\
\hline XP & Rohprotein \\
\hline
\end{tabular}




\section{1. $\quad$ Einleitung}

Mit zunehmender Komplexität von Produktionssystemen in der Tierproduktion steigen die Anforderungen hinsichtlich Umweltschutz und Wirtschaftlichkeit und somit auch die Ansprüche an eine bestmögliche Versorgung der Nutztiere. Eine bedarfsgerechte Proteinversorgung ist daher von großem Interesse.

Beim Geflügel beinhaltet der Bedarf an Proteinen, wie bei allen Monogastern, im eigentlichen Sinne einen Bedarf an Aminosäuren. Aufgrund der Unfähigkeit essentielle Aminosäuren selbst im Organismus zu synthetisieren, ist das Geflügel auf die bedarfsangepasste Zufuhr mit der Nahrung angewiesen. Eine zuverlässige Bewertung des Aminosäurenbedarfes ist somit unabdinglich für die Formulierung von Futtermischungen.

Bekannt ist ebenfalls, dass die Aminosäuren in einem idealen Verhältnis zueinander stehen sollen, damit das zugeführte Protein auch optimal genutzt werden kann, da eine Aminosäureimbalanz in der Nahrung zu einer Senkung der Proteinsynthese auf ein durch die erstlimitierende Aminosäure vorgegebenes Niveau führt (DE LA HIGUERA et al. 1998). Folglich kann das Leistungspotential der Tiere bei einer defizitären Versorgung nicht optimal ausgeschöpft werden. Ein weiterer Effekt der Fütterung eines idealen Proteins ist die niedrigere N-Ausscheidung der Tiere. Überschüssiger Stickstoff aus nicht nutzbaren Aminosäuren hingegen muss energieaufwendig entgiftet werden, was eine Belastung des Stoff-wechsels darstellt. Demzufolge entlastet ein optimales Aminosäureangebot den Stoffwechsel.

Aufgrund der zuvor genannten Aspekte ist die Ableitung idealer Aminosäurenverhältnisse und Aminosäurenbedarfswerte von größtem Interesse. Eine große Anzahl an diversen Modellen zur Ableitung idealer Aminosäurenverhältnisse und Bedarfswerte für wachsendes Geflügel wurde dokumentiert, wie zum Beispiel Dosis-Wirkungs-Studien mit stufenweiser Aminosäurensupplementation (BAKER et al. 2002, Baker 2003) oder die Ableitung idealer Verhältnisse, bei der man die Veränderung der Stickstoffausscheidung aufgrund der stufenweisen Depletion mit einer Aminosäure betrachtet (WANG und FULLER 1989).

Studien zum Lysin- und Threoninbedarf von wachsendem Geflügel (SAMADI und LIEBERT 2007a, b, 2008) sowie von Schweinen (THONG und LIEBERT 2004a, b) belegen die Eignung des exponentiellen N-Verwertungsmodells (GEBHARDT 1966, LIEBERT und 
GEBHARDT 1986) zur Ableitung eines nach Leistung und Verfügbarkeit der Futteraminosäuren differenzierten Aminosäurebedarfs von wachsenden Monogastriern.

In Anlehnung daran war das Ziel der vorliegenden Arbeit, auf Grundlage des exponentiellen N-Verwertungsmodelles (GEBHARDT 1966) zunächst den N-Erhaltungsbedarf und das maximale theoretische N-Retentionsvermögen als Modellparameter für Broilerküken der genetischen Herkunft Ross $308 \mathrm{zu}$ bestimmen. Darauf aufbauend sollten experimentell die Methioninwirksamkeit in Diäten für Broiler dieses Genotyps ermittelt werden, auf deren Grundlage leistungsabhängige Ableitungen zum Methioninbedarf ermöglicht werden sollten. Darüber stand, eingeordnet in das Idealprotein-Konzept beim Mastgeflügel, die Ableitung optimaler Verhältnisse der Aminosäuren Lysin, Threonin, Tryptophan, Arginin, Isoleucin und Valin im Mittelpunkt der Untersuchungen. 


\section{Literaturüberblick}

In diesem Kapitel wird eine Übersicht über den aktuellen Kenntnisstand vermittelt. Als Einstieg dienen Angaben zum Aminosäurenbedarf von Mastgeflügel. Der folgende Abschnitt der Literaturübersicht bezieht sich auf Untersuchungen zum Idealprotein. Ferner wird auf die in dieser Arbeit betrachteten Aminosäuren eingegangen sowie eine Übersicht über deren Funktion und Stoffwechselvorgänge gegeben. Dabei wird das Augenmerk speziell auf die schwefelhaltigen Aminosäuren gelegt. Abschließend erfolgt eine Darstellung ausgewählter Verfahren/Konzepte zur Aminosäurenbedarfsableitung.

\subsection{Aminosäurenbedarf von Masthähnchen}

Der in vivo abgeleitete Aminosäurenbedarf weist innerhalb einer Tierart eine Abhängigkeit von zahlreichen Faktoren auf. Während in erster Linie die Leistung des Tieres den Bedarf bestimmt, spielen zudem genetische Herkunft, Alter, Umwelt, Kondition der Tiere sowie nutritive Einflussfaktoren eine Rolle (HOFFMANN und GEBHARDT 1973, LIEBERT und GEBHARDT 1986, 1988b, LECLERCQ 1998, BAE et al. 1999, SCHUTTE und DE JONG 2004, BREGENDAHL 2008). Unter Betrachtung der zuvor genannten Punkte lässt sich die Schwierigkeit erklären, Aminosäurenbedarfswerte unterschiedlicher Autoren miteinander zu vergleichen, da verschiedene Parameter, Methoden und variierende Leistungshöhen zugrunde gelegt wurden.

Die von verschiedenen Quellen gegebenen Bedarfsempfehlungen an essentiellen Aminosäuren von Broilern unterschiedlicher Wachstumsperioden sind in Tabelle 2.1 zusammengefasst. Es ist ersichtlich, dass gemäß dieser Quellen Unterschiede in den entsprechenden

Empfehlungen bestehen. Es sollte jedoch beachtet werden, dass es sich bei diesen Bedarfsvorgaben um Empfehlungen für mittlere Leistungen der Populationen handelt. Die zuvor genannten Punkte können als Ursache für die Abweichungen im Aminosäurenbedarf angeführt werden. Zudem wird deutlich, dass sich mit zunehmendem Alter der Tiere der prozentuale Bedarf an Aminosäuren reduziert und die Broiler somit geringere Anforderungen an Aminosäuren im Futter stellen. Die in der Tabelle 2.1 zitierten Empfehlungen des NRC 


\section{Literaturüberblick}

(1984)

gelten für den 1. - 21. LT unter der Bedingung, dass der Rohproteingehalt 23 Prozent und die umsetzbare Energie 13,40 MJ/kg im Futter beträgt.

Tabelle 2.1: Angaben zum Aminosäurenbedarf von Broilern (g/kg)

\begin{tabular}{|c|c|c|c|c|c|c|c|}
\hline \multirow{2}{*}{$\begin{array}{l}\text { Quelle } \\
\text { Alter }\end{array}$} & \multicolumn{2}{|c|}{$\begin{array}{c}\text { BAKER et al. } \\
\text { (1993)* }\end{array}$} & \multirow{2}{*}{$\begin{array}{c}\begin{array}{c}\text { NRC } \\
(\mathbf{1 9 8 4})\end{array} \\
0 .-3 . \text { LW }\end{array}$} & \multicolumn{2}{|c|}{$\begin{array}{l}\text { NRC } \\
\text { (1994) }\end{array}$} & \multicolumn{2}{|c|}{$\begin{array}{c}\text { GFE } \\
(1999)\end{array}$} \\
\hline & $0 .-3 . \mathrm{LW}$ & 3. $-6 . \mathrm{LW}$ & & $0 .-3 . \mathrm{LW}$ & $3 .-6 . \mathrm{LW}$ & $\overline{0 .-3 . \mathrm{LW}}$ & $3 .-6 . \mathrm{LW}$ \\
\hline Lysin & 10,7 & 8,1 & 12,0 & 11,0 & 10 & 12,4 & 11,25 \\
\hline Methionin & 3,9 & 2,9 & 5,0 & 5,0 & 3,8 & 4,5 & 4,3 \\
\hline Threonin & 7,2 & 5,7 & 8,0 & 8,0 & 7,4 & 8,2 & 8,4 \\
\hline Tryptophan & 1,7 & 1,4 & 2,3 & 2,0 & 1,8 & 1,9 & 1,9 \\
\hline Leucin & 11,7 & 8,8 & 13,5 & 12,0 & 10,9 & 13,9 & 14,0 \\
\hline Isoleucin & 7,2 & 5,6 & 8,0 & 8,0 & 7,3 & 8,5 & 8,6 \\
\hline Arginin & 11,2 & 8,7 & 14,4 & 12,5 & 11,0 & 13,3 & 13,0 \\
\hline Valin & 8,2 & 6,5 & 8,2 & 9,0 & 8,2 & 11,9 & 12,1 \\
\hline Histidin & 3,4 & 2,6 & 3,5 & 3,5 & 3,2 & 3,9 & 3,8 \\
\hline
\end{tabular}

* (verdauliche Basis)

\subsection{Idealprotein}

Bei wachsendem Geflügel existieren neben den essentiellen Aminosäuren (AS) noch Aminosäuren, die im Organismus synthetisiert werden können. Weisen alle essentiellen Aminosäuren sowie die Summe der nicht-essentiellen Aminosäuren im Futter vergleichbar ausgeprägte Limitationen auf, so spricht man vom „Idealprotein“ (JEROCH 2004).

Vereinfacht lässt sich darunter ein Aminosäurenmuster im Futterprotein beschreiben, bei dem das relative Verhältnis der essentiellen Aminosäuren im Vergleich zum Lysin genau den Anforderungen des tierischen Organismuses entspricht und keine der essentiellen Aminosäuren limitierend wirkt oder im Überschuss vorliegt.

Der Überschuss einer Aminosäure im Futter kann in einem gesteigerten Bedarf an einer strukturell oder chemisch verwandten Aminosäure resultieren. NESHEIM et al. (1972) fand heraus, dass eine überschüssige Aminosäure zu einer beschleunigen Katabolisierung anderer Aminosäuren führt und somit den Bedarf dieser Aminosäuren erhöht. Solche Interaktionen bestehen beispielsweise zwischen Lysin und Arginin (D`MELLO und LEWIS 1970a, NIESS 


\section{Literaturüberblick}

1978), Leucin und Valin sowie zwischen Threonin und Tryptophan (D`MELLO und LEWIS 1970b).

Die Zusammensetzung eines idealen Proteins richtet sich nach dem Bedarf und damit nach dem physiologischen Zustand des Tieres. Eine Aminosäurenzusammensetzung entsprechend dem Idealprotein führt zu einer optimalen Nutzung aller essentiellen Aminosäuren und zu einer effizienten Proteinverwertung. Folglich kann das Leistungspotential der Tiere effizienter genutzt werden.

Zur Bestimmung des Idealproteins können verschiedene Methoden angewendet werden. Neben einer Vielzahl an Ableitungen anhand von Literaturdaten, existieren noch eine Reihe von Konzepten zur Aminosäurenbedarfsbestimmung, die im Kapitel 2.4 näher erläutert werden. Dabei kann sich das Profil auf Bruttoaminosäuren bzw. auf verdauliche Aminosäuren beziehen. Bisher wurden solche Idealproteine für wachsende Schweine (WANG und FULLER 1989), Broiler (BAKER und HAN 1994) und Legehennen (JAIS et al. 1995, KIRCHGESSNER et al. 1995, BREGENDAHL et al. 2008) experimentell ermittelt.

\subsection{Aminosäuren}

Aminosäuren gehören als Bausteine der Proteine und Peptide zu den wichtigsten organischen Stoffen der lebenden Zelle. Im Folgenden werden die Aminosäuren Lysin, Threonin, Tryptophan, Arginin, Isoleucin, Valin und Methionin/Cystein separat betrachtet.

\subsubsection{Lysin}

Studien belegen, dass die Aminosäure Lysin (Lys) im tierischen Organismus eine zentrale und essentielle Rolle bei der Proteinsynthese einnimmt, nur an wenigen Umsetzungsprozessen beteiligt und hauptsächlich im Ansatz zu finden ist (CHUNG und BAKER 1992, EMMERT und BAKER 1997). Die relative Bedeutung von Lys ist im Erhaltungsumsatz im Vergleich zu anderen Aminosäuren wie z.B. Threonin, Isoleucin, Valin oder Cystein geringer einzuschätzen (BAKER 1995, EMMERT und BAKER 1997) und steigt nach Ansicht von EMMERT und BAKER (1997) mit zunehmendem Alter der Tiere vergleichsweise langsamer 


\section{Literaturüberblick}

an. Die Empfehlungen zur Lysinversorgung geben Werte zwischen 9,0 und 12,5 g/kg Futter vor. Das NRC (1994) empfiehlt bei Broilern bis zur 3. Lebenswoche 11,0 g Lys, zwischen der 3. und 6. Woche 10,0 g Lys und zwischen der 6. und 8. Woche 8,5 g Lys je kg Futter. GRISONI et al. (1991) zeigten, dass die Bandbreite der Lysinbedarfswerte von Broilern sehr stark von den zu optimierenden Parametern abhängt. Insofern lag der Lysinbedarf von männlichen Broilern (4. bis 7. Lebenswoche) bei 9,8 g/kg Futter, wenn die Optimierung des Futteraufwandes im Fokus der Betrachtung stand. Sollte hingegen der Fettansatz minimiert werden, waren vergleichsweise deutlich höhere Lysingehalte von etwa $11,0 \mathrm{~g} / \mathrm{kg}$ Futter erforderlich. Eine höhere Konzentration an Lys wurde auch verlangt, wenn der Bezugspunkt die Erlangung eines optimalen bzw. maximalen Brustfleischanteils, anstatt des optimalen bzw. maximalen Zuwachses oder des Futteraufwandes war (BAKER et al. 2002, REZAEI et al. 2004). Unter Berücksichtigung des Futteraufwandes kalkulierten HAN und BAKER (1994) einen Lys-Bedarf von 8,9 g/kg Futter bzw. 8,5 g/kg Futter auf Basis verdaulichtem Proteins für männliche bzw. weibliche Broiler, was in einer Mais-Soja-Futtermischung einem Gesamtlysingehalt von $10,1 \mathrm{~g} / \mathrm{kg}$ für männlichen und $9,7 \mathrm{~g} / \mathrm{kg}$ für weibliche Broiler entsprach. ROSTAGNO et al. (2007) empfahlen für weibliche und männliche Cobb-Broiler 11,2 und 11,6 g Lysin je kg Futter. DOZIER et al. (2009) kalkulierten einen Lys-Bedarf im Futter von 10 g/kg Futter bzw. 11 g/kg Futter auf Basis verdaulichtem Proteins.

\subsubsection{Threonin}

Neben seiner Funktion als Körperproteinbaustein kommen Threonin (Thr) noch einer Vielzahl anderer Funktionen im Organismus zu, welche die Vergleichbarkeit von Versuchsergebnissen erschweren. L-Thr ist beispielsweise an der Synthese von Körperproteinen, wie Muskeln und Federn, Verdauungsenzymen und Immunsubstanzen beteiligt. Die Katabolisierung liefert z.B. Glycin und Pyruvat (KIDD und KERR 1996, KIDD 2000).

Die Untersuchungen zum Threoninbedarf von Broilern zeigen eine große Variationsbreite in den Bedarfszahlen, die einen Bereich von 5,5 bis 7,9 $\mathrm{g}$ Thr je $\mathrm{kg}$ Futter in der Ration einschließt. Im Hinblick auf Imbalanzen im Aminosäurenmuster kann der Threoninbedarf empfindlich reagieren. ROBBINS (1987) wie auch RANGEL-LUGO und AUSTIC (1994) zeigten, dass der Threoninbedarf vom Proteingehalt in der Ration und den Proteinquellen abhängt. In drei Versuchen bestätigten RANGEL-LUGO und AUSTIC (1994), dass der Threoninbedarf von jungen Broilern vom Rohproteingehalt der Ration beeinflusst wird. In 


\section{Literaturüberblick}

Mischungen mit 20 bzw. 25\% Rohprotein wurde eine maximale Zunahme bei 7,6 g bzw. 9,0 g Thr je kg Futter und eine optimale Futterverwertung bei 6,9 bzw. 9,0 g Thr je kg Futter erreicht. Mit jeder Erhöhung des Rohproteingehaltes um 1\% in der Ration stieg der Threoninbedarf in diesem Bereich um 0,02 bis 0,03\%. BERTRAM und Mitarbeiter (1989) konnten aus ihren Versuchen mit jungen Broilern zeigen, dass der höchste Zuwachs mit einem Threoningehalt im Futter von 7,7 g Thr je kg Futter erreicht wurde, während die beste Futterver-wertung bereits bei einem Threoningehalt im Futter von 7,2 g/kg Futter lag. WEBEL et al. (1996) postulierten, dass die Gehalte an Thr von der 3. bis 6. bzw. von der 6. bis 8. Lebenswoche mit 7,0 g bzw. 6,0 g Thr je kg Futter bedarfsdeckend waren, um ein optimales

Wachstum und eine günstige Futterverwertung zu gewährleisten. AYASAN et al. (2009) führte Versuche mit Ross 308 Broilern im Altersabschnitt 22. - 42. LT durch und gab Bedarfskonzentrationen von $0,74 \% \mathrm{Thr}$ im Futter an. Um eine optimale Futterverwertung zu erhalten, gaben AHMADI und GOLIAN (2010) für Diäten mit 18,71\% XP 0,75\% Thr an.

\subsubsection{Tryptophan}

Das Tryptophan (Trp) ist eine für das Geflügel unentbehrliche Aminosäure, die dem Organismus in erster Linie als Baustein zur Proteinsynthese dient. Daneben erfüllt diese Aminosäuren zahlreiche weitere Funktionen im Stoffwechsel (z.B. Vorstufe des Niacins, Funktion im Leberstoffwechsel) der Tiere. Die Bedarfempfehlungen für Trp schwanken in einem Bereich zwischen 1,5 bis 2,2 g Trp je kg Futter. STEINHART und KIRCHGESSNER (1984) haben zur Bedarfermittlung einen Wachstumsversuch mit verschiedenen Zulagen von L-Trp durchgeführt. Die besten Ergebnisse hinsichtlich Gewichtszunahme, Futteraufnahme und Futteraufwand konnten mit 2,2 g Trp je kg Futter erzielt werden. FREEMANN (1979) bestimmte den Bedarf für männliche Broilerküken (0. - 7. LT) mit 2,2 g Trp je kg Futter. SMITH und WALDROUP (1988) berichteten, dass bei männlichen Broilern (0. - 21. LT) ein Tryptophangehalt von 1,6 g je kg Futter ausreicht. In Folge des Anstieges des Trp-Gehaltes auf einen Wert von 2,6 g/kg, konnten die Autoren keinen signifikanten Einfluss auf die Futteraufnahme, Gewichtszunahme oder Futteraufwand feststellen. Die Bedarfsempfehlungen des NRC (1994) für Mastgeflügel in den ersten drei Lebenswochen beziehen sich auf 2,0 $\mathrm{g}$ Trp je kg Futter. LARBIER und LECLERCQ (1994) postulierten, dass der Trp-Bedarf ausgedrückt als Relation zum Lysingehalt in der Ration 19,2\% und 18\% betragen sollte. Nach 


\section{Literaturüberblick}

LIN und HSU (1994) konnte ein Gehalt an Trp von 1,8 g Trp je kg Futter, bedingt durch einen relativ hohen Proteingehalt $(22,6 \%)$ zu guten Wachstumsleistungen führen.

\subsubsection{Arginin}

Die Aminosäure Arginin (Arg) ist für optimales Wachstum und N-Bilanz in wachsenden Tieren unentbehrlich (BORMAN et al. 1946, MILNER et al. 1974). Während bei ausgewachsenen Säugetieren Arg zur Bedarfsdeckung synthetisiert werden kann, sind Küken nicht in der Lage Arg de novo zu synthetisieren und weisen daher eine komplette Abhängigkeit vom diätetischen Arg auf, um ihren Bedarf zur Proteinsynthese oder anderen Funktionen (z. B. förderliche Effekte auf Immunstatus und Wundheilung) zu decken (BARBUL et al. 1980, 1990, KIDD et al. 2001, TAMIR und RATNER 1963). Arg wirkt in Verbindung mit Lysin, indem Lys den Transport von Arg aus dem Blut in die Zellen verzögert und somit für eine erhöhte Arginin-Plasmakonzentration sorgt. Methionin zeigt ebenfalls eine Interaktion mit Arginin. Beide Aminosäuren werden u. a. für die Synthese von Kreatin benötigt (KESHAVARZ und FULLER 1971). Für den Argininbedarf von Broilern (0. - 18. LT) empfiehlt das NRC (1994) 12,5 g Arginin je kg Futter. CORZO und KIDD (2003) haben zur Bedarfermittlung eine Studie mit Broilern vom 0. - 18. LT zur Bestimmung des Arginin-bedarfs durchgeführt. Die Ergebnisse zeigten, dass Lebendmassezuwachs und Futteraufwand mit einer Konzentration von 1,15\% und 1,28\% Arg im Futter optimierten werden konnten.

\subsubsection{Isoleucin}

Das Isoleucin (Ile) ist potentiell limitierend in Diäten mit geringen Proteingehalten für Legehennen mit Supplementationen von Lysin, Methionin und Tryptophan (KESHAVARZ 1997). KLAIN et al. (1960) und DEAN und SCOTT (1965) empfohlen einen Ile-Gehalt für Geflügel (0. - 21. LT) zwischen $0,6 \%$ und $0,8 \%$ im Futter. BARBOUR und LATSHAW (1992) postulierten, dass der Bedarf zwischen 7,2 und 8,4 g Ile je kg Futter variiert. Im Anschluss an die zuvor genannten Bedarfswerte von Küken im Altersabschnitt 0. - 21. LT befinden sich nur relativ wenig Studien in der Literatur bezüglich der Bewertung des Isoleucinbedarfes von adulten Tieren ab dem 21. LT. Das NRC (1994) empfiehlt 0,73\% Ile in 


\section{Literaturüberblick}

der Diät von Broilern zwischen dem 21. und 42. LT. KIDD et al. (2000) bewertete den Bedarf für männliche Broiler mittels Gaben von adäquaten und defizitären Isoleucinkonzentrationen (NRC 1994) im Futter und gaben an, dass Broiler, die mit 90\% des empfohlenen Isoleucinbedarfs versorgt wurden einen verminderten Brustfleischanteil aufwiesen.

\subsubsection{Valin}

Diese unentbehrliche Aminosäure hat einen bedeutenden Einfluss auf die Funktionen von Muskeln und ist für die Aufrechterhaltung von Nervenfunktionen von großer Bedeutung (SCHMIDT und SCHMIDT 2004). Sie kann im Intermediärstoffwechsel als Vorstufe von Neurotransmittern fungieren. Die Literaturdaten bezüglich des Valinbedarfs variieren bei Broilern vom 0. - 21. LT in einem Bereich zwischen 6,9 und $11 \mathrm{~g}$ Val je kg Futter (KLAIN et al. 1960, DEAN und SCOTT 1965, BAKER et al. 1979, NRC 1984, NRC 1994, GFE 1999). Baker et al. (2002) nutzten Broilerdiäten mit ansteigenden Valinkonzentrationen. Basierend auf Lebendmassezuwachs und Futteraufwand als Antwortkriterium berichteten Baker et al. (2002) von einem Valinbedarf von 8,1 und 8,2 g/kg Futter (Verdaulichkeitsbasis). BAE et al. (1999) verwiesen auf einen Val-Bedarf von 7,7 g/kg Futter basierend auf Lebendmassezuwachs und Futteraufwand unter Verwendung von Mischungen mit $230 \mathrm{~g}$ XP/kg Futter. FARRAN und THOMAS (1990) berichteten von Bedarfswerten zwischen 8,8 und 9,0 g Val je kg Futter für Lebendmassezuwachs und Futteraufwand.

\subsubsection{Schwefelhaltige Aminosäuren und deren relevante Vorstufe}

Die schwefelhaltigen Aminosäuren (SAA) Methionin (Met) und Cystein (Cys) sind schwefelhaltige proteinogene Aminosäuren. Met, welches im Geflügelfutter häufig die erstlimitierende Aminosäure (SAUER et al. 2008, BUNCHASAK 2009) darstellt, nimmt im tierischen Organismus verschiedene Funktionen wahr. Eine relevante Funktion hat Met in der Proteinsynthese, wobei im Rahmen der Translation diese als Starter-Aminosäure fungiert. VIEIRA et al. (2004) hoben v. a. die Unentbehrlichkeit der SAA für Muskelansatz und Federsynthese hervor. Eine besondere Bedeutung liegt auch darin, dass Met die Rolle eines Schwefel- sowie Methyldonators im Stoffwechsel wahrnimmt (BUNCHASAK 2009). Die 


\section{Literaturüberblick}

Methylübertragung erfolgt nach einer Aktivierung mit ATP, welches mit Methionin das sogenannte ,aktive Methyl“ bildet und als Co-Substrat für viele Methyltransferasen fungiert (HEIMANN 1976). Als Methylgruppen-Donator ist es unter anderem für die Biosynthese von Cholin, Adrenalin, Nukleinsäuren, Liponsäure und Taurin relevant (Abbildung 2.1). Weiterhin besteht ein Bedarf dieser Aminosäure zur Synthese von Polyamiden, die eine Rolle bei der Nukleolus- und Zellteilung besitzt (BUNCHASAK 2009).

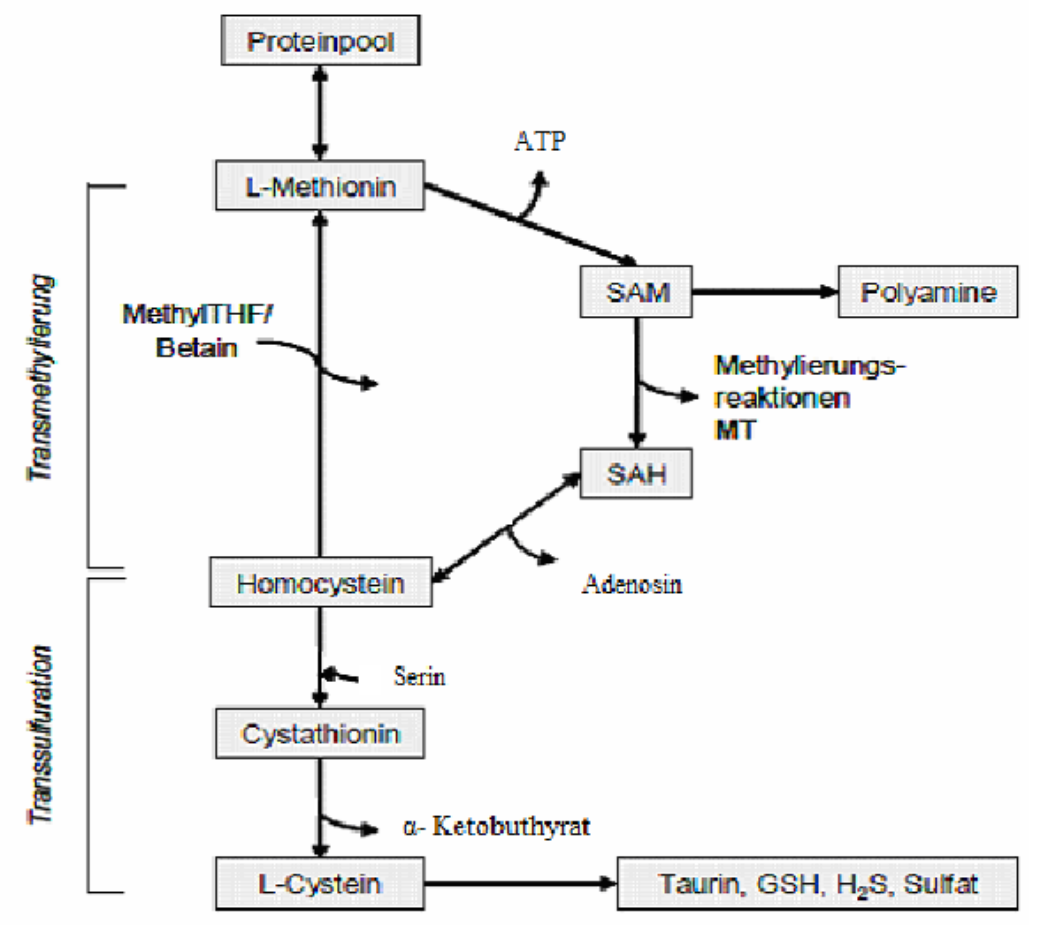

Abbildung 2.1: Stoffwechsel des Methionins (nach FINKELSTEIN und MUDD 1966)

Cystein und sein Dimer Cystin erfüllen bei Zellvorgängen eine besondere Funktion als Oxydations-Reduktion-System. Die Bildung der Aminosäure Cystein ist mit dem Abbau von Met verknüpft, während eine Umkehrung der Reaktionsschritte im tierischen Organismus hingegen nicht möglich ist. Aus diesem Grund besteht die Möglichkeit den Bedarf an SAA allein durch Met zu decken, jedoch nicht durch Cystein.

Das NRC (1994) gibt den Bedarf an Met mit 5,0 g/kg Futter an (NRC 1984, 1994). MORRIS et al. (1992) berichteten, dass der Methioninbedarf linear mit dem Proteingehalt der Ration ansteigt. Für Rationsgestaltungen bei Broilern empfehlen sie, unabhängig vom Proteingehalt der Ration immer ein Methioningehalt von mindestens 2,5\% im Rohprotein einzustellen. HUYGHEBAERT et al. (1994) konnte aus Untersuchungen ermitteln, dass der Bedarf an Met und Cys für eine optimale Mastleistung im Altersabschnitt zwischen 15 und 35 


\section{Literaturüberblick}

Tagen über $0,86 \%$ bei $20,5 \%$ Rohprotein liegt, bzw. $0,95 \%$ Met bei $24,5 \%$ Rohprotein. Zudem verbessert sich die Schlachtkörperqualität durch erhöhte Zulagen an DL-Methionin. BAKER et al. (1996) berichten, dass im Altersabschnitt 3. bis 6. Woche die SAA einen Anteil von 7,2 g/kg im Futter betragen sollten. LECLERCQ et al. (1993) waren der Auffassung, dass Broiler mit einem hohem Potential für den Proteinansatz höhere Gehalte an SAA im Futter benötigen.

Für den wachsenden Broiler ist Met eine der wichtigsten Aminosäuren. Eine Unter- oder Überversorgung kann eine Aminosäurenimbalanz verursachen. Beim Defizit an Met kommt es zu einer Reihe von signifikant negativen Einflüssen. Neben Inhibitation des Wachstums, negativen Einflüssen auf die Futterverwertung, den Feder- und Körperproteinansatz sowie auf die Konzentration an freien SAA im Blutplasma (LECLERCQ et al. 1993) führt ein Mangel an L-Methionin auch zu schweren Leberschäden (Leberzirrhose, -verfettung) sowie zu einer Induktion metabolischer Erkrankungen. Der Zusatz von Met zu Geflügeldiäten korrelierte mit der Tendenz zur Reduktion von Körperfett (ROSTAGNO et al. 1995) und der Verbesserung der Wachstumsleistung. Auf der anderen Seite führt eine überschüssige Fütterung von Met zu einer Verschlechterung des Wachstums (HARPER et al. 1970). Der Grund dafür liegt darin, dass Met im Stoffwechsel für die Methylgruppenlieferung verantwortlich ist. Eine Begrenzung bei der Methylgruppenübertragung führt zu einer Beschränkung in der Futterproteinverwertung bzw. der Proteinsynthese im Körper.

Da Met in kommerziellen Mischungen für das Geflügel häufig die erstlimitierende Aminosäure darstellt, wird es supplementiert, um den Bedarf an SAA für Wachstum und Erhaltung zu decken. Synthetische Methioninquellen sind DL-Methionin (DLM) oder DL-2-Hydroxy-4Methylthiobuttersäure, auch als Methionin-Hydroxy-Analog (MHA) bekannt, welches als Calciumsalz oder als freie Säure zur Verfügung steht. Während DLM eine Reinheit von 99\% besitzt, verfügt MHA noch über 12\% Wasser und weist daher nur eine Reinheit von $88 \%$ auf (SAUER et al. 2008).

Methionin-Hydroxy-Analog (MHA) ist ein wichtiges kommerzielles Produkt, dass einen SAA-Spareffekt aufweist. Dieses Produkt besteht aus einem 1:1 Verhältnis von D- und LIsomeren (BAKER und BOEBEL 1980). Über die Wirksamkeit (MHA relativ zu DLM) liegen in der Literatur unterschiedliche Befunde vor. Obwohl umfangreiche Studien hinsichtlich der Absorption von MHA durchgeführt wurden, erfolgten relativ wenige Untersuchungen zur Beschreibung der Stoffwechselvorgänge im Dünndarm. Da im Proteinstoffwechsel nur L-Methionin genutzt wird, müssen beide Isomere (D- und L-Isomer) 


\section{Literaturüberblick}

des MHAs in L-Met transformiert werden, während nur das D-Isomer von DLM überführt werden muss (Abbildung 2.2). Die Überführung von MHA in eine aktive Aminosäure erfordert zwei enzymatische Schritte: Oxidation des $\alpha$-Kohlenstoffs, gefolgt von Transaminierung (DIBNER und KNIGHT 1984, DILGER und BAKER 2008). Die erste Reaktion ist eine stereo-spezifische Oxidation, bei der verschiedene Enzyme involviert sind: Peroxisomal L-2-Hydroxy-Säure-Oxidase und mitrochondriale D-2-Hydroxy-SäureDehydrogenase, die die Oxidation von L-MHA und D-MHA katalysieren (DIBNER und KNIGHT 1984). Dabei bringen sie die korrespondierenden $\alpha$-Ketosäure, 2-Keto-(4methylthio)Butansäure (KMB) hervor. Das spezifische Enzyme L-2-Hydroxysäure-Oxidase wurde in der Leber und Niere lokalisiert (GORDON und SIZER 1965), wobei DS-2-OHSäure-Dehydrogenase in zahl-reichen Geweben, einschließlich der Leber, Niere, Skelettmuskulatur, Gehirn, Darm, Milz und Pankreas nachgewiesen wurde (DIBNER und KNIGHT 1984). Nach Formation des intermediaten KMB, erfolgt der zweite Schritt, die Umwandlung zu L-Met durch Trans-aminierung (HARTER und BAKER 1977, KNIGHT und DIBER 1984).

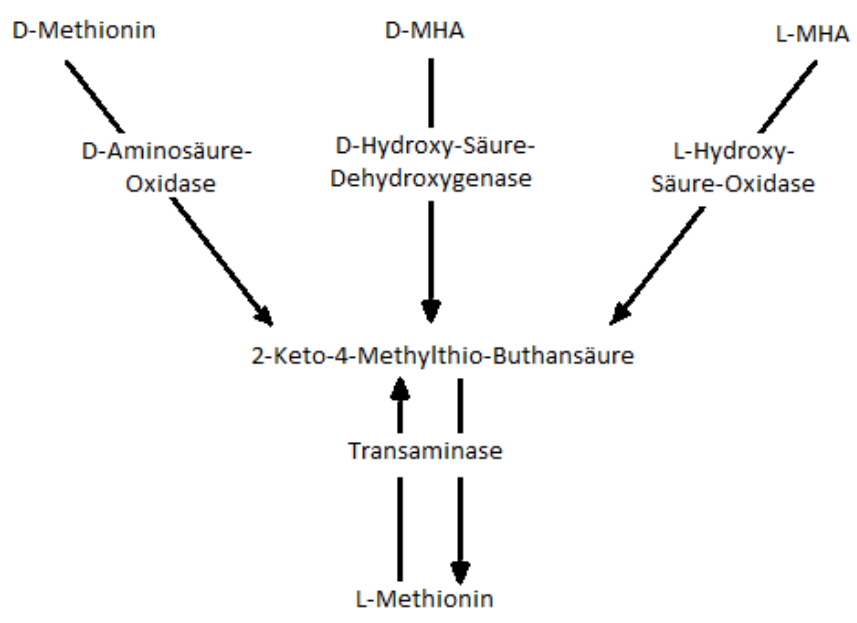

Abbildung 2.2: Umwandlung von D-Met und DL-MHA zu L-Methionin (nach SAUNDERSON 1991)

Unterschiede in der intestinalen Absorption und im Metabolismus von DLM und MHA lassen unterschiedliche Nutzung erwarten. DREW et al. (2003) berichteten, dass MHA langsamer aus dem Lumen des Dünndarms aufgenommen wird als DLM. Zudem haben viele Studien die relative Wirksamkeit von MHA und DLM in Geflügel und Schweinen zum Gegenstand gehabt (HUYGHEBAERT 1993, HOEHLER und HOOGE, 2003, LIU et al. 2004) und relative Wirksamkeiten von 62 bis 100\% (äquimolarer Basis) ermittelt (BOEBEL und BAKER 1982, BUNCHASAK et al. 2006, CHRISTENSEN und ANDERSON 1980, HUYGHEBAERT 1993, HOEHLER und HOOGE 2003, LEMME et al. 2002). 


\subsection{Bestimmung des Aminosäurenbedarfes}

Dieser Abschnitt des Literaturüberblicks gibt einen Einblick in die Methoden zur Bestimmung des qualitativen und quantitativen Bedarfs an essentiellen Aminosäuren von Mastgeflügel. Neben dem Idealproteinkonzept erfolgen Ausführungen hinsichtlich der faktoriellen Bedarfsableitung sowie der Dosis-Wirkungsstudien. Im Anschluss daran wird das exponentielle N-Verwertungsmodell vorgestellt, auf dem die vorliegende Arbeit aufbaut.

\subsubsection{Idealprotein-Konzept}

Das “Idealprotein"-Konzept basierte ursprünglich auf der Hypothese, dass ein direkter Bezug zwischen dem Aminosäurebedarfsmuster und dem Aminosäuremuster im Ganzkörperprotein besteht. Definitionsgemäß entspricht dieses Konzept dem relativen (prozentualen) Verhältnis der essentiellen Aminosäuren im Vergleich zum Lysin als Referenzaminosäure. Es wird vorwiegend dann angewendet, wenn der Bedarf an der in Futtermitteln häufig erstlimitierenden Aminosäure Lysin bekannt ist. Aufgrund der festen Relationen der übrigen essentiellen Aminosäuren zum Lysin lässt sich der Bedarf an den übrigen Aminosäuren direkt ableiten. Der Bedarf an den übrigen Aminosäuren wird in diesem Fall relativ zum Lysin $($ Lysin $=100)$ angegeben, gemäß dem im Ganzkörper bestimmten Aminosäuremuster. Das Idealprotein spiegelt somit die optimalen Relationen zwischen den essentiellen Aminosäuren im Futterprotein wieder, die zur Bedarfsdeckung für Erhaltung und Wachstum erforderlich sind.

Während der absolute Aminosäurenbedarf einer Variabilität unterliegt, bleiben die Verhältnisse zwischen den einzelnen Aminosäuren relativ stabil, da sie weniger stark von Faktoren, wie Körpergröße, Geschlecht oder Futteraufnahme abhängig sind (RODEHUTSCORD und PACK 1999).

Das Konzept vom Idealprotein wurde bereits 1944 von ALMQUIST und GRAU publiziert (CHUNG und BAKER 1992, BAKER und HAN 1994, FULLER 1994, NRC, 1994, MACK et al. 1999, BAKER et al. 2002). Aufgrund der relativ einfachen Analysenmethodik dieser Aminosäure sowie deren Hauptfunktion im Körper wird Lysin vorzugsweise als 


\section{Literaturüberblick}

Referenzaminosäure genutzt. Zudem liegen für Lysin die umfangreichsten Untersuchungen zum quantitativen Bedarf vor. Aufgrund dessen, dass Lys fast ausschließlich zum Proteinansatz genutzt wird (BAKER 1997, EMMERT und BAKER 1997), wird der Bedarf nicht durch andere metabolische Funktionen beeinflusst (MILES und CHAPMAN 2010). Die exakte Bestimmung des Lysinbedarfes ist daher essentiell und ein relevanter Aspekt, da sie die Basis zur Bedarfableitung aller unentbehrlichen Aminosäuren darstellt. BAKER et al. (2002) postulierten zur präzisen Aminosäuren-Bedarfsableitung die Verwendung einer einheitlichen Basalmischung. Zudem sollten gemäß BAKER et al. (2002) alle Diäten isonitrogen und isoenergetisch sein.

Basierend auf verschiedenen Literaturempfehlungen zum idealen Aminosäuremuster für männliche Broiler (AUSTIC 1994, BAKER und HAN 1994, BOORMAN und BURGESS 1986, COON 2004, CRESWELL und SWICK 2001, CVB 1996, DEGUSSA 2003, GFE 1999, HOEHLER und LEMME 2005, NRC 1994, RHONE-POULENC 1993) wurde unter Mittelwertbildung (und Berücksichtigung von stark abweichenden Werten) ein „optimales Aminosäurenverhältnis“ ermittelt. Dies wurde in der Tabelle 2.2 den Empfehlungen von GRUBER et al. (1999), des NRC (1994) und GFE (1999) zur Veranschaulichung gegenübergestellt.

Tabelle 2.2: Zusammenstellung ausgewählter „idealer Aminosäurenverhältnisse“ für Broiler (Lysin=100)

\begin{tabular}{|c|c|c|c|c|c|c|}
\hline \multirow{2}{*}{$\begin{array}{l}\text { Alter } \\
\text { Quellen }\end{array}$} & \multicolumn{2}{|c|}{ 0. - 3. Woche } & \multicolumn{2}{|c|}{ 4. - 6. Woche } & \multirow[b]{2}{*}{$\begin{array}{l}\text { GRUBER } \\
\text { et al. } 1999\end{array}$} & \multirow[b]{2}{*}{$\begin{array}{c}\text { Mittelwert aus } \\
\text { Literaturangaben* }\end{array}$} \\
\hline & NRC 1994 & GFE 1999 & NRC 1994 & GFE 1999 & & \\
\hline Lys & 100 & 100 & 100 & 100 & 100 & 100 \\
\hline Met & 45 & 36 & 38 & 38 & 37 & 40 \\
\hline Met + Cys & 82 & 71 & 72 & 87 & 70 & 74 \\
\hline Thr & 73 & 67 & 74 & 76 & 66 & 66 \\
\hline Trp & 18 & 16 & 18 & 17 & 14 & 16 \\
\hline Leu & 109 & 112 & 109 & 125 & 108 & 110 \\
\hline Ile & 73 & 69 & 73 & 78 & 63 & 69 \\
\hline Arg & 114 & 108 & 110 & 117 & 108 & 105 \\
\hline Val & 82 & 96 & 82 & 109 & 81 & 80 \\
\hline His & 32 & 32 & 32 & 33 & 38 & 34 \\
\hline
\end{tabular}

*(AUSTIC 1994, BAKER und HAN 1994, BOORMAN und BURGESS 1986, COON 2004, CRESWELL und SWICK 2001, CVB 1996, DEGUSSA 2003, GFE 1999, HOEHLER und LEMME 2005, NRC 1994, RHONE-POULENC 1993) 


\subsubsection{Faktorielle Bedarfsbestimmung}

Die faktorielle Bedarfsbestimmung basiert auf dem Konzept, dass sich der Gesamtbedarf an Aminosäuren aus verschiedenen Teilbeträgen zusammensetzt. Beim wachsenden Geflügel bildet der Gesamtbedarf an jeder essentiellen Aminosäure die Summe aus dem Bedarf für Erhaltung und dem Bedarf für Körperansatz, der als Leistungsbedarf den Ansatz in den Federn und im federfreien Tierkörper widerspiegelt. Die Differenzierung des Gesamtansatzes in diesen zwei Fraktionen ist aufgrund einer unterschiedlichen Aminosäurenzusammensetzung (insbesondere SAA und Lysin) sowie eines unterschiedlichen Federanteils am Gesamtkörper im Verlauf des Wachstums erforderlich.

Gleichsam der Bestimmung des N-Erhaltungsbedarfes nach Columbus (1951) werden die endogenen Harn- und Darmverluste bei N-freier Diät für den Nettoerhaltungsbedarf der Aminosäuren ermittelt. Im Hinblick auf den Erhaltungsbedarf essentieller Aminosäuren beim wachsenden Geflügel liegen jedoch nur sehr wenige, häufig ältere Publikationen vor, während die geringe Anzahl neuer Untersuchungen (FERNANDEZ et al. 1995, EDWARDS et al. 1997, EDWARDS und BAKER 1999) noch nicht ausreichend sind, um allgemeingültige Aussagen über den Erhaltungsbedarf einzelner essentieller Aminosäuren zu treffen.

Der Aminosäurenansatz entspricht bei wachsenden Tieren dem Netto-Leistungsbedarf von Aminosäuren. Zur Ableitung des Bruttobedarfs wird die aminosäurenspezifische Gesamtverwertung benötigt, in der die Verwertungsverluste der Verdauung und des Intermediärstoffwechsels berücksichtigt sind.

Das faktorielle Modell unterstellt eine lineare Beziehung zwischen der Aminosäurenaufnahme und der Leistung und setzt einen konstanten Erhaltungsbedarf voraus. Betrachtet man den linearen Zusammenhang zwischen Aminosäurenaufnahme und dem Proteinansatz, so entspricht dieser nicht dem physiologischen Verlauf, denn durch die endogene Regulation bestehen kurvilineare Relationen zwischen der Aminosäurenaufnahme und dem Protein- bzw. Aminosäurenansatz (GEBHARDT et al. 1977, GEBHARDT 1980, WIESEMÜLLER 1984). Zudem sollte der Aspekt berücksichtigt werden, dass ein zunehmender Proteinverzehr mit dem Anstieg des Proteinturnovers korreliert, woraus ein erhöhter Proteinerhaltungsbedarf resultiert (MILLWARD et al. 1976, REEDS et al. 1980a, b, 1981).

Für wachsende Broiler wurde die faktorielle Methode z.B. von HURWITZ et al. (1978, 1980), MURAMATSU et al. (1991), FISCHER (1998), GOUS (1998) und GFE (1999), zur Ableitung des Aminosäurenbedarfes herangezogen. 


\section{Literaturüberblick}

\subsubsection{Dosis-Wirkungs-Studien}

Die am häufigsten verwendeten Verfahren zur Ermittlung von Bedarfsempfehlungen für Aminosäuren sind die Dosis-Wirkungsstudien. Im Folgenden werden die Supplementationsmethode und Verdünnungsmethode separat betrachtet und kurz erläutert.

\subsubsection{Supplementationsmethode}

Die Supplementationsmethode beruht auf Untersuchungen, bei denen die Wirkung zwischen der Aminosäurendosierung im Futter und einem Leistungsparameter, wie z. B. das Wachstum, untersucht wurde (D`MELLO 1982). Die Grundlage bildet eine Basaldiät, in der die zu prüfende Aminosäure im Mangel vorliegt, während die übrigen Komponenten bedarfsdeckend und möglichst konstant gehalten werden. Diese Referenzdiät wird mit der zu testenden Aminosäure in kristalliner Form entsprechend supplementiert. Die daraus resultierenden graduell ansteigenden Konzentrationen schließen sowohl den Mangel- als auch den Überschussbereich ein. Dadurch variiert die Aminosäurenkonzentration im Futter und somit die Aufnahme der zu testenden Aminosäure. Für die einzelnen Parameter (z. B. Lebendmassezunahme, Futteraufwand, Proteinansatz) ergeben sich dann Dosis-WirkungsBeziehungen. Insofern wird die Wirkung geprüft, die die Aminosäurenzufuhr auf eine bestimmte Leistung realisiert.

Der Aminosäurebedarf ist bei diesem Vorgehen als die minimale Konzentration einer essentiellen Aminosäure definiert, die eine maximale Leistung gewährleistet. Nur wenn eine möglichst große Spannweite zwischen Limitierung und Überdosierung erreicht wird, sind genügend Daten vorhanden, um über die erstellte Dosis-Wirkungs-Kurve, den jeweiligen Bedarf abzuleiten. Zur Ermittlung dieses Wertes gibt es verschiedene Auswertungsverfahren der Kurvenverläufe (MORRIS 1983). Dabei können sich für die einzelnen Parameter unterschiedliche Versorgungsniveaus ergeben. Ein Großteil der Arbeiten zum Aminosäurebedarf greift auf die "Broken-line"-Analyse zurück, bei der der Schnittpunkt einer ansteigenden sowie einer horizontalen Regressionsgeraden nach der Methode der "kleinsten Quadrate" mathematisch bestimmt wird. Die Abszisse des Schnittpunkts determiniert den anzusetzenden Aminosäurebedarf. Somit wird ein Punkt im Kurvenverlauf bestimmt, der als Bedarf definiert ist (MORRIS 1983). 


\section{Literaturüberblick}

Das exponentielle Modell hingegen bietet die Möglichkeit, über eine Variation des relativen Ausschöpfungsgrades des Grenzwertes, einen leistungsabhängigen Aminosäurenbedarf zu berechnen.

Aufgrund der abgestuften Aminosäurenzulagen kann das Aminosäurenmuster in den Diäten erheblichen Variationen unterlegen sein, die wiederum zu Wechselwirkungen zwischen den Aminosäuren führen können (D`MELLO 1994b, ISHIBASHI und OTHA 1999). Des Weiteren darf bei der Formulierung der Basaldiät nur die zu untersuchende Aminosäure bedarfsbegrenzend wirken. Dies setzt eine gewisse Kenntnis über den Bedarf der nicht zu untersuchenden Aminosäuren sowie deren Wechselwirkungen voraus.

\subsubsection{Verdünnungsmethode}

Bei dieser Methode wird eine Basaldiät vorgelegt, in der nur die betreffende Aminosäure, für die eine Bedarfsempfehlung ermittelt werden soll, limitierend wirkt. Durch steigende Dosierungen einer N-freien bzw. proteinfreien Komponente erfolgt eine Verdünnung dieser Basalmischung, wodurch eine abgestufte Aufnahme der Test-Aminosäure realisiert wird. Im Gegensatz zur Supplementationmethode variiert bei dieser Vorgehensweise das Aminosäurenmuster der Diät nicht (GOUS und MORRIS 1985).

\subsubsection{Exponentielles N-Verwertungsmodell}

Eine weitere Methode zur Bedarfsableitung von Aminosäuren stellt das exponentielle NVerwertungsmodell nach GEBHARDT (1966) und dessen systematische Weiterentwicklung (LIEBERT und GEBHARDT 1986) dar, welches bislang zur Bedarfsbestimmung erstlimitierender Aminosäuren bei monogastrischen Nutztieren wie Schwein (LIEBERT und GEBHARDT 1986, 1988a, b, LIEBERT et al. 1987, THONG 2003, WESSELING 2003, THONG und LIEBERT 2004a, b, LIEBERT und WECKE 2010, WECKE und LIEBERT 2010a,b), Broiler (LIEBERT 1978, RIMBACH und LIEBERT 2000, SAMADI und 


\section{Literaturüberblick}

LIEBERT 2007, LIEBERT 2008) und Nutzfischen (LIEBERT und BENKENDORFF 2007, LIEBERT 2008) zum Einsatz kam.

Grundlage dieses Modells ist die von GEBHARDT $(1963,1966)$ unter Einbeziehung eines Exponentialterms abgeleitete Stickstoffwirkungskurve. Wird die N-Retention, die sich aus dem zu deckenden N-Erhaltungsbedarf (NMR) und dem N-Ansatz zusammensetzt, als Funktion der N-Aufnahme aufgetragen, so folgt sie nach GEBHARDT (1963) dem Wachstumsgesetz (BERTALANFFY 1951, MISCHERLICH 1956). Das maximale NRetentionsvermögen $\left(\mathrm{NR}_{\max } \mathrm{T}\right)$ stellt in dieser Funktion den theoretischen Grenzwert der NRetention dar. Dieser art-, geschlechts-, alters- und genotypabhängige Grenzwert (HOFFMANN 1971) definiert einen theoretischen Grenzwert, welcher in der Praxis jedoch nicht ausgeschöpft wird (SAMADI und LIEBERT 2006). Zur Ermittlung dieses Grenzwertes dienen N-Steigerungsversuche. Die Vorgehensweise entspricht dem Prinzip der Verdünnungstechnik (GOUS und MORRIS 1985) bei konstanter Proteinqualität in allen NStufen. Die erhaltenen Ergebnisse können über die nichtlineare Parameterschätzung zur Berechnung des maximalen N-Retentionsvermögens sowie des NMR (LE KHAC 1985, DÄNICKE 1993) herangezogen werden.

Der Zusammenhang zwischen der N-Aufnahme und der N-Bilanz wurde häufig mathematisch mit quadratischer Funktion beschrieben (WIESEMÜLLER und POPPE 1969, HOFFMANN et al. 1982) und die höchsten N-Bilanzwerte als maximales N-Ansatzvermögen für verschiedene Altersabschnitte bezeichnet.

Der NMR setzt sich nach COLUMBUS (1951) summarisch aus den endogenen Harn-N und Darmverlust-N zusammen und wird als die mit (-1) multiplizierte N-Bilanz bei N-freier Diät definiert. In diesem Modell stellt der NMR, wie auch von COLUMBUS (1951), GEBHARDT (1966) und HOFFMANN (1971) beschrieben, eine konstante Größe dar. Der NMR wird vorzugsweise aus einer nichtlinearen Regression zwischen N-Aufnahme und N-Exkretion abgeleitet (THONG und LIEBERT 2004a, SAMADI und LIEBERT 2006a,b, WECKE und LIEBERT 2009). Da zwischen der Körpermasse der Versuchstiere und dem NErhaltungsbedarf ein Zusammenhang besteht, werden alle Versuchsdaten auf die 2/3 Potenz der Lebendmasse (kg) bezogen, was dem mathematischen Ansatz der Wachstumsgesetzmäßigkeiten nach BERTALANFFY (1951) entspricht. Der Bezug auf die metabolische Lebendmasse ist nicht zwingend notwendig, erleichtert aber die Vergleichbarkeit der Werte. So wird der NMR zu dem Punkt auf der y-Achse, an dem die Wirkungskurve beginnt. Hierbei ist es nach GEBHARDT $(1966,1980)$ irrelevant, ob der N-Erhaltungsbedarf als negative 


\section{Literaturüberblick}

Bilanz bei N-freier Kost dargestellt wird oder ob der Schnittpunkt des N-Erhaltungsbedarfes durch den Nullpunkt und die N-Retention auf die y-Achse aufgetragen wird.

Der Parameter b (b-Wert) charakterisiert über den Anstieg der Wirkungskurve die Qualität des verwendeten Futterproteins und kann direkt als Proteinqualitätsmaß Anwendung finden. Die Proteinqualität wird von den tierspezifischen Faktoren Genotyp, Geschlecht, Alter und Lebendmasse beeinflusst, die ihrerseits die Höhe des $\mathrm{NR}_{\max } \mathrm{T}$ festlegt (HOFFMANN 1971). Dem hingegen steht die Proteinqualität zwar in direkter Beziehung zum Grenzwert der Funktion, hat aber keinen Einfluss auf den $\mathrm{NR}_{\max } \mathrm{T}$, was trotz identischer Proteinträger bei verschiedenen Grenzwerten $\mathrm{zu}$ Variationen im b-Wert führt. Allerdings liefert dieser Parameter b keine direkten Vergleichsmöglichkeiten mit klassischen Proteinverwertungskennzahlen (z.B. PNu) und findet nur im Definitionsbereich von $\mathrm{NR}_{\max } \mathrm{T}$ Geltung. Unter Verwendung der Grundzusammenhänge des N-Verwertungsmodels kann der Parameter im Kontext des Proteinvergleiches zur Standardisierung von PNu-Werten herangezogen werden (THONG und LIEBERT 2004a, b). Er ermöglicht zudem eine Proteinbewertung, die von der Höhe der N-Aufnahme unabhängig ist (GEBHARDT 1966).

Zwischen der Proteinqualität (b) und der Konzentration (c) der limitierenden Aminosäure im Futterprotein besteht ein direkter, linearer Zusammenhang (GEBHARDT 1980, LIEBERT 1978, WECKE und GEBHARDT 1982), sodass zwischen diesen beiden Parametern ein Bezug hergestellt werden kann. Aus diesem definierten Zusammenhang zwischen der Konzentration der limitierenden Aminosäure (LAA) und der Proteinqualität resultiert, dass die LAA, insofern sie den einzigen begrenzenden Faktor der Futtermischung darstellt, einen direkten Einfluss auf die Höhe des Proteinansatzes hat. Basierend auf dieser Prämisse beschreibt die Steigerung der linearen Regression zwischen b und c, als Quotient $\mathrm{bc}^{-1}$, die Wirksamkeit der limitierenden Aminosäure (GEBHARDT 1980, LIEBERT 1995a, b), welche nur im Limitierungsbereich Geltung besitzt und mit Überschreitung der Grenze des Limitierungsbereiches die Wirksamkeit verringert. Dieser Fakt beschreibt aber nicht die Wirkungs-möglichkeit der limitierenden Aminosäure, sondern zeigt die Grenzen der Limitierung auf (WECKE und GEBHARDT 1982) und bietet die Möglichkeit, unterschiedliche Proteinträger auf der Basis der gleichen limitierenden Aminosäure zu bewerten und zu vergleichen. Des Weiteren besteht die Grundlage zur Ableitung des leistungs- und wirksamkeitsabhängigen Aminosäurenbedarfes, da mit Kenntnis der Wirksamkeit der Bedarf der limitierenden Aminosäure für eine definierte Leistung bestimmt werden kann. 
Die Aminosäure-Wirksamkeit $\left(b c^{-1}\right)$ wird durch den Umfang der Freisetzung der Futteraminosäure aus dem Proteinverband, die Absorption sowie die intermediäre Verwertung bestimmt und beinhaltet somit tierspezifische wie futtermittelspezifische Anteile. Da über die Konzentration der LAA im Futterprotein eine Abhängigkeit von der absoluten Bedarfshöhe vorliegt, ist die Größe dieses Parameters aminosäurenspezifisch. Demzufolge sind Wirksamkeitsvergleiche, die über die $b c^{-1}$-Werte erfolgen, auf die jeweilig betrachtete LAA zu begrenzen.

Die ermittelten Werte können unter Einbindung von tatsächlich geleisteten täglichen NAnsatzwerten und der dazugehörigen mittleren Lebendmasse sowie des realisierten Ausschöpfungsgrades des maximalen theoretischen N-Ansatzvermögens zur Bedarfsableitung herangezogen werden. Eine detaillierte Darstellung zur Anwendung des beschriebenen Modells sowie zu den genannten Parametern findet sich in Kapitel 4.6.2. 


\section{Versuchszielstellung}

Zielsetzung der vorliegenden Arbeit war, nach der grundlegenden Vorgehensweise im Rahmen des exponentiellen N-Verwertungsmodelles (GEBHARDT 1966, 1988, SAMADI und LIEBERT 2007a, b, 2008) die Aminosäurewirksamkeit beim Masthähnchen (Ross 308) unter spezifischer Fokussierung der schwefelhaltigen Aminosäuren Methionin und Cystein zu bewerten und neue Erkenntnisse zum Idealprotein-Konzept beim Mastgeflügel zu erhalten.

Dabei sollten folgende Schwerpunkte in den Mittelpunkt gestellt werden:

1. Neubewertung der genotypabhängigen Modellparameter $\mathrm{NMR}$ und $\mathrm{NR}_{\max } \mathrm{T}$ als Grundlage für die Modellanwendungen

2. Vergleich zweier unterschiedlicher Methioninquellen - DL-Methionin und 2Hydroxy-4-Methylthiobuttersäure (MHA) - bezüglich deren Wirksamkeit

3. Erfassung des Einflusses des Met:Cys-Verhältnisses auf die ermittelte Methioninwirksamkeit

4. Ermittlung des Methioninbedarfs

5. Einfluss des Met:Cys Verhältnisses auf den Methioninbedarf

6. Ermittlung des idealen Aminosäurenverhältnisses im Hinblick auf die Aminosäuren Lysin, Threonin, Tryptophan, Isoleucin, Arginin und Valin

Zur Lösung der experimentellen Zielstellung wurden insgesamt 10 Einzelversuche durchgeführt. Inwiefern das Alter der Broiler Einfluss auf die Untersuchungsparameter hatte, konnte aufgrund der Differenzierung der Versuche in zwei Wachstumsperioden zumindest teilweise mit berücksichtigt werden. 


\section{Material und Methoden}

Ausgehend von der zugrunde liegenden Zielstellung werden in diesem Kapitel die einzelnen Versuche vorgestellt. Zunächst erfolgt eine konzentrierte Darstellung des Versuchsaufbaues, um einen Überblick über die durchgeführten Untersuchungen zu geben. Im Folgenden werden Tiermaterial, Versuchsdiäten, Tierhaltung und Versuchsdurchführung sowie analytische und mathematisch-statistische Auswertungsmethoden betrachtet.

\subsection{Versuchsaufbau}

Die Studien waren in drei Untersuchungskomplexe unterteilt, die an insgesamt ca. 2400 Masthähnchen in 10 Einzelversuchen durchgeführt wurden. Neben sechs NBilanzuntersuchungen wurden vier Wachstumsversuche unter Einbeziehung der Körperanalytik ausgewertet. Entsprechend unterschiedlicher inhaltlicher Schwerpunkte wurden die Einzelversuche insgesamt drei Untersuchungskomplexen zugeordnet. Der erste Versuchskomplex beinhaltete die Bestimmung des N-Erhaltungsbedarfes und des maximalen theoretischen N-Retentionsvermögens. Auf diesen Modellparametern aufbauend wurde einerseits im zweiten Versuchskomplex auf die Methioninwirksamkeit eingegangen, auf deren Grundlage leistungsabhängige Ableitungen zum Methioninbedarf ermöglicht werden sollten während andererseits im dritten Versuchskomplex im Hinblick auf das Idealprotein die Ableitung optimaler Aminosäurenverhältnisse im Fokus der Untersuchungen standen.

Die Tabelle 4.1 und Tabelle 4.2 geben Aufschluss über ausgewählte Angaben zu den NBilanzversuchen und den z. T. parallel durchgeführten Wachstumsversuchen. Hierbei werden Daten hinsichtlich der Anzahl, der in den Versuchen befindlichen Küken, dem Versuchszeitraum sowie Angaben zu anderen ausgewählten Parametern einbezogen. 
Tabelle 4.1: Ausgewählte Angaben zu den durchgeführten Versuchen (Komplex I und II)

\begin{tabular}{|c|c|c|c|c|c|}
\hline & \multirow{2}{*}{$\begin{array}{c}\text { Untersuchungs- } \\
\text { komplex I } \\
\text { Versuch } 1\end{array}$} & \multicolumn{4}{|c|}{ Untersuchungskomplex II } \\
\hline & & Versuch 2 & Versuch 3 & Versuch 4 & Versuch 5 \\
\hline & $\begin{array}{l}\text { Bilanz- } \\
\text { versuch }\end{array}$ & $\begin{array}{l}\text { Bilanz- } \\
\text { versuch }\end{array}$ & $\begin{array}{c}\text { Wachstums- } \\
\text { versuch }\end{array}$ & $\begin{array}{l}\text { Bilanz- } \\
\text { versuch }\end{array}$ & $\begin{array}{c}\text { Wachstums- } \\
\text { versuch }\end{array}$ \\
\hline Versuchszeitraum & 10. -20 & $10 .-20$ & $0 .-21$ & 10. -20 . & $0 .-21$ \\
\hline (LT der Küken)* & $25 .-35$. & $25 .-35$ & $21 .-35$. & $25 .-35$ & 21. -35 . \\
\hline \multirow{2}{*}{ Anzahl Küken* } & 36 & 36 & 240 & 36 & 216 \\
\hline & 36 & 36 & & 36 & \\
\hline Anzahl der & 6 & 5 & 5 & 5 & 5 \\
\hline Gruppen* & 6 & 5 & 5 & 5 & 5 \\
\hline Anzahl der & 6 & 7 & 5 & 7 & 5 \\
\hline Wiederholungen & & & & & \\
\hline
\end{tabular}

Tabelle 4.2: Ausgewählte Angaben zu den durchgeführten Versuchen (Komplex III)

\begin{tabular}{|c|c|c|c|c|c|}
\hline & \multicolumn{5}{|c|}{ Untersuchungskomplex III } \\
\hline & Versuch 6 & Versuch 7 & Versuch 8 & Versuch 9 & Versuch 10 \\
\hline & $\begin{array}{l}\text { Bilanz- } \\
\text { Versuch }\end{array}$ & $\begin{array}{c}\text { Wachstums- } \\
\text { versuch }\end{array}$ & $\begin{array}{l}\text { Bilanz- } \\
\text { versuch }\end{array}$ & $\begin{array}{l}\text { Bilanz- } \\
\text { versuch }\end{array}$ & $\begin{array}{c}\text { Wachstums- } \\
\text { versuch }\end{array}$ \\
\hline Versuchszeitraum & $10 .-20$. & $0 .-21$. & $10 .-20$ & $10 .-20$ & $0 .-21$. \\
\hline (LT der Küken)* & $25 .-35$. & $21 .-35$. & $25 .-35$ & $25 .-35$ & $21 .-35$. \\
\hline \multirow{2}{*}{ Anzahl Küken* } & 36 & 360 & 36 & 36 & 420 \\
\hline & 36 & 360 & 36 & 36 & 336 \\
\hline Anzahl der & 7 & 6 & 7 & 5 & 7 \\
\hline Gruppen* & 7 & 6 & 7 & 5 & 7 \\
\hline $\begin{array}{c}\text { Anzahl der } \\
\text { Wiederholungen }\end{array}$ & 5 & 6 & 5 & 7 & 6 \\
\hline
\end{tabular}

* Differenziert nach Wachstumsphase (Starterperiode und Growerperiode) 


\subsubsection{Untersuchungskomplex I}

Im Mittelpunkt dieses Untersuchungskomplexes stand die Ermittlung des maximalen theoretischen $\mathrm{N}$-Retentionsvermögens $\left(\mathrm{NR}_{\max } \mathrm{T}\right)$ und des $\mathrm{N}$-Erhaltungsbedarfes (NMR).

$\mathrm{Zu}$ diesem Zweck wurde ein N-Bilanzversuch (Versuch 1) durchgeführt, der zwei Wachstumsphasen (10. - 20. LT und 25. - 35. LT) einbezog. Zur Durchführung des Versuches wurden je Wachstumsphase 36 Masthähnchen in Stoffwechselkäfige eingestallt, die jeweils auf 6 Gruppen aufgeteilt wurden (siehe Tabelle 4.1).

\subsubsection{Untersuchungskomplex II}

Dieser Untersuchungskomplex diente zur vergleichenden Betrachtung der Wirksamkeit zweier Methioninquellen (DL-Methionin und Methionin-Hydroxy-Analog). Zur Lösung der Problemstellung wurden insgesamt zwei Bilanzversuche (Versuch 2 und 4) beim Küken durchgeführt. Parallel zu jeder Bilanzstudie erfolgte zeitgleich ein Wachstumsversuch (Versuch 3 und 5) mit vergleichender Ganzkörperanalyse.

In der N-Bilanzstudie wurden, wie im Versuchskomplex I, jeweils 36 Masthähnchen pro Wachstumsphase (10. - 20. LT und 25. - 35. LT) in Käfige eingestallt.

Die Wachstumsversuche umfassten den Versuchszeitraum vom 0. - 21. Lebenstag der Küken (Starterperiode) und den 21. - 35. Lebenstag der Küken (Growerperiode). Die mittlere Anfangslebendmasse der 240 Broilerküken im Versuch 3 betrug 55 g. Die 216 Broiler der Versuchsreihe 5 hatten zu Beginn des Versuches eine mittlere Lebendmasse von $49 \mathrm{~g}$. Während in der Bilanzstudie die Broiler nach Abschluss der Starterperiode ausgestallt und für die Growerperiode neue Tiere eingestallt wurden, erfolgte in den Wachstumsversuchen zum Wechsel der Wachstumsphasen kein Austausch der Tiere. In allen Versuchen des Versuchskomplexes II wurden die Broiler jeweils auf fünf Gruppen aufgeteilt (siehe Tabelle 4.1).

Neben der vergleichenden Betrachtung der Methioninwirksamkeit von DL-Methionin und Methionin-Hydroxy-Analog sollte im Anschluss dessen das exponentielle N-Verwertungsmodell zur Methioninbedarfsableitung genutzt werden. 


\subsubsection{Untersuchungskomplex III}

Der Gegenstand dieses Untersuchungskomplexes war die Ermittlung des idealen Verhältnisses der essentiellen Aminosäuren Threonin, Tryptophan, Isoleucin, Arginin und Valin in Relation zum Lysin.

Dieser Untersuchungskomplex umfasste drei N-Bilanz- (Versuch 6, 8, 9) und zwei Wachstumsversuche $(7,10)$. Die Versuchsabläufe der N-Bilanz und Wachstumsversuche sind analog zu den vorangegangenen Versuchskomplexen. Im Versuch 6, 8 und 10 wurden die Masthähnchen auf jeweils sieben Gruppen verteilt. Die Anzahl der Broiler in den einzelnen N-Bilanzversuchen betrug in der Starter- und Growerperiode jeweils 36 Masthähnchen. Die zum Versuch 6 parallel durchgeführte Wachstumsstudie (Versuch 7) umfasste jeweils 360 Broiler. In den Versuchen 9 und 10 wurden die insgesamt 72 Broilerküken (Versuch 9) des N-Bilanzversuches und insgesamt 756 Broilerküken des Wachstums-versuches (Versuch 10) auf jeweils 5 bzw. 7 Gruppen und zwei Wachstumsperioden verteilt.

In diesem Versuchskomplex erfolgte in den N-Bilanzstudien, wie auch in den Wachstumsversuchen ein Austausch der Broiler zu Beginn der Growerperiode.

Die einzelnen Angaben der Versuche im Versuchskomplex III sind der Tabelle $4.2 \mathrm{zu}$ entnehmen.

\subsection{Tiermaterial}

Die in den Untersuchungen eingesetzten Küken entstammten der genetischen Herkunft Ross 308 (Geflügelhof Möckern). Vor Anlieferung der Tiere erfolgte eine Geschlechtertrennung nach der Japanischen Methode. Hinsichtlich Vitalität und Konstitution verhielten sich die am Schlupftag übernommen männlichen Broilerküken ohne weitere Auffälligkeiten. 


\subsection{Versuchsdiäten}

Dieser Abschnitt vermittelt einen Einblick in Konzeption, Herstellung und detaillierte Zusammensetzung der verwendeten Versuchsdiäten.

\subsubsection{Mischkonzeption}

Im Folgenden wird kurz auf die Protein-, Energieträger, Mineralien und Vitamine eingegangen, die Bestandteil der einzelnen Diäten sind. Detailliertere Angaben zur Zusammensetzung der Diäten, sowie zu deren Rohnährstoff- und Energiegehalt finden sich, differenziert nach den Versuchskomplexen im Kapitel 4.3.3.

\subsubsection{Proteinträger}

Die Auswahl der untersuchten Proteinträger erfolgte unter dem Gesichtspunkt, so wenig kristalline Aminosäurenzusätze wie nötig in den Mischungen zu verwenden, um den Bedarf an Aminosäuren (mit Ausnahme der jeweils limitierenden Aminosäure) zu decken. Ein weiteres Kriterium bezog sich auf den Aspekt, dass die in den einzelnen Versuchen verwendeten Futtermischungen bereits nativ eine Limitierung an der $\mathrm{zu}$ bewertenden Aminosäure aufwies.

\subsubsection{2. $\quad$ Energieträger, Mineralien und Vitamine}

Die in den einzelnen Mischungen verwendeten Hauptenergielieferanten waren Weizenstärke und Sojaöl. Das mit einem überwiegenden Anteil an PUFA (54\% Linol- und 5\% Linolen-

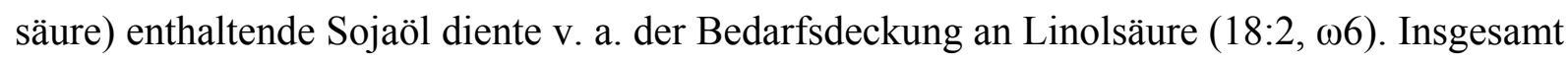
waren alle Diäten weitgehend isoenergetisch. 
Zur Ermittlung der Wirksamkeit der erstlimitierenden und damit die Proteinqualität bestimmenden Aminosäure wurden nach den Erfordernissen des N-Verwertungsmodells (vergleiche Kapitel 2.4.4) in den einzelnen Versuchskomplexen Methionin/Cystein-, Lysin-, Threonin-, Tryptophan-, Arginin-, Isoleucin- und Valin-limitierte Versuchsdiäten formuliert, die sich in ihrem Gehaltswerten sowie dem Energiegehalt an die Empfehlungen des NRC (1994) bzw. GFE (1999) anlehnten.

Um den Bedarf an Makromineralien zu decken, kamen Monocalciumphosphat (MCP) bzw. Dicalciumphosphat (DCP), Calciumcarbonat $\left(\mathrm{CaCO}_{3}\right)$ sowie Natriumchlorid $(\mathrm{NaCl})$ zum Einsatz. Ein nach Vorgaben der Einrichtung kommerziell hergestellter Premix (Deutsche Vilomix GmbH) diente als Vitamin- und Spurenelementquelle. Die Tabelle 4.3 zeigt die Zusammensetzung des Premixes.

Tabelle 4.3: Zusammensetzung des Premixes: VM Broiler Vilomix (je kg Premix)

\begin{tabular}{cc}
\hline Vitamin/Spurenelement & pro kg Premix \\
\hline Vitamin A & $1.200 .000 \mathrm{I} . \mathrm{E}$. \\
Vitamin $\mathrm{D}_{3}$ & $350.000 \mathrm{I.E}$. \\
Vitamin E & $4.000 \mathrm{mg}$ \\
Vitamin $\mathrm{B}_{1}$ & $250 \mathrm{mg}$ \\
Vitamin $\mathrm{B}_{2}$ & $800 \mathrm{mg}$ \\
Vitamin $\mathrm{B}_{6}$ & $600 \mathrm{mg}$ \\
Vitamin $\mathrm{B}_{12}$ & $3.200 \mathrm{mg}$ \\
Vitamin $\mathrm{K}_{3}$ & $450 \mathrm{mg}$ \\
Nicotinsäure & $4.500 \mathrm{mg}$ \\
Ca-Panthothenat & $1.500 \mathrm{mg}$ \\
Folsäure & $120 \mathrm{mg}$ \\
\hline
\end{tabular}

\begin{tabular}{cc}
\hline Vitamin/Spurenelement & pro kg Premix \\
\hline Biotin & $5000 \mathrm{mg}$ \\
Cholinchlorid & $55.000 \mathrm{mg}$ \\
Eisen & $3.000 \mathrm{mg}$ \\
Kupfer & $2.000 \mathrm{mg}$ \\
Mangan & $10.000 \mathrm{mg}$ \\
Zink & $8.000 \mathrm{mg}$ \\
Jod & $120 \mathrm{mg}$ \\
Selen & $40 \mathrm{mg}$ \\
Kobalt & $40 \mathrm{mg}$ \\
BHT & $10.000 \mathrm{mg}$ \\
\end{tabular}




\subsubsection{Herstellung der Versuchsdiäten}

Die betreffenden Hauptkomponenten der verschiedenen Futtermischungen sind den einzelnen Versuchskomplexen im Kapitel 4.3.3 „Versuchsdiäten“ $\mathrm{zu}$ entnehmen. Bevor eine Formulierung und Herstellung der Futtermischungen erfolgte, wurden die zu verwendenden Einzelfuttermittelkomponenten auf ihre Zusammensetzung bezüglich der Rohnährstoffe und Aminosäurengehalte analysiert.

Die Herstellung der Futtermischungen für die Geflügelversuche erfolgte mit Chargenmischern unterschiedlichen Fassungsvermögens der Fa. Lödige (Typ M20MK bzw. Typ FM130D1MZ). Zur Realisierung einer möglichst hohen Mischgenauigkeit in den Diäten wurde eine Vormischung, bestehend aus denjenigen Komponenten mit einem Anteil von $\leq 5 \%$, bereitet. Zudem wurde für jedes Versuchsfutter die Vormischung mit einem Proteinträger der Hauptkomponenten auf ca. 8 kg aufgefüllt. Der anschließende Mischvorgang, der Vormischung der Kleinkomponenten, erfolgte in einem Exaktmischer mit einem Fassungsvermögen von $10 \mathrm{~kg}$ (Fa. Lödige, Typ M20MK). Die derart erstellte Vormischung wurde daraufhin in einem $50 \mathrm{~kg}$ Exaktmischer (Fa. Lödige, Typ FM130D1MZ) mit den verbleibenden Hauptkomponenten der Diät vermischt, wobei die Ölzugabe erst nach wenigen Minuten Mischzeit erfolgte. Zusätzlich wurde dem Gemisch wenige Minuten nach Zugabe des Öls noch 5 - 15\% Wasser, entsprechend dem jeweiligen Wasserbindungsvermögen zugeführt, was eine Pelletierung der Futtermischungen ermöglichte.

Das fertige Futtergemisch wurde den Küken in pelletierter Form zur Verfügung gestellt, welches mittels Pelletpresse (Typ 3530 der Fa. Lister) kompaktiert wurde. Dabei wurde nach Wachstumsphasen differenziert. Die Futtermischungen für die Starterperiode wurden unter Zuhilfenahme einer Lochmatritze von 2,2 mm pelletiert und verabreicht. Das pelletierte Futter für die Growerperiode kam mit einem mittleren Pelletdurchmesser von $3 \mathrm{~mm}$ zum Einsatz. Nach der Futterpelletierung erfolgte die Trocknung über Nacht durch Lufttrocknung oder unter zu Hilfenahme eines Umlufttrockners bei $40^{\circ} \mathrm{C}$.

Im Anschluss an den Trocknungsvorganges wurden die Pellets bis zur Verfütterung gelagert. Die Futtermischung mit 6,1\% XP im Untersuchungskomplex I erwies sich, aufgrund des hohen Anteils an Weizenquellstärke, als schwer pelletierbar. Daher wurde diese Mischung in einem Kutter (Fa. Müller und Söhne) unter Zugabe von Wasser konfundiert, im Anschluss dessen auf Blechen ausgebreitet und 24 Stunden bei $40^{\circ} \mathrm{C}$ im Umlufttrockner getrocknet. 


\subsubsection{Versuchsdiäten}

Die den jeweiligen Versuchskomplexen zugeordneten Futtermischungen werden nachfolgend detailliert beschrieben. Allgemeingültig ist, dass die Fütterung nach einem zweiphasigen Fütterungsregime durchgeführt worden ist, in dem die Futtermischungen dem Alter der Tiere angepasst wurden. Somit wurde zu Beginn eine Starter- und im Anschluss dessen eine Growerfuttermischung dargeboten. Die letztere enthielt im Vergleich zum Starterfutter einen höheren Energiegehalt bei geringerem Anteil an Protein.

Die Rohrnährstoff- und Energiegehalte der Futtermischungen in den Bilanz- und Wachstumsversuchen wurden nach den NRC-Empfehlungen für Geflügel (NRC, 1994) ausgerichtet. Die Einstellung der jeweils gewünschten Aminosäurenverhältnisse erfolgte, (wenn nicht anders ausgewiesen) in Anlehnung an das NRC (1994). Der Aminosäuenausgleich erfolgte über kristalline Aminosäuren und wird in den einzelnen Versuchen detailliert ausgewiesen.

\subsubsection{Untersuchungskomplex I}

Zur Ermittlung der Modellparameter, die für Ableitungen mit dem exponentiellen NVerwertungsmodell benötigt werden, wurde ein N-Bilanzversuch durchgeführt. Als Futter kamen 6 Testdiäten mit gestuftem Proteingehalt (36,7\%, 30,6\%, 24,4\%, 18,3\%, 12,2\% und 6,1\% (Starterdiät) bzw. 34,9\%, 29,1\%, 23,3\%, 17,5\%, 11,6\%, 5,8\% (Growerdiät)) zum Einsatz, deren Zusammensetzung in den Tabelle 4.4 bis 4.7 dargestellt ist. Die Diäten basierten auf einer Mischung aus den Hauptkomponenten Sojaproteinkonzentrat (SPC), Erbsen und Mais und wiesen neben einem identischen Aminosäurenverhältnis eine Limitierung in den schwefelhaltigen Aminosäuren Methionin/Cystein auf. Durch Verdünnung mit einer $\mathrm{N}$-freien Komponente (Weizenquellstärke) konnte bei identischen Aminosäurenverhältnissen ein abgestufter Proteingehalt in den Futtermischungen verwirklicht werden.

Angaben zur Zusammensetzung, Energie-, Rohnährstoff- und Aminosäurengehalte der Starterfuttermischungen finden sich in Tabelle 4.4 und Tabelle 4.5. 
Tabelle 4.4: Zusammensetzung der Startermischungen (g/kg) im Versuch 1

\begin{tabular}{|c|c|c|c|c|c|c|}
\hline \multirow[b]{2}{*}{ Komponenten } & \multicolumn{5}{|c|}{ Futtermischungen } & \multirow[b]{2}{*}{$\begin{array}{c}\text { N } 6 \\
(6,1 \%)\end{array}$} \\
\hline & $\begin{array}{c}\text { N 1 } \\
(36,7 \%) \\
\end{array}$ & $\begin{array}{c}\text { N 2 } \\
(30,6 \%)\end{array}$ & $\begin{array}{c}\text { N 3 } \\
(24,4 \%)\end{array}$ & $\begin{array}{c}\text { N 4 } \\
(18,3 \%) \\
\end{array}$ & $\begin{array}{c}\text { N 5 } \\
(12,2 \%) \\
\end{array}$ & \\
\hline SPC & 370,00 & 308,33 & 246,67 & 185,00 & 123,30 & 61,67 \\
\hline Mais & 219,60 & 183,00 & 139,90 & 109,80 & 73,20 & 36,60 \\
\hline Erbsen & 150,00 & 125,00 & 100,00 & 75,00 & 50,00 & 25,00 \\
\hline Sojaöl & 120,00 & 108,00 & 95,00 & 83,00 & 70,00 & 58,00 \\
\hline Weizenkleber & 100,00 & 83,33 & 66,67 & 50,00 & 33,33 & 16,67 \\
\hline $\mathrm{DCP} *$ & 16,00 & 18,50 & 21,50 & 24,30 & 27,00 & 29,50 \\
\hline $\mathrm{CaCO}_{3}$ & 10,00 & 8,70 & 7,30 & 6,20 & 4,95 & 3,80 \\
\hline Premix** & 10,00 & 10,00 & 10,00 & 10,00 & 10,00 & 10,00 \\
\hline Weizenquellstärke & 30,00 & 153,74 & 311,56 & 455,30 & 606,82 & 757,36 \\
\hline $\mathrm{NaCl}$ & 1,40 & 1,40 & 1,40 & 1,40 & 1,40 & 1,40 \\
\hline
\end{tabular}

* DCP $=$ Dicalciumphosphat

** Zusammensetzung des Premixes siehe Tabelle 4.3

Tabelle 4.5: Energie-, Rohnährstoff- \& Aminosäurengehalte der Startermischungen (\% FS) (Versuch 1)

\begin{tabular}{|c|c|c|c|c|c|c|}
\hline \multirow[b]{2}{*}{ Inhaltsstoffe } & \multicolumn{5}{|c|}{ Futtermischungen } & \multirow[b]{2}{*}{$\begin{array}{c}\text { N } 6 \\
(6,1 \%)\end{array}$} \\
\hline & $\begin{array}{c}\text { N 1 } \\
(36,7 \%)\end{array}$ & $\begin{array}{c}\mathrm{N} 2 \\
(30,6 \%)\end{array}$ & $\begin{array}{c}N 3 \\
(24,4 \%)\end{array}$ & $\begin{array}{c}\text { N } 4 \\
(18,3 \%)\end{array}$ & $\begin{array}{c}\text { N } 5 \\
(12,2 \%)\end{array}$ & \\
\hline ME (MJ/kg TS) & 15,03 & 15,04 & 15,02 & 15,03 & 15,01 & 15,02 \\
\hline Trockensubstanz & 92,38 & 92,68 & 93,07 & 93,38 & 93,72 & 94,07 \\
\hline Rohprotein & 36,72 & 30,60 & 24,43 & 18,36 & 12,24 & 6,13 \\
\hline Rohfett & 13,67 & 12,21 & 10,61 & 9,18 & 7,62 & 6,15 \\
\hline Rohfaser & 2,50 & 2,15 & 1,78 & 1,44 & 1,09 & 0,73 \\
\hline Rohasche & 6,60 & 6,21 & 5,85 & 5,52 & 5,16 & 4,78 \\
\hline $\begin{array}{l}\mathrm{N} \text {-freie } \\
\text { Extraktstoffe }\end{array}$ & 40,51 & 48,83 & 57,33 & 65,50 & 73,89 & 82,21 \\
\hline Lysin & 1,823 & 1,519 & 1,214 & 0,911 & 0,607 & 0,304 \\
\hline Threonin & 1,396 & 1,163 & 0,928 & 0,698 & 0,465 & 0,096 \\
\hline Methionin & 0,574 & 0,479 & 0,382 & 0,287 & 0,191 & 0,096 \\
\hline Cystein & 0,661 & 0,551 & 0,440 & 0,331 & 0,220 & 0,110 \\
\hline
\end{tabular}

Die Tabellen 4.6 und 4.7 zeigen die Angaben zur Zusammensetzung, Energie-, Rohnährstoffund Aminosäurengehalte der Growerfuttermischungen. Eine detailliertere Betrachtung der einzelnen Aminosäurengehalte und Aminosäurenmuster finden sich im Anhang in der Tabelle A 1 und der Tabelle A 2. 
Tabelle 4.6: Zusammensetzung der Growerfuttermischungen (g/kg) im Versuch 1

\begin{tabular}{lcccccc}
\hline & \multicolumn{7}{c}{ Futtermischungen } & N5 & N6 \\
\cline { 2 - 7 } Komponenten & $\mathbf{N 1}$ & $\mathbf{N 2}$ & $\mathbf{N 3}$ & $\mathbf{N 4}$ & $\mathbf{N}$ & $\mathbf{( 5 , 8 \% )}$ \\
\hline SPC & $\mathbf{( 3 4 , 9 \% )}$ & $\mathbf{( 2 9 , 1 \% )}$ & $\mathbf{( 2 3 , 3 \% )}$ & $\mathbf{( 1 7 , 5 \% )}$ & $\mathbf{( 1 1 , 6 \% )}$ & 58,59 \\
Mais & 351,50 & 292,91 & 234,34 & 175,75 & 117,14 & 34,77 \\
Erbsen & 208,62 & 173,90 & 139,08 & 104,31 & 69,54 & 23,75 \\
Sojaöl & 142,50 & 118,50 & 95,00 & 71,25 & 47,50 & 63,00 \\
Weizenkleber & 133,35 & 118,50 & 104,49 & 91,10 & 77,00 & 15,84 \\
DCP* & 95,00 & 79,17 & 63,34 & 47,50 & 31,66 & 28,03 \\
CaCO 3 & 15,20 & 17,58 & 20,43 & 22,80 & 25,65 & 3,61 \\
Premix** & 9,50 & 8,27 & 6,94 & 5,89 & 4,70 & 10 \\
Weizenquellstärke & 10 & 10 & 10 & 10 & 10 & 761,02 \\
NaCl & 33 & 179,78 & 325,00 & 470,00 & 615,41 & 1,40 \\
\hline
\end{tabular}

* DCP $=$ Dicalciumphosphat

** Zusammensetzung des Premixes siehe Tabelle 4.3

Tabelle 4.7: Energie-, Rohnährstoff- \& Aminosäurengehalte der Growermischungen (\% FS) (Versuch 1)

\begin{tabular}{lcccccc}
\hline & \multicolumn{7}{c}{ Futtermischungen } \\
\cline { 2 - 7 } Inhaltsstoffe & $\mathbf{N 1}$ & $\mathbf{N 2}$ & $\mathbf{N 3}$ & $\mathbf{N 4}$ & $\mathbf{N 5}$ & $\mathbf{N 6}$ \\
& $\mathbf{( 3 4 , 9 \% )}$ & $\mathbf{( 2 9 , 1 \% )}$ & $\mathbf{( 2 3 , 3 \% )}$ & $\mathbf{( 1 7 , 5 \% )}$ & $\mathbf{( 1 1 , 6 \% )}$ & $\mathbf{( 5 , 8 \% )}$ \\
\hline ME (MJ/kg TS) & 15,42 & 15,35 & 15,30 & 15,26 & 15,21 & 15,16 \\
Trockensubstanz & 92,53 & 92,84 & 93,16 & 93,48 & 93,80 & 94,12 \\
Rohprotein & 34,88 & 29,07 & 23,26 & 17,45 & 11,63 & 5,82 \\
Rohfett & 14,92 & 13,19 & 11,54 & 9,95 & 8,29 & 6,64 \\
Rohfaser & 2,39 & 2,05 & 1,72 & 1,38 & 1,05 & 0,71 \\
Rohasche & 6,31 & 5,95 & 5,62 & 5,27 & 4,95 & 4,59 \\
N-freie & & & & & & \\
Extraktstoffe & 41,498 & 49,745 & 57,862 & 65,954 & 74,079 & 82,238 \\
Lysin & 1,732 & 1,443 & 1,154 & 0,866 & 0,577 & 0,289 \\
Threonin & 1,326 & 1,105 & 0,884 & 0,663 & 0,442 & 0,221 \\
Methionin & 0,546 & 0,455 & 0,364 & 0,273 & 0,182 & 0,091 \\
Cystein & 0,628 & 0,524 & 0,419 & 0,314 & 0,209 & 0,105 \\
\hline
\end{tabular}




\subsubsection{Untersuchungskomplex II}

Zur Untersuchung der relativen Methioninwirksamkeit standen DLM (DL-Methionin), 2Amino-4-Methylthiobuttersäure, 99 \%) und MHA (2-Hydroxy-4-Methylthiobuttersäure, 88\%, Handelsname Rhodimet 88 auf Silikon-Dioxid Träger) zur Verfügung.

Zur Ableitung wurden Futtermischungen mit einer Limitierung in den schwefelhaltigen Aminosäuren benötigt, um die Methioninwirksamkeit zu ermitteln. Dazu wurden zwei Basalmischungen (Kontrolldiäten) formuliert, die hauptsächlich auf den Proteinträgern Mais, Sojaextraktionsschrot, Ackerbohnen und Erbsen basierten. Die Supplementation von L-LysinHCl, L-Threonin, L-Isoleucin, L-Arginin und L-Valin diente zur Deckung des Bedarfes dieser Aminosäuren und zur Erweiterung des Limitierungsbereiches der schwefelhaltigen Aminosäuren Methionin und Cystein nach dem Aminosäurenmuster des NRC (1994).

Die Kontrolldiäten (NC) des Versuches 2 bzw. 3 sowie 4 bzw. 5 waren analog in ihrer Zusammensetzung der Einzelkomponenten. Aufgrund der Verwendung unterschiedlicher Chargen Sojaschrot zwischen den Versuchen zeigen sich trotz identischer mengen- und komponentenbezogener Formulierung der Mischungen geringe chargenbedingte Variabilitäten in den Energie-, Rohnährstoff- und Aminosäurengehalte, die in der Tabelle 4.9 und der Tabelle 4.11 näher charakterisiert werden. Der kalkulierte Rohproteingehalt betrug 18,2\% im Versuch 2 bzw. 3 und 18,0\% im Versuch 4 bzw. 5.

Die Met-limitierten Kontrolldiäten wurden durch 2 Stufen Methionin (DLM oder MHA) + LCystein- $\mathrm{HCl} \cdot \mathrm{H}_{2} \mathrm{O}$ (Versuch 2 und 3) bzw. Methionin (DLM oder MHA) (Versuch 4 und 5) supplementiert. Dabei wurde darauf geachtet, dass die Zugaben an DL-Methionin und MHA, bezüglich ihrer wirkaktiven Substanz, äquivalent waren. Für die Berechnung der Methioninäquivalente wurde davon ausgegangen, dass DL-Methionin eine Reinheit von 99\% aufweist und MHA 65\% aktive Substanz enthält. Ein Vergleich beider Methioninquellen war somit hinsichtlich der Methioninwirksamkeit möglich. Die Zugabe an L-Cystein- $\mathrm{HCl} \cdot \mathrm{H}_{2} \mathrm{O}$ (Versuch 2 und 3) wurde so gewählt, dass das Met:Cys-Verhältnis innerhalb der Mischungen des Versuches 2 und 3 konstant blieb.

Tabelle 4.8 und Tabelle 4.10 geben einen Überblick über die Zusammensetzung der Met/Cyslimitierten Starter- und Growermischungen der Versuche 2, 3, 4 und 5. 
Tabelle 4.8: Zusammensetzung der Starterfuttermischungen (g/kg) im Untersuchungskomplex II

\begin{tabular}{|c|c|c|c|c|c|c|c|c|c|}
\hline \multirow[b]{2}{*}{ Komponenten } & \multirow{2}{*}{$\begin{array}{c}\text { Kontrolldiäten } \\
\text { NC }\end{array}$} & \multicolumn{4}{|c|}{ Versuch 2 und 3} & \multicolumn{4}{|c|}{ Versuch 4 und 5} \\
\hline & & $\begin{array}{l}\text { M+ } \\
\text { C I }\end{array}$ & $\begin{array}{l}\text { M+ } \\
\text { C II }\end{array}$ & $\begin{array}{c}\text { MHA+ } \\
\text { C I }\end{array}$ & $\begin{array}{c}\text { MHA+ } \\
\text { C II }\end{array}$ & M I & M II & MHA I & MHA II \\
\hline Mais & 475,00 & 475,00 & 475,00 & 475,00 & 475,00 & 475,00 & 475,00 & 475,00 & 475,00 \\
\hline $\begin{array}{l}\text { Sojaextraktionss } \\
\text { chrot }\end{array}$ & 225,00 & 225,00 & 225,00 & 225,00 & 225,00 & 225,00 & 225,00 & 225,00 & 225,00 \\
\hline Ackerbohnen & 110,00 & 110,00 & 110,00 & 110,00 & 110,00 & 110,00 & 110,00 & 110,00 & 110,00 \\
\hline Erbsen & 100,00 & 100,00 & 100,00 & 100,00 & 100,00 & 100,00 & 100,00 & 100,00 & 100,00 \\
\hline Weizenstärke & 37,03 & 33,78 & 30,56 & 33,10 & 29,20 & 33,78 & 30,56 & 33,10 & 29,20 \\
\hline $\mathrm{CaCO}_{3}$ & 15,00 & 15,00 & 15,00 & 15,00 & 15,00 & 15,00 & 15,00 & 15,00 & 15,00 \\
\hline Sojaöl & 10,00 & 10,00 & 10,00 & 10,00 & 10,00 & 10,00 & 10,00 & 10,00 & 10,00 \\
\hline Premix* & 10,00 & 10,00 & 10,00 & 10,00 & 10,00 & 10,00 & 10,00 & 10,00 & 10,00 \\
\hline $\mathrm{MCP} * *$ & 10,00 & 10,00 & 10,00 & 10,00 & 10,00 & 10,00 & 10,00 & 10,00 & 10,00 \\
\hline L-Lysine-HCl & 2,70 & 2,70 & 2,70 & 2,70 & 2,70 & 2,70 & 2,70 & 2,70 & 2,70 \\
\hline L-Valin & 1,45 & 1,45 & 1,45 & 1,45 & 1,45 & 1,45 & 1,45 & 1,45 & 1,45 \\
\hline $\mathrm{NaCl}$ & 1,44 & 1,44 & 1,44 & 1,44 & 1,44 & 1,44 & 1,44 & 1,44 & 1,44 \\
\hline L-Threonin & 1,00 & 1,00 & 1,00 & 1,00 & 1,00 & 1,00 & 1,00 & 1,00 & 1,00 \\
\hline L-Isoleucin & 0,88 & 0,88 & 0,88 & 0,88 & 0,88 & 0,88 & 0,88 & 0,88 & 0,88 \\
\hline L-Arginin & 0,50 & 0,50 & 0,50 & 0,50 & 0,50 & 0,50 & 0,50 & 0,50 & 0,50 \\
\hline $\begin{array}{l}\text { L-Cystein- } \\
\mathrm{HCl} \cdot \mathrm{H}_{2} \mathrm{O}\end{array}$ & - & 2,25 & 4,47 & 2,25 & 4,47 & - & - & - & - \\
\hline $\begin{array}{l}\text { DL- } \\
\text { Methionin }\end{array}$ & - & 1,00 & 2,00 & - & - & 1,00 & 2,00 & - & - \\
\hline MHA & - & - & - & 1,68 & 3,36 & - & - & 1,68 & 3,36 \\
\hline
\end{tabular}

* Zusammensetzung des Premixes siehe Tabelle 4.3

** $\mathrm{MCP}=$ Monocalciumphosphat

Tabelle 4.9: Energie-, Rohnährstoff- \& Aminosäurengehalte der Starterfuttermischungen (\% FS), Untersuchungskomplex II

\begin{tabular}{|c|c|c|c|c|c|c|c|c|c|c|}
\hline \multirow[b]{2}{*}{$\begin{array}{l}\text { Inhalts- } \\
\text { stoffe }\end{array}$} & \multicolumn{5}{|c|}{ Versuch 2 und 3} & \multicolumn{5}{|c|}{ Versuch 4 und 5} \\
\hline & NC & $\begin{array}{l}\text { M+ } \\
\text { C I }\end{array}$ & $\begin{array}{l}\text { M+ } \\
\text { C II }\end{array}$ & $\begin{array}{c}\text { MHA+ } \\
\text { C I }\end{array}$ & $\begin{array}{c}\text { MHA+ } \\
\text { C II }\end{array}$ & NC & M I & M II & MHA I & MHA II \\
\hline $\begin{array}{l}\mathrm{ME} \\
(\mathrm{MJ} / \mathrm{kg} \mathrm{TS})\end{array}$ & 13,16 & 13,13 & 13,10 & 13,10 & 13,04 & 13,37 & 13,38 & 13,38 & 13,35 & 13,32 \\
\hline $\begin{array}{l}\text { Trocken- } \\
\text { substanz }\end{array}$ & 90,79 & 90,81 & 90,31 & 91,55 & 91,66 & 91,81 & 90,04 & 90,31 & 90,60 & 90,23 \\
\hline Rohprotein & 18,73 & 18,91 & 18,98 & 18,11 & 18,35 & 18,65 & 18,35 & 18,46 & 18,50 & 18,53 \\
\hline Rohfett & 4,12 & 4,12 & 4,12 & 4,12 & 4,12 & 4,38 & 4,38 & 4,38 & 4,38 & 4,38 \\
\hline Rohfaser & 4,34 & 4,34 & 4,34 & 4,34 & 4,34 & 4,40 & 4,40 & 4,40 & 4,40 & 4,40 \\
\hline Rohasche & 6,33 & 6,33 & 6,33 & 6,33 & 6,33 & 6,21 & 6,21 & 6,21 & 6,21 & 6,21 \\
\hline $\begin{array}{l}\text { N-freie } \\
\text { Extraktstoffe }\end{array}$ & 66,48 & 66,3 & 66,23 & 67,1 & 66,86 & 66,36 & 66,66 & 66,55 & 66,51 & 66,48 \\
\hline Lysin & 1,249 & 1,249 & 1,249 & 1,249 & 1,249 & 1,225 & 1,225 & 1,225 & 1,225 & 1,225 \\
\hline Methionin* & $\begin{array}{l}0,250 \\
(0,24)\end{array}$ & $\begin{array}{l}0,348 \\
(0,34)\end{array}$ & $\begin{array}{l}0,447 \\
(0,43)\end{array}$ & $\begin{array}{l}0,350 \\
(0,34)\end{array}$ & $\begin{array}{l}0,450 \\
(0,45)\end{array}$ & $\begin{array}{l}0,244 \\
(0,24)\end{array}$ & $\begin{array}{l}0,343 \\
(0,33)\end{array}$ & $\begin{array}{l}0,441 \\
(0,43)\end{array}$ & $\begin{array}{l}0,345 \\
(0,36)\end{array}$ & $\begin{array}{l}0,445 \\
(0,46)\end{array}$ \\
\hline Cystein* & $\begin{array}{l}0,357 \\
(0,28)\end{array}$ & $\begin{array}{l}0,510 \\
(0,41)\end{array}$ & $\begin{array}{l}0,661 \\
(0,55)\end{array}$ & $\begin{array}{l}0,510 \\
(0,41)\end{array}$ & $\begin{array}{l}0,661 \\
(0,57)\end{array}$ & $\begin{array}{l}0,332 \\
(0,29)\end{array}$ & $\begin{array}{l}0,332 \\
(0,27)\end{array}$ & $\begin{array}{l}0,332 \\
(0,28)\end{array}$ & $\begin{array}{l}0,332 \\
(0,29)\end{array}$ & $\begin{array}{l}0,332 \\
(0,29)\end{array}$ \\
\hline
\end{tabular}

* kalkuliert mittels Kalkulationsprogramm Hybrimin ${ }^{\circledR}$ (Ver. 3.9.) basierend auf analysierte Einzelkomponenten, Werte in Klammern beziehen sich auf Analyse der Mischungen 
Tabelle 4.10: Zusammensetzung der Growerfuttermischungen (g/kg) im Untersuchungskomplex II

\begin{tabular}{|c|c|c|c|c|c|c|c|c|c|}
\hline \multirow[b]{2}{*}{ Komponenten } & \multirow{2}{*}{$\begin{array}{c}\text { Kontrolldiät } \\
\text { NC }\end{array}$} & \multicolumn{4}{|c|}{ Versuch 2 und 3} & \multicolumn{4}{|c|}{ Versuch 4 und 5} \\
\hline & & $\begin{array}{l}\text { M+ } \\
\text { C I }\end{array}$ & $\begin{array}{l}\text { M+ } \\
\text { C II }\end{array}$ & $\begin{array}{c}\text { MHA+ } \\
\text { C I }\end{array}$ & $\begin{array}{c}\text { MHA+ } \\
\text { C II }\end{array}$ & M I & M II & MHA I & MHA II \\
\hline Mais & 475,00 & 475,00 & 475,00 & 475,00 & 475,00 & 475,00 & 475,00 & 475,00 & 475,00 \\
\hline $\begin{array}{l}\text { Sojaextraktionsschr } \\
\text { ot }\end{array}$ & 225,00 & 225,00 & 225,00 & 225,00 & 225,00 & 225,00 & 225,00 & 225,00 & 225,00 \\
\hline Ackerbohnen & 110,00 & 110,00 & 110,00 & 110,00 & 110,00 & 110,00 & 110,00 & 110,00 & 110,00 \\
\hline Erbsen & 100,00 & 100,00 & 100,00 & 100,00 & 100,00 & 100,00 & 100,00 & 100,00 & 100,00 \\
\hline Weizenstärke & 37,03 & 33,78 & 30,56 & 33,10 & 29,20 & 33,78 & 30,56 & 33,10 & 29,20 \\
\hline $\mathrm{CaCO}_{3}$ & 15,00 & 15,00 & 15,00 & 15,00 & 15,00 & 15,00 & 15,00 & 15,00 & 15,00 \\
\hline Sojaöl & 10,00 & 10,00 & 10,00 & 10,00 & 10,00 & 10,00 & 10,00 & 10,00 & 10,00 \\
\hline Premix* & 10,00 & 10,00 & 10,00 & 10,00 & 10,00 & 10,00 & 10,00 & 10,00 & 10,00 \\
\hline $\mathrm{MCP} * *$ & 10,00 & 10,00 & 10,00 & 10,00 & 10,00 & 10,00 & 10,00 & 10,00 & 10,00 \\
\hline L-Lysine-HCl & 2,70 & 2,70 & 2,70 & 2,70 & 2,70 & 2,70 & 2,70 & 2,70 & 2,70 \\
\hline L-Valin & 1,45 & 1,45 & 1,45 & 1,45 & 1,45 & 1,45 & 1,45 & 1,45 & 1,45 \\
\hline $\mathrm{NaCl}$ & 1,44 & 1,44 & 1,44 & 1,44 & 1,44 & 1,44 & 1,44 & 1,44 & 1,44 \\
\hline L-Threonin & 1,00 & 1,00 & 1,00 & 1,00 & 1,00 & 1,00 & 1,00 & 1,00 & 1,00 \\
\hline L-Isoleucin & 0,88 & 0,88 & 0,88 & 0,88 & 0,88 & 0,88 & 0,88 & 0,88 & 0,88 \\
\hline L-Arginin & 0,50 & 0,50 & 0,50 & 0,50 & 0,50 & 0,50 & 0,50 & 0,50 & 0,50 \\
\hline $\begin{array}{l}\text { L-Cystein- } \\
\mathrm{HCl} \cdot \mathrm{H}_{2} \mathrm{O}\end{array}$ & - & 2,25 & 4,47 & 2,25 & 4,47 & - & - & - & - \\
\hline DL-Methionin & - & 1,00 & 2,00 & - & - & 1,00 & 2,00 & - & - \\
\hline MHA & - & - & - & 1,68 & 3,36 & - & - & 1,68 & 3,36 \\
\hline
\end{tabular}

* Zusammensetzung des Premixes siehe Tabelle 4.3

** $\mathrm{MCP}=$ Monocalciumphosphat

Tabelle 4.11: Energie-, Rohnährstoff- \& Aminosäurengehalte der Growerfuttermischungen (\% FS), Untersuchungskomplex II

\begin{tabular}{|c|c|c|c|c|c|c|c|c|c|c|}
\hline \multirow[b]{2}{*}{$\begin{array}{l}\text { Inhalts- } \\
\text { stoffe }\end{array}$} & \multicolumn{5}{|c|}{ Versuch 2 und 3} & \multicolumn{5}{|c|}{ Versuch 4 und 5} \\
\hline & NC & $\begin{array}{l}\text { M+ } \\
\text { C I }\end{array}$ & $\begin{array}{l}\text { M+ } \\
\text { C II }\end{array}$ & $\begin{array}{c}\text { MHA+ } \\
\text { C I }\end{array}$ & $\begin{array}{c}\text { MHA+ } \\
\text { C II }\end{array}$ & NC & M I & M II & MHA I & MHA II \\
\hline $\begin{array}{l}\mathrm{ME} \\
(\mathrm{MJ} / \mathrm{kg} \mathrm{TS})\end{array}$ & 14,01 & 13,98 & 13,95 & 13,95 & 13,98 & 14,20 & 14,20 & 14,21 & 14,17 & 14,15 \\
\hline $\begin{array}{l}\text { Trocken- } \\
\text { substanz }\end{array}$ & 88,97 & 88,43 & 88,04 & 88,76 & 88,39 & 91,04 & 89,02 & 89,20 & 89,15 & 89,64 \\
\hline Rohprotein & 17,19 & 16,67 & 16,76 & 17,07 & 16,87 & 16,88 & 16,58 & 16,67 & 16,65 & 16,84 \\
\hline Rohfett & 6,89 & 6,89 & 6,89 & 6,89 & 6,89 & 7,11 & 7,11 & 7,11 & 7,11 & 7,11 \\
\hline Rohfaser & 4,01 & 4,01 & 4,01 & 4,01 & 4,01 & 4,07 & 4,07 & 4,07 & 4,07 & 4,07 \\
\hline Rohasche & 5,61 & 5,61 & 5,61 & 5,61 & 5,61 & 5,50 & 5,50 & 5,50 & 5,50 & 5,50 \\
\hline $\begin{array}{l}\text { N-freie } \\
\text { Extraktstoffe }\end{array}$ & 66,3 & 66,82 & 66,73 & 66,42 & 66,62 & 66,44 & 66,74 & 66,65 & 66,67 & 66,48 \\
\hline Lysin & 1,149 & 1,149 & 1,149 & 1,149 & 1,149 & 1,127 & 1,127 & 1,127 & 1,127 & 1,127 \\
\hline Methionin* & $\begin{array}{l}0,230 \\
(0,23)\end{array}$ & $\begin{array}{l}0,328 \\
(0,33)\end{array}$ & $\begin{array}{l}0,427 \\
(0,41)\end{array}$ & $\begin{array}{l}0,330 \\
(0,33)\end{array}$ & $\begin{array}{l}0,430 \\
(0,44)\end{array}$ & $\begin{array}{l}0,225 \\
(0,24)\end{array}$ & $\begin{array}{l}0,323 \\
(0,34)\end{array}$ & $\begin{array}{l}0,422 \\
(0,42)\end{array}$ & $\begin{array}{l}0,325 \\
(0,33)\end{array}$ & $\begin{array}{l}0,425 \\
(0,44)\end{array}$ \\
\hline Cystein* & $\begin{array}{l}0,328 \\
(0,26)\end{array}$ & $\begin{array}{l}0,481 \\
(0,40)\end{array}$ & $\begin{array}{l}0,632 \\
(0,54)\end{array}$ & $\begin{array}{l}0,481 \\
(0,41)\end{array}$ & $\begin{array}{c}0,632 \\
(0,53)\end{array}$ & $\begin{array}{l}0,305 \\
(0,27)\end{array}$ & $\begin{array}{l}0,305 \\
(0,27)\end{array}$ & $\begin{array}{l}0,305 \\
(0,28)\end{array}$ & $\begin{array}{l}0,305 \\
(0,25) \\
\end{array}$ & $\begin{array}{l}0,305 \\
(0,25)\end{array}$ \\
\hline
\end{tabular}

* kalkuliert mittels Kalkulationsprogramm Hybrimin ${ }^{\circledR}$ (Ver. 3.9.) basierend auf analysierte Einzelkomponenten, Werte in Klammern beziehen sich auf Analyse der Mischungen 


\subsubsection{Untersuchungskomplex III}

In Wachstums- sowie Stoffwechselversuchen sollten ausgewählte Fragen zum Idealprotein für männliche Broiler des Genotyps Ross 308 in Abhängigkeit vom Alter untersucht werden. Die für die Versuche formulierten drei Basalmischungen (BC) basierten auf einem Gemisch, bestehend aus den proteinhaltigen Hauptkomponenten Mais, Fischmehl, Weizen, Ackerbohnen und Weizengluten. Die Auswahl der verwendeten Proteinträger erfolgte vorrangig unter dem Gesichtspunkt, einen möglichst hohen Anteil der Bedarfsdeckung durch native Aminosäuren zu erreichen. Unter diesem Aspekt wurde ein Anteil an Fischmehl notwendig, der von praxisnahen Futtermischungen deutlich abweicht. Diese Komponentenwahl ermöglichte durch den hohen Anteil an Fischmehl eine weitestgehend ausbalancierte Futtermischung, die die Anforderungen bezüglich der nativen Aminosäuregehalte erfüllte (Tabelle 4.12, Tabelle 2.1, Tabelle 4.13) und einen Zusatz an kristallinen Aminosäuren kaum erforderlich machte.

Basierend auf verschiedenen Ableitungen zum idealen Aminosäuremuster für wachsende männliche Broilerküken (AUSTIC 1994, BAKER und HAN 1994, BOORMAN und BURGESS 1986, COON 2004, CRESWELL und SWICK 2001, CVB 1996, DEGUSSA 2003, GFE 1999, HOEHLER und LEMME 2005, NRC 1994, RHONE-POULENC 1993) wurde unter Mittelwertbildung (und Berücksichtigung von stark abweichenden Werten) ein „optimales Aminosäurenverhältnis“ abgeleitet. Diese Mittelwerte aus der Literatur (Tabelle 2.2) bildete die Grundlage zur Formulierung der einzelnen Basalmischungen in diesem Untersuchungskomplex.

Das, aus der Literatur, abgeleitete gemittelte Aminosäurenmuster (Tabelle 2.2) sowie die Aminosäurenverhältnisse der Basalmischungen I, II, III sind in der Tabelle A 6 dargestellt. Die Zusammensetzungen der drei Basalmischungen (BC), differenziert nach Wachstumsphase (Starter und Grower), sind in der nachfolgenden Tabelle 4.12 dargestellt. 
Tabelle 4.12: Zusammensetzung der Basalmischung des Untersuchungskomplexes III (g/kg)

\begin{tabular}{|c|c|c|c|c|c|c|}
\hline \multirow[b]{3}{*}{ Komponenten } & \multicolumn{6}{|c|}{ Basalmischungen } \\
\hline & \multicolumn{3}{|c|}{ Starterperiode } & \multicolumn{3}{|c|}{ Growerperiode } \\
\hline & $\begin{array}{l}\text { Versuch } \\
6 \text { und } 7\end{array}$ & $\begin{array}{c}\text { Versuch } \\
8 \\
\end{array}$ & $\begin{array}{l}\text { Versuch } \\
9 \text { und } 10\end{array}$ & $\begin{array}{l}\text { Versuch } \\
6 \text { und } 7\end{array}$ & $\begin{array}{c}\text { Versuch } \\
8 \\
\end{array}$ & $\begin{array}{l}\text { Versuch } \\
9 \text { und } 10\end{array}$ \\
\hline Mais & 430,00 & 400,00 & 380,00 & 395,60 & 370,43 & 352,26 \\
\hline Weizen & 180,00 & 140,00 & 150,00 & 165,60 & 129,66 & 139,05 \\
\hline Fischmehl & 170,00 & 200,00 & 204,00 & 156,40 & 185,22 & 189,11 \\
\hline Ackerbohnen & 130,00 & 150,00 & 150,00 & 119,60 & 138,91 & 139,05 \\
\hline Weizengluten & 40,00 & 30,00 & 40,00 & 36,80 & 27,78 & 37,08 \\
\hline Weizenstärke & 11,80 & 42,00 & 48,30 & 78,14 & 100,80 & 117,94 \\
\hline Sojaöl & 20,00 & 20,00 & 5,00 & 30,00 & 30,00 & 10,00 \\
\hline Premix* & 10,00 & 10,00 & 10,00 & 10,00 & 10,00 & 10,00 \\
\hline $\mathrm{CaCO}_{3}$ & 4,00 & 4,00 & 9,20 & 2,00 & 2,00 & - \\
\hline Zellulose & - & 1,60 & 1,20 & 2,00 & 3,00 & 3,40 \\
\hline DL-Methionin & 0,600 & 0,74 & 0,53 & 0,55 & 0,65 & 0,48 \\
\hline L-Cystein- $\mathrm{HCl} \cdot \mathrm{H}_{2} \mathrm{O}$ & 1,90 & 1,66 & 1,60 & 1,75 & 1,55 & 1,47 \\
\hline L-Arginin & 1,70 & - & 0,17 & 1,56 & - & 0,16 \\
\hline
\end{tabular}

* Zusammensetzung des Premixes siehe Tabelle 4.3

Nach Herstellung der Basalmischung erfolgte anschließend eine Verdünnung dieser mittels $\mathrm{N}$-freier Komponente auf ein Niveau von $80 \%$. Um diesen Verdünnungseffekt erzielen zu können, wurde Weizenquellstärke als Ersatz für die Proteinquelle genutzt, sodass eine Reduzierung der Rohprotein- und Aminosäurengehalte erfolgte, ohne das Aminosäurenmuster zu beeinflussen.

Zur Erstellung der einzelnen Mischungen mit definierter limitierender Position einzelner Aminosäuren, wurden die verdünnten Basalmischungen mittels Aminosäuren wieder auf 100\% aufgefüllt. Ausgenommen davon war die zu untersuchende Aminosäure. In den Versuchen 6, 8 und 10 waren Aminosäuren mit limitierender Position Lys, Thr, Trp Arg, Ile, Val. Im Stoffwechselversuch 9 standen Arg und Trp im nicht im Fokus der Betrachtung, während im Wachstumsversuch $7 \mathrm{Thr}$ nicht untersucht wurde. Zur Erzielung eines deutlicheren Effektes, hinsichtlich der Ableitung des idealen Aminosäurenverhältnisses, erfolgte in den Versuchen 9 und 10 eine Verdünnung der Aminosäuren Isoleucin und Valin auf $70 \%$. Während in diesen Versuchen eine Kompensation des durch die Verdünnung abgesenkten N- Gehaltes mittels Glutaminsäure erfolgte, fand in den Versuchen 6, 7 und 8 nur teilweise ein Ausgleich statt. Des Weiteren wurde in den Versuchen 8, 9 und 10 der Lysingehalt im Starterfutter von $12,5 \mathrm{~g} / \mathrm{kg}$ auf $13,5 \mathrm{~g} / \mathrm{kg}$ und im Growerfutter von $11,5 \mathrm{~g} / \mathrm{kg}$ auf $12,5 \mathrm{~g} / \mathrm{kg}$ erhöht. 
In der Tabelle 4.13 sind die Energie-, Rohnährstoff- und Aminosäurengehalte der Basalmischung des Untersuchungskomplexes III dargestellt.

Tabelle 4.13: Energie-, Rohnährstoff- \& Aminosäurengehalte der Basalmischungen (\% FS), Untersuchungskomplex III

\begin{tabular}{|c|c|c|c|c|c|c|}
\hline \multirow[b]{2}{*}{ Inhaltsstoffe } & \multicolumn{3}{|c|}{ Startermischung } & \multicolumn{3}{|c|}{ Growermischung } \\
\hline & $\begin{array}{l}\text { Versuch } \\
6 \text { und } 7\end{array}$ & $\begin{array}{c}\text { Versuch } \\
8 \\
\end{array}$ & $\begin{array}{l}\text { Versuch } \\
9 \text { und } 10\end{array}$ & $\begin{array}{l}\text { Versuch } \\
6 \text { und } 7\end{array}$ & $\begin{array}{c}\text { Versuch } \\
8 \\
\end{array}$ & $\begin{array}{l}\text { Versuch } \\
9 \text { und } 10\end{array}$ \\
\hline $\begin{array}{l}\mathrm{ME} \\
(\mathrm{MJ} / \mathrm{kg} \mathrm{TS})\end{array}$ & 14,81 & 15,14 & 14,41 & 15,05 & 15,36 & 14,64 \\
\hline Trockensubstanz & 88,55 & 89,23 & 89,01 & 89,05 & 89,64 & 89,43 \\
\hline Rohprotein & 22,91 & 23,90 & 23,90 & 21,08 & 22,14 & 22,15 \\
\hline Rohfett & 5,65 & 7,01 & 5,06 & 6,37 & 7,65 & 5,23 \\
\hline Rohfaser & 2,26 & 2,24 & 2,21 & 2,25 & 22,21 & 2,24 \\
\hline Rohasche & 5,23 & 5,47 & 6,09 & 4,72 & 4,97 & 4,88 \\
\hline $\begin{array}{l}\text { N-freie } \\
\text { Extraktstoffe }\end{array}$ & 62,95 & 61,38 & 62,74 & 65,58 & 43,03 & 65,5 \\
\hline Lys & 1,25 & 1,35 & 1,35 & 1,15 & 1,25 & 1,25 \\
\hline Thr & 0,81 & 0,90 & 0,90 & 0,75 & 0,83 & 0,83 \\
\hline $\operatorname{Trp}$ & 0,23 & 0,25 & 0,26 & 0,21 & 0,23 & 0,24 \\
\hline Arg & 1,31 & 1,43 & 1,42 & 1,21 & 1,33 & 1,31 \\
\hline Ile & 0,84 & 0,93 & 0,93 & 0,77 & 0,86 & 0,86 \\
\hline Val & 1,02 & 1,10 & 1,11 & 0,94 & 1,02 & 1,03 \\
\hline
\end{tabular}




\subsection{Tierhaltung und Versuchsdurchführung}

In diesem Kapitel werden die Abläufe der durchgeführten Versuche unter Differenzierung von N-Bilanz- und Wachstumsversuchen beschrieben. Die Versuche wurden in den Versuchseinrichtungen der Abteilung Tierernährungsphysiologie der Universität Göttingen im Zeitraum von November 2007 bis April 2010 durchgeführt. Diese verliefen ohne Komplikationen. Alle Tierabgänge wurden protokolliert und lagen im normalen Bereich.

\subsubsection{Stoffwechselversuche (N-Bilanzversuche)}

Gegenstand dieser Studien war die Messung der täglichen Stickstoffaufnahme und Stickstoffausscheidung, um über die Differenz des N-Inputs und der N-Exkretion die täglich Stickstoffbilanz abzuleiten. Die Untersuchungen wurden mit jeweils 2 x 36 Tieren in zwei Wachstumsperioden durchgeführt.

\subsubsection{Haltung und Fütterung}

Bei Stoffwechselversuchen teilte sich die gesamte Versuchszeit in Vor- und Hauptperiode auf. Die Bilanzmessungen wurden in zwei Altersabschnitten durchgeführt, welche sich auf den Zeitraum vom 10. - 20. LT (Starter) und auf den Zeitraum vom 25. - 35. LT (Grower) bezogen. Bis zum Beginn der Vorperiode wurden die Tiere mit einem handelsüblichen Broilerstarterfutter bzw. mit der Kontrollmischung der Versuche gefüttert. Die Aufzucht bis $\mathrm{zu}$ diesem Zeitpunkt erfolgte standardisiert bei konventioneller Bodenhaltung auf Einstreu. Die sich vom 3. bis zum 10. Lebenstag (Starter) bzw. 18. bis zum 25. Lebenstag (Grower) ersteckende Vorperiode diente zur Gewöhnung der Küken an die Haltungsform in Stoffwechselkäfigen und an das Versuchsfutter. Zur besseren Eingewöhnung wurden die, der mittleren Lebendmasse entsprechenden Küken, vorerst paarweise in die Stoffwechselkäfige eingestallt. Am 7. LT (Starter) bzw. 23. LT (Grower) erfolgte die Separierung und Verteilung der Tiere auf die einzelnen Versuchsgruppen, wobei das Futter zur Vermeidung von Streuverlusten weitgehend rationiert verabreicht wurde. 
Nach Ablauf der Vorperiode schloss sich unverzüglich die Hauptperiode an, die über 10 Tage verlief und sich in zwei Sammelphasen von jeweils 5 Tagen gliederte. Zu Beginn und am Ende jeder Sammelperiode wurde das Gewicht der Tiere erfasst. Futter und Wasser stand den Tieren in allen Versuchen ad libitum zur Verfügung. Eine Ausnahme bildete dabei der NSteigerungsversuch (Versuch 1). Dort wurde die Futtermenge gezielt rationiert, um eine möglichst gleiche Trockensubstanzaufnahme und somit eine möglichst deutliche Differenzierung zwischen den Gruppen bezüglich der N-Aufnahme zu erhalten.

Durch Einzeltierwägung zu Beginn der Versuche konnte auf vergleichbare Lebendmassen aller Versuchsgruppen geachtet werden. Die mittlere Lebendmasse der Tiere zu Beginn der Hauptperiode sowie weitere ausgewählte Aspekte zu den einzelnen Versuchen sind aus der Tabelle 4.1 und der Tabelle 4.2 zu entnehmen.

Zur Durchführung der Bilanzversuche standen Stoffwechselkäfige mit Stabrosten und sich darunter befindlichen Sammelblechen zur Verfügung, welche durch ihre Konstruktion eine quantitative Exkrementsammlung ermöglichte. Während die Käfige der Starterperiode über eine Standfläche von $30 \mathrm{~cm} \times 25 \mathrm{~cm}$ und einer Standhöhe von $26 \mathrm{~cm}$ verfügten, wiesen die Käfige der Growerperiode eine Standfläche von $80 \mathrm{~cm} \times 80 \mathrm{~cm}$ und eine Standhöhe von $35 \mathrm{~cm}$ auf.

Die relative Luftfeuchte betrug 45 - 60\%. Eine stabile Raumheizung wurde in der gesamten Versuchszeit gewährleistet und an die altersabhängigen Vorgaben für Geflügel angepasst. Der Luftaustausch erfolgte in allen Versuchsräumen durch eine zentralgesteuerte Lüftungsanlage. Das Beleuchtungsregime wurde mittels roter Neonröhren durchgeführt, die eine Beleuchtung von $23 \mathrm{~h}$ pro Tag realisierten. 


\subsubsection{Datenerfassung}

Zur Ermittlung der Bilanzdaten wurden die Küken zu Beginn und am Ende der Sammelperioden gewogen und die Lebendmasse erfasst. Die während der Sammelperioden anfallenden Exkrementmengen wurden zwei Mal täglich ohne Säurevorlage in Plastikeimern gesammelt und durch Zurückwiegen der gefüllten Plastikeimer unter Abzug der Behälterleermasse quantitativ am Ende jeder Sammelperiode ermittelt. Die Erfassung des Futter-verzehrs erfolgte täglich nach Abzug des Restfutters von der gegebenen Futtermenge. Eine aliquote Menge bei der täglichen Einwaage wurde in luftdicht verschließbare Gläser gesammelt und für TS-Analysen zurückgestellt. Zudem wurden Streuverluste erfasst und berücksichtigt.

\subsubsection{Gewinnung und Aufbereitung der Exkremente}

Zur quantitativen Erfassung der in den Bilanzversuchen anfallenden Exkremente wurde während der Hauptperiode zweimal täglich eine Sammlung durchgeführt. Die Verwahrung der gesammelten Exkremente erfolgte in luftdicht verschließbaren Plastikeimern, welche unverzüglich nach der Sammlung bei $-20^{\circ} \mathrm{C}$ zwischengelagert wurden. Vor Beginn der Exkrementsammlung erfolgte die Entfernung von Verunreinigungen, die eventuell in Form von Hautschuppen, Federn und Futterpartikel auftreten konnten.

Die gemäß der Sammelperioden anfallenden Exkrementmengen wurden zur Weiterbearbeitung der Tiefkühlung entnommen, über Nacht bei Zimmertemperatur aufgetaut und anschließend mit einem elektrischen Rührstab (Fa. Braun) unter Zugabe von demineralisiertem Wasser gründlich homogenisiert. Nach der Homogenisierung wurden die Proben, wie im Kapitel 4.5.2 beschrieben, einer Stickstoffanalyse nach dem Verfahren von DUMAS (1990) unterzogen. Parallel dazu wurde eine Trockensubstanzermittlung durchgeführt. 


\subsubsection{Wachstumsversuch}

Parallel zu den Stoffwechselversuchen wurden teilweise Wachstumsversuche durchgeführt, die zur vergleichenden Betrachtung und zur Bestimmung von Proteinansatz und Wachstum dienten. Die Untersuchungen wurden parallel zum Stoffwechselversuch ebenfalls in zwei Durchgängen (Starter- und Growerperiode) durchgeführt. Eine Übersicht zur Anzahl der Tiere, zu den Gruppen und zu weiteren ausgewählten Parametern sind der Tabelle 4.1 und der Tabelle $4.2 \mathrm{zu}$ entnehmen.

\subsubsection{Haltung und Fütterung}

Der Versuchszeitraum bezog sich beim Wachstumsversuch auf die Phase vom 1. - 36. Lebenstag. Dabei erfolgte wiederum eine Unterteilung in die beiden Wachstumsphasen: Die Starterperiode umfasste dabei den 1. - 21. Lebenstag, während die Growerperiode den Zeitraum vom 21. - 36. Lebenstag beinhaltete.

Zum Versuchsbeginn wurden die Küken gewogen, der Mittelwert bestimmt und hinsichtlich ihrer Lebendmasse gleichmäßig über die Gruppen verteilt, so dass die einzelnen Versuchsgruppen den Mittelwert der zur Verfügung stehenden Tiere repräsentierten. Zur Haltung der Versuchstiere wurden Gruppenboxen mit Einstreu (Hobelspäne) bereitgestellt. Jede Box hatte eine Fläche ca. 1,2 $\mathrm{m}^{2}$ und war mit Rinnentrögen und selbstfüllenden Rundtränken aus-gestattet. Alle Gruppen und Subgruppen waren über die verfügbaren Buchten randomisiert verteilt. Die Besetzung der Boxen ist der Tabelle 4.1 und der Tabelle $4.2 \mathrm{zu}$ entnehmen.

In Abhängigkeit von der Futteraufnahme musste das Futter mehrmals täglich zugelegt werden, um eine ad libitum Fütterung zu gewährleisten. Da die Wachstumsversuche parallel $\mathrm{zu}$ den Stoffwechseluntersuchungen stattfanden, waren Luftfeuchtigkeit und Beleuchtungsdauer im Versuchsraum analog zu den Bedingungen im Stoffwechselversuch. Alle im Versuch integrierten Räume wurden vor dem Aufstallen der Eintagsküken auf eine Temperatur von $32^{\circ} \mathrm{C}$ eingestellt und im Verlauf des Versuchs an die altersabhängigen Vorgaben für Geflügel angepasst. 


\subsubsection{Datenerfassung}

Zur Ermittlung der Wachstumsdaten und des Futterverzehrs wurden die Küken separat im wöchentlichen Abstand gewogen. Dabei wurde darauf geachtet, dass die Lebendmassefeststellung der Broiler immer zum gleichen Zeitpunkt stattfand. Somit konnte die entsprechende Zuwachsrate aus der Differenz zwischen den jeweiligen Lebendmassen am Ende und $\mathrm{zu}$ Beginn des Versuchskomplexes kalkuliert werden. Zeitgleich erfolgte die Rückwaage der Futterreste. Hierfür wurde der Futterverzehr nach Abzug des Restfutters ermittelt. Aus der täglichen Lebendmassezunahme und dem Futterverzehr wurde der Futteraufwand kalkuliert.

\subsubsection{Schlachtung und Aufbereitung der Ganzkörperproben}

Zur Bestimmung des Nährstoffansatzes in den Broilern erfolgten zu bestimmten Zeitabschnitten Ganzkörperanalysen. Um vergleichbare Ansatzdaten zu erhalten, wurde zum Versuchsbeginn (1. LT) eine bezüglich der Lebendmasse repräsentative Gruppe von 15 Referenztieren (Nullgruppe) ausgewählt, genüchtert und getötet. Nach Ablauf der Starter(21. LT) und Growerperiode (35. LT) wurden Küken entnommen und über Nacht genüchtert. Die Körpermasse der ausgewählten Tiere sollten dabei annähernd dem Gruppenmittel entsprechen. Am Ende der Nüchterungszeit wurden die Tiere erneut gewogen und durch $\mathrm{CO}_{2}$ Inhalation umgehend verlustlos getötet, anschließend in Plastiktüten bzw. Autoklaviergläsern einzeln verpackt und bis zur weiteren Aufbereitung bei $-20{ }^{\circ} \mathrm{C}$ im Gefrierraum aufbewahrt.

Für die Nährstoffbestimmung der Ganzkörper erfolgte eine Autoklavierung ( $4 \mathrm{~h}$ bei $110{ }^{\circ} \mathrm{C}$ ) mit anschließender Zerkleinerung mit einem Fleischwolf und Homogenisierung. Zur weiteren Bearbeitung wurde dieses Homogenisat dann der Tiefkühlung entnommen, über Nacht schonend bei $+4^{\circ} \mathrm{C}$ aufgetaut und anschließend, wie im Kapitel 4.5.2 beschrieben, einer Stickstoffanalyse nach dem Verfahren von DUMAS (1990) unterzogen. Der Stickstoffzuwachs einer Gruppe ergab sich nach der Methode der vergleichenden Ganzkörperanalyse aus der Differenz der Stickstoffmenge nach Ablauf des jeweiligen Versuchskomplexes und der Stickstoffmenge der Referenztiere zu Versuchsbeginn (Nullgruppe). Parallel dazu wurden eine Trockensubstanz- sowie eine Rohascheanalyse 
durchgeführt. Die N-Bestimmung fand in 3 Wiederholungen statt, die Bestimmung von Trockensubstanz (TS) und Rohasche in zwei Wiederholungen. Der Rohfettgehalt ergab sich rechnerisch aus der Summe, der auf die Trockensubstanz bezogenen Ergebnisse für den Rohprotein- und den Rohaschegehalt, die von 100 subtrahiert wurden. Der sehr geringe Gehalt an N-freien Extraktstoffen ist dabei in der Rohfettfraktion enthalten.

\subsection{Analytik}

Die für die Untersuchung erforderlichen Probenanalysen wurden im Labor der Abteilung Tierernährungsphysiologie der Universität Göttingen durchgeführt. $\mathrm{Zu}$ den relevanten analytischen Aspekten gehörten die analytische Bearbeitung der Futtermittel (Einzelkomponenten und Futtermischungen), sowie die analytische Bearbeitung des Tiermaterials (Ganzkörper und Exkremente). In sämtlichen Proben wurde der Nährstoffgehalt mit zwei bis drei Parallelen bestimmt, die bei zu starker Abweichung der Variationskoeffizienten zwischen den Parallelbestimmungen wiederholt wurden.

\subsubsection{Analytische Aufarbeitung der Einzelkomponenten und der Futtermischungen}

Unmittelbar vor Beginn der Analysen wurden die Einzelkomponenten wie auch die Futtermischungen mittels eines $0,5 \mathrm{~mm}$-Siebeinsatzes in einer Mühle zerkleinert.

\subsubsection{Rohnährstoffe}

Die Bestimmung der Rohnährstoffe in den Futtermischungen, Exkrementen bzw. Ganzkörpern erfolgte auf Grundlage der Weender Rohnährstoffanalytik. Als Durchführungsanleitung für die Weender Rohnährstoffanalytik dienten die bei NAUMANN und BASSLER (1976 - 1997) beschriebenen amtlichen VDLUFA-Analyseverfahren. 
Die N-Menge im Futter nach Vermahlung (0,5 mm Siebgröße) in den Frischexkrementen und in den Ganzkörpern wurde nach Homogenisierung mit dem Verfahren von Dumas unter Verwendung des Kohlenstoff-Stickstoff-Analysators FP 2000 der Firma Leco Instruments bestimmt. Das Messprinzip beruht auf einer vollständigen oxygenen Verbrennung der eingebrachten Probe bei einer Temperatur von $>1000^{\circ} \mathrm{C}$ in reiner Sauerstoffatmosphäre. Die aus dem Stickstoffanteil der Probe stammenden Stickoxide werden bei diesem Messprinzip von den anderen Verbrennungsgasen getrennt und mittels eines Katalysators zu elementarem Stickstoff reduziert. Durch Reduzierung der entstehenden Stickoxide $\left(\mathrm{NO}_{\mathrm{x}}\right)$ zu $\mathrm{N}_{2}$ an elementarem Kupfer und anschließender Adsorption des $\mathrm{CO}_{2}$ an $\mathrm{NaOH}$ auf einem Silikatcarrier wird der N-Gehalt in einer Wärmeleitfähigkeits-Messzelle detektiert und daraus der Stickstoffanteil der Ausgangsprobe berechnet. Nach Multiplikation mit 6,25 konnte der Proteingehalt erfasst werden.

Aus der Summe der Weender Rohnährstoffe XP, XL, XA und XF (bezogen auf die Trockensubstanz) wurden die N-freien Extraktstoffe (NfE) rechnerisch ermittelt.

\subsubsection{Aminosäuren}

Die Aminosäureanalytik erfolgte säulenchromatographisch durch Ionenaustausch mit dem automatischen Aminosäureanalysator LC 3000 A-00166 (Fa. Eppendorf). Zur chromatographischen Trennung der Aminosäuren wurde die Probe mit 6 N Salzsäure versetzt. Durch die stattfindende saure Hydrolyse erfolgte die Trennung der in der Probe enthaltenden einzelnen Aminosäuren aus den Peptidketten. Da bei dem Hydrolyseprozess die Aminosäuren Methionin und Cystein sowie das Tryptophan zerstört werden, mussten diese Aminosäuren deshalb in einem ersten vorbereitenden Schritt in Gegenwart von Wasserstoffperoxid und phenolhaltiger Ameisensäure oxidiert werden, bevor die Proteinbausteine durch Hydrolyse voneinander getrennt werden konnten. Das gewonnene Hydrolysat wurde in beiden Fällen mit einer $2 \mathrm{~N}$ Natronlauge in einer Pufferlösung auf einen pH-Wert von 2,2 titriert, mit der Aminosäure Norleucin versetzt und in den Autosampler des Aminosäureanalysators (Eppendorf LC 3000, Biotronik) appliziert. Die zugesetzte Aminosäure Norleucin diente dabei als interner Eichstandard, welcher über die gemessene Peakfläche eine Quantifizierung der Aminosäuren ermöglichte. Die Trennung der Aminosäuren erfolgte durch Elution mit Pufferlösungen verschiedenen pH-Wertes, wobei eine Anfärbung des Eluats mit NinhydrinReagenz eine photometrische Extinktionsmessung in einer Durchflussküvette ermöglichte. 
Die Berechnung der Peakflächen der Chromatogramme der einzelnen Aminosäuren erfolgte im Vergleich zu einem Standard und lieferte die jeweiligen Aminosäure-Konzentrationen im Probenmaterial. Da Tryptophan mit dem oben beschriebenen Verfahren einer quantitativen Bestimmung nicht zugänglich war, wurde diese anhand des Rohproteingehaltes mit Hilfe einer Regression des Programms AminoDat 1.1 (DEGUSSA 1997) regressiv berechnet.

\subsection{Berechnete Parameter}

Im Folgenden werden grundlegende Parameter, die für die Auswertung der Versuche relevant waren, sowie die Modellberechnung zum exponentiellen N-Verwertungsmodell aufgezeigt.

\subsubsection{Grundlegende Parameter}

Auf der Grundlage des Futterverzehrs und der Lebendmasseentwicklung ist es möglich in Verbindung mit den Analyseergebnissen von Futter, Exkrementen und Ganzkörpern grundlegende Parameter zu berechnen.

\section{a) Lebendmassezunahme}

Die Lebendmassezunahme ( $\mathrm{g} / \mathrm{d})$ wird wie folgt definiert:

$L M Z=\frac{\text { Endmasse }- \text { Anfangsmasse }}{\text { Versuchstage }}$

\section{b) Futteraufwand}

Der Futteraufwand (g/g) ist definiert als der Futterverzehr (g/d) in Bezug zur LMZ (g/d).

$F A=\frac{\text { Futteraufnahme }}{\text { Lebendmassezunahme }}$

\section{c) N-Deposition}

Die Stickstoffdeposition (g/d) ist definiert als die Differenz zwischen N-Menge (g) im Tierkörper zu Versuchsende und Versuchsbeginn, bezogen auf die Versuchstage.

$N D=\frac{N D_{\text {Ende }}-N D_{\text {Anfang }}}{d}$ 


\subsubsection{Modellberechnung}

Die Berechnung der Parameter in den durchgeführten Versuchen erfolgte auf Grundlage des exponentiellen N-Verwertungsmodells nach GEBHARDT (1966). Sie dienten der Bestimmung der Proteinqualität (b), der Aminosäure-Wirksamkeit $\left(\mathrm{bc}^{-1}\right)$ sowie der Ermittlung des lebendmasse- und wirksamkeitsabhängigen Aminosäurebedarfs für einen definierten Proteinansatz. Die Basisfunktion des Modells (4) beschreibt den Verlauf der N-Retention wie folgt:

$\mathrm{NR}=\mathrm{NR}_{\max } \mathrm{T}\left(1-\mathrm{e}^{-\mathrm{b} \cdot \mathrm{NI}}\right)$

Gleichung (5) beschreibt die N-Ansatz-Kurve:

$\mathrm{ND}=\mathrm{NR}_{\max } \mathrm{T}\left(1-\mathrm{e}^{-\mathrm{b} \cdot \mathrm{NI}}\right)-\mathrm{NMR}$

wobei:

$$
\begin{aligned}
\mathrm{NR} & =\text { tägliche N-Retention (ND+NMR) } & {\left[\mathrm{mg} / \mathrm{LM}_{\mathrm{kg}}{ }^{0,67} / \mathrm{d}\right] } \\
\mathrm{ND} & =\text { tägliche N-Deposition (ND) oder N-Bilanz } & {\left[\mathrm{mg} / \mathrm{LM}_{\mathrm{kg}}{ }^{0,67} / \mathrm{d}\right] } \\
\mathrm{NI} & =\text { tägliche N-Aufnahme } & {\left[\mathrm{mg} / \mathrm{LM}_{\mathrm{kg}}{ }^{0,67} / \mathrm{d}\right] } \\
\mathrm{NEX} & =\text { tägliche N-Ausscheidung } & {\left[\mathrm{mg} / \mathrm{LM}_{\mathrm{kg}}{ }^{0,67} / \mathrm{d}\right] } \\
\mathrm{NMR} & =\text { täglicher N-Erhaltungsbedarf } & \\
\mathrm{NR}_{\max } \mathrm{T} & =\text { theoretisches Maximum für die tägliche N-Retention } & {\left[\mathrm{mg} / \mathrm{LM}_{\mathrm{kg}}{ }^{0,67} / \mathrm{d}\right] } \\
\mathrm{ND}_{\max } \mathrm{T} & =\text { theoretisches Maximum für den täglichen N-Ansatz } & {\left[\mathrm{mg} / \mathrm{LM}_{\mathrm{kg}}{ }^{0,67} / \mathrm{d}\right] } \\
\mathrm{NR}_{\max } \mathrm{T} & =\mathrm{ND}_{\max } \mathrm{T}+\mathrm{NMR} & \\
\mathrm{e} & =\text { Grundzahl der natürlichen Logarithmen (ln) } & \\
\mathrm{b}= & \text { Proteinqualität (Anstieg der N-Retentionskurve, der Anstieg der } & \\
& \text { Kurve für eine gegebenen Proteinqualität ist keine Funktion von NI) } &
\end{aligned}
$$

$\mathrm{NR}_{\max } \mathrm{T}$ ist artspezifisch und innerartlich abhängig vom Genotyp, Geschlecht, Lebendmasse und Alter und bezeichnet einen genetisch determinierten, theoretischen Grenzwert für das maximale tägliche N-Retentionsvermögen. Die Grenzwerte $\mathrm{NR}_{\max } \mathrm{T}$ und $\mathrm{ND}_{\max } \mathrm{T}$ spiegeln daher das genetische Potential der Tiere für N-Retention bzw. N-Ansatz wieder, welches durch mathematische Grenzwertschätzung (= theoretischer Grenzwert) ermittelt wird, in der Praxis jedoch nicht erreicht werden kann (SAMADI und LIEBERT 2006). Für Anwendungen 
bei Aminosäure-Bedarfsrechnungen ist es notwendig, die exponentielle Funktion in Gleichung (4) zu logarithmieren. Nach der Logarithmierung kann die Proteinqualität b berechnet werden:

$b=\frac{\ln N R_{\max } T-\ln \left(N R_{\max } T-N R\right)}{N I}$

Die Ergebnisse der Berechnung von b werden nach GEBHARDT (1980) multipliziert mit dem Faktor $10^{6}$ angegeben, um besser handhabbare Zahlenwerte vergleichen zu können. Die Variable b, die den Anstieg der N-Retentionskurve kennzeichnet, ist unabhängig von der NAufnahme und unmittelbar von der Qualität des eingesetzten Futterproteins abhängig, wenn nicht durch andere Nahrungsfaktoren eine Limitierung der Proteinverwertung erfolgt. Somit kann in der Gleichung (7) für eine definierte N-Retention, in Abhängigkeit von einer bestimmten Proteinqualität die N-Aufnahme berechnet werden.

$N I=\frac{\ln N R_{\max } T-\ln \left(N R_{\max } T-N R\right)}{b}$

Die in Gleichung 4 beschriebene N-Wirkungskurve kann in die Wirkungskurve der limitierenden Aminosäure (LAA) überführt werden, wobei NI durch die Aufnahme an LAA (LAAI) zu ersetzen ist. Der Multiplikator 16 resultiert aus der Konzentrationsangabe (g/16gN) für die LAA im Futterprotein. Dabei wird folgender Zusammenhang deutlich:

$N I=\frac{16 \cdot L A A I}{c}$

Wird entsprechend (6) anstelle der N-Aufnahme (NI) über die Konzentration der limitierenden Aminosäure (c) im Futterprotein (in g/16 g N) die Aufnahme an limitierender Aminosäure einbezogen, ergibt sich eine Möglichkeit (Samadi und LIEBERT 2006a,b ) zur Bewertung der Wirksamkeit dieser Aminosäure $\left(\mathrm{bc}^{-1}\right)$ :

$b c^{-1}=\frac{\ln N R_{\max } T-\ln \left(N R_{\max } T-N R\right)}{16 \cdot L A A I}$

wobei: 


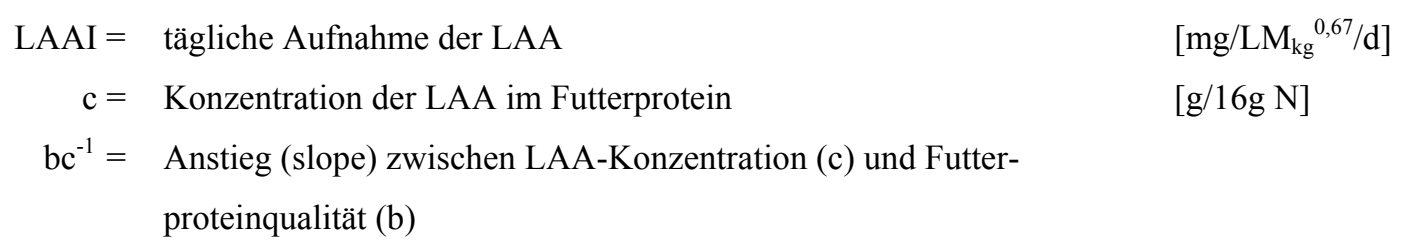

Zwischen $\mathrm{b}$ und der LAA-Konzentration (c) besteht im Limitierungsbereich eine direkte lineare Beziehung, so dass $\mathrm{bc}^{-1}$ der regressiv ermittelten Steigung der Funktion entspricht (GEBHARDT 1980, LIEBERT und GEBHARDT 1980) und die Wirksamkeit der jeweiligen Aminosäure reflektiert. Die berechnete Wirksamkeit ist somit unabhängig von der Aufnahme der Aminosäure im Limitierungsbereich.

Ist die Aminosäure-Wirksamkeit $\left(\mathrm{bc}^{-1}\right)$ einer Futtermischung oder eines Einzelproteins bekannt, so kann durch Umstellen der Gleichung (9) die LAAI beschrieben werden als der Bedarf an der limitierenden Aminosäure bei einer definierten Wirksamkeit für eine bestimmte Leistung (LIEBERT und GEBHARDT 1986, THONG und LIEBERT 2004a, b):

$L A A I=\frac{\ln N R_{\max } T-\ln \left(N R_{\max } T-N R\right)}{16 \cdot b c^{-1}}$

Somit ist es möglich, durch die Gleichung (10) bei einem gegebenen Genotyp $\left(\mathrm{NR}_{\max } \mathrm{T}\right)$ die notwendige Aminosäurezufuhr (LAAI) in Abhängigkeit von der Leistungshöhe (NR) und der Aminosäure-Wirksamkeit zu berechnen (SAMADI und LIEBERT 2006 b). Diese wird als leistungs- und wirksamkeitsabhängiger Bedarf verstanden.

\subsubsection{Berechnung der relativen Wirksamkeit von MHA zu DLM}

Zur Ermittlung der Wirksamkeit von MHA relativ zu DLM (=100) im Untersuchungskomplex II wurde folgende Formel zur Bestimmung der DLM- und MHA-Wirksamkeit angewandt:

relativeWirksamkeit $=\frac{\Delta b}{\Delta c}=\frac{b_{\text {Testdiät }}-b_{\text {Kontrolldiät }}}{c_{\text {Testdiät }}-c_{\text {Kontrolldiät }}}$

Die ermittelte MHA-Wirksamkeit wird anschließend in Relation zur DLM-Wirksamkeit gesetzt und in Prozent angegeben. 


\subsection{Mathematisch statistische Auswertung}

Die während der Versuchsreihen erhobenen Daten wurden mit dem Statistikprogramm SPSS 17.0 für Windows statistisch bearbeitet.

Der arithmetische Mittelwert und die Standardabweichung wurden anhand der Einzelwerte errechnet. Dabei diente der DIXON-Ausreißertest (SACHS 1968) der biostatistischen Identifikation und Ausgrenzung von stark abweichenden Einzelwerten (Ausreißern) innerhalb der Messreihen mit einer Irrtumswahrscheinlichkeit von $\mathrm{p} \leq 0,05$.

Die Grenzwerte der exponentiellen Funktion zwischen N-Aufnahme und N-Retention im ersten Untersuchungskomplex wurde mittels nichtlinearer Regressionsanalyse durch Levenberg-Maquardt Algoritmus abgeleitet.

Zur Feststellung der Signifikanz von Unterschieden wurden die Daten im zweiten und dritten Untersuchungskomplex einer einfaktoriellen Varianzanalyse (ANOVA) unter Verwendung eines multiplen Mittelwertsvergleichs (Tukey-Test) unterzogen. Unterschiedliche Hochbuchstaben innerhalb der Spalten kennzeichnen signifikant verschiedene Mittelwerte ( $p$ $\leq 0,05)$. 


\section{Ergebnisse}

In diesem Kapitel erfolgt eine Darstellung der Hauptergebnisse innerhalb der einzelnen Untersuchungskomplexe. Die zur Auswertung erforderlichen Teilergebnisse können dem Tabellenanhang entnommen werden.

\subsection{Untersuchungskomplex I}

NMR und $\mathrm{NR}_{\max } \mathrm{T}$ wurden für männliche Broiler der genetischen Herkunft Ross 308 ermittelt und dienten für die weiteren Versuche als grundlegende Modellparameter.

\subsection{1. $\quad N$-Erhaltungsbedarf (NMR)}

Die Ergebnisse des N-Bilanzversuches unter Verwendung von Futtermischungen mit gestuftem Proteingehalt, bezogen auf zwei Wachstumsphasen, sind in Tab. 5.1 zusammengefasst.

Tabelle 5.1: Ergebnisse des N-Bilanzversuchs differenziert nach Wachstumsperiode (Versuch 1) *

\begin{tabular}{|c|c|c|c|c|c|c|}
\hline Futtermischung & $\mathbf{N} 1$ & $\mathbf{N} 2$ & $\mathbf{N} 3$ & $\mathbf{N} 4$ & N 5 & N 6 \\
\hline \multicolumn{7}{|c|}{ Starter $(10 .-20$. LT $)$} \\
\hline Mittlere LM (kg) & $0,320 \pm 0,1$ & $0,316 \pm 0,1$ & $0,291 \pm 0,1$ & $0,258 \pm 0,1$ & $0,191 \pm 0,03$ & $0,101 \pm 0,01$ \\
\hline TS-Aufnahme (g/d) & $33 \pm 6$ & $34 \pm 6$ & $32 \pm 8$ & $31 \pm 3$ & $22 \pm 4$ & $7 \pm 2$ \\
\hline $\mathrm{NI}\left(\mathrm{mg} / \mathrm{LM}_{\mathrm{kg}}{ }^{0,67}\right)$ & $4516^{\mathrm{f}} \pm 252$ & $3943^{\mathrm{e}} \pm 312$ & $3026^{\mathrm{d}} \pm 371$ & $2402^{c} \pm 239$ & $1397^{\mathrm{b}} \pm 167$ & $347^{\mathrm{a}} \pm 75$ \\
\hline $\operatorname{NEX}\left(\mathrm{mg} / \mathrm{LM}_{\mathrm{kg}}{ }^{0,67}\right)$ & $2115^{\mathrm{d}} \pm 245$ & $2022^{\mathrm{d}} \pm 206$ & $1410^{c} \pm 287$ & $979^{b} \pm 151$ & $546^{\mathrm{a}} \pm 47$ & $335^{\mathrm{a}} \pm 50$ \\
\hline $\mathrm{ND}\left(\mathrm{mg} / \mathrm{LM}_{\mathrm{kg}}{ }^{0,67}\right)$ & $2402^{\mathrm{e}} \pm 299$ & $1920^{\mathrm{d}} \pm 351$ & $1616^{c} \pm 262$ & $1423^{c} \pm 181$ & $851^{\mathrm{b}} \pm 181$ & $12^{a} \pm 75$ \\
\hline \multicolumn{7}{|c|}{ Grower (25. - 35. LT) } \\
\hline Mittlere LM (kg) & $1,095 \pm 0,3$ & $1,218 \pm 0,2$ & $1,246 \pm 0,2$ & $1,148 \pm 0,1$ & $1,084 \pm 0,1$ & $0,680 \pm 0,1$ \\
\hline TS-Aufnahme (g/d) & $73 \pm 16$ & $79 \pm 12$ & $78 \pm 10$ & $67 \pm 11$ & $72 \pm 10$ & $17 \pm 6$ \\
\hline $\mathrm{NI}\left(\mathrm{mg} / \mathrm{LM}_{\mathrm{kg}}{ }^{0,67}\right)$ & $4132^{\mathrm{f}} \pm 361$ & $3503^{\mathrm{e}} \pm 173$ & $2957^{\mathrm{d}} \pm 175$ & $2039^{c} \pm 297$ & $1618^{\mathrm{b}} \pm 158$ & $258^{\mathrm{a}} \pm 79$ \\
\hline $\operatorname{NEX}\left(\mathrm{mg} / \mathrm{LM}_{\mathrm{kg}}{ }^{0,67}\right)$ & $2184^{\mathrm{f}} \pm 232$ & $1768^{\mathrm{e}} \pm 154$ & $1289^{\mathrm{d}} \pm 82$ & $870^{c} \pm 129$ & $672^{b} \pm 80$ & $357^{\mathrm{a}} \pm 74$ \\
\hline $\mathrm{ND}\left(\mathrm{mg} / \mathrm{LM}_{\mathrm{kg}}{ }^{0,67}\right)$ & $1948^{\mathrm{e}} \pm 178$ & $1735^{\mathrm{de}} \pm 133$ & $1669^{\mathrm{d}} \pm 213$ & $1169^{c} \pm 200$ & $946^{\mathrm{b}} \pm 126$ & $-99^{a} \pm 36$ \\
\hline
\end{tabular}

* Mittelwert \pm SD 
Abbildung 5.1 stellt die Ergebnisse zum N-Erhaltungsbedarf (NMR) dar.

Basierend auf exponentieller Fittung der N-Exkretion in Abhängigkeit von der N-Aufnahme wurde der Schnittpunkt mit der y-Achse bestimmt und somit der den unterschiedlichen Wachstumsphasen entsprechende tägliche $\operatorname{NMR}\left(295 \mathrm{mg} / \mathrm{LM}_{\mathrm{kg}}{ }^{0,67}\right.$ bzw. $313 \mathrm{mg} / \mathrm{LM}_{\mathrm{kg}}{ }^{0,67}$ ) ermittelt.

Die Ergebnisse des in beiden Altersabschnitten analysierten Schnittpunktes mit der y-Achse waren sehr ähnlich (Abbildung 5.1). Folglich wurde der Mittelwert dieser beiden Schätzungen eruiert und im Weiteren als Arbeitswert für den täglichen N-Erhaltungsbedarf verwendet $\left(\mathrm{NMR}=304 \mathrm{mg} / \mathrm{LM}_{\mathrm{kg}}{ }^{0,67}\right)$.

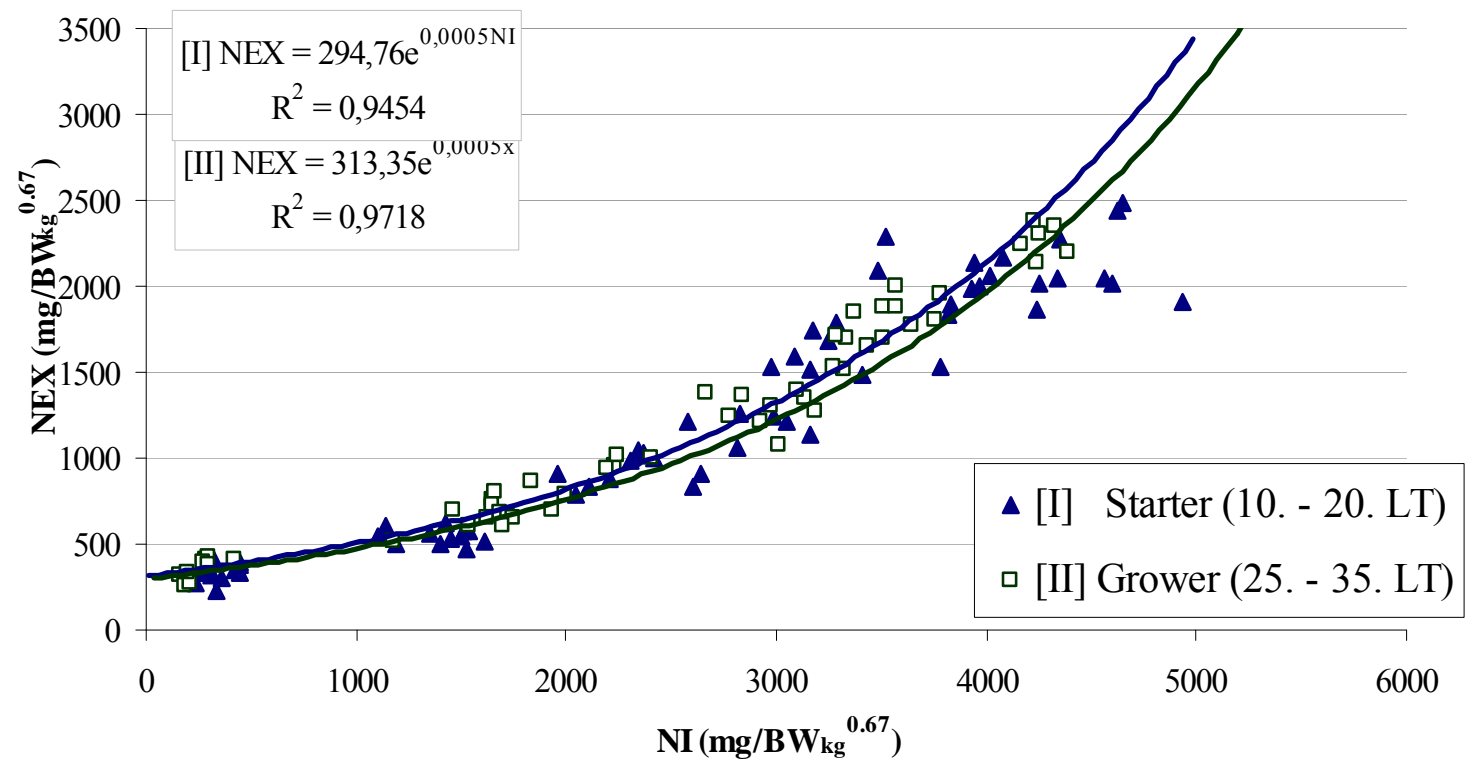

Abbildung 5.1: Ableitung des täglichen N-Erhaltungsbedarfes (NMR) männlicher Broilerküken der genetischen Herkunft Ross 308, differenziert nach Wachstumsphasen 


\subsubsection{Maximales tägliches $N$-Retentionsvermögen $\left(N R_{\max } T\right)$}

Die zusammengefassten experimentellen Daten zur Ermittlung des $\mathrm{ND}_{\max } \mathrm{T}$ als Grenzwert der exponentiellen Funktion für männliche Broiler, welcher für die Starterperiode (10. - 20. LT) $3696 \mathrm{mg} / \mathrm{LM}_{\mathrm{kg}}{ }^{0,67}$ pro Tag und $2797 \mathrm{mg} / \mathrm{LM}_{\mathrm{kg}}{ }^{0,67}$ pro Tag für die Growerperiode (25. - 35. LT) betrug, ist in Tabelle 5.1 zusammengefasst.

Abbildung 5.2 stellt die Approximation der e-Funktion an die experimentellen Werte dar. Die Ergebnisse demonstrierten, dass das genetische Potential zur Proteindeposition wachsender Broiler mit zunehmendem Alter sinkt. Unter Addition des NMR ergab sich für die untersuchten Wachstumsperioden ein $\mathrm{NR}_{\max } \mathrm{T}$ von $3991 \mathrm{mg} / \mathrm{LM}_{\mathrm{kg}}{ }^{0,67}$ innerhalb der Starterperiode (10. - 20. LT) sowie von $3110 \mathrm{mg} / \mathrm{LM}_{\mathrm{kg}}^{0,67}$ für die Growerperiode (25.- 35. LT).

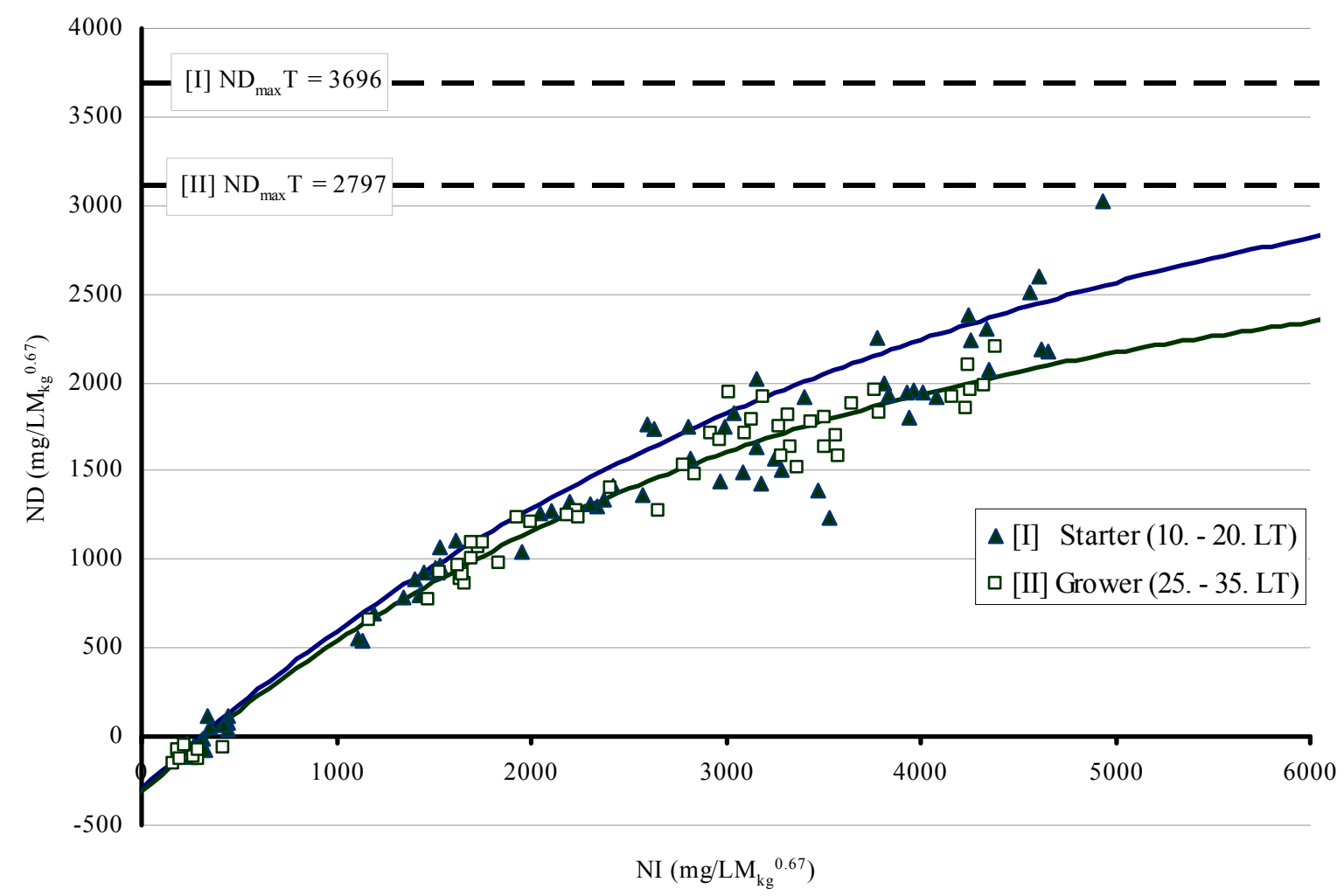

Abbildung 5.2: Ableitung von ND $_{\max }$ T für männliche Broilerküken der genetischen Herkunft Ross 308, differenziert nach Wachstumsphase 


\subsection{Untersuchungskomplex II}

Dieser Untersuchungskomplex diente, unter Verwendung der im Untersuchungskomplex I ermittelten Basisdaten des exponentiellen N-Verwertungsmodells, zur vergleichenden Betrachtung der Wirksamkeit zweier unterschiedlicher Methioninquellen. Dazu wurden zwei N-Bilanzversuche sowie zwei Wachstumsstudien mit unterschiedlichen Met:CysVerhältnissen, basierend auf SAA-limitierenden Basaldiäten durchgeführt, die zum einen eine Supplementation mit DL-Methionin (DLM) bzw. Methionin-Hydroxy-Analog (MHA) umfassten (Versuch 4 und 5) und zum anderen, zusätzlich zur DLM/MHA-Supplementation, im Versuch 2 und 3 noch eine Cysteinzulage erhielten. Des Weiteren sollte aus der Methionin/Cystein limitierenden Basalmischung der Bedarf an Methionin abgeleitet werden. Zur Ermittlung der Versuchsergebnisse wurden, die in den Diäten analysieren Aminosäurenkonzentrationen (Tabelle 4.9 und Tabelle 4.11, Werte in Klammern) verwendet.

\subsubsection{Ermittlung der Methioninwirksamkeit von MHA relativ zu DLM}

Zwei N-Bilanz-Studien sowie zwei Wachstumsversuche zur vergleichenden Betrachtung der Methioninwirksamkeit der Methioninquellen DLM und MHA sollten dazu dienen, die Wirksamkeit dieser Komponenten in den eingesetzten Testmischungen sowie dessen Variabilität bei verschiedenen Met:Cys-Verhältnissen zu ermitteln. Zu diesem Zweck wurde zum einen eine Met-limitierte Basalmischung (NC) jeweils mit 0,1\% DLM (MI) bzw. einem äquimolaren Anteil an MHA (MHA I) oder mit 0,2\% DLM (MII) bzw. einem äquimolaren Anteil an MHA (MHA II) kombiniert (Versuch 4 und 5). Zum anderen wurde in zwei weiteren Versuchen (Versuch 2 und 3) eine Basalmischung mit vergleichbaren MetSupplementationen (vgl. MI, MII, MHAI, MHAII) kombiniert, wobei zusätzlich eine L-Cys$\mathrm{HCl} \cdot \mathrm{H}_{2} \mathrm{O}$ Supplementation vorgenommen wurde, sodass in allen Diäten dieser Versuche ein analoges Met:Cys-Verhältnis vorlag. Dies sollte beim Vergleich der beiden Versuche eventuelle Einflüsse des Cysteins bzw. Met:Cys-Verhältnisses auf die Met-Wirksamkeit erkennen lassen.

Im folgendem werden die Ergebnisse der Studien zur Ermittlung der Methioninwirksamkeit von MHA im Vergleich zum DLM differenziert nach Versuchsart, d.h. Stoffwechsel- und Wachstumsversuch betrachtet. Eine Zusammenfassung der Resultate zur Proteinqualität, 
Methioninwirksamkeit sowie Methionin/Cystein-Wirksamkeit nach Verabreichung der einzelnen Diäten geben die Tabellen 5.2 bis 5.5 wieder.

\subsubsection{Stoffwechselversuche}

Dieser Komplex unterteilt sich in zwei differenziert betrachtete Versuche, die innerhalb der beiden Wachstumsperioden ausgewertet wurden. Der erste Versuch stellt die Ergebnisse der mit DLM+Cys bzw. MHA+Cys-supplementierten Basalmischungen dar. Im zweiten Versuch werden die Resultate aus den DLM- bzw. MHA-supplementierten Diäten aufgeführt.

\section{Versuch 2: Met+Cys-Supplementation}

Tabelle 5.2 vermittelt eine Übersicht zu den in Versuch 2 ermittelten Modellparametern (b, $\left.\mathrm{bc}_{\mathrm{Met}^{-1}}{ }^{-1} \mathrm{bc}_{\mathrm{SAA}}{ }^{-1}\right)$. Eine detaillierte Darstellung der Ergebnisse sind den Tabellen des Anhanges (Tabelle A 12 und A 13) zu entnehmen.

Die beobachtete Proteinqualität (b-Werte) wies in der Met/Cys-limitierten Kontrollmischung in der Starterperiode (10. - 20. LT) einen mittleren Wert von 232 auf. Signifikant höher lagen die b-Werte der mit einer der beiden Methioninquellen supplementierten Diäten mit 324 $(\mathrm{M}+\mathrm{C} \mathrm{I})$ bzw. $311(\mathrm{MHA}+\mathrm{C} \mathrm{I})$. Ein weiterer signifikanter Anstieg der b-Werte bei höherer Supplementation $(\mathrm{M}+\mathrm{CII}$ bzw. MHA+CII) war nicht festzustellen. Mit zunehmender Konzentration an Methionin in den Mischungen war lediglich ein tendenzieller Anstieg in der Proteinqualität zu verzeichnen. Die höchste Proteinqualität kennzeichnete die Diät M+C II mit einem b-Wert von 347. Beim Vergleich der Methioninquellen zeigte sich, dass die DLM supplementierten Diäten tendenziell höhere Proteinqualitäten innerhalb der Supplementationsstufen aufwiesen.

Die Werte für die Methioninwirksamkeit, berechnet als Quotient aus b-Wert und Methioninkonzentration in der jeweiligen Diät, variierten in einem Bereich von 136 bis 176. Letzterer $\mathrm{bc}_{\mathrm{Met}}{ }^{-1}$-Wert ergab sich für die Kontrollmischung NC. Der Wert für die Diät M+C I (175) war dabei nahezu identisch. Durch eine weitere DLM-Supplementation sank die Methioninwirksamkeit signifikant auf einen Wert von 149. Im Vergleich dazu lagen die Ergebnisse zur Methioninwirksamkeit bei den MHA supplementierten Diäten niedriger, was insbesondere für die zweite Supplementationsstufe galt. Die Wirksamkeit der schwefelhaltigen Aminosäuren 
insgesamt, ausgewiesen als Quotient aus b-Wert und Methionin+Cystein-Konzentration, wies mit Zulage der ersten Met+Cys-Supplementation tendenziell niedrigere $b c_{S A A}{ }^{-1}$-Werte mit 79 $(\mathrm{M}+\mathrm{C} \mathrm{I})$ und $76(\mathrm{MHA}+\mathrm{C} \mathrm{I})$ auf. Einen signifikanten Abfall in der SAA-Wirksamkeit realisierte die zweite Supplementationsstufe mit den Diäten M+C II (66) und MHA+C II (60).

Tabelle 5.2: Ergebnisse des Stoffwechselversuches mit DLM/MHA-Supplementation bei konstantem Met:Cys-Verhältnis (Versuch 2) *

\begin{tabular}{|c|c|c|c|c|c|}
\hline $\begin{array}{c}\text { Diät } \\
\text { (Met: Cys) }\end{array}$ & $\begin{array}{c}\text { NC } \\
(46: 54)\end{array}$ & $\begin{array}{l}M+C ~ I \\
(45: 55)\end{array}$ & $\begin{array}{c}\text { M+C II } \\
(44: 56)\end{array}$ & $\begin{array}{c}\text { MHA+C I } \\
(45: 55)\end{array}$ & $\begin{array}{c}\text { MHA+C II } \\
(45: 55)\end{array}$ \\
\hline \multicolumn{6}{|c|}{ Starterperiode (10. - 20. LT) } \\
\hline$b$-Wert & $232^{\mathrm{a}} \pm 17$ & $324^{\mathrm{bc}} \pm 29$ & $347^{\mathrm{c}} \pm 33$ & $311^{\mathrm{b}} \pm 17$ & $328^{\mathrm{bc}} \pm 24$ \\
\hline relativ zu NC & 100 & 139 & 149 & 134 & 141 \\
\hline $\mathrm{c}_{\text {Met }}$ & 1,319 & 1,851 & 2,320 & 1,847 & 2,418 \\
\hline $\mathrm{c}_{\mathrm{SAA}}$ & 2,857 & 4,083 & 5,287 & 4,075 & 5,480 \\
\hline $\mathrm{bc}_{\mathrm{Met}}^{-1}$-Wert & $176^{\mathrm{c}} \pm 13$ & $175^{\mathrm{c}} \pm 16$ & $149^{\mathrm{b}} \pm 14$ & $168^{\mathrm{c}} \pm 9$ & $136^{\mathrm{a}} \pm 10$ \\
\hline $\mathrm{bc}_{\mathrm{SAA}}^{-1}$-Wert & $81^{\mathrm{b}} \pm 6$ & $79^{\mathrm{b}} \pm 7$ & $66^{\mathrm{a}} \pm 6$ & $76^{\mathrm{b}} \pm 4$ & $60^{\mathrm{a}} \pm 4$ \\
\hline \multicolumn{6}{|c|}{ Growerperiode (25. - 35. LT) } \\
\hline b-Wert & $281^{\mathrm{a}} \pm 24$ & $515^{\mathrm{bc}} \pm 43$ & $532^{\mathrm{bc}} \pm 77$ & $488^{\mathrm{b}} \pm 45$ & $571^{\mathrm{c}} \pm 74$ \\
\hline relativ zu NC & 100 & 183 & 189 & 174 & 203 \\
\hline$c_{\text {Met }}$ & 1,374 & 1,951 & 2,400 & 1,947 & 2,565 \\
\hline $\mathrm{c}_{\mathrm{SAA}}$ & 2,926 & 4,316 & 5,562 & 4,307 & 5,654 \\
\hline $\mathrm{bc}_{\mathrm{Met}}^{-1}$-Wert & $204^{\mathrm{a}} \pm 18$ & $264^{\mathrm{b}} \pm 22$ & $222^{\mathrm{a}} \pm 32$ & $250^{\mathrm{b}} \pm 23$ & $223^{\mathrm{a}} \pm 30$ \\
\hline $\mathrm{bc}_{\mathrm{SAA}}^{-1}$-Wert & $96^{\mathrm{a}} \pm 8$ & $119^{\mathrm{b}} \pm 10$ & $96^{\mathrm{a}} \pm 14$ & $113^{\mathrm{b}} \pm 10$ & $101^{\mathrm{a}} \pm 13$ \\
\hline
\end{tabular}

* Mittelwert \pm Standardabweichung

Die b-Werte lagen in der Growerperiode zwischen 281 und 571. Die höchste Proteinqualität zeigte in dieser Wachstumsperiode die Diät MHA+C II mit 571. Wie erwartet, realisierte die Diät NC den niedrigsten b-Wert mit 281, der sich signifikant von den supplementierten Mischungen unterschied ( $\mathrm{p} \leq 0,05)$. Damit wurde bestätigt, dass die basale Mischung erstlimitierend an Met bzw. den SAA war. Durch die Supplementation von DLM+Cys stieg die Proteinqualität nach Zulage der ersten Supplementationsstufe signifikant $(p \leq 0,05)$ an, wurde allerdings nach Zulage der zweiten Supplementationsstufe nur noch tendenziell erhöht. Die Verbesserung der Proteinqualität in den MHA+Cys-supplementierten Diäten konnte jedoch auch zwischen den Supplementationsstufen statistisch gesichert werden. Beim Vergleich beider Methioninquellen innerhalb der ersten Supplementationsstufe zeigte sich eine tendenziell höhere Proteinqualität für die DLM+Cys-supplementierte Diät, während innerhalb 
der zweiten Supplementationsstufen eine tendenziell höhere Proteinqualität für die MHA+Cys-supplementierte Diät vorlag.

Der Parameter für die Methioninwirksamkeit $\left(\mathrm{bc}_{\mathrm{Met}^{-1}}\right)$ variierte in einem Bereich von 204 und 264. Die niedrigste Methioninwirksamkeit realisierte die Kontrolldiät NC (204). Mit der Met+Cys-Supplementation erhöhte sich die Methioninwirksamkeit signifikant für die Diät M+C I (264) und MHA+C I (250). Die Wirksamkeit wies mit Zulage der ersten DLM+CysSupplementation einen tendenziell höheren $b_{\text {Met }}-$ Wert (264) als die Diät MHA+C I (250) auf. Für die Diät M+C II (222) im Vergleich mit der Diät MHA+C II (223) wurde eine analoge Wirksamkeit realisiert. Die Wirksamkeit der SAA, ausgewiesen als Quotient aus b-Wert und Methionin+Cystein-Konzentration, wies mit Zulage der ersten Met+Cys-Supplementation signifikant höhere $\mathrm{bc}_{\mathrm{SAA}^{-}}{ }^{-1}$-Werte mit $119(\mathrm{M}+\mathrm{C}$ I) und $113(\mathrm{MHA}+\mathrm{C}$ I) auf. Die Diäten $\mathrm{M}+\mathrm{C}$ II (96) und MHA+C II (101) lagen im Bereich der NC-Diät.

Die kalkulierte Wirksamkeit des MHA im Vergleich zum DLM (=100) in Abhängigkeit von der Supplementationsstufe ist in der Abbildung 5.3 aufgeführt.

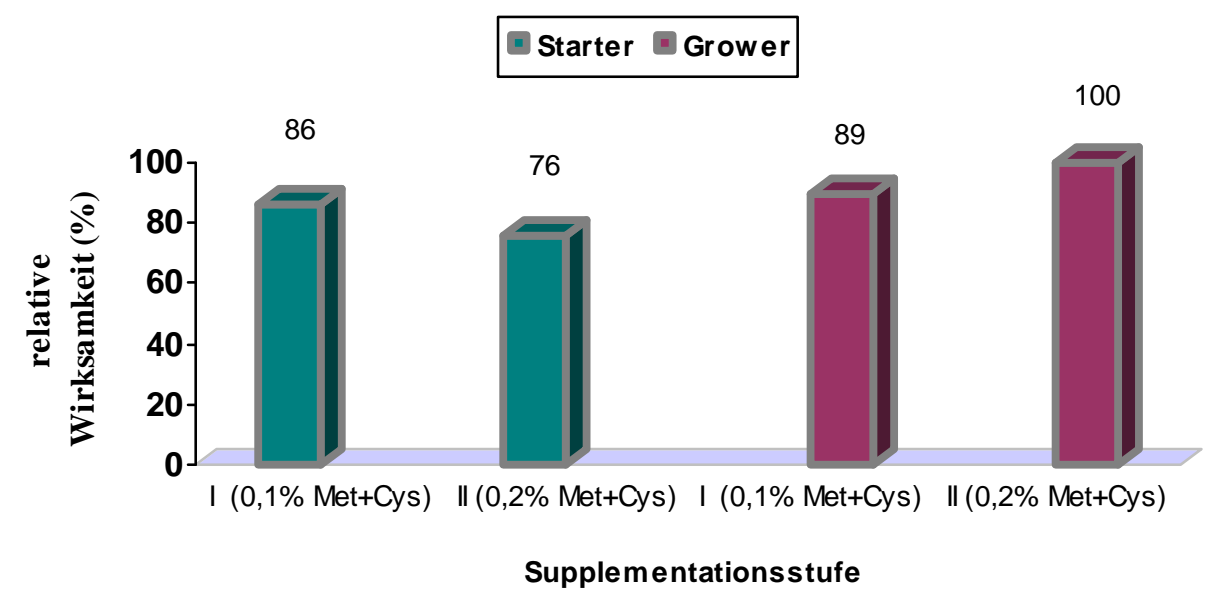

\section{Abbildung 5.3: Wirksamkeit von MHA relativ zu DLM (=100\%) (Versuch 2)}

Die Berechnung der Wirksamkeit des MHA im Vergleich zum DLM (relativen Wirksamkeit) erfolgte mit der Gleichung 11. Die in der Abbildung 5.3 dargestellten Wirksamkeiten von MHA relativ zu DLM liegen deutlich unter der des DLM, ausgenommen der relativen Wirksamkeit, die aus dem Vergleich der höchsten Methioninkonzentrationen in der Growerperiode resultierte. Mit einem Wert von 100\% liegt diese im Bereich der Referenzaminosäure DLM (100\%). In der Starterperiode bewirkte ein zunehmender 
Anteil an MHA+Cys in den Mischungen eine niedrigere MHA-Wirksamkeit; in der Growerperiode hingegen eine höhere.

\section{Versuch 4: Met-Supplementation}

Die kalkulierten Modellparameter aus dem Versuch $4\left(\mathrm{~b}, \mathrm{bc}_{\mathrm{Met}}{ }^{-1}, \mathrm{bc}_{\mathrm{SAA}}{ }^{-1}\right)$ sind in der Tabelle 5.3 zusammengefasst.

Die Proteinqualität, dargestellt als b-Wertes wies in der Starterperiode Werte zwischen 209 und 355 auf. Die höchste Proteinqualität realisierte die Diät M II mit 355, gefolgt von den Diäten mit MHA-Supplementation. Den niedrigsten b-Wert lieferte die Kontrollmischung NC. Die Proteinqualität wurde durch die Supplementation von DLM signifikant beeinflusst. Während mit Zulage der ersten Supplementationsstufe eine Proteinqualität von 300 erreicht wurde, konnte mit Zulage der zweiten Supplementationsstufe eine weitere signifikante Verbesserung $(b=355)$ aufgezeigt werden. Ein ähnliches Bild ergab sich für die MHAsupplementierten Diäten, wobei jedoch nur ein tendenziell höherer b-Wert zwischen den beiden Diäten MHA I und MHA II vorlag. Die statistisch signifikanten Unterschiede in der Proteinqualität zwischen der basalen Kontrollmischung NC und den Testdiäten bestätigte, dass die basale Mischung im Hinblick auf Methionin bzw. Met/Cys limitierend war. Beim Vergleich beider Methioninquellen innerhalb der ersten Supplementationsstufen zeigte sich eine tendenziell höhere Proteinqualität für die MHA-supplementierte Diät, während innerhalb der zweiten Supplementationsstufen eine tendenziell höhere Proteinqualität für die DLMsupplementierte Diät vorlag.

Die Methioninwirksamkeit, ausgewiesen als $b_{\mathrm{Met}^{-1}}{ }^{-1}$ Wert, variierte in der Starterperiode in einem Bereich von 130 bis 164. Die in der Kontrollmischung vorliegende Methioninwirksamkeit realisierte einen $b_{\mathrm{Met}^{-1}}-$ Wert von 157. Nach Verabreichung der Diät M I wurde ein tendenzieller Anstieg der Methioninwirksamkeit mit einem $b_{\mathrm{Met}^{-1}}{ }^{-1}$ Wert von 164 erzielt. Durch Zulage weiterem DLM zeigte sich ein tendenzieller Abfall in der Methioninwirksamkeit, welcher mit einem $b_{\mathrm{Met}^{-1}}{ }^{-1}$ Wert von 150 leicht unter dem der Kontrollmischung einzuordnen war. Die Diät MHA lag mit einer Methioninwirksamkeit von 159 im Bereich der Methioninwirksamkeit der Kontrollmischung NC. Die Diät MHA II (130) verdeutlichte die niedrigste Methioninwirksamkeit, welche signifikant niedriger war, als die der Diäten MHA I (159) und M I (164). Ein Vergleich der Methioninwirksamkeiten der DLM-supplementierten Gruppen mit den MHA-supplementierten Gruppen zeigte tendenziell höhere Wirksamkeiten bezüglich der DLM-Addition. Die Wirksamkeiten der schwefelhaltigen Aminosäuren (SAA), 
ausgewiesen als Quotient aus dem b-Wert und der entsprechenden SAA-Konzentration, wiesen mit der Zulage der ersten Methioninsupplementation tendenziell höhere $b_{\mathrm{SAA}^{-1}}{ }^{-W e r t e}$ von 90 (M I) und 88 (MHA I) auf. Eine tendenziell niedrigere SAA-Wirksamkeit zeigte sich nach Verabreichung einer weiteren Zulage an MHA, während die zusätzliche DLMSupplementation einen $\mathrm{bc}_{\mathrm{SAA}}{ }^{-1}$-Wert realisierte, der analog zu dem der Diät M I war.

Tabelle 5.3: Ergebnisse des Stoffwechselversuchs mit DLM/MHA-Supplementation bei variierendem Met:Cys-Verhältnis (Versuch 4) *

\begin{tabular}{|c|c|c|c|c|c|}
\hline $\begin{array}{l}\text { Diät } \\
\text { (Met: Cys) }\end{array}$ & $\begin{array}{c}\text { NC } \\
(46: 54)\end{array}$ & $\begin{array}{c}\text { M I } \\
(55: 45)\end{array}$ & $\begin{array}{c}\text { M II } \\
(61: 39)\end{array}$ & $\begin{array}{l}\text { MHA I } \\
\text { (55:45) }\end{array}$ & $\begin{array}{c}\text { MHA II } \\
(62: 38)\end{array}$ \\
\hline \multicolumn{6}{|c|}{ Starterperiode (10. - 20. LT) } \\
\hline$b$-Wert & $209^{\mathrm{a}} \pm 25$ & $300^{\mathrm{b}} \pm 54$ & $355^{\mathrm{c}} \pm 51$ & $316^{\mathrm{bc}} \pm 75$ & $329^{\mathrm{bc}} \pm 43$ \\
\hline relativ zu NC & 100 & 143 & 170 & 151 & 157 \\
\hline $\mathrm{c}_{\mathrm{Met}}$ & 1,332 & 1,826 & 2,372 & 1,988 & 2,527 \\
\hline $\mathrm{c}_{\mathrm{Met}}+$ Cys & 2,942 & 3,321 & 3,916 & 3,589 & 4,119 \\
\hline $\mathrm{bc}_{\mathrm{Met}^{-1}-\text { Wert }}$ & $157^{\mathrm{ab}} \pm 19$ & $164^{\mathrm{b}} \pm 30$ & $150^{\mathrm{ab}} \pm 21$ & $159^{\mathrm{b}} \pm 38$ & $130^{\mathrm{a}} \pm 17$ \\
\hline $\mathrm{bc}_{\mathrm{SAA}}{ }^{-1}-$ Wert & $71^{\mathrm{a}} \pm 9$ & $90^{\mathrm{ab}} \pm 16$ & $91^{\mathrm{ab}} \pm 13$ & $88^{\mathrm{ab}} \pm 21$ & $80^{\mathrm{ab}} \pm 10$ \\
\hline \multicolumn{6}{|c|}{ Growerperiode (25. - 35. LT) } \\
\hline b-Wert & $283^{\mathrm{a}} \pm 84$ & $350^{\mathrm{bc}} \pm 58$ & $439^{\mathrm{d}} \pm 53$ & $339^{\mathrm{ab}} \pm 24$ & $401^{\mathrm{cd}} \pm 50$ \\
\hline relativ zu NC & 100 & 124 & 155 & 120 & 141 \\
\hline$c_{\text {Met }}$ & 1,448 & 2,044 & 2,517 & 1,980 & 2,624 \\
\hline $\mathrm{c}_{\mathrm{Met}+\mathrm{Cys}}$ & 3,077 & 3,668 & 4,195 & 3,480 & 4,115 \\
\hline $\mathrm{bc}_{\mathrm{Met}^{-1}-\text { Wert }}$ & $196^{\mathrm{b}} \pm 58$ & $171^{\mathrm{ab}} \pm 28$ & $175^{\mathrm{ab}} \pm 21$ & $171^{\mathrm{ab}} \pm 12$ & $153^{\mathrm{a}} \pm 19$ \\
\hline $\mathrm{bc}_{\mathrm{SAA}}{ }^{-1}-$ Wert & $92^{\mathrm{a}} \pm 27$ & $95^{\mathrm{a}} \pm 16$ & $105^{\mathrm{a}} \pm 13$ & $97^{\mathrm{a}} \pm 7$ & $97^{\mathrm{a}} \pm 12$ \\
\hline
\end{tabular}

* Mittelwerte \pm Standardabweichung

Die Proteinqualität in der Growerperiode nahm Werte zwischen 283 und 439 an. Die höchste Proteinqualität wies in dieser Wachstumsperiode die Diät M II mit einem b-Wert von 439 aus. Wie erwartet, realisierte die Diät NC den niedrigsten b-Wert mit 283, der sich signifikant von den supplementierten Mischungen unterschied (vgl. Starterperiode). Durch Supplementation von DLM stieg die Proteinqualität nach Zulage der ersten Supplementationsstufe mit einem bWert von 350 signifikant an und realisierte nach Zulage der zweiten Supplementationsstufe einen b-Wert von 439, der ebenfalls höher war $(p \leq 0,05)$. Ein Anstieg in der Proteinqualität der MHA-supplementierten Diäten konnte nur mit der zweiten MHA-Supplementation statistisch gesichert werden. Ein Vergleich der Methioninquellen innerhalb der Zulagestufen zeigte eine tendenziell höhere Proteinqualität der DLM-supplementierte Diät. Der Parameter für die Methioninwirksamkeit $\left(\mathrm{bc}_{\mathrm{Met}}{ }^{-1}\right)$ in den untersuchten Diäten variierte in einem Bereich 
von 153 und 196. Die höchste Methioninwirksamkeit realisierte die Diät NC, die niedrigste wurde in der Diät MHA II beobachtet. Der zwischen diesen beiden Mischungen beobachtet Unterschied konnte statistisch gesichert werden. Die Zulage an MHA bzw. DLM in den Diäten bewirkte eine abfallende Methioninwirksamkeit. Während die Diäten M I und M II relativ analoge Werte von 171 (M I) und 175 (M II) repräsentierten, sank die Methioninwirksamkeit mit zunehmenden MHA-Gehalt in den Mischungen tendenziell und

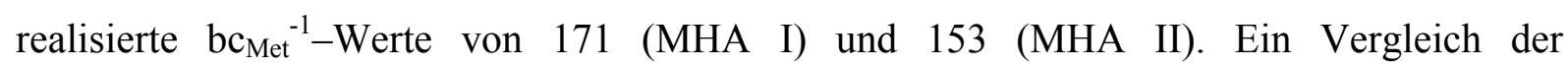
Methioninwirksamkeit der DLM-supplementierten Gruppen mit den MHA-supplementierten Gruppen verdeutlichte für die erste Supplementationsstufe analoge $b c_{M e t}{ }^{-1}-$ Werte sowie für die zweite Supplementations-stufe tendenziell höhere $\mathrm{bc}_{\mathrm{Met}}{ }^{-1}$-Werte bezüglich der DLM-Addition. Die Wirksamkeiten der SAA, ausgewiesen als Quotient aus dem b-Wert und der entsprechenden SAA-Konzentration wiesen mit Zulage der ersten Methioninsupplementation tendenziell höhere $\mathrm{bc}_{\mathrm{SAA}^{-1}}{ }^{-W}$ Werte auf. Eine tendenziell höhere SAA-Wirksamkeit zeigte sich nach Verabreichung einer weiteren DLM-Zulage, während die zusätzliche MHASupplementation einen vergleichbaren $b_{\mathrm{SAA}^{-1}}$-Wert zur Diät MHA I realisierte.

Die sich aus den Bilanzparametern ergebene Wirksamkeit für MHA relativ zu DLM (=100\%) (Gleichung 11) zeigt die die Abbildung 5.4 in Abhängigkeit vom Supplementationslevel und Wachstumsphase.

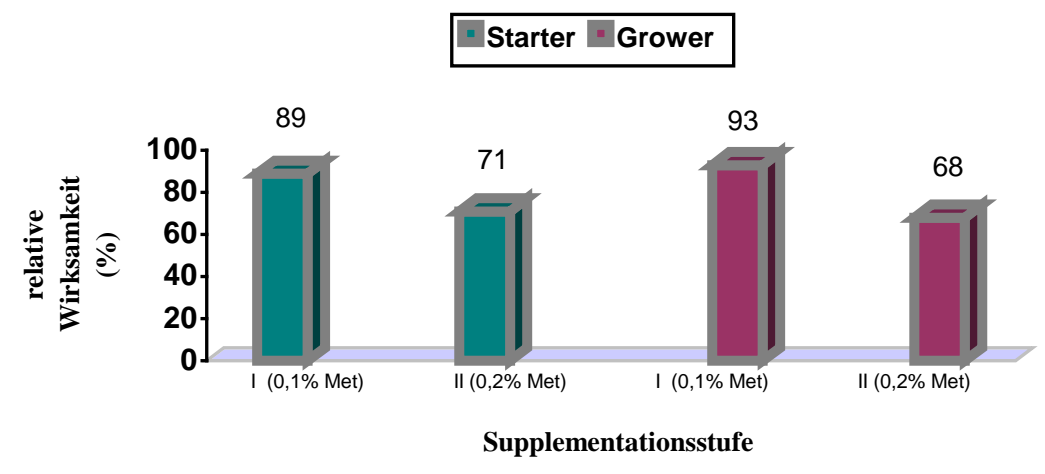

Abbildung 5.4: Wirksamkeit von MHA relativ zu DLM (= 100\%) (Versuch 4)

Die in der Abbildung 5.4 dargestellten Wirksamkeiten von MHA in Relation zum DLM lagen mit Werten von 68\% bis 93\% deutlich unter der des DLM (=100\%). In der Starterperiode wirkte sich ein zunehmender Anteil an MHA in den Mischungen negativ auf die Wirksamkeit des MHAs im Vergleich zur DLM-Supplementation aus. In der Growerperiode zeigte sich ein ähnliches Bild. 


\subsubsection{Wachstumsversuche}

Dieser Komplex unterteilt sich in zwei Versuche, die unabhängig von den beiden Wachtumsperioden ausgewertet wurden. Der erste Versuch stellt die Ergebnisse der mit DLM+Cys bzw. MHA+Cys-supplementierten Basalmischung dar. Im zweiten Versuch werden die Resultate aus den DLM bzw. MHA-supplementierten Diäten aufgeführt.

\section{Versuch 3: Met+Cys-Supplementation}

Tabelle 5.4 vermittelt eine Übersicht über die erzielten Ergebnisse. Die Lebendmassezunahme zeigte Werte im Bereich von 19 bis $76 \mathrm{~g} / \mathrm{d}$, wobei die Kontrollgruppe den geringsten Zuwachs verzeichnete. Die Wachstumsleistung von $76 \mathrm{~g} / \mathrm{d}$, die nach Zulage von $0,2 \%$ DLM+Cys beobachtet wurde, war signifikant höher als die der MHA $+\mathrm{C}$ II Gruppe. Diät M+C I erreichte mit $70 \mathrm{~g} / \mathrm{d}$ eine LMZ, die sich signifikant von der MHA+C I Gruppe $(60 \mathrm{~g} / \mathrm{d})$ unterschied, nicht aber von den Diäten M+C II und MHA + C II. Die signifikant niedrigste Futteraufnahme von $58 \mathrm{~g} / \mathrm{d}$ ergab sich nach Verabreichung der Kontrollmischung. Die höchsten Futteraufnahmen wurden nach Gabe der DLM-supplementierten Diäten erreicht. Die Ergebnisse zum Futteraufwand fallen sehr homogen aus, wobei erwartungsgemäß der Futteraufwand der Kontrollgruppe NC mit einem Wert von 3,15 g/g signifikant erhöht war. Die anderen Werte variieren in einem Bereich von 1,58 - 1,80 g/g. Die niedrigste NDeposition (ND) erzielte mit $0,47 \mathrm{~g} / \mathrm{d}$ die Diät NC, während für die Diät $\mathrm{M}+\mathrm{C}$ II mit 2,11 g/d die höchste ND vorlag. Ein N-Ansatz in vergleichbarer Größenordnung wie die letztgenannte Diät erzielte die Diät $\mathrm{M}+\mathrm{C}$ I mit $1,98 \mathrm{~g} / \mathrm{d}$. Darunter liegende Werte zeigten die Diäten mit MHA-Zulage $(1,67 \mathrm{~g} / \mathrm{d}$ und 1,89 g/d). Die Diäten mit DLM-Supplementation wiesen signifikant höhere N-Ansatzwerte auf als die Diäten mit MHA-Supplementation.

Die Proteinqualität zeigte eine signifikante Verbesserung nach Zulage von DLM bzw. MHA. Mit zunehmender Konzentration an Met in den Diäten konnte ein Anstieg im b-Wert beobachtet werden, wobei dieser für die Diäten mit MHA-Supplementation statistisch gesichert waren. Im Vergleich dazu konnte mit Zulage von DLM in der zweiten Supplementationsstufe $(\mathrm{M}+\mathrm{C}$ II) nur noch eine tendenzielle Verbesserung erzielt werden. 
Tabelle 5.4: Ergebnisse des Wachstumsversuches mit DLM/MHA-Supplemetation bei konstantem Met:Cys-Verhältnis (Versuch 3) *

\begin{tabular}{|c|c|c|c|c|c|}
\hline $\begin{array}{l}\text { Diät } \\
\text { (Met:Cys) }\end{array}$ & $\begin{array}{c}\text { NC } \\
(46: 54)\end{array}$ & $\begin{array}{l}M+C I \\
(45: 55)\end{array}$ & $\begin{array}{c}M+C \text { II } \\
(44: 56)\end{array}$ & $\begin{array}{c}\text { MHA+C I } \\
(45: 55)\end{array}$ & $\begin{array}{c}\text { MHA+C II } \\
(45: 55)\end{array}$ \\
\hline \multicolumn{6}{|c|}{ (1. - 5. Woche) } \\
\hline Anfangsmasse (g) & $55 \pm 1$ & $55 \pm 1$ & $55 \pm 1$ & $54 \pm 4$ & $55 \pm 1$ \\
\hline Endmasse (g) & $707 \pm 40$ & $2492 \pm 108$ & $2708 \pm 91$ & $2163 \pm 172$ & $2442 \pm 101$ \\
\hline Futteraufnahme (g/d) & $58^{\mathrm{a}} \pm 2$ & $117^{\mathrm{cd}} \pm 2$ & $120^{\mathrm{d}} \pm 4$ & $108^{b} \pm 4,80$ & $110^{b c} \pm 6$ \\
\hline Zuwachs (g/d) & $19^{a} \pm 1$ & $70^{\mathrm{cd}} \pm 3$ & $76^{d} \pm 3$ & $60^{b} \pm 5$ & $68^{c} \pm 3$ \\
\hline \multirow{2}{*}{ Futteraufwand (g/g) } & $3,15^{b}$ & $1,68^{\mathrm{a}}$ & $1,58^{\mathrm{a}}$ & $1,80^{\mathrm{a}}$ & $1,62^{\mathrm{a}}$ \\
\hline & $\pm 0,29$ & $\pm 0,08$ & $\pm 0,02$ & $\pm 0,12$ & $\pm 0,07$ \\
\hline \multirow{2}{*}{ N-Deposition (g/d) } & $0,47^{\text {a }}$ & $1,98^{\mathrm{cd}}$ & $2,11^{\mathrm{d}}$ & $1,67^{b}$ & $1,89^{\mathrm{c}}$ \\
\hline & $\pm 0,03$ & $\pm 0,09$ & $\pm 0,07$ & $\pm 0,14$ & $\pm 0,08$ \\
\hline b-Wert & $134^{\mathrm{a}} \pm 11$ & $315^{c} \pm 20$ & $326^{c} \pm 6$ & $276^{\mathrm{b}} \pm 22$ & $310^{c} \pm 15$ \\
\hline $\mathrm{bc}_{\mathrm{Met}}^{-1}-\mathrm{Wert}$ & $99^{\mathrm{a}} \pm 8$ & $166^{\mathrm{d}} \pm 11$ & $138^{b c} \pm 2$ & $146^{b} \pm 12$ & $125^{\mathrm{a}} \pm 6$ \\
\hline $\mathrm{bc}_{\mathrm{SAA}}{ }^{-1}-$ Wert & $46^{\mathrm{d}} \pm 4$ & $39^{c} \pm 3$ & $24^{\mathrm{a}} \pm 0,4$ & $34^{\mathrm{b}} \pm 3$ & $23^{\mathrm{a}} \pm 1$ \\
\hline
\end{tabular}

* Mittelwerte \pm Standardabweichung

Der Parameter für die Methioninwirksamkeit $\left(\mathrm{bc}_{\mathrm{Met}}{ }^{-1}\right)$ in den untersuchten Diäten variierte in einem Bereich von 99 und 166, wobei die Kontrollmischung den geringsten Wert aufwies. Ein Vergleich der Methioninwirksamkeit der DLM-supplementierten Gruppen mit den MHAsupplementierten Gruppen verdeutlichte höhere Methioninwirksamkeiten bezüglich der DLM-Addition innerhalb der Supplementationsstufen. Die signifikant höchste Methioninwirksamkeit wurde bei Verabreichung der Futtermischung M+C I mit 166 realisiert. Die Diät MHA+C I erreichte eine signifikant niedrigere Methioninwirksamkeit von 146. Durch weitere Gaben an Methionin nahm die Methioninwirksamkeit für beide Methioninquellen ab. Die Diät $\mathrm{M}+\mathrm{C}$ II erzielte dabei einen signifikanten Abfall in der Methioninwirksamkeit im Vergleich zur Diät M+C I, blieb aber auf einem signifikant höheren Level als die Kontroll-mischung. Bei der Diät MHA+C II zeigte sich kein signifikanter Unterschied zur Kontrolldiät, wohl aber zur Diät M+C I. Die SAA-Wirksamkeit (bc $\left.\mathrm{SAA}^{-1}\right)$ nahm mit zunehmendem Anteil an Met bzw. MHA in den Mischungen ab. Während zwischen den Diäten $\mathrm{M}+\mathrm{C}$ I und $\mathrm{MHA}+\mathrm{C}$ I noch signifikante Unterschiede bestanden, wiesen die Diäten $\mathrm{M}+\mathrm{C}$ II und MHA+C II keine Unterschiede auf.

Die Berechnung der Wirksamkeit des MHA im Vergleich zum DLM (relativen Wirksamkeit) erfolgte mit der Gleichung 11. Die in der Abbildung 5.5 dargestellten Wirksamkeiten von MHA relativ zu DLM wiesen relativ analoge Werte auf. Im Vergleich zu den Mischungen mit 
DLM-Supplementation lagen die Wirksamkeiten für MHA mit 79\% und 81\% unter der des $\operatorname{DLM}(100 \%)$.

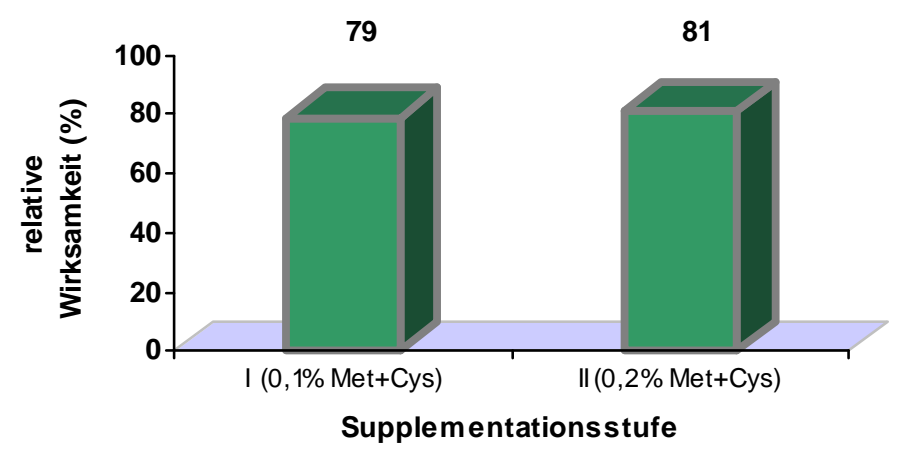

Abbildung 5.5: Wirksamkeit von MHA im Vergleich zu DLM (= 100\%) (Versuch 3)

\section{Versuch 5: Met-Supplementation}

Einen Überblick zu den Versuchsergebnissen gewährt Tabelle 5.5.

Der Lebendmassezuwachs nahm ein weites Spektrum von Werten zwischen 20 - $67 \mathrm{~g} / \mathrm{d}$ an. Einen hohen Lebendmassezuwachs (LMZ) realisierten die Diäten mit der höchsten Supplementationsstufe von jeweils 64 bzw. 67 g/d, wobei die Zulage von DLM die höchsten Werte realisierte. Das geringste Wachstum wies die NC-Gruppe mit 19 g/d auf.

Die höchste Futteraufnahme wurde in diesem Versuch für die Gruppen mit der höchsten Methioninsupplementation M II und MHA II bestimmt. Darunter lagen die Futteraufnahmen der Gruppen M I und MHA I. Der Futteraufwand war für die Kontrollmischung mit einem Wert von 3,07 g/g am größten, gefolgt von der Gruppe MHA I mit 2,21 g/g und der Gruppe M I mit 1,98 g/g. Durch die DLM- bzw. MHA-Supplementation konnte der gegenüber den Testgruppen erhöhte Futteraufwand der Kontrollgruppe signifikant gesenkt werden.

Der resultierende N-Ansatz variierte in einem Bereich von 0,542 bis 1,843 g/d, wobei vergleichbar mit der N-Aufnahme die Gruppen M II und MHA II mit 1,843 g/d bzw. 1,699 g/d die höchsten Ansatzwerte erzielten. Es folgten die Gruppen M I und MHA I mit Werten von 1,156 und $0,997 \mathrm{~g} / \mathrm{d}$. Der geringste N-Ansatz war bei der Kontrollgruppe NC zu verzeichnen. Insgesamt lagen die Werte für den N-Ansatz der Testgruppen deutlich niedriger als die im Versuch 3 in Zusammenhang mit der Methionin- und Cysteinsupplementation. 
Tabelle 5.5: Ergebnisse des Wachstumsversuchs mit DLM/MHA-Supplementation bei variierendem Met:Cys-Verhältnis (Versuch 5) ${ }^{1}$

\begin{tabular}{|c|c|c|c|c|c|}
\hline $\begin{array}{l}\text { Diät } \\
\text { (Met:Cys) }\end{array}$ & $\begin{array}{c}\text { NC } \\
(46: 54)\end{array}$ & $\begin{array}{c}\text { M I } \\
(55: 45)\end{array}$ & $\begin{array}{c}\text { M II } \\
(61: 39)\end{array}$ & $\begin{array}{l}\text { MHA I } \\
(55: 45)\end{array}$ & $\begin{array}{c}\text { MHA II } \\
(62: 38)\end{array}$ \\
\hline \multicolumn{6}{|c|}{ (1. - 5. Woche) } \\
\hline Anfangsmasse (g) & $49 \pm 0,2$ & $49 \pm 0,4$ & $48 \pm 0,1$ & $49 \pm 0,1$ & $49 \pm 0,1$ \\
\hline Endmasse (g) & $745 \pm 44$ & $1565 \pm 152$ & $2398 \pm 76$ & $1372 \pm 80$ & $2277 \pm 159$ \\
\hline Futteraufnahme (g/d) & $61^{\mathrm{a}} \pm 4$ & $86^{b} \pm 5$ & $109^{c} \pm 3$ & $83^{b} \pm 3$ & $108^{c} \pm 6$ \\
\hline Zuwachs (g/d) & $20^{\mathrm{a}} \pm 1$ & $43^{b} \pm 4$ & $67^{\mathrm{c}} \pm 2$ & $38^{\mathrm{b}} \pm 2$ & $64^{\mathrm{c}} \pm 5$ \\
\hline \multirow{2}{*}{ Futteraufwand (g/g) } & $3,07^{\mathrm{d}}$ & $1,98^{\mathrm{b}}$ & $1,62^{\mathrm{a}}$ & $2,21^{\mathrm{c}}$ & $1,70^{\mathrm{a}}$ \\
\hline & $\pm 0,13$ & $\pm 0,09$ & $\pm 0,02$ & $\pm 0,11$ & $\pm 0,05$ \\
\hline \multirow{2}{*}{ N-Deposition (g/d) } & $0,542^{\mathrm{a}}$ & $1,156^{\mathrm{b}}$ & $1,843^{\mathrm{c}}$ & $0,997^{\mathrm{b}}$ & $1,699^{\mathrm{c}}$ \\
\hline & $\pm 0,03$ & $\pm 0,12$ & $\pm 0,06$ & $\pm 0,06$ & $\pm 0,12$ \\
\hline$b$-Wert & $141^{\mathrm{a}} \pm 6$ & $226^{\mathrm{c}} \pm 12$ & $310^{\mathrm{e}} \pm 6$ & $199^{b} \pm 11$ & $281^{\mathrm{d}} \pm 11$ \\
\hline $\mathrm{bc}_{\mathrm{Met}}^{-1}$-Wert & $77^{\mathrm{a}} \pm 3$ & $119^{c} \pm 6$ & $128^{\mathrm{d}} \pm 2$ & $102^{b} \pm 6$ & $110^{b} \pm 5$ \\
\hline $\mathrm{bc}_{\mathrm{SAA}}{ }^{-1}$-Wert & $36^{\mathrm{a}} \pm 2$ & $66^{\mathrm{c}} \pm 4$ & $77^{\mathrm{d}} \pm 1$ & $57^{b} \pm 3$ & $69^{c} \pm 3$ \\
\hline
\end{tabular}

Die Proteinqualität wies b-Werte zwischen 141 und 310 auf, wobei die Kontrolldiät die niedrigste Proteinqualität aufzeigte, gefolgt von der Diät MHA I ( $b=199)$. Mit zunehmendem Anteil an Met in den Diäten konnte ein signifikanter Anstieg in der Proteinqualität beobachtet werden. Innerhalb der Supplementationsstufen existierten signifikanten Unterschiede, wobei nach DLM Supplementation jeweils signifikant höhere b-Werte beobachtet wurden.

Die Methioninwirksamkeit $\left(\mathrm{bc}_{\mathrm{Met}}{ }^{-1}\right)$ nahm mit zunehmendem Anteil an Met in den Mischungen zu. Die Betrachtung der Methioninwirksamkeit wies auf signifikant erhöhte $b_{\text {Met }}{ }^{-1}$-Werte für die Met-supplementierten Diäten im Vergleich zur Kontrollmischung NC hin. Hohe Werte verzeichneten die Diäten mit DLM-Supplementation M II (128) und M I (119), welche sich signifikant unterscheiden. Es folgen die Diäten mit MHA-Zusatz, die eine Methioninwirksamkeit von 110 (MHA II) sowie 102 (MHA I) aufwiesen. Innerhalb der Testdiäten mit MHA-Supplementation existierten keine signifikanten Unterschiede.

Die SAA-Wirksamkeit $\left(\mathrm{bc}_{\mathrm{SAA}^{-1}}\right)$ nahm mit zunehmendem Anteil an Met in den Mischungen zu. Die Betrachtung der SAA-Wirksamkeit wies auf signifikant erhöhte $b c_{\text {Met }}{ }^{-1}-$ Werte für die Met-supplementierten Diäten im Vergleich zur Kontrollmischung NC hin. Hohe Werte verzeichneten die Diäten mit DLM-Supplementation M I (66) und M II (77), welche sich unterschieden $(\mathrm{p} \leq 0,05)$. Die Diäten mit MHA-Zusatz, die eine SAA-Wirksamkeit von 57 (MHA I) sowie 69 (MHA II) aufweisen unterschieden sich ebenfalls signifikant. 
Der Zusatz von MHA resultierte im Vergleich zur DLM-Supplementation tendenziell in einem schlechterem Lebendmassezuwachs, Futteraufwand, N-Ansatz und Methioninwirksamkeit. Nach Durchführung des Wirksamkeitsvergleichs zwischen DLM und MHA ergaben sich Wirksamkeiten des MHAs in den einzelnen Diäten, die folgende Werte aufwiesen:

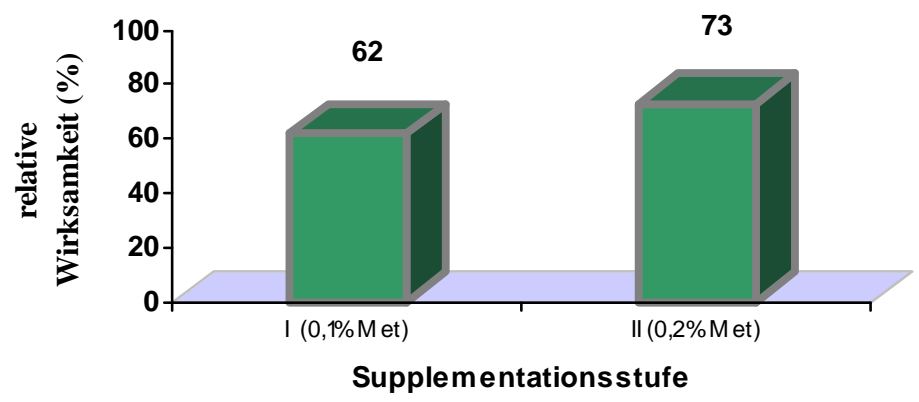

Abbildung 5.6: Wirksamkeit von MHA im Vergleich zu DLM (= 100\%) (Versuch 5)

Die Berechnung der MHA-Wirksamkeit relativ zu DLM erfolgte nach Gleichung 11. Die in der Abbildung 5.6 dargestellten Wirksamkeit von MHA relativ zu DLM wies mit einer höheren Methioninkonzentration in den Diäten eine höhere relative Wirksamkeit auf. Im Vergleich zu den Mischungen mit DLM-Supplementation lag die relative Wirksamkeit von MHA mit Werten von $62 \%$ und $73 \%$ unter der des DLM. 


\subsubsection{Ableitungen zum Methioninbedarf}

Dieser Abschnitt diente zur Ermittlung des Methioninbedarfes. Die ermittelten Methioninwirksamkeiten der Versuche 2 und 4, die bereits im vorangegangenen Abschnitt dargestellt wurden, dienten als Grundlage zur Methioninbedarfsableitung. Einen Überblick zu den Versuchsergebnissen gewähren die Tabellen 5.2 und 5.3.

Der tägliche Bedarf an Aminosäuren wurde in Abhängigkeit vom Rohproteinansatz und der täglichen Futteraufnahme ermittelt. Als Grundlage dienten der im Versuchskomplex I (Kapitel 5.1) ermittelte NMR mit $304 \mathrm{mg} \mathrm{N} / \mathrm{LM}_{\mathrm{kg}}{ }^{0,67}$ pro Tag und einem $\mathrm{NR}_{\max } \mathrm{T}$ von 3991 $\mathrm{mg} \mathrm{N} / \mathrm{LM}_{\mathrm{kg}}{ }^{0,67}$ (Starterperiode) und $3110 \mathrm{mg} \mathrm{N} / \mathrm{LM}_{\mathrm{kg}}{ }^{0,67}$ (Growerperiode).

Um eine hohe Ausschöpfung des maximalen theoretischen N-Depositionsvermögens $\left(\mathrm{ND}_{\max } \mathrm{T}\right) \mathrm{zu}$ realisieren, wurde eine hohe Methioninzufuhr benötigt. Ein niedriger Proteinansatz erforderte dagegen eine niedrige Met-Aufnahme. Ein Leistungsbereich von 69\% Ausschöpfung des $\mathrm{ND}_{\max } \mathrm{T}$ setzte eine Met-Zufuhr von $498 \mathrm{mg} / \mathrm{LM}_{\mathrm{kg}}{ }^{0,67} / \mathrm{d}$ in der Altersperiode 10. - 20. LT voraus, während in dem Bereich von 41\% Ausschöpfung ein Bedarf von $244 \mathrm{mg} / \mathrm{LM}_{\mathrm{kg}}{ }^{0,67} / \mathrm{d}$ anzusetzen war. Bezogen auf einen Broiler mit einer Lebendmasse von $500 \mathrm{~g}$ entspricht dieses einer Zufuhr an Methionin von $313 \mathrm{mg} / \mathrm{d}$ bzw. 154 mg/d. In Ab-hängigkeit von der vorgegebenen Futteraufnahme variiert der im Futter erforderliche Gehalt an Methionin derart, dass bei vergleichbarem Proteinansatz eine höhere Futteraufnahme eine geringere Konzentration dieser Aminosäuren im Futter erfordert. Bei einer täglichen Futteraufnahme von $50 \mathrm{~g}$ betrug der wirksamkeitsabhängige Bedarf 0,63\% (10 g XP-Ansatz/d). Nahmen die Tiere hingegen täglich $70 \mathrm{~g}$ auf sank die Bedarfskonzentration auf einen Wert von $0,45 \%$. Ein deutlicher Abfall ergab sich bei vergleichbarer täglicher Futteraufnahme in einem mittleren Leistungsbereich (6 g XP-Ansatz/d). Dort lag die im Futter erforderlichen Konzentrationen an Methionin bei 0,31\% und 0,22\%.

Das berechnete Methioninbedarfsspektrum für differenzierte Ansatz- und Verzehrshöhen ist in Tabelle 5.6 für die Starterperiode aufgeführt. 
Tabelle 5.6: Kalkulierter Methioninbedarf in Abhängigkeit vom Proteinansatz, Methioninwirksamkeit und täglicher Futteraufnahme (Starterperiode, mittlere LM:500g)

\begin{tabular}{lccc}
\hline NC-Diät & \multicolumn{3}{c}{ Starter } \\
\hline XP-Ansatz $(\mathrm{g} / \mathrm{d})$ & $6^{1}$ & $8^{2}$ & $10^{3}$ \\
Met-Wirksamkeit $\left(\mathrm{bc}^{-1}\right)$ & & 157 & 498 \\
Met-Bedarf $\left(\mathrm{mg} / \mathrm{LM}_{\mathrm{kg}}{ }^{0,67}\right)$ & 244 & 352 & 313 \\
Met-Bedarf $(\mathrm{mg} / \mathrm{d})$ & 154 & 221 & \\
Optimale Met-Konzentration in der Diät $(\%)$, in Abhängigkeit von der Futteraufnahme \\
Futteraufnahme (g/d) \\
50 & 0,31 & 0,44 & 0,63 \\
60 & 0,26 & 0,37 & 0,52 \\
70 & 0,22 & 0,32 & 0,45 \\
\hline
\end{tabular}

${ }^{1}$ Deposition ca. $41,4 \%$ des theoretischen Maximums der täglichen N-Deposition $\left(\mathrm{mg} / \mathrm{LM}_{\mathrm{kg}}{ }^{0,67}, \mathrm{ND}_{\max } \mathrm{T}\right)$

${ }^{2}$ Deposition ca. $55,2 \%$ von $\mathrm{ND}_{\max } \mathrm{T}$

${ }^{3}$ Deposition ca. $69,0 \%$ von $\mathrm{ND}_{\max } \mathrm{T}$

Der berechnete Bedarfsbereich, der sich in Abhängigkeit des gewünschten Proteinansatzes ergab und die in den Growerfuttermischungen vorgefundene Wirksamkeit der schwefelhaltigen Aminosäure Methionin einschloss, ist in Tabelle 5.7 aufgeführt. Wie aus der Tabelle $5.7 \mathrm{zu}$ entnehmen, sowie analog zu den Erläuterungen zur Ableitung des Methioninbedarfs in der Starterperiode, erfordern unterschiedliche ND unterschiedliche Methioningehalte. Bei einer N-Deposition von ca. $77 \%$ von $\mathrm{ND}_{\max }$ T lag der Methioninbedarf bei $500 \mathrm{mg} / \mathrm{LM}_{\mathrm{kg}}{ }^{0,67} / \mathrm{d}$, während in einem mittleren Bereich von 46\% Ausschöpfung ein Bedarf von $230 \mathrm{mg} / \mathrm{LM}_{\mathrm{kg}}{ }^{0,67} / \mathrm{d}$ anzusetzen war. Wies der Broiler eine Lebendmasse von $1800 \mathrm{~g}$ auf, betrug die entsprechende Methioninzufuhr 742 mg/d (73\% Ausschöpfung) bzw. $341 \mathrm{mg} / \mathrm{d}$ (46\% Ausschöpfung). Bei einer hohen Futteraufnahme verringerte sich die notwendige Methioninkonzentration im Futter (0,49\% bei $150 \mathrm{~g} / \mathrm{d}$ Futteraufnahme, $20 \mathrm{~g} \mathrm{XP-Ansatz/d})$ im Vergleich zu einer niedrigeren Futteraufnahme, die einen höheren Methioningehalt erforderte $(0,57 \%$ bei $130 \mathrm{~g} / \mathrm{d}$ Futteraufnahme, $20 \mathrm{~g}$ XP-Ansatz/d), um einen vergleichbaren Proteinansatz $\mathrm{zu}$ erzielen. Eine Herabsetzung der Ausschöpfung von $\mathrm{ND}_{\max } \mathrm{T}$ auf $46 \%$ verringerte den Met-Bedarf deutlich. Hier waren bei vergleichbarer Futteraufnahme eine Methioninkonzentration im Futter von 0,23\% (150 g tägliche Futteraufnahme) und 0,26\% (130 g tägliche Futteraufnahme) erforderlich. 
Tabelle 5.7: Kalkulierter Methioninbedarf in Abhängigkeit vom Proteinansatz, Methioninwirksamkeit und täglichen Futteraufnahme (Growerperiode, mittlere LM:1800g)

\begin{tabular}{lccc}
\hline NC-Diät & \multicolumn{3}{c}{ Grower } \\
\hline XP-Ansatz $(\mathrm{g} / \mathrm{d})$ & $12^{1}$ & $16^{2}$ & $20^{3}$ \\
Met-Wirksamkeit $\left(\mathrm{bc}^{-1}\right)$ & & 196 & 500 \\
Met-Bedarf $\left(\mathrm{mg} / \mathrm{LM}_{\mathrm{kg}}{ }^{0,67}\right)$ & 230 & 337 & 742 \\
Met-Bedarf (mg/d) & 341 & 500 &
\end{tabular}

Optimale Met-Konzentration in der Diät (\%), in Abhängigkeit von der Futteraufnahme

Futteraufnahme (g/d)

\begin{tabular}{llll}
130 & 0,26 & 0,38 & 0,57 \\
140 & 0,24 & 0,36 & 0,53 \\
150 & 0,23 & 0,33 & 0,49 \\
\hline
\end{tabular}

${ }^{1}$ Deposition ca. $46,2 \%$ des theoretischen Maximums der täglichen N-Deposition $\left(\mathrm{mg} / \mathrm{LM}_{\mathrm{kg}}{ }^{0,67}, \mathrm{ND}_{\max } \mathrm{T}\right)$

${ }^{2}$ Deposition ca. $61,5 \%$ von $\mathrm{ND}_{\max } \mathrm{T}$

${ }^{3}$ Deposition ca. $76,9 \%$ von $\mathrm{ND}_{\max } \mathrm{T}$

Nachfolgend wird der Methioninbedarf in Abhängigkeit des Met:Cys-Verhältnisses für unterschiedliche XP-Ansatzdaten dargestellt. Dies sollte eventuelle Einflüsse des Cysteins bzw. des Met:Cys-Verhältnisses auf den Methioninbedarf bzw. SAA-Bedarf geltend machen. Zur vergleichenden Betrachtung dienten die Diäten mit der ersten Supplementationsstufe (Diät M I und Diät M+C I).

Tabelle 5.8: Kalkulierter Met-Bedarf in Abhängigkeit vom täglichen XP-Ansatz und täglicher Futteraufnahme bei variierendem Met:Cys-Verhältnis (Starterperiode, mittlere LM:500g)

\begin{tabular}{|c|c|c|c|c|c|c|}
\hline $\begin{array}{l}\text { Diät } \\
\text { (Met:Cys) }\end{array}$ & \multicolumn{3}{|c|}{$\begin{array}{l}M+C \text { I } \\
(45: 55)\end{array}$} & \multicolumn{3}{|c|}{$\begin{array}{c}\text { M I } \\
(55: 45)\end{array}$} \\
\hline XP-Ansatz (g/d) & $6^{1}$ & $8^{2}$ & $10^{3}$ & $6^{1}$ & $8^{2}$ & $10^{3}$ \\
\hline Met-Wirksamkeit $\left(\mathrm{bc}^{-1}\right)$ & & 175 & & & 164 & \\
\hline Met-Bedarf $\left(\mathrm{mg} / \mathrm{LM}_{\mathrm{kg}}{ }^{0,67}\right)$ & 219 & 315 & 447 & 234 & 337 & 477 \\
\hline Met-Bedarf (mg/d) & 138 & 198 & 281 & 147 & 212 & 300 \\
\hline \multicolumn{7}{|c|}{ Optimale Met-Konzentration in der Diät (\%), in Abhängigkeit von der Futteraufnahme } \\
\hline \multicolumn{7}{|l|}{ Futteraufnahme (g/d) } \\
\hline 50 & 0,28 & 0,40 & 0,56 & 0,29 & 0,42 & 0,60 \\
\hline 60 & 0,23 & 0,33 & 0,47 & 0,25 & 0,35 & 0,50 \\
\hline 70 & 0,20 & 0,28 & 0,40 & 0,21 & 0,30 & 0,43 \\
\hline
\end{tabular}

${ }^{1}$ Deposition ca. $41,4 \%$ des theoretischen Maximums der täglichen $\mathrm{N}-$ Deposition $\left(\mathrm{mg} / \mathrm{LM}_{\mathrm{kg}}{ }^{0,67}, \mathrm{ND}_{\max } \mathrm{T}\right)$

${ }^{2}$ Deposition ca. $55,2 \%$ von $\mathrm{ND}_{\max } \mathrm{T}$

${ }^{3}$ Deposition ca. $69,0 \%$ von $\mathrm{ND}_{\max } \mathrm{T}$ 
Die Supplementation von DLM wie auch DLM in Kombination mit Cystein erfordern bei einem hohen Proteinansatz hohe Methioninmengen zur Erreichung der angstrebten Leistung, während ein niedriger Proteinansatz mit geringen Methioninmengen im Futter einhergeht. In Abhängigkeit von der Methioninwirksamkeit der eingesetzten Futtermischung variiert entsprechend die erforderliche Methioninversorgung innerhalb einer angestrebten Leistung, wobei eine hohe Wirksamkeit verringernd auf die notwendige Methioninversorgung und umgekehrt eine niedrige Wirksamkeit erhöhend wirkt. Durch die Supplementation von DLM+Cys resultierten leicht höhere Methioninwirksamkeiten als im Vergleich zur DLMZulage, was zu einem geringeren Methioninbedarf führte. In einem hohen Leistungsbereich von $69 \%$ Ausschöpfung des $\mathrm{ND}_{\max } \mathrm{T}$ war ein Methioninbedarf von $447 \mathrm{mg} / \mathrm{LM}_{\mathrm{kg}}{ }^{0,67} / \mathrm{d}$ anzusetzen wenn DLM in Kombination mit Cys supplementiert wurde, während bei Zulage von DLM per se ein höherer Wert von $477 \mathrm{mg} / \mathrm{LM}_{\mathrm{kg}}{ }^{0,67} / \mathrm{d}$ vorlag. Bezogen auf ein Masthähnchen mit einer Lebendmasse von $500 \mathrm{~g}$ entsprach dies einer notwendigen Methioninzufuhr von $281 \mathrm{mg} / \mathrm{d}$ (M+C I) bzw. $300 \mathrm{mg} / \mathrm{d}$ (M I). In Abhängigkeit von der vorgegebenen Futteraufnahme erhöhte bzw. verminderte sich der im Futter erforderliche Methioningehalt, wobei eine höhere Futteraufnahme eine geringere Methioninkonzentration im Futter notwendig werden ließ, um einen vergleichbaren Proteinansatz zu erzielen. Bei einer täglichen Futteraufnahme von $50 \mathrm{~g}$ beträgt die erforderliche Methioninkonzentration in Abhängigkeit von der Methioninwirksamkeit (M+C I) 0,56\% bzw. (M I) 0,60\% bei 69\% Ausschöpfung des $\mathrm{ND}_{\max } \mathrm{T}$.

Tabelle 5.9: Kalkulierter Met-Bedarf in Abhängigkeit vom täglichen XP-Ansatz und täglicher Futteraufnahme bei variierendem Met:Cys-Verhältnis (Growerperiode, mittlere LM:1800g)

\begin{tabular}{|c|c|c|c|c|c|c|}
\hline $\begin{array}{l}\text { Diät } \\
\text { (Met:Cys) }\end{array}$ & \multicolumn{3}{|c|}{$\begin{array}{l}M+C ~ I \\
(45: 55)\end{array}$} & \multicolumn{3}{|c|}{$\begin{array}{c}\text { M I } \\
(55: 45)\end{array}$} \\
\hline XP-Ansatz (g/d) & $12^{1}$ & $16^{2}$ & $20^{3}$ & $12^{1}$ & $16^{2}$ & $20^{3}$ \\
\hline Met-Wirksamkeit $\left(\mathrm{bc}^{-1}\right)$ & & 264 & & & 171 & \\
\hline Met-Bedarf (mg/LM ${ }_{\mathrm{kg}}{ }^{0,67}$ prod) & 171 & 251 & 371 & 264 & 387 & 573 \\
\hline Met-Bedarf (mg/d) & 253 & 371 & 551 & 391 & 573 & 850 \\
\hline \multicolumn{7}{|c|}{ Optimale Met-Konzentration in der Diät (\%), in Abhängigkeit von der Futteraufnahme } \\
\hline \multicolumn{7}{|l|}{ Futteraufnahme (g/d) } \\
\hline 130 & 0,19 & 0,29 & 0,42 & 0,30 & 0,44 & 0,65 \\
\hline 140 & 0,18 & 0,27 & 0,39 & 0,28 & 0,41 & 0,61 \\
\hline 150 & 0,17 & 0,25 & 0,37 & 0,26 & 0,38 & 0,57 \\
\hline
\end{tabular}

\footnotetext{
${ }^{1}$ Deposition ca. $46,2 \%$ des theoretischen Maximums der täglichen N-Deposition $\left(\mathrm{mg} / \mathrm{LM}_{\mathrm{kg}}{ }^{0,67}, \mathrm{ND}_{\max } \mathrm{T}\right)$

${ }^{2}$ Deposition ca. $61,5 \%$ von $\mathrm{ND}_{\max } \mathrm{T}$

${ }^{3}$ Deposition ca. $76,9 \%$ von $\mathrm{ND}_{\max } \mathrm{T}$
} 
Vergleichbare Ergebnisse lieferten die Growerperiode. In einem hohen Leistungsbereich von $77 \%$ Ausschöpfung des $\mathrm{ND}_{\max } \mathrm{T}$ war eine Met-Konzentration von $371 \mathrm{mg} / \mathrm{LM}_{\mathrm{kg}}{ }^{0,67} / \mathrm{d}$ erforderlich, wenn DLM in Kombination mit Cys supplementiert wurde, während bei Zulage von DLM per se ein höherer Wert von $573 \mathrm{mg} / \mathrm{LM}_{\mathrm{kg}}{ }^{0,67} / \mathrm{d}$ vorlagt. Bezogen auf ein Masthähnchen mit einer Lebendmasse von $1800 \mathrm{~g}$ entsprach dies einer notwendigen Methioninzufuhr von $551 \mathrm{mg} / \mathrm{d}(\mathrm{M}+\mathrm{C}$ I) bzw. $850 \mathrm{mg} / \mathrm{d}$ (M I). In Abhängigkeit von der vorgegebenen Futteraufnahme erhöhte bzw. verminderte sich der im Futter erforderliche Methioningehalt, wobei eine höhere Futteraufnahme eine geringere Methioninkonzentration im Futter notwendig werden ließ, um einen vergleichbaren Proteinansatz zu erzielen. Bei einer täglichen Futteraufnahme von $130 \mathrm{~g}$ beträgt die erforderliche Methioninkonzentration in Abhängigkeit von der Methioninwirksamkeit (M+C I) 0,42\% bzw. (M I) 0,65\% bei 77\% Ausschöpfung des $\mathrm{ND}_{\max } \mathrm{T}$. 


\subsection{Untersuchungskomplex III}

Drei weitere N-Bilanzversuche sollten dazu dienen, die Kenntnisse zu den optimalen Aminosäurenverhältnissen im Futter weiter zu entwickeln. $\mathrm{Zu}$ diesem Zweck wurde das Resultat von N-Bilanzmessungen nach Gabe einer ausbalancierten Basalmischung (BC) jeweils mit Testdiäten verglichen, die unterschiedliche Aminosäuren als LAA aufwiesen: Lys-limitierte Diät (LYS), Thr-limitierte Diät (THR), Trp-limitierte Diät (TRP), Arglimitierte Diät (ARG), Ile-limitierte Diät (ILE) und Val-limitierte Diät (VAL). Zum anderen wurden zwei Wachstumsversuche zur vergleichenden Betrachtung durchgeführt.

Als Grundlage der Datenauswertung dienten wiederum die im Versuchskomplex I (Kapitel 5.1 ) ermittelten Modellparameter für den täglichen NMR (304 mg N/LM ${ }_{\mathrm{kg}}{ }^{0,67}$ ) bzw. NR ${ }_{\max } \mathrm{T}(3991 \mathrm{mg}$ $\mathrm{N} / \mathrm{LM}_{\mathrm{kg}}{ }^{0,67}$ in der Starterperiode bzw. $3110 \mathrm{mg} \mathrm{N} / \mathrm{LM}_{\mathrm{kg}}{ }^{0,67}$ in der Growerperiode).

\subsubsection{Ableitungen zum Idealprotein - Stoffwechselversuche}

Dieser Komplex gibt die drei N-Bilanzstudien wieder, die differenziert für Starter- und Growerperiode ausgewertet wurden. Die Versuche 6 und 8 beinhalten Ergebnisse mit den Aminosäuren Lysin, Threonin, Tryptophan, Arginin, Isoleucin und Valin als LAA, während im Versuch 9 ausschließlich die Aminosäuren Lysin, Threonin Isoleucin und Valin im Fokus der Betrachtung stehen. Die zusammengefassten Ergebnisse der Stoffwechselstudien zum Idealprotein präsentieren die Tabelle 5.10, Tabelle 5.11 und die Tabelle 5.12.

\section{Stoffwechselversuch 6}

Tabelle 5.10 vermittelt eine Übersicht $\mathrm{zu}$ den Hauptergebnissen des Versuches. Eine detailliertere Darstellung der Ergebnisse ist dem Anhang (Tabellen A22 und A23) zu entnehmen.

Die „Verdünnung“ der Basaldiät (BC) zeigte in der Starterperiode bei der Gruppe LYS die deutlichsten Effekte. Während nur für die Diät LYS ein signifikanter Einfluss auf die TI und NI beobachtet werden konnte, zeigte sich im Hinblick auf die N-Deposition (ND) und 
Proteinqualität ebenfalls für THR und ARG deutliche Effekte $(p \leq 0,05)$. Hinsichtlich des Vergleiches mit der Gruppe BC realisierten diese Gruppen niedrigere ND-Werte.

Die Proteinqualität (b) der Diät BC betrug 323. Die Ermittlung der Proteinqualität in den AAreduzierten Futtermischungen ergab, dass die Qualität nur in den Diäten LYS, THR und ARG signifikant abgesenkt war. Die limitierende Position der Aminosäuren Lys, Thr und Arg wurde somit erreicht. Die biostatistischen Ergebnisse zum b-Wert der Diäten TRP, ILE und VAL ließen hingegen keine Rückschlüsse auf signifikante Unterschiede zur Diät BC zu, was indiziert, dass die limitierende Position der Aminosäuren Trp, Ile und Val in den jeweiligen Diäten offenbar nicht erreicht wurde.

Basierend auf dem exponentiellen Modell erfolgt nach Überschreiten des Limitierungsbereiches eine Reduzierung des $b c^{-1}$-Wertes. Übertragen auf die AA-reduzierten Futtermischungen LYS, THR, TRP, ARG, ILE und VAL bedeutet dies ein Anstieg der Aminosäurenwirksamkeit $\left(\mathrm{bc}^{-1}\right)$, wenn die limitierende Position erreicht wurde.

Allerdings war für die Diät LYS keine höhere Lys-Wirksamkeit erkennbar, trotz signifikant niedrigerem $b$-Wert.

Die Diäten THR und ARG wiesen zwar eine höhere Aminosäurenwirksamkeit auf, jedoch ohne Signifikanz. Die Diäten TRP, ILE und VAL zeigten signifikant höhere Aminosäurenwirksamkeiten.

Die Proteinqualität in den AA-reduzierten Growerfuttermischungen ergab, dass die Qualität nur in den Diäten LYS signifikant abgesenkt war. Trotz limitierender Position konnte auch in der Growerperiode kein Anstieg in der Lys-Wirksamkeit ermittelt werden. Dies ließ vermuten, dass in der Diät BC bereits eine Limitierung durch Lysin vorlag.

Die Diäten TRP und ILE wiesen eine höhere Trp- bzw. Ile-Wirksamkeit auf.

Unter Berücksichtigung der limitierenden Position des Lysins in der Diät BC konnte geschlussfolgert werden, dass in der Diät BC die Aminosäuren Trp, Ile und Val im Überschuss vorlagen. Die Verdünnung der Diät BC bewirkte ausschließlich einen Abbau des Über-schusses. 
Tabelle 5.10: Ergebnisse des N-Bilanzversuchs 6 zum Idealprotein ${ }^{1}$

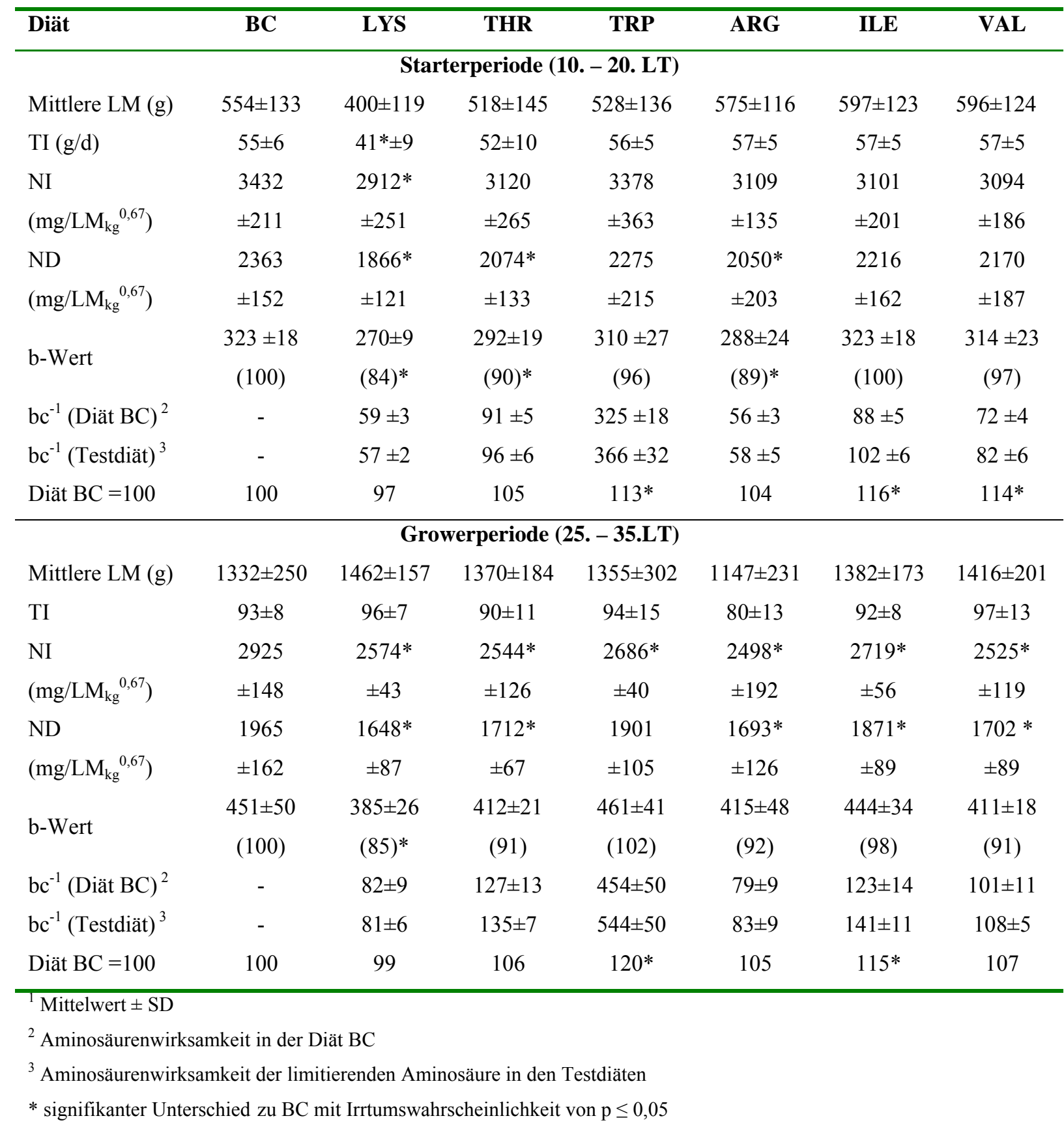

Basierend auf dem Quotienten aus der Lysinwirksamkeit der Diät BC und der Aminosäurenwirksamkeit der Testdiät ergab sich ein optimales Aminosäurenverhältnis im Versuchs 6 von Thr: Trp: Arg: Ile: Val = 61\%: 16\%: 102\%: 57\%: 72\% relativ zu Lys in der Starterperiode und Thr: Trp: Arg: Ile: Val =61\%: 15\%: 99\%: 58\%: 77\% relativ zu Lys in der Growerperiode. 


\section{Stoffwechselversuch 8}

Tabelle 5.11 vermittelt eine Übersicht zu den Hauptergebnissen des Versuches. Eine detailliertere Darstellung der Ergebnisse ist dem Anhang (Tabellen A29 und A30) zu entnehmen.

Aus den Ergebnissen des Versuches 6 resultierte die Vermutung, dass in der Diät BC bereits eine Limitierung durch Lysin vorlag. Eine weitere Absenkung des Lysingehaltes in der Diät LYS würde daher keinen Anstieg in der Lys-Wirksamkeit bewirken. Deshalb wurde in den Versuchen 8, 9 und 10 eine Erhöhung des Lysingehaltes von 12,5 g/kg auf 13,5 g/kg Futter (Starterperiode) bzw. 11,5 g/kg auf 12,5 g/kg Futter (Growerperiode) vorgenommen.

Die Diäten LYS, THR, TRP, ARG, ILE und VAL zeigten keinen Einfluss auf die TI in beiden Wachstumperioden. Im Hinblick auf die ND ergaben sich in der Starterperiode für die Gruppen LYS, TRP und ARG geringere Werte $(\mathrm{p} \leq 0,05)$. In der Growerperiode wurde dies bei allen Gruppen beobachtet.

Die Ermittlung der Proteinqualität in den Starterfuttermischungen ergab, dass die b-Werte der Diäten LYS, THR, TRP und ARG signifikant abgesenkt waren. Diese Aminosäuren lagen somit im Limitierungsbereich. Obwohl ILE und VAL keinen niedrigeren $(p \leq 0,05) b$-Wert aufwiesen, wurde in diesen Diäten eine signifikant höhere AA-Wirksamkeit realisiert. Für die Diät THR konnte eine signifikant höhere Thr-Wirksamkeit bestätigt werden, während für die Diät LYS hingegen numerisch eine geringere Lys-Wirksamkeit realisiert wurde, trotz signifikant niedrigerem $b$-Wert.

Die Proteinqualität war in allen AA-reduzierten Growerdiäten signifikant niedriger als in der Diät BC. Im Gegensatz zur Starterperiode lagen somit in allen Testdiäten die jeweiligen Aminosäuren im Limitierungsbereich.

Hinsichtlich der effizienten Nutzung der einzelnen Aminosäuren ergab sich nur für Thr eine höhere Wirksamkeit, die allerdings nur tendenziell war. Sowohl für LYS als auch für VAL zeigte sich ein signifikant geringeren $b^{-1}$-Wert. Für die Diäten THR, ARG und ILE zeigten sich eine tendenziell niedrigere Thr-, Arg- oder Ile-Wirksamkeit. 
Der im Vergleich zu Versuch 6 höhere Lysingehalt ließ eine deutlichere Limitierung der anderen zu untersuchenden Aminosäuren erkennen.

Tabelle 5.11: Ergebnisse des N-Bilanzversuchs 8 zum Idealprotein ${ }^{1}$

\begin{tabular}{|c|c|c|c|c|c|c|c|}
\hline Diät & BC & LYS & THR & TRP & ARG & ILE & VAL \\
\hline \multicolumn{8}{|c|}{ Starterperiode (10. - 20. LT) } \\
\hline Mittlere LM (g) & $624 \pm 160$ & $625 \pm 144$ & $688 \pm 155$ & $640 \pm 149$ & $673 \pm 155$ & $672 \pm 166$ & $674 \pm 157$ \\
\hline $\mathrm{TI}(\mathrm{g} / \mathrm{d})$ & $62 \pm 8$ & $64 \pm 10$ & $69 \pm 7$ & $62 \pm 7$ & $68 \pm 8$ & $67 \pm 10$ & $67 \pm 8$ \\
\hline $\mathrm{NI}\left(\mathrm{mg} / \mathrm{LM}_{\mathrm{kg}}{ }^{0,67}\right)$ & $\begin{array}{l}3711 \\
\pm 181\end{array}$ & $\begin{array}{l}3462 \\
\pm 145\end{array}$ & $\begin{array}{l}3513 \\
\pm 173\end{array}$ & $\begin{array}{l}3367 \\
\pm 317\end{array}$ & $\begin{array}{l}3470 \\
\pm 166\end{array}$ & $\begin{array}{l}3456 \\
\pm 177\end{array}$ & $\begin{array}{l}3462 \\
\pm 301\end{array}$ \\
\hline $\begin{array}{l}\mathrm{ND} \\
\left(\mathrm{mo} / \mathrm{IM}_{1} 0,67\right)\end{array}$ & $\begin{array}{c}2500 \\
+97\end{array}$ & $\begin{array}{c}2027^{*} \\
+93\end{array}$ & $\begin{array}{l}2317 \\
+136\end{array}$ & $\begin{array}{r}2128^{*} \\
+179\end{array}$ & $\begin{array}{r}2170^{*} \\
+137\end{array}$ & $\begin{array}{l}2374 \\
+146\end{array}$ & $\begin{array}{l}2385 \\
+270\end{array}$ \\
\hline $\mathrm{b}$-Wert & $\begin{array}{c}327 \pm 11 \\
(100)\end{array}$ & $\begin{array}{c}254 \pm 13 \\
(78)^{*}\end{array}$ & $\begin{array}{c}305 \pm 15 \\
(93)^{*}\end{array}$ & $\begin{array}{c}281 \pm 16 \\
(86)^{*}\end{array}$ & $\begin{array}{c}280 \pm 18 \\
(86)^{*}\end{array}$ & $\begin{array}{c}323 \pm 24 \\
(99)\end{array}$ & $\begin{array}{c}327 \pm 39 \\
(100)\end{array}$ \\
\hline $\mathrm{bc}^{-1}(\text { Diät BC) })^{2}$ & - & $58 \pm 2$ & $88 \pm 3$ & $312 \pm 11$ & $55 \pm 2$ & $84 \pm 3$ & $71 \pm 2$ \\
\hline $\mathrm{bc}^{-1}{\text { (Testdiät })^{3}}^{3}$ & - & $52 \pm 3$ & $95 \pm 5$ & $312 \pm 18$ & $53 \pm 3$ & $97 \pm 7$ & $83 \pm 10$ \\
\hline Diät BC $=100$ & 100 & $90 *$ & $108 *$ & 100 & 96 & $115^{*}$ & $117 *$ \\
\hline \multicolumn{8}{|c|}{ Growerperiode (25. - 35. LT) } \\
\hline Mittlere LM (g) & $1821 \pm 242$ & $1785 \pm 230$ & $1788 \pm 24$ & $1847 \pm 243$ & $1777 \pm 234$ & $1828 \pm 251$ & $1845 \pm 239$ \\
\hline $\mathrm{TI}(\mathrm{g} / \mathrm{d})$ & $121 \pm 8$ & $125 \pm 9$ & $126 \pm 9$ & $127 \pm 8$ & $123 \pm 12$ & $128 \pm 9$ & $128 \pm 8$ \\
\hline $\mathrm{NI}\left(\mathrm{mg} / \mathrm{LM}_{\mathrm{kg}}{ }^{0,67}\right)$ & $\begin{array}{l}3207 \\
\pm 137\end{array}$ & $\begin{array}{c}3051 \\
\pm 57\end{array}$ & $\begin{array}{c}3116 \\
\pm 78\end{array}$ & $\begin{array}{c}3085 \\
\pm 93\end{array}$ & $\begin{array}{c}2987 * \\
\pm 197\end{array}$ & $\begin{array}{l}3105 \\
\pm 100\end{array}$ & $\begin{array}{c}3085 \\
\pm 99\end{array}$ \\
\hline $\begin{array}{l}\mathrm{ND} \\
\left(\mathrm{mg} / \mathrm{LM}_{1} 0,67\right)\end{array}$ & $\begin{array}{c}2089 \\
+36\end{array}$ & $\begin{array}{l}1792 * \\
+108\end{array}$ & $\begin{array}{c}1853^{*} \\
+33\end{array}$ & $\begin{array}{c}1914^{*} \\
+32\end{array}$ & $\begin{array}{l}1798^{*} \\
\pm 109\end{array}$ & $\begin{array}{c}1836^{*} \\
+65\end{array}$ & $\begin{array}{c}1794 * \\
+115\end{array}$ \\
\hline $\mathrm{b}$-Wert & $\begin{array}{c}459 \pm 25 \\
(100)\end{array}$ & $\begin{array}{l}369 \pm 1 \\
(80)^{*}\end{array}$ & $\begin{array}{l}381 \pm 25 \\
(83)^{*}\end{array}$ & $\begin{array}{c}406 \pm 26 \\
(88)^{*}\end{array}$ & $\begin{array}{c}380 \pm 35 \\
(83)^{*}\end{array}$ & $\begin{array}{c}376 \pm 17 \\
(82)^{*}\end{array}$ & $\begin{array}{c}366 \pm 35 \\
(80)^{*}\end{array}$ \\
\hline $\mathrm{bc}^{-1}(\text { Diät BC) })^{2}$ & - & $82 \pm 4$ & $123 \pm 7$ & $437 \pm 23$ & $77 \pm 4$ & $118 \pm 6$ & $100 \pm 5$ \\
\hline $\mathrm{bc}^{-1}$ (Testdiät) $^{3}$ & - & $75 \pm 6$ & $118 \pm 8$ & $451 \pm 29$ & $72 \pm 7$ & $112 \pm 5$ & $92 \pm 9$ \\
\hline Diät $B C=100$ & 100 & $91^{*}$ & 96 & 103 & 94 & 95 & $92 *$ \\
\hline
\end{tabular}

Basierend auf dem Quotienten aus der Lysinwirksamkeit der Diät BC und der Aminosäurenwirksamkeit der Testdiät ergab sich ein optimales Aminosäurenverhältnis im Versuch 8 von Thr:Trp:Arg:Ile:Val = 61\%:19\%:109\%:60\%:70\% relativ zu Lys in der Starterperiode und Thr:Trp:Arg:Ile:Val = 69\%:18\%:113\%:73\%:88\% relativ zu Lys in der Growerperiode. 


\section{Stoffwechselversuch 9}

Tabelle 5.11 vermittelt eine Übersicht zu den Hauptergebnissen des Versuches. Eine detailliertere Darstellung der Ergebnisse ist dem Anhang (Tabellen A31 und A32) zu entnehmen.

Für die Diäten ILE und VAL wurde in diesem Versuch eine weitergehende Absenkung der jeweiligen Aminosäuren auf 70\% vorgenommen. Die „Verdünnung“ der Diät BC hatte in der Starter- und Growerperiode einen statistisch gesicherten Einfluss auf die Proteinqualität bei allen AA-reduzierten Mischungen. Dies zeigt, dass die Verdünnung auf $70 \%$ zu einer eindeutigen Limitierung der Aminosäuren Ile (Diät ILE) und Val (Diät VAL) führte.

In der Starterperiode wurde einerseits für die Diäten LYS, THR, ILE und VAL ein Effekt auf die Lys-, Thr-, Ile- und Val-Wirksamkeit erzielt. Andererseits konnte in der Growerperiode kein signifikanter Effekt auf die Aminosäurenwirksamkeit nachgewiesen werden. Betrachtet man die Lys-Wirksamkeit so wurde, wie schon in den Versuchen 6 und 8, bei der Diät LYS eine niedrigere Lys-Wirksamkeit ermittelt.

Tabelle 5.12: Ergebnisse des N-Bilanzversuchs 9 zum Idealprotein ${ }^{1}$

\begin{tabular}{|c|c|c|c|c|c|}
\hline Diät & $\mathrm{BC}$ & LYS & THR & ILE & VAL \\
\hline \multicolumn{6}{|c|}{ Starterperiode (10. - 20. LT) } \\
\hline Mittlere LM (g) & $538 \pm 150$ & $380 \pm 121$ & $468 \pm 152$ & $441 \pm 137$ & $387 \pm 121$ \\
\hline $\mathrm{TI}(\mathrm{g} / \mathrm{d})$ & $63 \pm 12$ & $43^{*} \pm 14$ & $54 \pm 14$ & $52 \pm 14$ & $45^{*} \pm 15$ \\
\hline $\mathrm{NI}\left(\mathrm{mg} / \mathrm{LM}_{\mathrm{kg}}{ }^{0,67}\right)$ & $4144 \pm 128$ & $3512 * \pm 474$ & $3808 \pm 314$ & $3753 \pm 330$ & $3477 * \pm 456$ \\
\hline $\mathrm{ND}\left(\mathrm{mg} / \mathrm{LM}_{\mathrm{kg}}{ }^{0,67}\right)$ & $2822 \pm 93$ & $2197 * \pm 372$ & $2540 * \pm 248$ & $2410 * \pm 195$ & $2379 * \pm 280$ \\
\hline b-Wert & $\begin{array}{c}370 \pm 25 \\
(100)\end{array}$ & $\begin{array}{c}287 \pm 48 \\
(78)^{*}\end{array}$ & $\begin{array}{c}332 \pm 43 \\
(90)^{*}\end{array}$ & $\begin{array}{c}306 \pm 27 \\
(82)^{*}\end{array}$ & $\begin{array}{c}326 \pm 35 \\
(88)^{*}\end{array}$ \\
\hline $\mathrm{bc}^{-1}(\text { Diät BC })^{2}$ & - & $66 \pm 4$ & $98 \pm 7$ & $95 \pm 6$ & $80 \pm 5$ \\
\hline $\mathrm{bc}^{-1}$ (Testdiät) $^{3}$ & - & $64 \pm 11$ & $110 \pm 14$ & $112 \pm 10$ & $100 \pm 11$ \\
\hline Diät $\mathrm{BC}=100$ & 100 & 97 & $112 *$ & $118^{*}$ & $125^{*}$ \\
\hline \multicolumn{6}{|c|}{ Growerperiode (25. - 35. LT) } \\
\hline Mittlere LM (g) & $1551 \pm 228$ & $1475 \pm 207$ & $1428 \pm 202$ & $1469 \pm 196$ & $1309 \pm 267$ \\
\hline $\mathrm{TI}(\mathrm{g} / \mathrm{d})$ & $120 \pm 6$ & $110 \pm 4$ & $109 \pm 7$ & $107 * \pm 9$ & $82 * \pm 22$ \\
\hline $\mathrm{NI}\left(\mathrm{mg} / \mathrm{LM}_{\mathrm{kg}}{ }^{0,67}\right)$ & $3578 \pm 187$ & $3345 \pm 289$ & $3377 \pm 249$ & $3240 \pm 311$ & $2651 * 610$ \\
\hline $\mathrm{ND}\left(\mathrm{mg} / \mathrm{LM}_{\mathrm{kg}}{ }^{0,67}\right)$ & $2199 \pm 193$ & $1806 * \pm 207$ & $1965 \pm 164$ & $1792 * \pm 222$ & $1492 * \pm 656$ \\
\hline$b$-Wert & $\begin{array}{c}470 \pm 80 \\
(100)\end{array}$ & $\begin{array}{c}343 \pm 40 \\
(73)^{*}\end{array}$ & $\begin{array}{c}391 \pm 37 \\
(83)^{*}\end{array}$ & $\begin{array}{c}352 \pm 51 \\
(75)^{*}\end{array}$ & $\begin{array}{c}340 \pm 92 \\
(72)^{*}\end{array}$ \\
\hline $\mathrm{bc}^{-1}(\text { Diät BC })^{2}$ & - & $83 \pm 14$ & $125 \pm 21$ & $120 \pm 20$ & $101 \pm 17$ \\
\hline $\mathrm{bc}^{-1}$ (Testdiät) $^{3}$ & - & $76 \pm 10$ & $130 \pm 12$ & $129 \pm 19$ & $104 \pm 28$ \\
\hline Diät $\mathrm{BC}=100$ & 100 & 92 & 104 & 108 & 103 \\
\hline
\end{tabular}


Basierend auf dem Quotienten aus der Lysinwirksamkeit der Diät BC und der Aminosäurenwirksamkeit der Testdiät ergab sich ein optimales Aminosäurenverhältnis im Versuch 9 von Thr:Ile:Val = 60\%:59\%:66\% relativ zu Lys in der Starterperiode und Thr:Ile:Val $=64 \%: 65 \%: 80 \%$ relativ zu Lys in der Growerperiode.

Ausgehend von den drei durchgeführten N-Bilanzstudien sind die ermittelten Aminosäurenverhältnisse in den unterschiedlichen Experimenten und Gruppen in der Abbildung 5.7 (Starterperiode) und in der Abbildung 5.8 (Growerperiode) dargestellt.

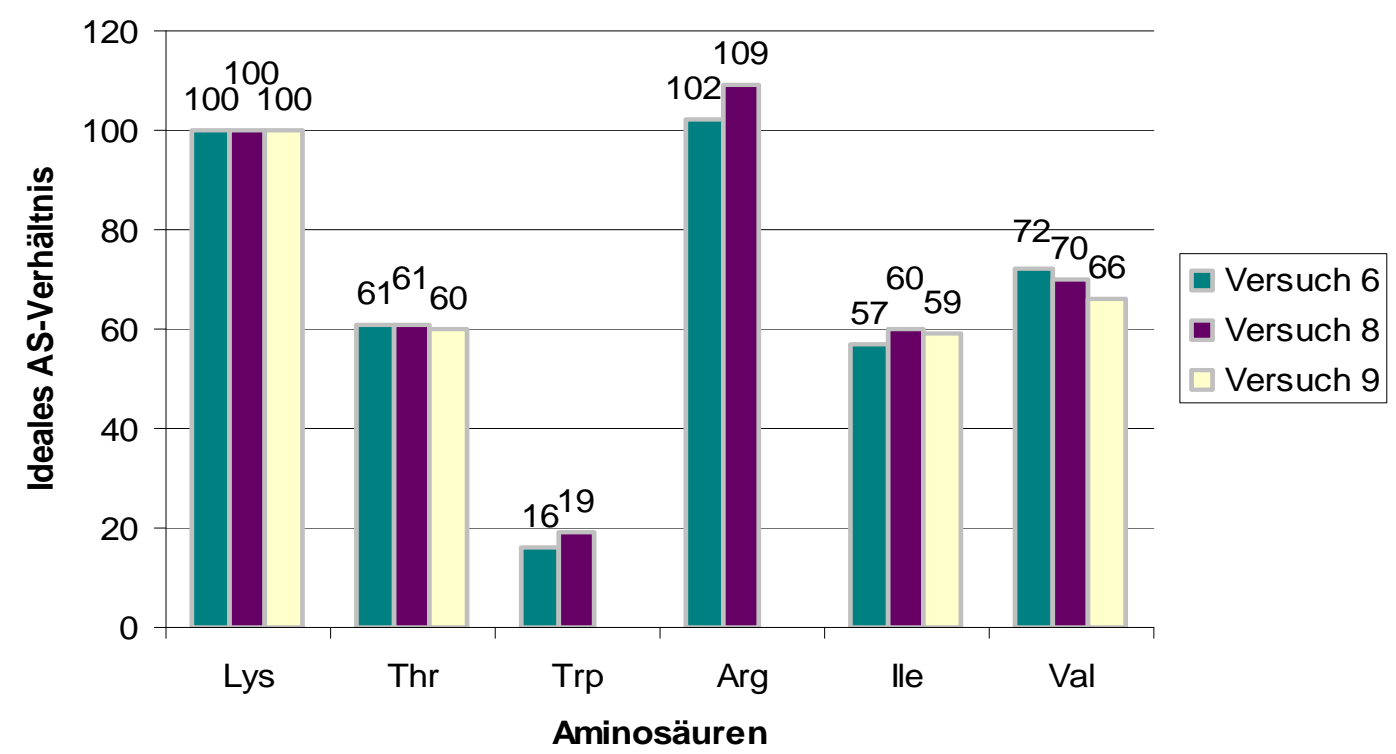

Abbildung 5.7: Das optimale Aminosäurenverhältnis (N-Bilanzversuche, Starterperiode)

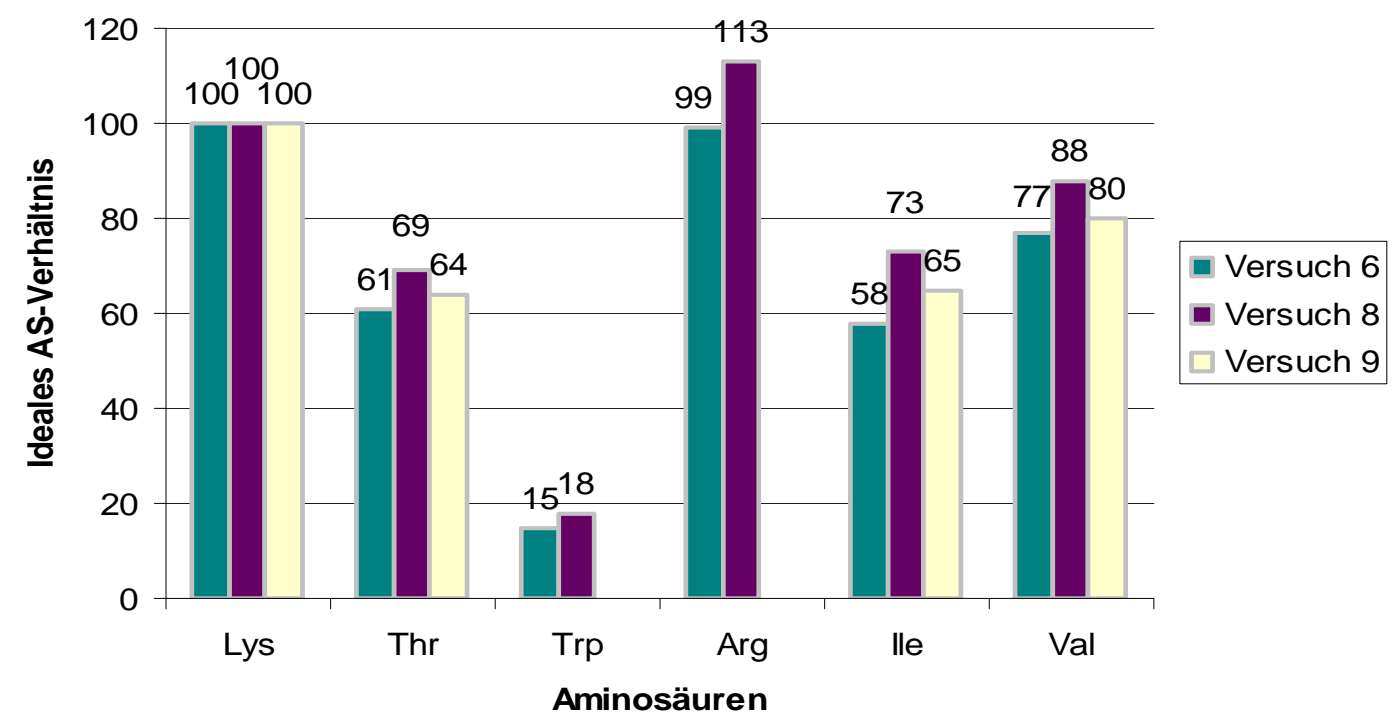

Abbildung 5.8: Das optimale Aminosäurenverhältnis (N-Bilanzversuche, Growerperiode) 
Die Tabelle 5.13 gibt unter Berücksichtigung, der drei ermittelten Aminosäurenverhältnisse in den Stoffwechselversuchen, eine zusammengefasste Darstellung (Mittelwertbildung) für die beiden Wachstumsperioden wieder.

Beim Vergleich der Ergebnisse der Starterperiode mit den der Growerperiode zeigten sich für die Aminosäuren Trp und Arg in den beiden Wachstumsperioden übereinstimmende Lys:Trpbzw. Lys:Arg-Verhältnisse. Die Ergebnisse zu den Aminosäuren Thr, Ile und Val hingegen wiesen auf einen altersbedingten Anstieg hin.

Tabelle 5.13: Geschlussfolgerte optimale Aminosäurenverhältnisse der N-Bilanzversuche differenziert nach Wachstumsphase

\begin{tabular}{lcccccc}
\hline & Lys & Thr & Trp & Arg & Ile & Val \\
\hline Starterperiode & 100 & 61 & 17 & 106 & 59 & 69 \\
Growerperiode & 100 & 65 & 17 & 106 & 65 & 82 \\
\hline
\end{tabular}




\subsubsection{Ableitungen zum Idealprotein - Wachstumsversuche}

Zusätzlich zu den N-Bilanzstudien wurden zwei Wachstumsversuch durchgeführt. Dieser Abschnitt zeigt die Ergebnisse der beiden Wachstumsversuche.

\section{Wachstumsversuch 7}

Tabelle 5.14 vermittelt eine Übersicht zu den Hauptergebnissen des Versuches. Eine detailliertere Darstellung der Ergebnisse ist dem Anhang (Tabellen A24 bis A28) zu entnehmen.

Tabelle 5.14: Ergebnisse des Wachstumsversuchs 7 zum Idealprotein ${ }^{1}$

\begin{tabular}{|c|c|c|c|c|c|c|}
\hline Diät & $\mathrm{BC}$ & LYS & TRP & $\mathrm{ARG}$ & ILE & VAL \\
\hline \multicolumn{7}{|c|}{ Starterperiode } \\
\hline $\begin{array}{l}\text { Anfangsmasse } \\
(\mathrm{g})\end{array}$ & $50 \pm 0,2$ & $50 \pm 0,2$ & $51 \pm 0,1$ & $50 \pm 0,2$ & $50 \pm 0,1$ & $50 \pm 0,2$ \\
\hline Endmasse (g) & $1089 \pm 26$ & $497 \pm 34$ & $852 \pm 53$ & $1031 \pm 82$ & $1098 \pm 26$ & $1033 \pm 52$ \\
\hline $\mathrm{FI}(\mathrm{g} / \mathrm{d})$ & $63 \pm 7$ & $53 \pm 8$ & $56 \pm 3$ & $63 \pm 5$ & $66 \pm 1$ & $60 \pm 4$ \\
\hline Zuwachs (g/d) & $49 \pm 2$ & $21 \pm 2$ & $38 \pm 3$ & $47 \pm 4$ & $50 \pm 1,2$ & $46 \pm 2$ \\
\hline Futteraufwand & 1,27 & $2,48^{*}$ & $1,48 *$ & 1,34 & 1,32 & 1,30 \\
\hline$(g / g)$ & $\pm 0,2$ & $\pm 0,4$ & $\pm 0,1$ & $\pm 0,04$ & $\pm 0,04$ & $\pm 0,06$ \\
\hline N-Deposition & 1,34 & $0,55^{*}$ & $1,00 *$ & $1,19^{*}$ & 1,35 & 1,24 \\
\hline$(\mathrm{g} / \mathrm{d})$ & $\pm 0,05$ & $\pm 0,05$ & $\pm 0,07$ & $\pm 0,1$ & $\pm 0,03$ & $\pm 0,07$ \\
\hline$h_{-}$Wert & $246 \pm 10$ & $146 \pm 27$ & $243 \pm 15$ & $272 \pm 9,8$ & $296 \pm 29$ & $292 \pm 6,6$ \\
\hline b-Wert & $(100)$ & $(59)^{*}$ & (99) & $(111)^{*}$ & $(120)^{*}$ & $(119)^{*}$ \\
\hline $\mathrm{bc}^{-1}$ (Diät BC) ${ }^{2}$ & & $45 \pm 1,8$ & $248 \pm 10$ & $43 \pm 1,7$ & $67 \pm 2,7$ & $55 \pm 2,2$ \\
\hline $\mathrm{bc}^{-1}$ (Testdiät) $^{3}$ & & $31 \pm 5,8$ & $287 \pm 18$ & $54 \pm 2,3$ & $59 \pm 1,9$ & $58 \pm 1,3$ \\
\hline $\mathrm{bc}^{-1}(\mathrm{BC}=100)$ & & $69 *$ & $116^{*}$ & $126^{*}$ & $88 *$ & $105^{*}$ \\
\hline \multicolumn{7}{|c|}{ Growerperiode } \\
\hline $\begin{array}{l}\text { Anfangsmasse } \\
\text { (g) }\end{array}$ & $1200 \pm 29$ & $1201 \pm 38$ & $1199 \pm 29$ & $1198 \pm 23$ & $1199 \pm 38$ & $1198 \pm 27$ \\
\hline Endmasse (g) & $2728 \pm 69$ & $2540 \pm 56$ & $2708 \pm 32$ & $2626 \pm 87$ & $2697 \pm 77$ & $2577 \pm 84$ \\
\hline $\mathrm{FI}(\mathrm{g} / \mathrm{d})$ & $179 \pm 5$ & $166 \pm 5$ & $176 \pm 3$ & $176 \pm 6$ & $165 \pm 4$ & $166 \pm 4$ \\
\hline Zuwachs (g/d) & $109 \pm 7$ & $94 \pm 5$ & $108 \pm 3$ & $102 \pm 5$ & $107 \pm 5$ & $99 \pm 5$ \\
\hline Futteraufwand & 1,64 & $1,77^{*}$ & 1,64 & 1,73 & 1,55 & 1,69 \\
\hline$(\mathrm{g} / \mathrm{g})$ & $\pm 0,09$ & $\pm 0,07$ & $\pm 0,05$ & $\pm 0,05$ & $\pm 0,05$ & $\pm 0,09$ \\
\hline N-Deposition & 3,0 & 2,9 & 3,0 & 2,9 & 3,1 & 2,9 \\
\hline$(g / d)$ & $\pm 0,3$ & $\pm 0,1$ & $\pm 0,1$ & $\pm 0,1$ & $\pm 0,1$ & $\pm 0,1$ \\
\hline b-Wert & $316 \pm 27$ & $372 \pm 11$ & $368 \pm 18$ & $355 \pm 16$ & $368 \pm 22$ & $368 \pm 25$ \\
\hline b-wert & $(100)$ & $(118)^{*}$ & $(116)^{*}$ & $(112)^{*}$ & $(116)^{*}$ & $(116)^{*}$ \\
\hline $\mathrm{bc}^{-1}$ (Diät BC) ${ }^{2}$ & & $58 \pm 5$ & $318 \pm 28$ & $55 \pm 5$ & $86 \pm 86$ & $71 \pm 6$ \\
\hline $\mathrm{bc}^{-1}{\text { (Testdiät })^{3}}^{3}$ & & $79 \pm 2$ & $434 \pm 21$ & $71 \pm 3$ & $74 \pm 4$ & $74 \pm 5$ \\
\hline $\mathrm{bc}^{-1}(\mathrm{BC}=100)$ & & $136^{*}$ & $136^{*}$ & $129 *$ & 86 & 104 \\
\hline
\end{tabular}


Die Ergebnisse dieses Versuchs sind schwierig zu interpretieren.

Trotz „Verdünnung“ der Diät BC wurde in beiden Wachstumsperioden ein höherer b-Wert in den Diäten THR, TRP, ARG, ILE und VAL (mit Ausnahme der Diät TRP in der Starterperiode) ermittelt.

Im Hinblick auf die Diät LYS zeigte sich ein deutlich niedrigerer b-Wert in der Starterperiode, der in der Growerperiode nicht realisiert wurde. In der Starterperiode wurde ein signifikanter Anstieg der AA-Wirksamkeit beobachtet, mit Ausnahme der Diäten LYS und ILE. In der Growerperiode zeigten die Diäten LYS, TRP und ARG höhere AAWirksamkeiten.

Basierend auf dem Quotienten aus der Lysinwirksamkeit der Diät BC und der Aminosäurenwirksamkeit der Testdiät ergab sich ein optimales Aminosäurenverhältnis im Versuch 7 von Trp: Arg: Ile: VAL= 16: 83: 76: 77 relativ zu Lys in der Starterperiode und Trp: Arg: Ile: VAL= 13: 81: 78: 79 relativ zu Lys in der Growerperiode.

\section{$\underline{\text { II Wachstumsversuch } 10}$}

Tabelle 5.15 vermittelt eine Übersicht $\mathrm{zu}$ den Hauptergebnissen des Versuches. Eine detailliertere Darstellung der Ergebnisse ist dem Anhang (Tabellen A33 und A37) zu entnehmen.

Die „Verdünnung“ der Diät BC zeigte v.a. in der Starterperiode einen deutlichen Einfluss auf den Futteraufwand und die N-Deposition.

Die Ermittlung der Proteinqualität in den AA-reduzierten Futtermischungen ergab, dass die Proteinqualität in allen AA-reduzierten Mischungen signifikant abgesenkt war. Somit nahmen die jeweiligen Aminosäuren in den AA-reduzierten Starter- und Growerfuttermischungen eine limitierende Position ein. Trotz limitierender Position war in der Starterperiode ein signifikanter Anstieg nur in der Ile- und Val-Wirksamkeit d. h. für die Diäten ILE und VAL erkennbar. In der Growerperiode konnte dies nur für die Diät TRP beobachtet werden. 
Tabelle 5.15: Ergebnisse des Wachstumsversuchs 10 zum Idealprotein ${ }^{1}$

\begin{tabular}{|c|c|c|c|c|c|c|c|}
\hline Diät & BC & LYS & THR & TRP & ARG & ILE & VAL \\
\hline \multicolumn{8}{|c|}{ Starterperiode } \\
\hline $\begin{array}{l}\text { Anfangsmasse } \\
(\mathrm{g})\end{array}$ & $45 \pm 0,2$ & $45 \pm 0,1$ & $45 \pm 0,3$ & $45 \pm 0,1$ & $45 \pm 0,3$ & $50,4 \pm 0,1$ & $45 \pm 0,1$ \\
\hline Endmasse (g) & $1178 \pm 41$ & $608 \pm 47$ & $777 \pm 110$ & $861 \pm 67$ & $820 \pm 32$ & $790 \pm 64$ & $816 \pm 126$ \\
\hline FI (g/d) & $67 \pm 2$ & $46 \pm 4$ & $46 \pm 3$ & $49 \pm 4$ & $50 \pm 3$ & $45 \pm 5$ & $45 \pm 4$ \\
\hline Zuwachs (g/d) & $54 \pm 2$ & $25 \pm 2$ & $35 \pm 5$ & $37 \pm 3$ & $37 \pm 2$ & $33 \pm 3$ & $35 \pm 6$ \\
\hline Futteraufwand & 1,23 & $1,89^{*}$ & $1,35^{*}$ & $1,34^{*}$ & $1,35^{*}$ & $1,36^{*}$ & $1,31^{*}$ \\
\hline$(g / g)$ & $\pm 0,04$ & $\pm 0,3$ & $\pm 0,2$ & $\pm 0,1$ & $\pm 0,1$ & $\pm 0,1$ & $\pm 0,1$ \\
\hline N-Deposition & 1,42 & $0,61^{*}$ & $0,89^{*}$ & $0,86^{*}$ & $0,89 *$ & $0,82 *$ & $0,83 *$ \\
\hline$(g / d)$ & $\pm 0,05$ & $\pm 0,06$ & $\pm 0,13$ & $\pm 0,08$ & $\pm 0,08$ & $\pm 0,07$ & $\pm 0,08$ \\
\hline & $242 \pm 8$ & $141 \pm 21$ & $207 \pm 26$ & $187 \pm 12$ & $189 \pm 28$ & $195 \pm 16$ & $209 \pm 31$ \\
\hline b-Wert & (100) & $(58)^{*}$ & $(86)^{*}$ & $(77)^{*}$ & $(78)^{*}$ & $(81)^{*}$ & $(86)^{*}$ \\
\hline$b c^{-1}(\text { Diät BC })^{2}$ & & $43 \pm 2$ & $64 \pm 2$ & $223 \pm 8$ & $41 \pm 1$ & $62 \pm 2$ & $48 \pm 2$ \\
\hline $\mathrm{bc}^{-1}$ (Testdiät) $^{3}$ & & $31 \pm 5$ & $69 \pm 9$ & $213 \pm 14$ & $40 \pm 6$ & $73 \pm 1$ & $64 \pm 9$ \\
\hline $\mathrm{bc}^{-1}(\mathrm{BC}=100)$ & & $72 *$ & 108 & 97 & 98 & $116^{*}$ & $133 *$ \\
\hline \multicolumn{8}{|c|}{ Growerperiode } \\
\hline $\begin{array}{l}\text { Anfangsmasse } \\
\text { (g) }\end{array}$ & $1131 \pm 11$ & $1129 \pm 10$ & $1133 \pm 6$ & $1133 \pm 14$ & $1234, \pm 8$ & $1135 \pm 7$ & $1132 \pm 6$ \\
\hline Endmasse (g) & $2662 \pm 93$ & $2499 \pm 61$ & $2528 \pm 75$ & $2594 \pm 82$ & $2566,2 \pm 61$ & $2320 \pm 102$ & $2325 \pm 65$ \\
\hline $\mathrm{FI}(\mathrm{g} / \mathrm{d})$ & $173 \pm 7$ & $166 \pm 7$ & $168 \pm 5$ & $168 \pm 6$ & $171 \pm 4$ & $152 \pm 6$ & $161 \pm 4$ \\
\hline Zuwachs (g/d) & $110 \pm 7$ & $98 * \pm 4,3$ & $100 \pm 5$ & $104 \pm 6$ & $102 \pm 4$ & $85 *_{ \pm} 7$ & $85 * \pm 5$ \\
\hline $\begin{array}{l}\text { Futteraufwand } \\
(g / g)\end{array}$ & $1,59 \pm 0,12$ & $1,70 \pm 0,01$ & $1,68 \pm 0,05$ & $1,62 \pm 0,05$ & $1,67 \pm 0,04$ & $1,8 * \pm 0,1$ & $1,90 * \pm 0,1$ \\
\hline N-Deposition & 3,15 & $2,50^{*}$ & $2,74^{*}$ & 2,912 & $2,753^{*}$ & $2,27 *$ & $2,288^{*}$ \\
\hline$(g / d)$ & $\pm 0,2$ & $\pm 0,11$ & $\pm 0,16$ & $\pm 0,17$ & $\pm 0,12$ & $\pm 0,19$ & $\pm 0,13$ \\
\hline h_Wert & $363 \pm 36$ & $266 \pm 6$ & $268 \pm 15$ & $323 \pm 20$ & $295 \pm 12$ & $257 \pm 21$ & $244 \pm 17$ \\
\hline b-Wert & $(100)$ & $(73)^{*}$ & $(74)^{*}$ & $(92)^{*}$ & $(81)^{*}$ & $(71)^{*}$ & $(67)^{*}$ \\
\hline$b c^{-1}$ (Diät BC) ${ }^{2}$ & & $64 \pm 6$ & $96 \pm 10$ & $335 \pm 34$ & $61 \pm 6$ & $93 \pm 9$ & $72 \pm 7$ \\
\hline $\mathrm{bc}^{-1}$ (Testdiät) $^{3}$ & & $59 \pm 1,3$ & $89 \pm 5$ & $372 \pm 23$ & $63 \pm 3$ & $94 \pm 8$ & $75 \pm 5$ \\
\hline $\mathrm{bc}^{-1}(\mathrm{BC}=100)$ & & 92 & 93 & $111^{*}$ & 103 & 101 & 104 \\
\hline
\end{tabular}

Basierend auf dem Quotienten aus der Lysinwirksamkeit der Diät BC und der Aminosäurenwirksamkeit der Testdiät ergab sich ein optimales Aminosäurenverhältnis im Versuch 10 von Thr: Trp: Arg: Ile: VAL= 62: 19: 107: 60: 67 relativ zu Lys in der Starterperiode und Thr: Trp: Arg: Ile: VAL= 73: 17: 102: 68: 86 relativ zu Lys in der Growerperiode.

Die in den Wachstumsstudien ermittelten Aminosäurenverhältnisse sind in der Abbildung [5.9 und in der Abbildung 5.10 dargestellt. 


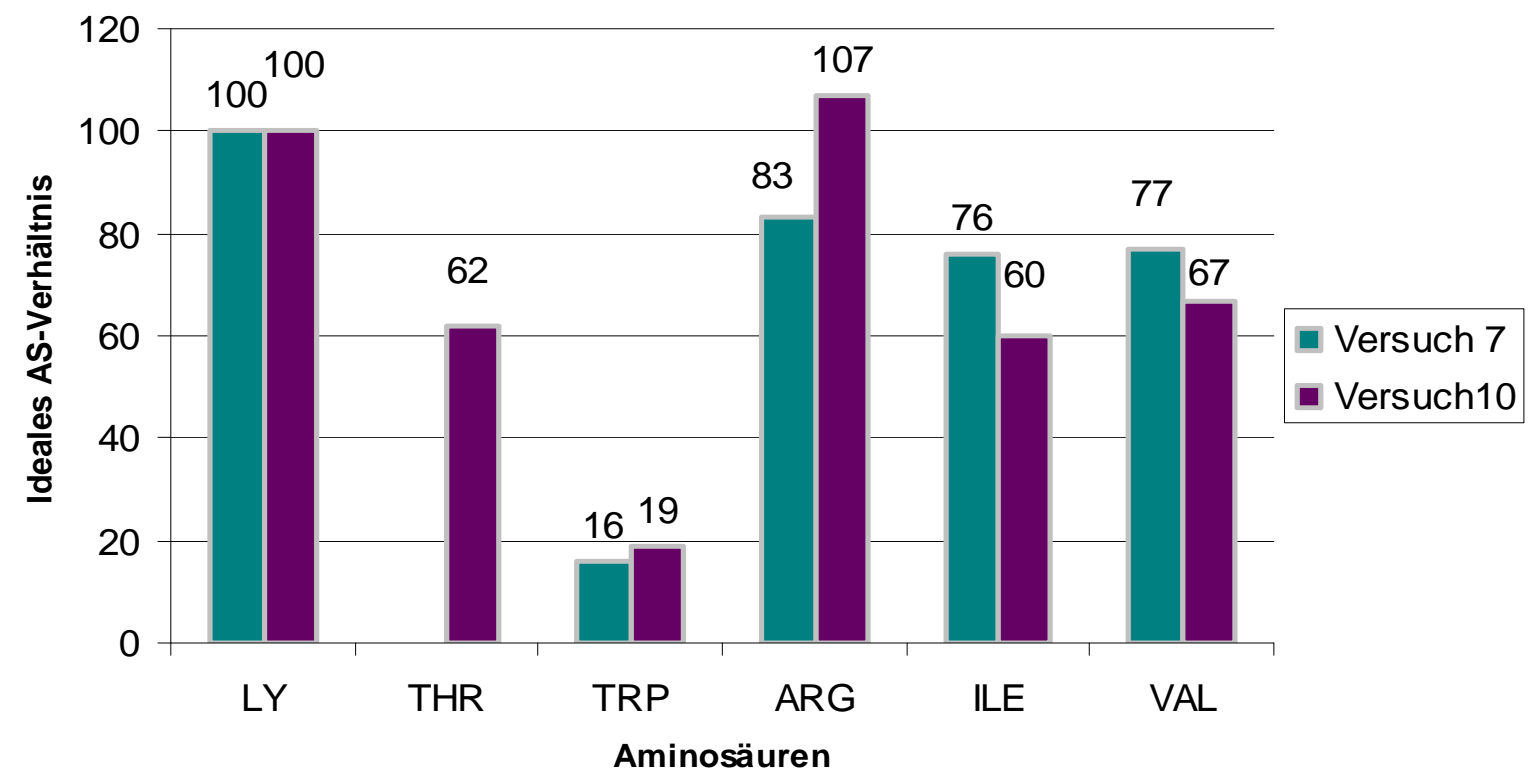

Abbildung 5.9: Das optimale Aminosäurenverhältnis (Wachstumsversuche, Starterperiode)

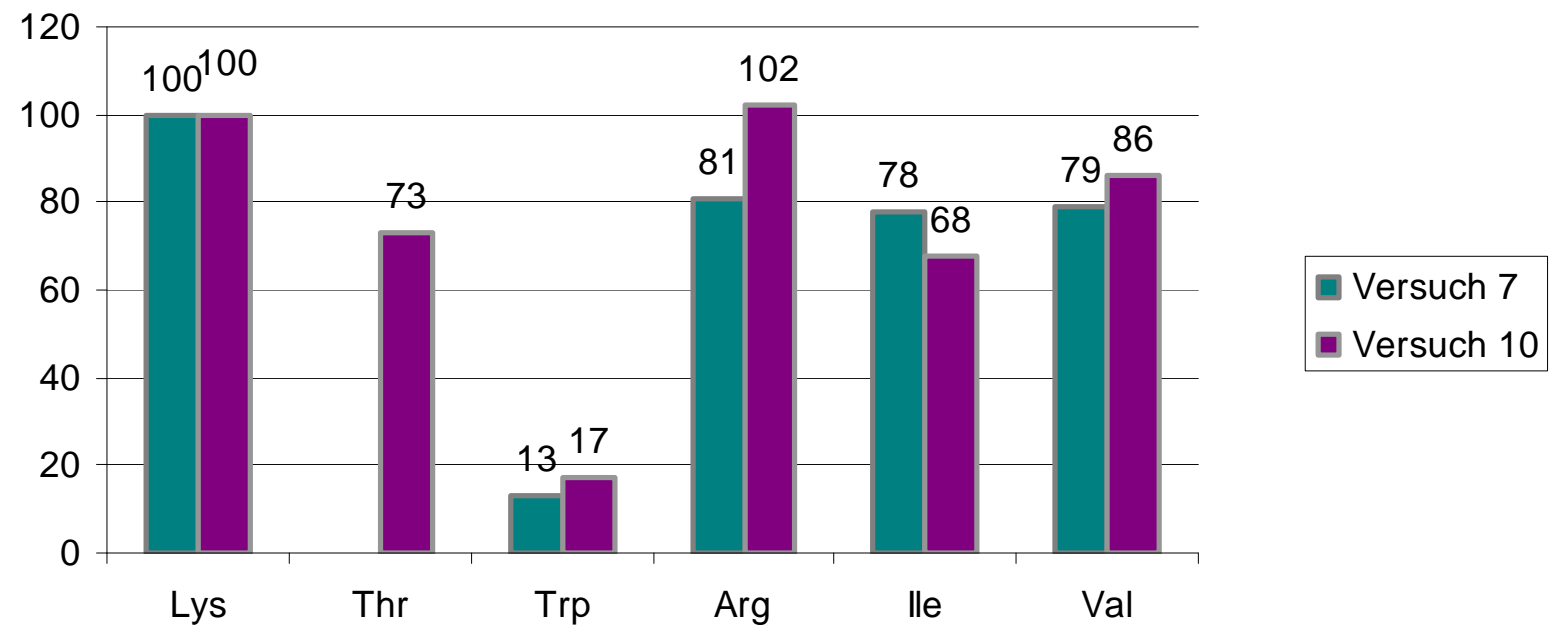

Abbildung 5.10: Das optimale Aminosäurenverhältnis (Wachstumsversuche, Growerperiode)

Die Tabelle 5.16 gibt die geschlussfolgerten idealen Aminosäurenverhältnisse der beiden Wachstumsversuche (Mittelwert beider Wachstumsversuche) für Starter- und Growerperiode wieder. Beim Vergleich des ermittelten idealen Verhältnisses in der Starterperiode mit dem der Growerperiode zeigten sich für die Aminosäuren Trp und Arg in den beiden Wachstumsperioden ähnliche Lys:Trp bzw. Lys:Arg -Verhältnisse. Die Ergebnisse zu den 
Aminosäuren Thr, Ile und Val hingegen wiesen, wie in den N-Bilanzuntersuchungen, auf einen alters-bedingten Anstieg hin.

Tabelle 5.16: Geschlussfolgerte optimale Aminosäurenverhältnisse der Wachstumsversuche differenziert nach Wachstumsphase

\begin{tabular}{lcccccc}
\hline & Lys & Thr & Trp & Arg & Ile & Val \\
\hline Starterperiode & 100 & 62 & 18 & 95 & 68 & 72 \\
Growerperiode & 100 & 73 & 15 & 92 & 73 & 82 \\
\hline
\end{tabular}




\section{Diskussion}

Nach der Darstellung der Untersuchungsergebnisse soll nachfolgend, unter Einbeziehung bereits bekannter Ergebnisse aus der Literatur, eine Einordnung der Untersuchungsbefunde vorgenommen werden.

Zunächst sollen die ermittelten Modellparameter (NMR und $\left.\mathrm{NR}_{\max } \mathrm{T}\right)$ diskutiert werden. Im Weiteren wird die beobachtete Methioninwirksamkeit unter Berücksichtigung zweier Methioninquellen diskutiert. Einen weiteren Betrachtungspunkt stellt die Bedarfsableitung zum Methionin dar. Schließlich werden die Ergebnisse zum Idealprotein diskutiert.

\subsection{Untersuchungskomplex I}

Ziel dieses Versuchskomplexes war, die Frage zu den Modellparametern NMR und $\mathrm{NR}_{\max } \mathrm{T}$ im Bezug auf Masthähnchen der genetischen Herkunft Ross 308 zu klären.

Im ersten Diskussionsteil (6.1.1) erfolgt eine vergleichende Diskussion zum NMR, während im Kap. 6.1.2 das maximale theoretische N-Retentionsvermögen betrachtet wird.

\subsubsection{N-Erhaltungsbedarf (NMR)}

Ein bekannter Aspekt ist, dass Tiere eine bestimmte Menge an Nährstoffen ausscheiden, auch wenn deren Aufnahme mit der Nahrung Null entspricht. Dieser Anteil wird gemeinhin als obligatorischer oder unvermeidlicher Verlust bezeichnet. Er ist vollständig endogenen Ursprungs und muss mindestens ersetzt werden, um die Menge an dem jeweiligen Element im Körper zu erhalten (Erhaltungsbedarf).

Gemäß der nach COLUMBUS (1951) formulierten Definition des Stickstofferhaltungsbedarfes setzt sich die bei einer N-freien Diät ermittelte Gesamtstickstoffausscheidung aus dem endogenen Harnstickstoff und dem Darmverluststickstoff zusammen. Dementsprechend stellt dieser Wert den mit (-1) multiplizierten N-Ansatz bei Verabreichung einer N-freien Diät dar. 


\section{Diskussion}

In der vorliegenden Arbeit wurde der NMR mit N-Steigerungsversuchen unter Anwendung des exponentiellen N-Verwertungsmodells (GEBHARDT 1966, LIEBERT und GEBHARDT 1986) regressiv geschätzt, wobei N-Bilanzdaten aus Diäten mit 6\% - 36\% XP in die Parameterschätzung eingingen. Die Ergebnisse beschreiben somit eine mathematische Simulation der N-Exkretion bei N-freier Fütterung. Die Ableitung des NMR erfolgte auf der Grundlage einer exponentiellen Anpassung der N-Exkretion in Abhängigkeit von der NAufnahme, wobei eine mathematisch approximierte Beziehung zwischen der N-Aufnahme (NI) und der N-Exkretion (NEX) besteht. Der am Schnittpunkt mit der y-Achse (N-Aufnahme $=0)$ abgeleitete NMR reflektiert die obligatorischen endogenen N-Verluste und ist nicht mit der Proteinmenge gleichzusetzen, die benötigt wird um die Körperproteinverluste zu ersetzen.

Zahlreiche Methoden wurden von verschiedenen Autoren in unterschiedlichen Spezies zur Bewertung des N-Erhaltungsbedarfes herangezogen. Allerdings zeigen diese Studien deutliche Unterschiede zwischen den verwendeten Methoden (KAUSHIK et al. 1995). Der Ansatz zur Bewertung des NMR mittels Regressionsanalyse in der vorliegenden Arbeit basierte auf N-Steigerungsversuchen unter Nutzung einer exponentiellen Funktion.

THONG und LIEBERT (2004a) leiteten den NMR in Versuchen mit Schweinen mittels quadratischer Funktion ab. Die physiologische Interpretation einer solchen Funktion kann jedoch entsprechend schwierig werden, insbesondere wenn der Peak der gefitteten Funktion für

NI $>0$ erfasst ist. Im Falle einer solchen quadratischen Funktion wurde teilweise ein Minimum beobachtet, welches im positiven Bereich der N-Aufnahme lag und somit einen Anstieg im NMR bis zur Intersektion mit der $y$-Achse und einen daraus ergebenden überbewerteten NMR beinhaltete, welches aus physiologischer Sicht nicht ausreichend erklärt werden kann.

In einer Untersuchung von LIEBERT et al. (2006) wurde die quadratische und exponentielle Funktion in einer Studie mit Tilapien gegenübergestellt. Die Autoren schlussfolgerten, dass sich die exponentielle Funktion im Vergleich zur quadratischen Funktion besser eignete.

Die Regression zwischen der täglichen N-Aufnahme und der N-Exkretion wurde an eine exponentielle Funktion angepasst. Das hohe Bestimmtheitsmaß von 0,95 (Starter) und 0,97 (Grower) kennzeichnet die gute Anpassung der Exponentialfunktion an die experimentell ermittelten Werte. Die Schnittpunkte mit der y-Achse für Starter- und Growerperiode zeigten sehr ähnlich Werte von $295 \mathrm{mg} \mathrm{N} / \mathrm{LM}_{\mathrm{kg}}{ }^{0,67}$ (Starterperiode) und $313 \mathrm{mg} \mathrm{N} / \mathrm{LM}_{\mathrm{kg}}{ }^{0,67}$ 
(Growerperiode). Folglich wurde der Mittelwert dieser beiden Parameter gebildet. Der durchschnittliche, als „Arbeitswert“ für den täglichen N-Erhaltungsbedarf angenommene NMR liegt für die betrachtete Genetik mit $304 \mathrm{mg} \mathrm{N} / \mathrm{LM}_{\mathrm{kg}}{ }^{0,67}$ auf einem mit anderen Literaturangaben vergleichbaren Niveau.

In Tabelle 6.1 sind einige Literaturangaben zum N-Erhaltungsbedarf zusammengestellt. Beim Vergleich dieser Daten wird die Variationsbreite der Werte, die in einem Bereich von 172 bis $591 \mathrm{mg} \mathrm{N} / \mathrm{LM}_{\mathrm{kg}}{ }^{0,67}$ pro Tag liegen, deutlich. Diese Schwankungen können einerseits auf methodisch bedingte Faktoren beruhen, andererseits aber auch durch biologische Einflüsse (genetische Herkunft des verwendeten Tiermaterials) sowie Umweltbedingungen erklärt werden. Die Tatsache, dass der ermittelte N-Erhaltungsbedarf nur für die untersuchte genetische Population zutrifft und nicht auf andere genetische Herkünfte übertragen werden kann, wurde u. a. von TEEKELL et al. (1968) für Geflügel gezeigt.

DÄNICKE (1993) und DÄNICKE et al. (1998) ermittelten regressiv einen NMR von 200 $340 \mathrm{mg} \mathrm{N} / \mathrm{LM}_{\mathrm{kg}}{ }^{0,67}$ pro Tag für männliche Lohmann-Broiler. Die GFE (1999) empfiehlt für die faktorielle Bedarfsableitung den von DÄNICKE (1993) mit 184 N-Bilanzwertpaaren über alle Altersabschnitte regressiv abgeleiteten täglichen NMR von $264 \mathrm{mg} \mathrm{N} / \mathrm{LM}_{\mathrm{kg}}{ }^{0,67}$. Dieser Wert weicht nur geringfügig vom Mittelwert aller einzeln ermittelten NMR-Werte der Untersuchung von DÄNICKE (1993) ab und liegt unter dem dieser Untersuchung.

In einer Studie von SAMADI und LIEBERT (2008) wurde für die genetische Herkunft Ross 308 der N-Erhaltungsbedarf mit N-Steigerungsversuchen unter Verwendung des NVerwertungsmodells (GEBHARDT 1963) regressiv geschätzt. Der ermittelte mittlere tägliche N-Erhaltungsbedarf von $221 \mathrm{mgN} / \mathrm{LM}_{\mathrm{kg}}{ }^{0,67}$ lag dabei unter dem in dieser Arbeit ermittelten NMR. In den Untersuchungen von KÖHLER et al. (1970), unter Anwendung der Isotopenverdünnungstechnik, betrug die Summe der täglichen endogenen N-Ausscheidungen $421 \mathrm{mg} \mathrm{N} / \mathrm{LM}_{\mathrm{kg}}{ }^{0,67}$ und lag somit deutlich über dem in dieser Untersuchung ermittelten NMR. 
Tabelle 6.1: Täglicher N-Erhaltungsbedarf (NMR) nach verschiedenen Literaturangaben

\begin{tabular}{lll}
\hline NMR $\left(\mathrm{mg} \mathrm{N}^{\mathrm{L}} \mathrm{LM}_{\mathrm{kg}}{ }^{0,67}\right)$ & Quelle & Genetik \\
\hline 421 & KÖHLER et al. (1970) & $\begin{array}{l}\text { White Rock x White } \\
\text { Rock }\end{array}$ \\
253 & VELU et al (1971) & $\begin{array}{l}\text { New Hampshire x } \\
\text { Columbian }\end{array}$ \\
188 & MURAMATSU und OKUMURA (1979a) & Weiße Leghorn \\
172 & MURAMATSU und OKUMURA (1979b) & Weiße Leghorn \\
$221-297$ & MURAMATSU et al (1984) & Weiße Leghorn \\
591 & KÖHLER et al. (1988) & Tera 726 \\
$390-540$ & MÜLLER et al. (1989) & Tera 82 \\
264 & DÄNICKE (1993) & Lohmann \\
180 & LEESON und SUMMERS (2001) & - \\
252 & SAMADI und LIEBERT (2006a) & Cobb 500 \\
173 & SAMADI und LIEBERT (2007a) & I 657 und \\
221 & SAMADI und LIEBERT (2008) & Red JA (Hubbard ISA) \\
304 & eigene Ergebnisse & Ross 308 308 \\
\hline
\end{tabular}

LEESON und SUMMERS (2001) fassten Daten aus N-freier Fütterung adulter Vögel zusammen und schlussfolgerten $180 \mathrm{mg} \mathrm{N} / \mathrm{LM}_{\mathrm{kg}}{ }^{0,67}$ pro Tag als entsprechenden NMR. Allerdings obliegt die proteinfreie Fütterung nicht dem Bereich einer physiologischen Proteinversorgung, was MITCHELL (1924) dazu veranlasste die Übertragbarkeit des bei Nfreier Ernährung ermittelten N-Erhaltungsbedarfes auf die Bedingungen der Proteinernährung bzw. des N-Ansatzes zu hinterfragen.

Frühere Untersuchungen indizierten deutliche Differenzen zwischen den unterschiedlichen Verfahren zur Ableitung des N-Erhaltungsbedarfes. GEBHARDT (1966) und HOFFMANN und GEBHARDT (1973) zeigten, dass geringe Gaben hochwertiger Proteine (Vollei) die NAusscheidung unter das Niveau der Ausscheidung bei N-freier Kost senken konnten und führten diese Erscheinungen auf Ergänzungswirkungen von endogenen und exogenen Aminosäuren zurück. KAUSHIK et al. (1995) postulierte, dass Diäten mit geringem Proteingehalten einen Sparmechanismus schaffen können, der in Folge dessen eine Modifikation im endogenen N-Verlust hervorruft. Im Hinblick auf die nicht-physiologische proteinfreie Fütterung ist es daher schwierig zuverlässige Vergleiche zu tätigen.

Gemäß dem in dieser Studie angewandtem Verfahren, wurde der ermittelte NMR zur Etablierung des Schnittpunktes der exponentiellen Funktion mit der y-Achse genutzt, um eine 
höhere mathematischen Zuverlässigkeit bezüglich des zu ermittelnden Grenzwertes $\left(\mathrm{ND}_{\max } \mathrm{T}\right)$ zu erreichen.

Andere Versuche waren mehr auf den Aminosäurenerhaltungsbedarf (EDWARDS et al. 1999, EDWARDS und BAKER 1999, SKLAN und NOY 2004) fokussiert, der mittels faktorieller Ableitung zur Ermittlung des Aminosäurenbedarfs geschätzt wurde. Von besonderem Interesse sind Untersuchungen, die die Zusammenhänge zwischen essentiellen Aminosäuren und endogenen N-Ausscheidungen zeigen (UHLEMANN und POPPE 1970). Neben dem Nachweis einer Beeinflussung des endogenen Harnstickstoffes durch die Proteinqualität, zeigten die Versuche eindeutig, dass die Synthese im Rahmen des Erhaltungsstoffwechsels nicht nur definierte N-Mengen sondern ebenso eine konkrete Aminosäurenzusammensetzung (= Proteinqualität) notwendig machen. HALLE et al. (1984) postulierten, dass der ermittelte Rohproteinerhaltungsbedarf nur bei gleicher Eiweißqualität Gültigkeit hat und eine Verschlechterung der Aminosäurenzusammensetzung der Futtermischungen zu einem erhöhten Erhaltungsbedarf führt.

In den in dieser Untersuchung verabreichten Mischungen wiesen die schwefelhaltigen Aminosäuren eine eindeutige Limitierung auf, während die verbleibenden Aminosäuren im Überschuss vorlagen. Die Proteinqualität war somit deutlich geringer als bei Mischungen mit idealem Aminosäurenverhältnissen, was wiederum zu einer vermehrten N-Ausscheidung und somit zu einem höheren Erhaltungsbedarf führt.

Studien zum Aminosäurenbedarf für Wachstum und Erhaltung zeigten deutliche Unterschiede in ihren Ergebnissen. So hatte FISCHER (1972) kalkuliert, dass der Lysinbedarf für schnelles Wachstum in wachsendem Geflügel 13\% des Aminosäurenbedarfs repräsentierte, während der Wert für den Erhaltungsbedarf adulter Tiere bei 4\% lag. Die Werte für die Aminosäure Methionin betrugen hingegen 9\% und 14\%. CHUNG et al. (1973) fanden in ihren Untersuchungen mit Legehennen geringe Unterschiede in der Wachstumsleistung bei Verabreichung von Diäten mit ansteigenden Methioninlevel und vermuteten das Methionin eine höhere Bedeutung für Erhaltung als für Wachstum aufweist. Auch ZIMMERMAN und SCOTT (1967) wiesen auf die unterschiedlichen Rollen einiger essentieller Aminosäuren für Wachstum und Erhaltung beim Küken hin. GRABER et al. (1971) fanden im Vergleich zum Wachstum für Erhaltung einen höheren Methioninbedarf. 


\subsubsection{Maximales theoretisches $\mathrm{N}$-Retentionsvermögen $\left(\mathrm{NR}_{\max } \mathrm{T}\right)$}

Wachstumsprozesse sind eng mit Stoffwechselprozessen des N-Umsatzes verknüpft (GEBHARDT 1973) und können über diese quantifiziert werden, da das Wachstum als Strukturmassenvergrößerung stets mit einem entsprechenden N-Ansatz verbunden ist. Allerdings sind die Möglichkeiten des täglichen N-Ansatzes begrenzt (GEBHARDT 1963, 1973).

Das maximale theoretische N-Retentionsvermögen $\mathrm{NR}_{\max } \mathrm{T}$ ist die Summe aus dem NErhaltungsbedarf (NMR) und dem maximale theoretische N-Depositionsvermögen $\mathrm{ND}_{\max } \mathrm{T}$.

Für den Genotyp Ross 308 und den untersuchten Altersabschnitten (10. - 20. LT und 25. - 35.

LT) wurde ein theoretischer Grenzwert für das maximale tägliche N-Ansatzvermögen in Höhe von $3696 \mathrm{mg} / \mathrm{LM}_{\mathrm{kg}}{ }^{0,67}$ und $2797 \mathrm{mg} / \mathrm{LM}_{\mathrm{kg}}{ }^{0,67}$ bestimmt. Unter Berücksichtigung des NMR ergab dies ein maximales N-Retentionsvermögen von $3990 \mathrm{mg} / \mathrm{LM}_{\mathrm{kg}}{ }^{0,67}$ (10. - 20. LT) und $3110 \mathrm{mg} / \mathrm{LM}_{\mathrm{kg}}^{0,67}$ (25. - 35. LT).

Vergleichbare Beobachtungen bezüglich $\mathrm{ND}_{\max } \mathrm{T}$ konnten im Rahmen früherer Untersuchungen von SAMADI und LIEBERT (2008) für den Genotyp Ross 308 gemacht werden (3660 - $3666 \mathrm{mg} / \mathrm{LM}_{\mathrm{kg}}{ }^{0,67}$ für 10. - 25. LT und 2741 - $2761 \mathrm{mg} / \mathrm{LM}_{\mathrm{kg}}{ }^{0,67}$ für 30. - 45. LT). Ähnliche Angaben zum ND ${ }_{\max } \mathrm{T}\left(3592 \mathrm{mg} / \mathrm{LM}_{\mathrm{kg}}{ }^{0,67}\right.$ für $10 .-25$. LT und $2723 \mathrm{mg} / \mathrm{LM}_{\mathrm{kg}}{ }^{0,67}$ für 30. - 45. LT) wurden für schnell wachsende Broiler der genetischen Herkunft Cobb etabliert (SAMADI und LIEBERT 2006a).

Im Vergleich mit langsam wachsenden Broilertypen (SAMADI und LIEBERT 2007a) zeichnete sich ein deutlich niedrigerer $\mathrm{ND}_{\max } \mathrm{T}\left(2789 \mathrm{mg} / \mathrm{LM}_{\mathrm{kg}}{ }^{0,67}\right.$ für 10 . - 25. LT und $2688 \mathrm{mg} / \mathrm{LM}_{\mathrm{kg}}{ }^{0,67}$ für 30. - 45. LT) für die langsam wachsende Genetik ab. HOFFMANN (1971) wies auf den Aspekt hin, dass die Höhe des Grenzwertes innerhalb einer Tierart in Abhängigkeit vom Genotyp, dem Alter bzw. der Lebendmasse und dem Geschlecht variiert. RIMBACH (2002) verglich die Genotypen Cobb 500 und Ross 208 hinsichtlich der absoluten Höhe des maximalen N-Retentionsvermögens. Die Ergebnisse zeigten, dass zwischen den geprüften Genoypen bezüglich der absoluten Höhe des maximalen N-Retentionsvermögens als auch im altersabhängigen Verlauf Unterschiede bestanden. Innerhalb des Altersabschnittes 10. - 15. LT war das maximale N-Retentionsvermögen der Cobb-Broiler um ca. $10 \%$ höher als das der Ross-Broiler. Innerhalb der Altersperioden 20. - 25. LT und 30. - 35. LT lag 
hingegen das maximale N-Retentionsvermögen der Ross-Broiler ca. 5\% über dem der CobbBroiler.

In den Untersuchungen von SAMADI und LIEBERT (2006a, 2007a, 2008) wurden wie in der vorliegenden Arbeit der NMR und $\mathrm{ND}_{\max } \mathrm{T}$ mit N-Steigerungsversuchen unter Anwendung des N-Verwertungsmodells regressiv geschätzt. Aus den Untersuchungen von SAMADI und LIEBERT (2006a, 2007a, 2008) wurde ersichtlich, dass die ermittelten Modellparameter klare Genotypeffekte aufwiesen. Hinsichtlich des $\mathrm{ND}_{\max } \mathrm{T}$ konnte zugleich eine Abhängigkeit vom Alter bzw. von der Lebendmasse aufgezeigt werden, die auch in der vorliegenden Arbeit beobachtet wurde. Somit zeigte der $\mathrm{ND}_{\max } \mathrm{T}$ einen kontinuierlichen Rückgang mit steigendem Lebensalter der Broiler.

RIMBACH und LIEBERT (1999) sowie WECKE und LIEBERT (2005) stellten bei Mastgeflügel und Schweinen ebenfalls eine Abnahme von $\mathrm{ND}_{\max } \mathrm{T}$ mit zunehmenden Alter fest.

HOFFMANN (1971), MÜLLER (1987) und DÄNICKE (1993) ermittelte hingegen bei männlichem Mastgeflügel einen altersbedingten Anstieg von $\mathrm{ND}_{\max } \mathrm{T}$. MÜLLER (1987) ordnete dies in einem Alter von 25. - 30. LT einem verstärkten Federwachstum zu (RIMBACH 2002).

Die Proteindeposition in wachsenden Tieren ist als Balance zwischen Proteinsynthese und Proteinabbau definiert. Beide Prozesse sind in Nutztieren von zahlreichen Einflussfaktoren abhängig, zu denen das Alter (MOEHN und DE LANGE 1998, RIMBACH und LIEBERT 1999), das Geschlecht (PROUDFOOT und HULAN 1978, AJANG et al. 1993, SEBASTIAN et al. 1997), die Genetik (BARBATO 1992, RENDEN et al. 1992, 1994, PESTI et al. 1996, FATUFE et al. 2004) und nutritive Faktoren (STERLING et al. 2003, ÇIFTCI und CEYLAN 2004) zählen. Das mit steigenden Alter abnehmende Potential für den N-Ansatz kann mit morphologischen Veränderungen im Darm (NITSAN et al. 1991, UNI et al. 1999), mit einer Veränderung in der Proteinsyntheserate (KANG et al. 1985) sowie mit einer verringerte Aminosäurendeposition im Schlachtkörper (SKLAN und NOY 2004) assoziiert werden. 


\subsection{Untersuchungskomplex II}

Im ersten Diskussionsteil dieses Untersuchungskomlexes (6.2.1) wird die ermittelte Methioninwirksamkeit des MHA im Vergleich zum DLM betrachtet. Im Kap. 6.2.2 erfolgt eine vergleichende Diskussion der kalkulierten Methioninbedarfswerte, während im letzten Abschnitt die Methioninbedarfswerte in Abhängigkeit vom Methionin/Cystein-Verhältnis erörtert werden (Kap. 6.2.3).

\subsubsection{Ermittlung der Methioninwirksamkeit von $M H A$ relativ zu DLM}

Der Gegenstand dieses Versuches war die Bewertung der relativen Wirksamkeit von MHA im Vergleich $\mathrm{zu}$ DLM sowie die vergleichende Beurteilung der Zulagewirkung beider Methioninquellen. Eine SAA-defizitäre Futterration wurde dazu in zwei verschiedenen Stufen entweder mit DLM oder mit MHA so ergänzt, dass ein analoger Gesamtmethioningehalt innerhalb jeder Ergänzungsstufe vorlag.

Wenn die Bioverfügbarkeit bzw. die Wirksamkeit eines essentiellen Nährstoffes verglichen werden soll, können nach HUYGHEBAERT (1993) und LEMME et al. (2002) nur dann Unterschiede erwartet werden, wenn die basale Diät ein deutliches Defizit in dem zu testenden Nährstoff vorweist. Aufgrund dessen, dass das Aminosäurenmuster der Körnerleguminosen Defizite bei den schwefelhaltigen Aminosäuren Methionin und Cyst(e)in aufweisen, wurde eine solche Futtermischung (NC) formuliert, die auf hohen Gehalten an Ackerbohnen und Erbsen basierte. Zusätzlich erfolge eine Supplementation von L-Lysin-HCl, L-Threonin, L-Isoleucin, L-Arginin und L-Valin. Dies sollte einerseits zur Deckung des Bedarfes dieser Aminosäuren und andererseits zur eindeutigen Limitierung der SAA diente. Im Vergleich zum NRC (1994) Fütterungsstandard, welcher ein Methioninanteil von 0,5\% (1. - 21. LT) in den Mischungen empfiehlt, war der Anteil an Methionin mit 0,25\% (Versuch 2 und 3) bzw. 0,244\% (Versuch 4 und 5) in den Basalmischungen um ca. 50 Prozent abgesenkt, sodass eine deutliche Limitierung dieser Aminosäure in den Basalmischungen vorlag. Hinzu kommt, dass die Verdaulichkeit der schwefelhaltigen Aminosäuren (Met und Cys) im Vergleich zu denen aus z. B. Sojaextraktionsschrot bedeutend geringer ist. 
Wie zu erwarten war, zeigten diejenigen Broiler, denen die Basaldiät angeboten wurde in beiden Versuchen deutlich geringere Leistungen als die Broiler, denen die Metsupplementierten Mischungen verabreicht wurden. Die Masthähnchen sprachen sehr gut auf die Met-supplementierten Diäten an. Im Vergleich zur Basaldiät konnte eine statistisch gesicherte Überlegenheit bezüglich Futteraufwand, Futteraufnahme, Zuwachsrate, N-Ansatz und b-Wert beobachtet werden, was die limitierende Position der schwefelhaltigen Aminosäuren in den basalen Mischungen bestätigte.

Zahlreiche Studien wurden durchgeführt, die als Gegenstand der Untersuchung die MHAWirksamkeit im Vergleich zum DLM hatten (RIBEIRO et al. 2001, SI et al. 2001, JANSMAN et al. 2003, VASQUEZ-ANON et al. 2004, BATEMAN et al. 2005, HOEHLER et al. 2005, PAYNE et al. 2006, YI et al. 2006, AHMAD 2008, DILGER und BAKER 2008, SAUER et al. 2008, SHOVELLER et al. 2009).

Bei der vergleichenden Betrachtung der Wirksamkeiten von MHA und DLM liegen unterschiedliche Befunde vor (SAUER et al. 2008). In einigen Studien zeigte MHA eine höhere Wirksamkeit als DLM (RIBEIRO et al. 2001, VASQUEZ-ANON et al. 2004), während in anderen Studien DLM eine höhere Wirksamkeit aufwies (JANSMAN et al. 2003, HOEHLER et al. 2005, PAYNE et al. 2006, DILGER und BAKER 2008). Gemäß JANSMAN et al. (2003) variierte die MHA-Wirksamkeit (relativ zu DLM) bei Broilern in der Literatur in einem Bereich zwischen 53\% und 97\%. REIFSNYDER et al. (1984), KNIGHT et al. (1998), RÖMER und ABEL (1999) und YI et al. (2006) berichten hingegen von einer analogen Wirksamkeit der getesteten Methioninquellen.

Die in der Literatur angegebenen Erklärungen für diese widersprüchlichen Aussagen sind umfassend. Einige Autoren (VAN WEERDEN et al. 1982, HUYGHEBAERT 1993, DREW et al. 2003) deuteten als Ursache unterschiedliche Arten von Basalmischungen, Alter und Genetik der im Versuch verwendeten Hühner sowie unterschiedliche Anteile an supplementiertem DLM und MHA an. HARMS et al. (1976) und VAN WEERDEN et al. (1998) bezogen die Zusammensetzung der Basaldiäten als Einflussgröße auf die relative Wirksamkeit ein. Diäten mit ausschließlich kristallinen AA zeigten geringere MHAWirksamkeiten, wenn die Vergleiche auf äquimolarer Basis gemacht wurden (SMITH 1966, FEATHERSTON und HORN 1974, KATZ und BAKER 1975, BAKER und BOEBEL 1980, VAN WEERDEN et al. 1982). Im Gegensatz dazu berichteten MACHLIN und GORDON (1959) sowie RÖMER und ABEL (1999) von molarer Äquivalenz zwischen MHA und DLM in Versuchen mit Diäten auf Basis nativer Komponenten. 
Beim Vergleich der Wirksamkeiten von DLM und MHA in dieser Arbeit zeigt sich eine Überlegenheit des DLM in allen Mischungen, mit Ausnahme der zweiten Met+CysSupplementationstufe in der Growerperiode (Versuch 2). In dieser Supplementationsstufe und Wachstumsphase wurde zwischen DLM und MHA eine analoge Wirksamkeit realisiert. Dieses Ergebnis stimmt mit den Untersuchungen von WALDROUP et al. (1981), HAN et al. (1990) und BUNCHASAK und KEAWARUN (2006) überein, die keine Unterschiede in der relativen Wirksamkeit von DLM und MHA auf äquimolarer Basis fanden. Auch DÄNNER und BESSEI (2003) berichteten von einer Äquivalenz, wenn Futteraufnahme, Futteraufwand, Lebendmasse und Lebendmassezuwachs als Responsekriterium herangezogen wurde.

VAZQUEZ-ANON et al. (2006) verglichen die Zuwachs-Wirkungskurven von MHA und DLM und schlussfolgerten, dass die zwei Methioninquellen unterschiedliche DosisWirkungs-Beziehungen vorweisen. In vier Versuchen, bei denen die Methioninquellen in jeweils drei äquimolaren Stufen verabreicht wurden, erfolgte die Ermittlung der Lebendmassezunahme mittels linearer, quadratischer und exponentieller Regression. Dabei zeigte sich, dass die Diäten mit DLM-Supplementationen deutlich höhere Leistungen bewirkten als nach MHA-Supplementationen. Dies konnte allerdings nur bei Mischungen mit einem deutlichen Defizit an Methionin beobachtet werden. Lag kein Methionindefizit vor bewirkte die MHA-Supplementation höhere Leistungen. Daher schlussfolgerten VAZQUEZ-ANON et al. (2006), dass DLM eine höhere Wirksamkeit in Met-limitierenden Mischungen besitzt, während MHA eine höhere Wirksamkeit in Mischungen ohne Met-Defizit hat.

CHRISTENSEN und ANDERSON (1980) untersuchten die relative Wirksamkeit von MHA-Ca (Calciumsalz des MHA) relativ zu L-Met und fanden in Diäten (0,21\% Met) mit geringer Met-Supplementation (0,08\%) eine höhere L-Met-Wirksamkeit. Dies hingegen wurde nicht bei Diäten $(0,21 \%$ Met $)$ mit höheren Met-Supplementationen $(0,16 \%)$ gefunden.

In dieser Arbeit zeigte sich beim Vergleich von DLM und MHA in allen Diäten eine höhere DLM-Wirksamkeit, mit Ausnahme der zweiten Met+Cys-Supplementationstufe in der Growerperiode (Versuch 2), bei der sich zwischen DLM und MHA eine analoge Wirksamkeit ergab. Diese wurde in Diäten mit einem Gehalt von 0,43\% Methionin und 0,63\% Cystein $($ SAA-Gehalt $=1,06 \%)$ ermittelt. Das NRC (1994) empfiehlt einen Methioningehalt im Futter für Mastgeflügel im Alter vom 21. bis 35. LT von $0,38 \%$ und einen Gehalt an SAA von 0,72\%. Daher lag bezüglich dieser Mischung die Vermutung nahe, dass Met nicht mehr limitierend wirkte und Cys im Überschuss zur Verfügung stand. 
DILGER und BAKER (2008) untersuchten den Einfluss von Cystein auf die Methioninwirksamkeit und fanden höhere MHA-Wirksamkeiten bei Diäten, die erstlimitierend in der Aminosäure Cys waren.

Auch Untersuchungen von KATZ und BAKER (1975), CHRISTENSEN und ANDERSON (1980), BOEBEL und BAKER (1982) führen indirekt den Beweis an, dass die relative MHAWirksamkeit größer ist, wenn eine Supplementation dieser Methioninquelle zu einer Basalmischung erfolgt, die erstlimitierend bezüglich der Aminosäuren Cyst(e)in ist. Ferner gaben Literaturdaten aus Broiler- und Schweineversuchen generell eine größere MHA-Wirksamkeit bei Studien mit Cys-defizitären Basalmischungen an (BAKER und BOEBEL 1980 sowie YI et al. 2006), als vergleichbare Studien in denen die Cysteinkonzentration in der Diät analog oder über den physiologischen Cys-Bedarf lag. Dieser Effekt konnte in dieser Arbeit aufgezeigt werden, wenn die relativen Wirksamkeiten der Supplementationsstufen 1 (Versuch 2 vs. Versuch 4) verglichen werden. Im Versuch 2, bei dem Met und Cys supplementiert wurden, konnte eine MHA-Wirksamkeit von 86\% (Starter) und 89\% (Grower) realisiert werden, während in den Diäten ohne Cysteinsupplementation eine relative MHAWirksamkeit von 89\% (Starter) und 93\% (Grower) erreicht wurde. Ferner, konnte aus den abgeleiteten relativen Wirksamkeiten vermutet werden, dass mit zunehmendem Anteil an Methionin sowie innerhalb des Methioninlevels ein zunehmender Anteil an Cystein in der Diät, die Wirksamkeit von MHA relativ zu DLM senkte z.B. in der Starterperiode MI (89\%), M+C I (86\%), M II (71\%).

KATZ und BAKER (1975) untersuchten den Einfluss des Met:Cys-Verhältnisses auf die MHA-Wirksamkeit. Sie berichteten von einem guten Wachstum, wenn ein Met:Cys-Verhältnis von 60:40 vorlag. Jedoch, wenn das Verhältnis 40:60 war, reduziert sich das Wachstum markant und resultierte oft in dem Tod der Tiere.

Im Experiment 2 und 3 dieses Versuchskomplexes lag das Met:Cys-Verhältnis konstant bei 46:54 (bei ansteigender SAA-Konzentration), während im Experiment 4 und 5 das Met:CysVerhältnis zwischen 46:54 (Basaldiät), 55:45 (erste Supplementationsstufe) und 60:40 (zweite Supplementationsstufe) variierte. Im Gegensatz zu KATZ und BAKER (1975) wurde keine höhere Mortalität sowie geringere Lebendmassezunahme beobachtet. Im Hinblick auf die Lebendmassezunahme zeigte sich eine größere Wachstumsleistung bei den Masthähnen, die die Diät mit dem Met:Cys-Verhältnis von 46:54 erhalten hatten, was aber eher aus dem Einfluss des höheren Gehaltes an Cys und somit an SAA in den Diäten resultierte, als durch das Met:Cys-Verhältnis selbst. 
Dennoch zeigte sich dass Variationen im Met:Cys-Verhältnis Auswirkungen auf die relative Wirksamkeit haben. In dem Stoffwechselversuch mit Diäten, die 0,44\% Met und 0,28\% Cys beinhalteten (weites Met:Cys-Verhältnis), wurde eine MHA-Wirksamkeit von 68\% relativ zu DLM (Grower) gefunden. Aber bei Diäten mit 0,34\% Met und 0,28\% Cys, konnte eine MHAWirksamkeit von 93\% relativ zu DLM ermittelt werden. In N-Bilanzstudien mit SAAdefizitären Diäten, die 0,21\% Methionin und 0,40\% Cyst(e)in beinhalteten (weites Met:CysVerhältnis), berichteten KIM et al. (2006) eine MHA-Wirksamkeit von 64\% relativ zu DLM, wenn ein Vergleich auf äquimolarer Basis stattfand. YI et al. (2006) nutzten als Kriterium die Wachstumsleistungen von Schweinen, welche eine basale Mischung mit 0,24\% Met und 0,26\% Cyst(e)in erhielten und fanden eine MHA-Wirksamkeit von 111\% relativ zu DLM (verglichen auf äquimolarer Basis). In der Arbeit von KIM et al. (2006) wurden DLM und MHA ausschließlich zur Versorgung mit Methionin benötigt, während in der Arbeit von YI et al. (2006) beide Methioninpräkursorkomponenten benötigt wurden, um nicht nur Methionin sondern auch Cys zu liefern. Daher scheint es, dass die Cyst(e)inkonzentration in den Diäten eine Hilfe sein kann, Unterschiede in den Wirksamkeiten der Methioninpräkursorkomponenten zu erklären.

In den Wachstumsversuchen dieses Versuchskomplexes wurde dieser Effekt allerdings nicht beobachtet. Indes wurde bei der Ermittlung der relativen Wirksamkeit von MHA relativ zu DLM in den Wachstumsversuchen nicht nach Wachstumsperioden differenziert, sondern für den gesamten Versuchszeitraum (0. - 35. LT) ermittelt. Da junge Tiere empfindlicher auf Nährstoffdefizite als ältere Tiere reagieren, konnten altersspezifische Unterschiede in den Wirksamkeiten (bezogen auf die Methioninwirksamkeit) daher nicht berücksichtigt und abgeleitet werden. BUNCHASAK und KEAWARUM (2006) untersuchten die Effekte von MHA auf die Wachstumsleistung von männlichen Broilern (Ross) im Altersabschnitt von 0. 6. Woche und gab verschiedene relative Wirksamkeiten für MHA und DLM zwischen der Starter- und Growerperiode an.

Zahlreiche Studien beziehen sich auf die physiologischen Ursachen um die unterschiedlichen Wirksamkeiten von MHA verglichen mit DLM erklären zu können (SAUNDERSON 1991, LINGENS und MOLNAR 1996, MAENS ENGLE-SCHAAN 1996b, LEMME 2002, MARTIN-VENEGAS et al. 2006). Im Hinblick auf den physiologischen Hintergrund wird die geringere MHA-Wirksamkeit mit einer reduzierten intestinalen Absorption von MHA, einer ineffizienten Überführung von MHA in L-Met nach der Absorption oder einer 


\section{Diskussion}

Kombination dieser beiden Faktoren im Zusammenhang gebracht (LINGENS und MOLNAR 1996, MAENS und ENGLE-SCHAAN 1996b).

Ferner sind beide Methioninquellen aus chemischer Sicht unterschiedlich. Während DLM eine Reinheit von 99\% besitzt, enthält das MHA-Molekül 12\% Wasser, 65\% Monomere, 19\% Dimere und 4\% Oligomere (LEMME 2002, HOEHLER et al. 2005). Untersuchungen von SAUNDERSON (1991) führten den Beweis an, dass Oligomere in MHA kaum absorbiert werden. Die MHA-Molekülfraktion, die in Form von Dimeren und Oligomeren vorliegt, verfügt über ein geringeres Biopotential als die monomerische Form (VAN WEERDEN et al. 1992). VAN WEERDEN et al. (1992) berichtete statistisch gesicherte niedrigere Wirksamkeiten von MHA-Oligmere verglichen mit dem kommerziellen Produktmix aus Mono-, Di- und Oligomeren, welches eine 66\%-ige Wirksamkeit von DLM erreicht.

Zudem wird nur L-Methionin im Proteinstoffwechsel genutzt. Um MHA als Methioninquelle nutzen zu können, müssen beide Isomere (D- und L-Isomer) des MHAs aber nur das DIsomer von DLM in L-Met überführt werden. Dies erfolgt in zwei Schritten: Oxidation des $\alpha$ Kohlenstoffs und anschließende Transaminierung (LEMME 2002, MARTIN-VENEGAS et al. 2006, SAUNDERSON 1991). Die dafür verantwortlichen Enzyme sind primär in der Leber und Niere lokalisiert. DIBNER und IVEY (1992) verwiesen auf eine 7-fach höhere Enzymaktivität in der Leber, allein durch die Umwandlung in keto-Methionin. Da dieser Umwandlungsprozess jedoch Energie verlangt, zeigt sich bei DLM derjenige Vorteil, dass nur D-Methionin umgewandelt werden muss.

Zudem kann der intestinale mikrobielle Abbau im Dünndarm von MHA (DREW et al. 2003, LEMME 2002) aber auch intestinale Absorptionsmechanismen (MAENZ und ENGELESCHAAN 1996) Ursachen für eine geringere Wirksamkeit sein. Um die verschiedenen Methioninquellen absorbieren zu können, besitzt der Körper spezifische Mechanismen, wobei die Absorption durch einfache Diffusion zu vernachlässigen ist (LINGENS und MOLNAR 1996, MAENZ und ENGELE-SCHAAN 1996). MAENZ und ENGELE-SCHAAN (1996) nahmen an, dass DLM und MHA mittels zweier unterschiedlicher Transportmechanismen entlang der Bürstensaummembran transportiert werden. Dabei gingen sie davon aus, dass für die Deportation von DLM ein „spezifisches System B Typ $\mathrm{Na}^{+}$-abhängiger Transporter“ besteht, während MHA via „ $\mathrm{H}^{+}$-abhängigen nicht-stereospezifischen System“ transportiert wird. Dieselbe Studie berichtete ebenfalls, dass L-Methionin eine höhere Affinität zu seinem Transporter besitzt und eine höhere Transportgeschwindigkeit vorweist als L-MHA. 


\subsubsection{Ableitungen zum Methioninbedarf}

Soll das N-Verwertungsmodell (GEBHARDT 1963, 1980) zur Ableitung des Methioninbedarfs herangezogen werden, muss gewährleistet sein, dass Met in den eingesetzten Diäten erstlimitierend ist. Nur unter dieser Voraussetzung kann die Methioninwirksamkeit $\left(\mathrm{bc}^{-1}\right)$ zur Ableitung des Methioninbedarfs herangezogen werden. Für die Ermittlung des Methioninbedarfs wurden zwei basale Versuchsfutter hergestellt, die eine stark ausgeprägte Limitation in den zu untersuchenden Aminosäuren aufwiesen. Das Ziel war ein Mischfutter herzustellen, welches möglichst geringe Konzentrationen an SAA darbot. Daher wurde auf hohe Anteile an natürlichen Proteinkomponenten, wie Ackerbohnen und Erbsen zurückgegriffen, welche nativ eine Limitation in den besagten Aminosäuren aufweisen. Zur Verstärkung dieses Effektes erfolgte zusätzlich die Supplementation ausgewählter Aminosäuren in kristallener Form, um die Position des Methionins als erstlimitierende Aminosäure eindeutig zu sichern (vgl. Kapitel $6.2 .1)$

Zur Ableitung der Methioninbedarfswerte, in Abhängigkeit vom Alter, diente das NVerwertungsmodell unter Verwendung der N-Bilanzdaten der NC-Diät des NBilanzversuches 4. Mit Hilfe der Methioninwirksamkeit der NC-Diät des Versuches 4 wurde der Methioninbedarf auf der Basis der mittleren Lebendmasse aller in den N-Bilanzversuchen des Untersuchungskomplexes II involvierten Broiler abgeleitet.

Die mit Hilfe des N-Verwertungsmodelles (GEBHARDT 1963) kalkulierten Proteinqualitäten (b-Werte) konnten durch die Methioninzulagen signifikant verbessert werden, was auf eine Limitierung des Methionins in den Basaldiäten hinwies. Die Möglichkeit zur Ableitung des Methioninbedarfs über die Methioninwirksamkeit war somit gegeben. Die kalkulierten Methioninbedarfswerte wiesen eine deutliche Abhängigkeit vom täglichen Proteinansatz und von der Aminosäure-Wirksamkeit des Futterproteins auf. Das Spektrum der Ergebnisse zur Aminosäure-Wirksamkeit war von dem im Futter enthaltenden SAA abhängig (vgl. Kapitel $6.2 .1)$.

Die übermäßige Anzahl an Studien zur Methioninbedarfsableitung aus der Literatur waren Ableitungen bei denen der Futteraufwand oder der Lebendmassezuwachs als Kriterium herangezogen wurde (CHAMRUSPOLLERT et al. 2002). Aus dem Spektrum der berechneten Angaben zum Methioninbedarf dieser Arbeit, wurde auf einem Methioninbedarf in 
Abhängigkeit vom Proteinansatz und Futteraufnahme bei einer mittleren Lebendmasse von 500g (10. - 20. LT) bzw. 1800g (25. - 35. LT) Bezug genommen. Die Wahl des Leistungsniveaus von 6,8 und $10 \mathrm{~g} / \mathrm{d}$ XP-Ansatz begründete sich auf praxisnahe Konditionen unter Verwendung des in der vorliegenden Untersuchung eingesetzten Genotyps Ross 308 und schloss die im gesamten Versuchskomplex beobachten Futteraufnahmen ein. Der mittels dieser Vorgaben berechnete Methioninbedarf lag in einem Intervall von $0,31 \%$ bis $0,63 \%$ des Futters bei einer Futteraufnahme von $50 \mathrm{~g} / \mathrm{d}$ für Broiler vom 10. bis 20. LT und zwischen $0,26 \%$ und $0,57 \%$ bei einer Futteraufnahme von $130 \mathrm{~g}$ bei Broilern vom 25. -35. LT.

Literaturempfehlungen zur optimalen Methioninbedarfsdeckung legten mit Werten von 0,18\% (KLAIN et al. 1960) bis 0,59\% (CHAMRUSPOLLERT et al. 2004b) deutliche Variationen dar. Als Ursache für die Bandbreite an Methioninbedarfsempfehlungen kommen zahlreiche Faktoren in Frage, wie z.B. das Geschlecht der Tiere, das Alter, die Genetik (ISHIBAHI und KAMETAKA 1985, CHAMRUSPOLLERT et al. 2002), die Wachstumsrate und Befiederung (ISHIBAHI und KAMETAKA 1985, KALINOWSKI et al. 2003a, b), den Protein-, Argininund Cyst(e)ingehalt im Futter (PESTI et al. 1981, CHAMRUSPOLLERT et al. 2004b), die Art der Basaldiät (TILLMAN und PESTI 1985), die Methioninwirksamkeit (MURAMATSU und OKUMURA 1980, CHUNG und BAKER 1992) sowie unterschiedliche experimentelle, physiologische Faktoren und Umwelteinflüsse (ISHIBAHI und KAMETAKA 1985, CHAMRUSPOLLERT et al. $2004 \mathrm{a}, \mathrm{b})$. Eine weitere mögliche Ursache für geringere Bedarfswerte konnte mit der Lebendmasse der Tiere in Zusammenhang gebracht werden. VIEIRA et al. (2004) fanden, dass die optimale SAA-Konzentration im Futter in Abhängigkeit vom angestrebten Produktionsziel, wie z.B. Optimierung des Wachstums, des Brustfleischanteils oder des Futteraufwandes korreliert. Unter der Prämisse konnte in Untersuchungen gezeigt werden, dass das optimale SAA-Level für Brustfleischproduktion höher ausfällt, als vergleichsweise das optimale SAA-Level für Zuwachs (SCHUTTE und PACK 1995).

Das NRC (1994) empfiehlt 0,50\% Met in den Futtermischungen für Geflügel in den ersten drei Lebenswochen. Diese Empfehlung korrespondierte mit dem in dieser Arbeit ermittelten Methioninbedarfswert bei einer täglichen Futteraufnahme von $60 \mathrm{~g}$ und einem XP-Ansatz von 10 g/Tag. Bei Diäten mit 0,82\% SAA schlussfolgerten WHEELER und LATSHAW (1981), dass die optimale Methioninkonzentration $41 \%$ an den SAA ausmacht. 
Das NRC (1994) empfiehlt 0,50\% Met in den Futtermischungen für Geflügel in den ersten drei Lebenswochen. Diese Empfehlung korrespondierte mit dem in dieser Arbeit ermittelten Methioninbedarfswert bei einer täglichen Futteraufnahme von $60 \mathrm{~g}$ und einem XP-Ansatz von 10 g/Tag. Bei Diäten mit 0,82\% SAA schlussfolgerten WHEELER und LATSHAW (1981), dass die optimale Methioninkonzentration $41 \%$ an den SAA ausmacht.

Die Bedarfskonzentration liegt nach BAKER et al. (1996) bei 0,38\% Met und 0,76\% SAA in diesem Altersabschnitt und war mit dem Ergebnis der vorliegenden Untersuchungen bei $8 \mathrm{~g}$ XP-Ansatz pro Tag und $60 \mathrm{~g}$ tägliche Futteraufnahme vergleichbar. KALINOWSKI et al. (2003a) untersuchten den Methionin- und Cysteinbedarf bei wachsendem Geflügel in Abhängigkeit von der Gefiederbildungsgeschwindigkeit und deutete auf einen konstanten MetBedarf von $0,50 \%$ in den Mischungen für Geflügel (0. bis 3. Lebenswoche) hin, unabhängig von der Gefiederbildungsrate. Basierend auf einer quadratischen Regressionsanalyse zwischen Zuwachs und Methioninlevel schlussfolgerten XIE et al. (2004) eine optimale Konzentration an Methionin in der Futtermischung von 0,481\% für Weiße Pekingenten (0. bis 21. LT). Ähnliche Werte (0,46 - 0,59\%) für männliche Broiler berichteten WALDROUP et al. (1979). Dieser aus der Literatur entnommene Bereich der Methioninbedarfsangaben korrespondiert mit denen in dieser Studie gemachten Beobachtungen, für die Wachstumsperiode vom 10. bis 20. LT. Abweichungen in den kalkulierten Bedarfswerten aus der Literatur können durch unterschiedliche experimentelle Faktoren auftreten. Basierend auf der indirekten Aminosäuren-Oxidations-Methode (IAAO) lag der von CHAMRUSPOLLERT et al. (2002) vermutete Methioninbedarf für männliche wie auch weibliche Ross x Ross Broilerküken (11. - 12. LT) bei 0,55 - 0,57\%. Im Vergleich dazu wurde in einem zweiten Versuch (Wachstumsstudie) ein Methioninbedarf von 0,52\% (Zuwachs) und 0,54\% (Futteraufwand) ermittelt. Unter Berücksichtigung des Aspektes, dass bei der IAAO-Methode die Oxidationsrate der Indikatoraminosäure gemessen wird, ist eine Adaptionsperiode erforderlich, um stabile Werte zu erhalten (AHMAD 2008). In den Untersuchungen von CHAMRUSPOLLERT et al. (2002) hingegen, fand keine Adaption der im Versuch eingesetzten Tiere an die experimentelle Diät statt. Vor Beginn des Versuches erfolgte vielmehr ein Fasten von 12h, was einen möglichen Einfluss auf die im Versuch ermittelten Bedarfswerte haben kann.

Die Abschätzung des Methioninbedarfs in der Growerperiode bei z.B. $16 \mathrm{~g}$ täglicher Proteindeposition wurden mit 0,38\% Met als ideale Konzentration, basierend auf $130 \mathrm{~g}$ 
realisierte tägliche Futteraufnahme kalkuliert. Dies zeigte eine Übereinstimmung mit der NRC (1994) Empfehlung von 0,38 \% Met in Diäten für Geflügel von der 3. bis 6. Lebenswoche.

Die auf SID (standardised ileal digestibility) basierenden Bedarfsangaben von HOEHLER und LEMME (2005) lagen mit 0,44\% Met für 23 bis 35 Tage alte Broiler über der zuvor genannten Empfehlung des NRC (1994). ISHIBASHI und KAMETAKA (1985) nutzten die direkte Aminosäurenoxidationsmethode zur Bestimmung des Methioninbedarfs bei männlichen White-Leghorn und ermittelten einen Bedarf von 0,47\% und 0,46\%, basierend auf Zuwachs und Futteraufwand.

Der Bedarf an Methionin bei „langsam- und schnell-federnden“ männlichen Broilern zwischen der 3. und 6. Lebenswoche wurde durch die Untersuchung von KALINOWSKI et al. (2003b) mit 0,46\% im Futter angegeben. Gemäß XIE et al. (2006) lag der optimale MetBedarf männlicher White Pekingenten vom 21. bis 49. LT für maximale Lebendmassezuwachs und Brustfleischanteil bei 0,377 und 0,379\%, was mit dem kalkulierten Methioninbedarf in der Growerperiode bei 16g täglicher Proteindeposition, basierend auf 130 g realisierter täglicher Futteraufnahme übereinstimmte.

Zusammenfassend betrachtet lagen die nach dem N-Verwertungsmodell nach GEBHARDT (1966) und seiner Weiterentwicklung (LIEBERT und GEBHARDT 1986) für AminosäureWirksamkeit und unterschiedliche Leistungsniveaus kalkulierten Methioninbedarfswerte in der Größenordnung der bisher publizierten Angaben zum Methioninbedarf von Mastgeflügel. Der Vorteil des verwendeten Modells besteht darin, dass tierspezifische, leistungs- und futterspezifische Parameter berücksichtigt werden und somit eine differenziertere Bedarfsempfehlung gegeben ist. 


\subsubsection{Ableitung zum Methionin/Cystein-Bedarf in Abhängigkeit vom Met:Cys- Verhältnis}

Methionin und Cystein nehmen z. T. unterschiedliche Funktionen im wachsenden Geflügel wahr (KALINOWSKI et al. 2003a, b). Auf der Basis essentieller Funktionen existiert ein physiologischer Bedarf für beide Aminosäuren. Aufgrund dessen, dass der Bedarf an Cys durch einen Überschuss an Methionin gedeckt werden kann, wird er gewöhnlich als Gemisch beider Aminosäuren ausgewiesen, obwohl relevante Implikationen zu dieser Kombination existieren. Der relative Anteil von Met und Cys zur Deckung des SAA-Bedarfs kann die Leistung des Tieres beeinflussen (ROTH und KIRCHGESSNER 1989).

Wie im Kapitel 6.2.2 erläutert, variieren die in der Literatur angegebenen Methioninbedarfsempfehlungen in einem Bereich zwischen 0,18\% und 0,59\%. Diese Schwankungsbreite ist auf diverse Ursachen zurückzuführen (TILLMAN und PESTI 1985, CHUNG und BAKER 1992, CHAMRUSPOLLERT et al. 2002), wobei ebenfalls das Met:Cys-Verhältnis einen relevanten Aspekt beinhaltet.

Die Untersuchung zum Methioninbedarf im Untersuchungskomplex II dieser Arbeit zeigte, dass die Methioninwirksamkeit in der Starterperiode im Vergleich zur Basaldiät durch den Zusatz von DLM in Kombination mit Cys keine Veränderung in der Methioninwirksamkeit aufzeigte, während die Supplementation von 0,1\% DLM einen Anstieg bewirkte. Letztere, in der Starterperiode auftretende Ergebnisse lassen vermuten, dass Met in der Diät M I und somit auch in der Diät M II nicht mehr eindeutig die Position der erstlimitierenden Aminosäure einnahm. Vielmehr verschob sich das Verhältnis durch die Methioninsupplementation in Richtung des Cys, sodass davon ausgegangen werden kann, dass Cys in diesen Mischungen mehr limitierend wirkte als Met. Studien zur Evaluierung idealer Aminosäurenverhältnisse unterstützen diese Vermutung (GFE 1999, GRUBER et al. 1999). GRUBER et al. (1999) ermittelte ein optimales Met:Cys-Verhältnis von 53:47. Die GFE (1999) empfahl ein ideales Met:Cys-Verhältnis im Futter von 51:49, während das Met:Cys-Verhältnis der Diät M I 55:45 und das Met:Cys-Verhältnis der Diät M II 61:39 betrug.

Der kalkulierte Met-Bedarf von wachsendem Geflügel (10. - 20. LT), welches mit einer Diät gefüttert wurde, die $0,1 \%$ supplementiertes Met enthielt, lag bei $337 \mathrm{mg} / \mathrm{LM}_{\mathrm{kg}}{ }^{0,67}$ pro Tag ( $8 \mathrm{~g} / \mathrm{d}$ XP-Ansatz). Wenn eine Met+Cys-Kombination verwendet wurde, lag die optimale 
Met-Konzentration im Futter bei $315 \mathrm{mg} / \mathrm{LM}_{\mathrm{kg}}{ }^{0,67}$ pro Tag (8 g/d XP-Ansatz). Im Organismus dient Met u. a zur Herstellung von Cys, da die Bildung von Cys mit dem Abbau von Met verknüpft ist. Bei Abwesenheit von Cystein kann Methionin somit den Cys-Bedarf decken. Diese Resultate indizieren daher, dass bei der Met+Cys-Supplementation weniger Met zur Deckung des Cys-Bedarfs herangezogen wurde.

GRABER und BAKER (1971) führten ähnliche Untersuchungen mit Broilern (9. - 14. LT) durch. Die Ergebnisse verdeutlichten, dass mit einer Kombination von Met und Cys 475 mg zur Bedarfsdeckung an SAA im Futter benötigt wurden, während bei einer Supplementation von Met per se $495 \mathrm{mg}$ benötigt wurden.

FUKAGAWA (2006) begründete den durch Cys auftretenden Methionin-Spareffekt mit einer Reduktion des Methioninabbaus während der Transsulfuration. Es scheint, dass Cys die Synthese von Met-aktivierenden Enzymen und Cystadionsynthease erschöpft, sodass die Umwandlung von Met zu Cys reduziert ist. Konsequenterweise resultiert dies in einem Anstieg in Homocystein, dass zu Lasten derjenigen Fraktion remethylisiert wird, welches die Umwandlung zu Cystathionin beinhaltet (FINKELSTEIN und MUDD 1967). Durch die Reduktion der Transsulfuration ist somit ein höherer Anteil an Methionin für die Proteinsynthese verfügbar (WEBEL und BAKER 1999).

In welchem Umfang Cystein Methionin ersetzen kann, war Gegenstand zahlreicher Studien (GRABER et al. 1971, STOCKLAND et al. 1973, SCOTT et al. 1982). GRABER et al. (1971) führte dazu Untersuchungen mit Broilern (14 LT) durch und ermittelte 56\% (Lebendmassezuwachs) und 60\% (Futteraufwand) des SAA-Gehaltes. Zur Bestimmung dieser Werte verwendeten GRABER et al. (1971) Mischungen mit einem SAA-Gehalt von 0,6\%. Bei Annäherung des Cysteinlevels an den „Replacement“ Wert, lag in den Mischungen ein Überschuss an SAA vor, was zu einer leichten Überbewertung der „Replacement“-Werte führte. Studien von SASSE und BAKER (1974) nutzten Diäten mit 0,4\% SAA und indizierten, dass Cys maximal 48\% (Lebendmassezuwachs) und 56\% (Futteraufwand) des SAA-Bedarfesdecken kann. STOCKLAND et al. (1973) untersuchte den Einfluss des Methionin- und Cysteingehaltes auf den SAA-Bedarf wachsender Ratten und gab an, dass der SAA-Anteil zur Bedarfsdeckung größer ist, wenn nur Methionin anstatt eine Kombination aus Methionin und Cystein in der Diät vorlag. Desto größer der Anteil an Methionin in der Diät war, desto höher war der notwendige Anteil an SAA in der Diät zur Bedarfsdeckung. 
Wenn eine Kombinationen von Met und Cys zu einer basalen Mischung supplementiert wurde, fanden WHEELER und LATSHAW (1981) einen Wert von ca. 54\% bei Geflügel im Altersabschnitt vom 0. - 21. LT. Diese Werte lagen über denen des NRC mit 45\%. Im Altersabschnitt 3. bis 6. Lebenswoche wurden höhere Werte in der Literatur ausgewiesen. BAKER et al. (1996) gaben Werte von 52\% für diesen Altersabschnitt an, während das NRC (1994) 47\% als Empfehlung aussprach. GRABER et al. (1971) ermittelte in einem Versuch mit Broilern (35 LT) 65\% (Lebendmassezuwachs) und 67\% (Futteraufwand).

ROTH und KIRCHGESSNER (1989) untersuchte den Einfluss der Met:Cys-Relation des Futters auf die Leistung von wachsenden Schweinen. Die Ergebnisse des Versuches verdeutlichten, dass eine sichere Bedarfsdeckung an SAA erst durch einen Mindestanteil an Met gewährleistet wird.

Der durch Cysteinsupplementation auftretende „Methionin-Spareffekt“ wurde besonders in der Growerperiode deutlich. Erfolgte bei diesen Tieren eine Fütterung mit der Mischung, bei der Met per se zugelegt wurde, lag ein täglicher Methioninbedarf von $387 \mathrm{mg} / \mathrm{LM}_{\mathrm{kg}}{ }^{0,67}$ (16 g/d XP-Ansatz) vor, während mit der Met+Cys-Kombination täglich nur $251 \mathrm{mg} / \mathrm{LM}_{\mathrm{kg}}{ }^{0,67}$ (16 g/d XP-Ansatz) zur Bedarfsdeckung erforderlich waren.

Mit ansteigendem Alter nimmt die Relevanz der Keratinsynthese in der Proteinsynthese insgesamt zu. Federn enthalten ca. 15-mal mehr Cys als Met (GFE 1999). Cystein ist somit die Hauptkomponente von Keratin, während Met durch seinen Abbau zu Cys involviert ist (LEESON und WALSH 2004). In Anbetracht des intensiven Wachstums der Broiler und des Federansatzes (WHEELER und LATSHAW 1979), lag die Vermutung nahe, dass insbesondere während der Growerperiode eine Supplementation von Met+Cys zur Ableitung niedrigerer Bedarfswerte für Met führt. Beim Vergleich mit der Starterperiode zeigte sich, dass die Supplementation von Met + Cys in der Growerperiode in einem größeren MethioninSpareffekt resultierte. Ein erhöhter Cys-Bedarf mit zunehmendem Alter der Broiler kann somit geschlussfolgert werden (GRABER et al. 1971).

KALINOWSKI et al. (2003a, b) untersuchte wie sich der Feder-Typ auf das Met:CysVerhältnis auswirkt. Die Autoren gaben einen konstanten Met-Gehalt von 0,50\% in den Mischungen für Geflügel (0. bis 3. Lebenswoche) und 0,46 \% im Futter für Geflügel (3. bis 6 . Lebenswoche) an, der unabhängig von der Gefiederbildungsrate war. Darüber hinaus beobachteten die Autoren einen geringeren Cys-Bedarf für langsam befiedernde männliche 
Broiler im Vergleich zu schnell befiedernden männlichen Broilern. Folglich wurde bei Anstieg der Cys-Konzentration in der Diät nur die Leistung von schnell befiedernden Broilern gesteigert.

Zusammenfassend kann festgehalten werden, dass die Supplementation von Met+Cys zu einer Met-limitierten Diät zu einer Reduktion des Met-Abbaus während der Transsulfuration führt. Somit ist weniger Met zur Bedarfsdeckung im Futter nötig.

Der durch Cysteinsupplementation auftretende „Methionin-Spareffekt“ wurde besonders in der Growerperiode deutlich. In Anbetracht des intensiven Wachstums der Broiler und des Federansatzes nimmt mit ansteigendem Alter die Relevanz der Keratinsynthese in der Proteinsynthese insgesamt zu. Ein erhöhter Cys-Bedarf mit zunehmendem Alter der Broiler kann somit geschlussfolgert werden. 


\subsection{Untersuchungskomplex III}

Versuchskomplexe III diente zur Ermittlung des optimalen Aminosäurenverhältnisses im wachsenden Geflügel. Basierend auf Grundsätzen der Verdünnungstechnik (GOUS und MORRIS 1985) wurde eine Basalmischung (BC) mit Weizenquellstärke verdünnt und anschließend, mit Ausnahme der jeweils limitierenden Aminosäure, mit kristallinen Aminosäuren wieder aufgefüllt. Unter Berücksichtigung von drei N-Bilanzstudien und zwei parallel durchgeführten Wachstumsversuchen sollte das ideale Verhältnis der Aminosäuren Threonin, Tryptophan, Arginin, Isoleucin und Valin in Relation zum Lysin evaluiert werde.

\subsubsection{Einordnung und Bewertung des ermittelten idealen Aminosäurenverhältnisses (N-Bilanzversuche)}

Der Aminosäurenbedarf für Mastgeflügel wird durch zahlreiche Faktoren beeinflusst, die eine akkurate Aminosäurenbedarfsbestimmung unter der Bedingung aller Einflussfaktoren nahezu unmöglich macht. Durch die Darstellung der Bedarfsdaten nach dem Idealprotein-Konzept kann dieses Problem behoben werden (SCHUTTE und DE JONG 2004).

Basierend auf der Hypothese, dass alle Futteraminosäuren genau in der Relation vorliegen in der sie vom Organismus benötigt werden (KIRCHGEßNER 1997) folgt, dass das „Idealprotein“ das optimale Verhältnis der essentiellen Aminosäuren im Futter zueinander angibt, wobei Lysin die Referenzaminosäure darstellt. EMMERT und BAKER (1997) begründeten die Wahl des Lysins als Referenzaminosäure mit den Aspekten, dass Lysin in praktischen Broilerdiäten häufig die „Zweit“-limitierende Aminosäure darstellt und sich eine Analyse in Futtermitteln als unkompliziert erweist. Des Weiteren führten EMMERT und BAKER (1997) an, dass Lysin primär für den Proteinansatz genutzt wird. Zudem liegen für Lysin die umfangreichsten Untersuchungen zum quantitativen Bedarf vor. Aufgrund dessen, dass der Bedarf an den übrigen Aminosäuren relativ zum Lysin angegeben wird, ist eine korrekte und zuverlässige Quantifizierung des Lysins unerlässlich.

Der Lysingehalt von 12,5g Lys/kg Futter (10. - 20. LT) bzw. 11,5g Lys/kg Futter (25. - 35. LT) der Diät BC in den Versuchen 6 und 7 wurde in Anlehnung an die Bedarfsempfehlungen der DEGUSSA (2003) und GFE (1999) abgeleitet und befand sich in Überein- 
stimung mit KIDD et al. (1997), BAKER (1997), HAN und BAKER (1991) und CORZO et al. (2005). Die Bewertung des Lysinbedarfs wird durch verschiedene Faktoren wie Proteinund Energielevel, die Qualität der Proteinquelle und dem Genotyp beeinflusst. Zusätzliche Variationen können die angewandte Methodik und die Bewertungskriterien liefern. Der Lysinbedarf zur Erlangung eines optimalen Brustfleischanteils kann höher sein als der, der für optimalen Zuwachs und Futteraufwand benötigt wird (REZAEI et al. 2004). BAKER et al. (2002) argumentierten, dass der Lysinbedarf für maximalen Futteraufwand in der von BAKER et al. (2002) durchgeführten Studie substanziell höher war als der für maximalen Lebendmassezuwachs. HAN und BAKER (1993, 1994) und MACK et al. (1999) kamen zu einer analogen Schlussfolgerung. Gemäß HOLSEIMER und RUESINK (1993) wird ebenfalls mehr Lys zur Erhöhung des Brustfleischanteils als für maximale Zuwachs benötigt.

Das NRC (1994) empfiehlt für Broiler zwischen 0. - 3. Lebenswoche 1,10\% Lysin und 1,00\% Lysin im Futter für die Altersperiode von 3. - 6. Lebenswoche. SI et al. (2001) zeigte mit Broilern (Cobb 500), dass sich das Wachstum und der Futteraufwand mit einem Anteil von $0,2 \%$ mehr Lysin im Altersabschnitt vom 0. - 21. LT und mit 0,1\% mehr Lysin in der Altersperiode vom 21. - 42. LT verbesserte. LABADAN et al. (2001) erhielten ein optimales Wachstum und einen optimalen Brustfleischansatz in Ross x Avian Hybriden (0. - 14. LT) bei 0,2\% mehr Lysin. AUSTIC (1994) bewertete in Diäten mit 23\% XP den Aminosäurenbedarf und deren relative Verhältnisse zueinander. Er postulierte, dass die vom NRC (1994) angegebene Empfehlung für die Aminosäure Lys in der Starterperiode zu gering sei und ein Gehalt von 1,3\% Lys in der Mischung (23\% XP) adäquater wäre. PLUMSTEAD et al. (2007) bewertete in zwei Versuchen mit vier gestaffelten Leveln an verdaulichem Lys den optimalen Bedarf für Broiler in der Altersperiode 0. - 21. LT. Der Bedarf betrug 1,19\% verdauliches Lysin (1,30\% Lysin) in einer Diät mit 22,4\% XP und 3000 - 3300 kcal/kg.

Das Lysin:Threonin-Verhältnis der vorliegenden Untersuchung wurde mit 100:61 für Broiler des Alterabschnittes 10. - 20. LT und 100:65 für Broiler des Alterabschnittes 21. - 35. LT bewertet. AUSTIC (1994) führte Studien mit Broilern im Altersabschnitt von 0. - 21. LT durch und schlug ein ähnliches Lys:Thr-Verhältnis von 100:62 für diesen Altersabschnitt vor. Baker et al. (2002) ermittelten in einem Versuch mit New Hampshire x Columbian Plymouth Rock Broilern (8. - 21. LT) ein optimales Lys:Thr-Verhältnis von 100:56, welches deutlich unter dem der vorliegenden Untersuchung lag. BAKER und HAN (1994) postulierten ein 
höheres Lys:Thr-Verhältnis von 100: 67 für Broiler während der ersten drei Lebenswochen. Zum Teil können die Abweichungen, die zwischen den vorliegenden Untersuchungen bestehen, mit den Bewertungskriterien, auf denen die Ableitungen beruhen, erklärt werden. Das von AUSTIC (1994) vermutete Verhältnis basierte auf Bruttoaminosäuren, das dieser Untersuchung auf der Wirksamkeit der Bruttoaminosäuren und das von BAKER und HAN (1994) auf Ebene der verdaulichen Aminosäuren.

ROBBINS (1987) und RANGEL-LUGO und AUSTIC (1994) zeigten eine Abhängigkeit des Threoninbedarfs vom Proteingehalt in der Ration sowie von den Proteinquellen. Sie vermuteten, dass mit Erhöhung des Rohproteingehaltes in der Ration der Threoninbedarf ansteigt. Des Weiteren dienten unterschiedliche Lysingehalte der Futtermischungen als Bewertungsgrundlage. Das kalkulierte Lys:Thr-Verhältnis von BAKER und HAN (1994) und BAKER et al. (2002) bezogen sich auf einen verdaulichen Lysingehalt von 1,07\% im Futter, während AUSTIC (1994) 1,30\% Lysin festsetzte. Die Empfehlungen des NRC (1994) und der GFE (1999) beruhten auf einem Lys:Thr-Verhältnis im Futter von 100:73 bzw. 100:67 für Broiler vom 0. - 21. LT.

MACK et al. (1999) vermutete ein Lys:Thr-Verhältnis von 100:63 für die Altersperiode 20. - 40. LT unter Anwendung des Broken-line-Modells, basierend auf Lebendmassezuwachs. Gemäß GRUBER et al. (1999) sollte das Lys:Thr-Verhältnis im Futter 100:66 (21. - 42. LT), gemäß des NRC (1994) 100:74 und gemäß der GFE (1999) 100:76 betragen. Die Schlussfolgerungen von COON (2004) und HOEHLER und LEMME (2005) stimmten mit dem Ergebnis der Growerperiode (21. - 35. LT) dieser Studie überein.

In der vorliegenden Studie wurde das optimale Verhältnis von Tryptophan zu Lysin mit 17\% abgeleitet. Die von der GFE (1999) für Mastgeflügel vom 0. - 21. LT empfohlenen und von BAKER et al. (2002) für Broiler vom 5. - 21. LT abgeleiteten Lys:Trp-Verhältnisse lassen eine recht gute Übereinstimmung mit den vorliegenden Ergebnissen zu.

BAKER und HAN (1994) sowie BAKER (1997) schlussfolgerten mit 100:16 ein vergleichbares Verhältnis.

MACK et al. (1999) schlussfolgerten ein Lys:Trp-Verhältnis von 100:19, also einen geringfügig höheren Trp-Anteil als in vorliegenden Untersuchungen. Dabei ist jedoch zu berücksichtigen, dass die Ableitung von MACK et al. (1999) auf Lebendmassezuwachs beruhte. Basiert diese Ableitung jedoch auf dem Futteraufwand, würden MACK et al. (1999) ein ideales Lys:Trp-Verhältnis von 100:17 erhalten. MACK et al. (1999) nutzten zur Bewertung verdaulicher Bedarfsdaten eine Mais-Sojabohnen-Diät, die auf einem geringen 
Proteingehalt (17,2\%) beruhte. Die Ableitung idealer Aminosäurenverhältnisse in ihrem Versuch erfolgte an Geflügel in der Growerperiode vom 20. bis 40. Lebenstag und auf Basis des Zuwachses und des Futteraufwandes. Aufgrund dessen, dass sie keine signifikante Response bezüglich des Futteraufwandes und des Lebendmassezuwachses erhielten, erlauben deren Daten keine gesicherte Bewertung des Lys:Trp-Verhältnisses.

Nach ROTH et al. (2001) sollte das Lysin:Arginin-Verhältnis 100:108 betragen. Im vorliegenden Versuch lag das bewertete optimale Lys:Arg-Verhältnis bei 100:106 in der Starter- wie auch in der Growerperiode. Damit ordnete sich das beobachtete optimale Verhältnis von Lysin zu Arginin in gemittelte Literaturdaten ein (AUSTIC 1994, BAKER und HAN 1994, BOORMAN und BURGESS 1986, COON 2004, CRESWELL und SWICK 2001, CVB 1996, DEGUSSA 2003, GFE 1999, HOEHLER und LEMME 2005, NRC 1994, RHONE-POULENC 1993), welche als Grundlage der Basalmischungen (BC) dieses Versuchskomplexes diente. Eine gute Übereinstimmung bestand auch zu den Versuchsergebnissen von BAKER und HAN (1994), die ein Lys:Arg-Verhältnis von 100:105 für Broiler (0. - 21.LT) ermittelten.

In vier Versuchsdurchgängen wurde von MENDES et al. (1997) der Einfluss von drei Lysinniveaus und vier Arginin-Lysin-Verhältnissen auf die Mast- und Schlachtleistung von Broilern untersucht. Sie schlussfolgerten, dass ein Lys:Arg-Verhältnis von 100:110 als ausreichend angesehen werden kann. Aus den Versuchsergebnissen von MACK et al. (1999) resultierte ein ideales Lys:Arg-Verhältnis von 100:112. Dabei ist jedoch zu berücksichtigen, dass die Ableitung von MACK et al. (1999) auf Lebendmassezuwachs beruhte. Basiert diese Ableitung jedoch auf dem Futteraufwand, würden MACK et al. (1999) ein ideales Lys:Trp-Verhältnis von 100:104 erhalten.

Nach MENDES et al. (1997) und KIDD und KERR (1998) haben höhere ARG/LYSQuotienten positive Auswirkungen auf die Mast- und Schlachtleistungen. Eine deutliche Verbesserung der Mast- und Schlachtleistung wurde in den Untersuchungen von LEITGEB et al. (2003) bei abgesenktem Rohproteingehalt mit einer L-Argininergänzung festgestellt. In den Startermischungen (1. - 21. LT) lag ein ideales Lys:Arg-Verhältnis von 100:104 bzw. 100:90 und in den Growermischungen ein ideales Lys:Arg-Verhältnis von 100:109 bzw. 100:93 vor.

Bei relativ hohen Proteingehalten in den Rationen wurden von RUITZN-FERIA et al. (2001) durch L-Argininzulagen keine positiven Auswirkungen auf die Lebendmasse verzeichnet. WALDROUP et al. (1998) setzten in einem Putenmastversuch über 18 Wochen Futter- 
mischungen ein, die 100, 110 und 120\% Arginin des NRC-Lysin-Levels (1994) beinhalteten. Sie testeten den Einfluss verschiedener Lys:Arg-Verhältnisse in Diäten (100:100, 100:110, 100:120, 100:130). Aus ihren Versuchsergebnissen ließ sich eine Wechselwirkung zwischen dem Lysingehalt und Arginin-Lysin-Level feststellen. Beim höchsten Lysingehalt reichte das niedrigste Lys:Arg-Verhältnis (100:100) für eine optimale Leistung aus, während beim niedrigsten Lysingehalt eine höhere L-Argininzufuhr die Lebendmasseentwicklung signifikant verbesserte.

Das in der vorliegenden Untersuchung ermittelte ideale Verhältnis von Lysin zu Isoleucin beträgt 100:59 für Broilerküken zwischen dem 10. LT und dem 21. LT. BAKER et al. (1993) ermittelte ein optimales Verhältnis von Lys zu Ile von 100:67 aus, basierend auf verdaulicher Aminosäurenbasis. Die Empfehlungen des NRC (1994) zur Versorgung der Broiler auf Basis der Bruttoaminosäuren beziehen sich auf ein ideales Lys:Ile-Verhältnis von 100:73 im ersten Mastabschnitt (0. - 21. LT). BAKER (1997) empfahl ein optimales Lys:Ile-Verhältnis von 100:67. Die dargestellten Verhältnisse weichen deutlich von dem dieser Untersuchung ab. Es ergaben sich jedoch nur geringe Abweichungen zu dem von BAKER et al. (2002) postulierten Lys:Ile-Verhältnis von 100:61.

Eine deutliche Abweichung des Lys:Ile-Verhältnisses der Growerperiode (21. - 35. LT) der vorliegenden Untersuchung (100:65) tritt im Vergleich mit den Empfehlungen des NRC (1994), GFE (1999), MACK et al. (1999) und HOEHLER und LEMME (2005) auf. So liegt das von dem NRC (1994), GFE (1999), MACK et al. (1999) und HOEHLER und LEMME (2005) empfohlenen Lys:Ile-Verhältnis bei 100:73, 100:78, 100:71 und 100:71. Das von GRUBER et al. (1999) nach dem Konzept des Idealproteins abgeleitete optimale Lys:IleVerhältnis lässt eine recht gute Übereinstimmung zu dem vorliegendem optimalen Lys:IleVerhältnis erkennen.

Das in der vorliegenden Untersuchung ermittelte ideale Verhältnis von Lys zu Val beträgt 100:69 für Broilerküken zwischen dem 10. LT und dem 21. LT und stimmt weitgehend mit dem NRC (1984) überein (100:68). BAKER (1997) und BAKER et al. (2002) bewerteten Val relativ zu Lys mit 77,5\% und 77\%. Im Vergleich zu den Studien von BAKER (1997) und BAKER et al. (2002) lag das ermittelte ideale Lys:Val-Verhältnis der vorliegenden Untersuchung deutlich niedriger. Dabei ist zu berücksichtigen, dass die Ableitung von BAKER et al. (2002) auf dem Broken-line Modell für Valin auf Gewichtsbasis und für Lysin auf Basis 
der Futteraufwand beruhte. Außerdem wurden in beiden Versuchen unterschiedliche Genotypen verwendet.

Im Hinblick auf die Growerperiode berichteten MACK et al. (1999) und ROTH et al. (2001) von einem analogen Lys:Val-Verhältnis (100:81). In Untersuchungen von CORZO et al. (2007) an Ross x Ross 708 Broilern im Altersabschnitt zwischen den 21. LT und 42. LT wurde gezeigt, dass ein Lys:Val-Verhältnis von 100:78 optimal für einen maximalen Lebendmassezuwachs ist. Das in der vorliegenden Untersuchung ermittelte ideale Lys:ValVerhältnis betrug 100:82 für Broilerküken zwischen dem 21. LT und dem 35. LT und lag somit über dem von CORZO et al. (2007) ermittelten. Möglicherweise resultierte die höhere Angabe aus der Verwendung unterschiedlicher Genotypen, Altersperioden und verschiedener Bewertungskriterien (Futteraufwand vs. Lebendmassezuwachs).

Das abgeleitete ideale Lys:Val-Verhältnis der Starterperiode (10. - 20. LT) lag in der vorliegenden Untersuchung deutlich unter dem der Angaben aus der Literatur. In der Growerperiode hingegen stimmt das abgeleitet Verhältnis weitgehend mit den Literaturangaben überein. Bedingt durch ihre Ähnlichkeit im Aufbau können sich Isoleucin und Valin gegenseitig beeinflussen (FARRAN und TOMAS 1990). D'MELLO (2003) postulierte, dass eine Erhöhung des Isoleucingehaltes im Futter in einem erhöhten Bedarf an Valin resultiert. Bei der Bedarfableitung sollte dieser Aspekt künftig stärker berücksichtigt werden.

Tabelle 6.3 gibt einen Überblick über die Aminosäurenverhältnisse, welche vom NRC (1994), GFE (1999), BAKER et al. (1993), CVB (1996), GRUBER et al. 1999) und AUSTIC (1994) empfohlen wurden. 
Tabelle 6.2: Publizierte Aminosäurenverhältnisse für Broiler

\begin{tabular}{|c|c|c|c|c|c|c|c|c|c|}
\hline Institution & NRC & $1994^{1}$ & GFE & $1999^{1}$ & $\begin{array}{r}\text { BAK } \\
1\end{array}$ & $\begin{array}{l}\mathrm{R} \text { et al. } \\
3^{2}\end{array}$ & $\begin{array}{c}\text { CVB } \\
1996^{2}\end{array}$ & $\begin{array}{c}\text { GRUBER } \\
\text { et al. } \\
1999^{1}\end{array}$ & $\begin{array}{c}\text { AUSTIC } \\
\text { 1994 }^{2}\end{array}$ \\
\hline Alter & $\begin{array}{c}0 .-21 . \\
\text { LT }\end{array}$ & $\begin{array}{c}21 .-42 . \\
\text { LT }\end{array}$ & $\begin{array}{c}0 .-21 . \\
\text { LT }\end{array}$ & $\begin{array}{c}21 .-42 . \\
\text { LT }\end{array}$ & $\begin{array}{c}0 .-21 . \\
\text { LT }\end{array}$ & $\begin{array}{c}21 .-42 . \\
\text { LT }\end{array}$ & $\begin{array}{c}0 .-42 . \\
\text { LT }\end{array}$ & - & $\begin{array}{c}0 .-21 . \\
\text { LT }\end{array}$ \\
\hline Lys & 100 & 100 & 100 & 100 & 100 & 100 & 100 & 100 & 100 \\
\hline Thr & 73 & 74 & 67 & 76 & 67 & 70 & 65 & 66 & 62 \\
\hline Trp & 18 & 18 & 16 & 17 & 16 & 17 & 16 & 14 & 18 \\
\hline Arg & 114 & 110 & 108 & 117 & 105 & 108 & 105 & 108 & 96 \\
\hline Ile & 73 & 73 & 69 & 78 & 67 & 69 & 66 & 63 & 65 \\
\hline Val & 82 & 82 & 96 & 109 & 77 & 80 & 80 & 81 & 69 \\
\hline
\end{tabular}

Das optimale Aminosäurenverhältnis von GRUBER et al. (1999) und des CVB (1996) zeigt im Vergleich zu dem ermittelten idealen Aminosäurenverhältnis der Starter- und Growerperiode dieser Studie die deutlichsten Übereinstimmungen.

Bei Betrachtung dieser untereinander und im Vergleich mit der vorliegenden Arbeit, zeigen sich deutliche Divergenzen zwischen den einzelnen Empfehlungen. Verschiedene Ursachen können in Betracht gezogen werden. Ein Teil der Diskrepanzen können mit der verwendeten Basis erklärt werden. Die z.B. vom NRC (1994) und AUSTIC (1994) vermuteten Verhältnisse basierten auf Bruttoaminosäuren, während die von BAKER et al. (1993) und CVB (1996) sich auf Basis verdaulicher Aminosäuren stützten. In der vorliegenden Untersuchung wurden die idealen AA-Verhältnisse auf Basis der AA-Wirksamkeit ermittelt. SCHUTTE und DE JONG (1996) stellten in Versuchen mit Legehennen die idealen Aminosäurenverhältnisse, basierend auf verdaulicher und Bruttoaminosäuren-Ebene gegenüber. Die Autoren zeigten, dass auf verdaulicher Basis für die meisten Aminosäuren differenzierte Verhältnisse erfasst wurden. Als Ursache gaben sie Unterschiede in der Aminosäurenverdaulichkeit an. Die Verdaulichkeiten des Rohproteins und der Aminosäuren sind von den Futterkomponenten abhängig. Zudem werden oftmals kristalline Aminosäuren mit einer Verdaulichkeit von 100\% (CHUNG und BAKER 1992) zugegeben, was bei der Übertragung von Bedarfsempfehlungen auf die Praxis berücksichtigt werden sollte (SCHUTTE und DE JONG 1996).

Weiterhin basieren die kalkulierten Verhältnisse auf unterschiedlichen Lysingehalten in den Diäten. Das Aminosäurenverhältnis von BAKER et al. (1993) bezogen sich auf einen verdaulichen Lysingehalt von 1,07\% (0. - 21. LT) und 0,81\% (21. - 42. LT). Diese Gehalte korrespondieren mit ca. 1,22 und 0,98\% totalem Lysin in Mais-Sojabohnen-Diäten. Das NRC 
(1994) legte Mischungen mit 1,10\% Lysin (0. - 21. LT) und 1,00\% Lysin (21. - 42. LT) zugrunde, während die berechneten Aminosäurenverhältnisse von AUSTIC (1994) auf Mischungen mit 1,30\% Lysin basierten.

Des Weiteren wurde in dieser Studie im Gegensatz zu zahlreichen Publikationen (BAKER und HAN 1994, BAKER et al. 2002, KIDD et al. 2004 und weitere) nach dem Prinzip der „Verdünnungstechnik“ (GOUS und MORRIS 1985) gearbeitet. Damit ergeben sich andere Voraussetzungen, statistische Methoden und Modelle zur Ableitung des Bedarfs an Aminosäuren, welche einen direkten Vergleich nicht erlauben. Beispielsweise überprüften VAZQUEZ und PESTI (1997) den Lysinbedarf für maximales Wachstum und Futterwirksamkeit von Broilern in den ersten drei Wochen. Verglichen mit dem Broken-lineModell resultierte das quadratische Modell in einem Lysinbedarf, der 16\% höher für den Lebendmassezuwachs und 20\% höher für den Futteraufwand war.

FISCHER et al. (1973) zeigte im Hinblick auf die gleichen Datensätze, dass die zur Ableitung des AA-Profils verwendete Broken-line Regressionsmethode in einem geringeren Aminosäurenbedarf resultierte als vergleichsweise eine applizierte nichtlineare Approximation.

Tabelle 6.3: Gegenüberstellung der abgeleiteten optimalen Aminosäurenverhältnisse (Starter und Grower) mit Literaturdaten

\begin{tabular}{lcccccc}
\hline & Lys & Thr & Trp & Arg & Ile & Val \\
\hline Starterperiode & 100 & 61 & 17 & 106 & 59 & 69 \\
Growerperiode & 100 & 65 & 17 & 106 & 65 & 82 \\
\hline Literaturdaten* & 100 & 66 & 16 & 105 & 69 & 80 \\
\hline *(AUSTIC 1994, BAKER und HAN 1994, BOORMAN und BURGESS 1986, COON 2004, CRESWELL und SWICK \\
2001, CVB 1996, DEGUSSA 2003, GFE 1999, HOEHLER und LEMME 2005, NRC 1994, RHONE-POULENC 1993)
\end{tabular}

Bei der Gegenüberstellung der beiden vorliegenden idealen Aminosäurenverhältnisse mit dem aus verschiedenen Literaturdaten kalkulierten optimalen Aminosäurenverhältnis (AUSTIC 1994, BAKER und HAN 1994, BOORMAN und BURGESS 1986, COON 2004, CRESWELL und SWICK 2001, CVB 1996, DEGUSSA 2003, GFE 1999, HOEHLER und LEMME 2005, NRC 1994, RHONE-POULENC 1993), wird deutlich, dass v. a. das für die Growerperiode abgeleitete Verhältnis deutliche Übereinstimmungen aufweist. Abweichungen treten in der Starterperiode (10. - 21. LT) für die Aminosäure Threonin, Isoleucin und Valin auf. So lag das dort ermittelte ideale Lys:Thr:Ile:Val-Verhältnis bei 100:61:59:69, während 


\section{Diskussion}

das aus verschiedenen Literaturdaten kalkulierte Lys:Thr:Ile:Val-Verhältnis bei 100:66:69:80 lag.

Bei diesen Aminosäuren kann davon ausgegangen werden, dass mit zunehmendem Alter der Tiere die relative Bedeutung der Aminosäuren Threonin, Isoleucin und Valin im Verhältnis zum Lysin ansteigt. Untermauert wird dieses durch Beobachtungen von EMMERT und BAKER (1997). Sie vermuteten, dass die altersabhängigen Unterschiede in den Aminosäurenverhältnissen im Wesentlichen durch Unterschiede im Erhaltungsbedarf der Tiere bedingt sind. Nach Ansicht der Autoren steigt der Erhaltungsbedarf mit zunehmendem Alter der Tiere für die Aminosäuren Thr, Ile und Val im Vergleich zum Lysin schneller an.

In Prozent des gesamten Aminosäurenbedarfes ist der Erhaltungsbedarf mit ca. 3 - 6\% für junges Geflügel minimal. EMMERT und BAKER (1997) vermuteten jedoch, dass dieser mit fortschreitendem Alter und Lebendmasse substanziell ansteigt. Im Gegensatz dazu konnte in Studien mit Schweinen und Ratten aufgezeigt werden, dass der Bedarf an Lysin im Hinblick auf Erhaltung sehr gering ist und mit fortschreitendem Alter und Lebendmasse der Broiler keinen substanziellen Anstieg verzeichnet. WEBEL et al. (1996) und EDWARDS et al. (1997) führten im Hinblick auf die Aminosäure Threonin Studien mit Geflügel in drei Altersperioden (0. - 21., 21. - 42. und 42. - 56. LT) durch und evaluierten unter separater Betrachtung des Bedarfes für Erhaltung und Wachstum den Bedarf dieser Aminosäure. Wie erwartet stieg der prozentuale Thr-Anteil, der für die Erhaltung benötigt wurde, mit fortschreitendem Alter der Tiere an (EMMERT und BAKER 1997).

Eine ähnliche Studie wurde mit Lysin durchgeführt (EDWARDS et al. 1996). Das Ergebnis dieser Studie reflektierte ebenfalls einen substantiellen Anstieg im Erhaltungsbedarf. Allerdings erschien ein beträchtlicher Unterschied hinsichtlich dessen, ob der Lysinansatz oder der Proteinansatz als Antwortkriterium fungierte. In Anlehnung an BAKER (1997) führt die Bewertung des Bedarfes für Erhaltung auf Basis des Proteinansatzes zu einem niedrigeren Wert. Dies lässt vermuten, dass der Anteil an Lysin, welches zur Erhaltung benötigt wird, substanziell höher erscheint, als von den Autoren vorab gedacht (EMMERT und BAKER 1997).

Da für die Aminosäure Thr eine im Verhältnis zum Proteinansatz deutlich höhere Relation zum Lysin im Erhaltungsbedarf vorliegt, ergibt sich mit zunehmender Lebendmasse und damit zunehmendem Erhaltungsanteil eine zu Lysin höhere Thr-Relation im Gesamtbedarf. Bei den weiteren AS verändert sich das Verhältnis zu Lysin unmerklich, ausgenommen davon sind die Aminosäuren Ile und Val. 


\subsubsection{Einordnung des ermittelten idealen Aminosäurenverhältnisses (Wachstumsversuche)}

Ausgehend von den zwei Wachstumsversuchen wurden folgende ideale Aminosäurenverhältnisse ermittelt (Lys: Thr: Trp: Arg: Ile: VAL= 100: 62: 18: 95: 68: 72 (Starterperiode) und Lys: Thr: Trp: Arg: Ile: VAL=100: 73: 15: 92: 73: 82 (Growerperiode)).

Das aus den Wachstumsversuchen (Versuch 7 und 10) geschlussfolgerte ideale Aminosäurenverhältnis der Starter- und Growerperiode zeigt beim Vergleich mit dem aus den N-Bilanzstudien deutliche Unterschiede. Bei der Gegenüberstellung können nur für Lys:Thr und Lys:Trp (Starterperiode) und Lys:Val (Growerperiode) Übereinstimmungen getroffen werden.

Im Hinblick auf den Versuch 7 sind, aufgrund der Effekte auf die Proteinqualität, die geschlussfolgerten idealen Verhältnisse allerdings mit Vorsicht zu behandeln.

Betrachtet man hingegen das ideale Aminosäurenverhältnis des Versuchs 10 seperat (Lys: Thr: Trp: Arg: Ile: VAL= 100: 62: 19: 107: 60: 67 (Starterperiode) und Lys: Thr: Trp: Arg: Ile: VAL= 100: 73: 17: 102: 68: 86 (Growerperiode)) so war nachzuweisen, dass dieses auf annähern gleichem Niveau mit dem geschlussfolgerten idealen Aminosäurenverhältnis der NBilanzversuche liegt. Im Hinblick auf die N-Bilanzversuche treten geringe Abweichungen in der Starterperiode für die Aminosäure Tryptophan (100:19 vs. 100:17) und in der Growerperiode für die Aminosäure Threonin (100:73 vs. 100:65) auf.

Die Ergebnisse des Wachstumsversuchs untermauern zudem den schon in den NBilanzversuchen beobachteten altersbedingten Anstieg für Thr, Ile und Val (vgl. Kapitel 6.3.2). So liegt das dort ermittelte ideale Lys:Thr:Ile:Val-Verhältnis bei 100:62:60:67 (Starterperiode) Lys:Thr:Ile:Val-Verhältnis bei 100:73:68:86 (Growerperiode).

Das aus dem Wachstumsversuch 10 geschlussfolgerte ideale Aminosäurenverhältnis der Starter- und Growerperiode liegt mit anderen Literaturangaben (Tabelle 6.2) auf vergleichbarem Niveau. Im Versuch wurde das optimale Verhältnis von Threonin zu Lysin mit 62\% (Starter) und 73\% (Grower) abgeleitet. Das von der AUSTIC (1994) für Mastgeflügel vom 0. - 21. LT empfohlenen und von der GFE (1999) und NRC (1994) für Broiler vom 21. - 42. LT abgeleiteten Lys:Thr-Verhältnisse lassen eine recht gute Übereinstimmung mit den vorliegenden Ergebnissen zu. BAKER et al. (1993) schlussfolgerten mit 100:70 ein vergleichbares Verhältnis. 
Das optimale Verhältnis von Tryptophan zu Lysin beträgt 19\% (Starter) und 17\% (Grower). Baker et al. (1993) schlussfolgerten ein niedrigeres Lys:Trp-Verhältnis von 100:16 für die Starterperiode. Das NRC (1994) empfiehlt ein Lys:Trp-Verhältnis von 100:18, also einen geringfügig abweichendes Verhältnis für beide Wachstumsperioden. In der Growerperiode zeigten sich Übereinstimmungen zu den Empfehlungen von BAKER et al. (1993) und der GFE (1999).

Das in der vorliegenden Untersuchung ermittelte ideale Verhältnis von Lysin zu Arginin beträgt 100:107 für Broilerküken zwischen dem 0. LT und dem 21. LT und 100:102 für Broilerküken zwischen dem 21. LT und dem 42. LT. Gute Übereinstimmungen zeigten sich in der Starterperiode. BAKER et al. (1993) ermittelten ein Lys:Arg-Verhältnis von 100:105, die GFE (1999) empfahl 100:108. Die Empfehlungen des NRC (1994) mit 100:114 und 100:110 hingegen lagen deutlich über dem des in der vorliegenden Untersuchung.

Das ideale Verhältnis von Lysin zu Isoleucin beträgt 100:60 für Broilerküken zwischen dem 0. LT und dem 21. LT und 100:68 für Broilerküken zwischen dem 21. LT und dem 42. LT. BAKER et al. (1993) ermittelte ein optimales Verhältnis von Lys zu Ile von 100:67, basierend auf verdaulicher Aminosäurenbasis. Die Empfehlungen des NRC (1994) zur Versorgung der Broiler auf Basis der Bruttoaminosäuren beziehen sich auf ein ideales Lys:Ile-Verhältnis von 100:73 im ersten Mastabschnitt (0. - 21. LT).

Das optimale Verhältnis von Lysin:Valin beträgt 100:67 (Starter) und 100:86 (Grower).

Die dargestellten Verhältnisse weichen deutlich von dem dieser Untersuchung ab. BAKER et al. (1993) ermittelte ein optimales Verhältnis von Lys zu Val von 100:77 und 100:80, basierend auf verdaulicher Aminosäurenbasis. Die Empfehlungen des NRC (1994) zur Versorgung der Broiler auf Basis der Bruttoaminosäuren beziehen sich auf ein ideales Lys:Val-Verhältnis von 100:82 für beide Altersperioden. Es ergaben sich jedoch nur geringe Abweichungen zu dem von AUSTIC et al. (1994) angegebenen Lys:Val-Verhältnis von 100:69. 


\section{Schlussfolgerung}

Der ermittelte NMR hat nur bei gleicher Eiweißqualität Gültigkeit und eine Verschlechterung der Aminosäurenzusammensetzung der Futtermischungen führt $\mathrm{zu}$ einem erhöhten Erhaltungsbedarf (HALLE et al. 1984). Die Mischungen dieser Untersuchung enthielten eine eindeutige Methionin-Limitierung. Da Methionin im Erhaltungsbedarf eine größere Bedeutung zukommt, kann dies einen höheren NMR erklären.

Übereinstimmend mit den Untersuchungen von SAMADI und LIEBERT (2008) wurde mit zunehmendem Alter ein abnehmendes genetisches Potential zur Proteindeposition beobachtet. Als Ursache hierfür können morphologischen Veränderungen im Darm, Veränderung in der Proteinsyntheserate sowie eine verringerte Aminosäurendeposition im Schlachtkörper (KANG et al. 1985, UNI et al. 1999, SKLAN und NOY 2004) angeführt werden.

In Met-limitierenden Futtermischungen kann für DLM im Vergleich zu MHA eine höhere Wirksamkeit geschlussfolgert werden.

Die MHA-Wirksamkeit ist vom Met:Cys-Verhältnis und dem Gehalt an Met bzw. Cys in der Diät abhängig. Es kann davon ausgegangen werden, dass mit zunehmendem Anteil an Methionin sowie innerhalb eines Methioninlevels ein abnehmender Anteil an Cystein in der Diät die Wirksamkeit von MHA relativ zu DLM sinkt.

Im Rahmen der Methioninbedarfsermittlung zeigte sich neben dem angestrebten N-Ansatz eine Abhängigkeit zum Met:Cys-Verhältnis bzw. Cys-Gehalt der Futtermischung. Bei einem höheren Cys:SAA-Verhältnis steigt die Methioninwirksamkeit an. Diese höhere Methioninwirksamkeit lässt eine Reduktion des Met-Abbaus während der Transsulfuration schluss-folgern, da Cystein ausreichend vorhanden ist. Infolge dessen steht eine größere Menge an Met für andere Funktionen im Organismus zur Verfügung.

Die Ergebnisse des Versuchskomplexes II basieren auf Mischungen mit hohen Gehalten an Leguminosen. Dies deutet auf eine geringere Cys-Verfügbarkeit in den Mischungen hin. Die in der vorliegenden Arbeit diskutierten Ergebnisse weisen somit auf einen weiteren Forschungsbedarf hin: 
- Überprüfung der kalkulierten Met-Bedarfswerte und damit Verifizierung der Praxisrelevanz des abgeleiteten Met-Bedarfs

- Ermittlung von Angaben zur Met-Wirksamkeit und Kalkulation eines leistungsabhängigen Met-Bedarfs unter Einbezug verschiedener Futterproteinmischungen

Die im Versuchskomplexes III ermittelten idealen Aminosäurenverhältnisse weisen mit der Literatur überwiegend Übereinstimmungen auf. Differenzen können mit Unterschieden bzgl. der verwendeten Basis (verdauliche oder Bruttoaminosäuren), den Lysingehalten, dem verwendeten Modell oder den Messkriterien (Zuwachs, Futteraufwand usw.) erklärt werden.

Aufgrund der in den Versuchen 6 und 7, 8 insignifikanten Effekte auf die Proteinqualität, müssen speziell im Fall von Ile und Val die geschlussfolgerten idealen Verhältnisse mit Vorsicht behandelt werden. Betrachtet man allerdings die ermittelten idealen Verhältnisse im Versuch 9 und 10, bei denen beide Aminosäuren im Limitierungsbereich vorlagen, zeigen sich ähnliche Ergebnisse.

Bei Betrachtung der Aminosäuren Threonin, Isoleucin und Valin zeigt sich ein altersbedingter Anstieg. Eine mögliche Erklärung könnte der mit zunehmendem Alter schneller ansteigende Erhaltungsbedarf für Thr, Ile und Val (im Vergleich zum Lysin) sein.

Aus den Ergebnissen des Versuchskomplexes III konnte somit der schon in früheren Studien (Samadi und Liebert 2006b, 2007a) vermutete altersbedingte Anstieg für Lys:Thr bestätigt werden. Zur Überprüfung der geschlussfolgerten Aminosäurenverhältnisse sowie des altersbedingten Anstieges für Lys:Ile und Lys:Val bedarf es weiterer Untersuchungen, unter Einbindung verschiedener Futterproteinmischungen.

Aus den ermittelten Angaben zum idealen Aminosäurenverhältnis sind weiterführend Bedarfsableitungen zu den Aminosäuren Lys, Thr, Trp, Arg, Ile und Val möglich. 


\section{Zusammenfassung}

Die vorliegende Untersuchung diente, nach der grundlegenden Vorgehensweise im Rahmen des exponentiellen N-Verwertungsmodelles (GEBHARDT 1966, SAMADI und LIEBERT 2008), die Aminosäurewirksamkeit beim Masthähnchen unter spezifischer Fokussierung der schwefelhaltigen Aminosäuren Methionin und Cystein zu bewerten und neue Erkenntnisse zum Idealprotein-Konzept beim Mastgeflügel zu erhalten. Dazu wurden Stoffwechsel- und Wachstumsversuche mit männlichen Ross 308 Broilerküken in jeweils zwei Altersperioden (Starter- und Growerperiode) durchgeführt. Die Beantwortung der komplexen Fragestellung erforderte ein Herangehen in drei separaten Versuchskomplexen, die folgende Zielstellungen umfassten:

Untersuchungskomplex I: Ermittlung des NMR (N-Erhaltungsbedarf) und $\mathrm{NR}_{\max } \mathrm{T}$ (theoretisches maximales N-Retentionsvermögen)

Untersuchungskomplex II: vergleichende Bertachtung der Methioninwirksamkeit zweier Methioninquellen (DL-Methionin (DLM) und 2-Hydroxy-4-methylthiobuttersäure (MHA)) und Ermittlung des Methioninbedarfs in Abhängigkeit vom Met:Cys-Verhältnis

Untersuchungskomplex III: Ableitung eines idealen Aminosäurenverhältnisses unter Betrachtung der Aminosäuren Lysin, Threonin, Tryptophan, Arginin, Isoleucin und Valin

Folgende Resultate wurden erzielt:

\section{$\underline{\text { NMR und NR }}$ max $\underline{T}$}

Der in einem N-Bilanzversuch ermittelte N-Erhaltungsbedarf (NMR) für Ross 308 Broiler betrug für die Altersperiode 10. - 20. LT $295 \mathrm{mg} / \mathrm{LM}_{\mathrm{kg}}{ }^{0,67}$ pro Tag und für die Altersperiode 25. - 35. LT $313 \mathrm{mg} / \mathrm{LM}_{\mathrm{kg}}{ }^{0,67}$ pro Tag. Da die Ergebnisse, des in beiden Altersabschnitten analysierten N-Erhaltungsbedarfes sehr ähnlich waren, wurde der Mittelwert dieser beiden Parameter eruiert. Der durchschnittliche, als „Arbeitswert“ für den täglichen NErhaltungsbedarf angenommene NMR betrug, für die unter der Studie betrachtete Genetik, somit $304 \mathrm{mg} / \mathrm{LM}_{\mathrm{kg}}{ }^{0,67}$ pro Tag. Die Bewertung des theoretischen Potentials für die tägliche $\mathrm{N}$-Retention $\left(\mathrm{NR}_{\max } \mathrm{T}\right)$ männlicher Broilerküken der genetischen Herkunft Ross 308 entsprach für die Altersperiode 10. - 20. LT $3991 \mathrm{mg} / \mathrm{LM}_{\mathrm{kg}}{ }^{0,67}$ pro Tag und $3110 \mathrm{mg} / \mathrm{LM}_{\mathrm{kg}}{ }^{0,67}$ pro Tag 
für die Altersperiode 25. - 35. LT. Die Ergebnisse demonstrierten, dass das genetische Potential zur Proteindeposition wachsender Broiler mit zunehmendem Alter sank.

\section{Methionin-Wirksamkeit}

Gegenüber der Negativkontrolle konnte durch die DL-Methionin- / MHA-Zulagen bzw. DL-Methionin- / MHA-Zulagen in Kombination mit Cystein der tägliche Zuwachs und der Futteraufwand signifikant verbessert werden. Beim Vergleich der relativen Wirksamkeit (Tabelle 1) von DLM und MHA in dieser Arbeit zeigt sich eine Überlegenheit des DLM in allen Mischungen, mit Ausnahme der zweiten Met+Cys-Supplementationsstufe in der Growerperiode, bei der eine Wirksamkeit von 100 erzielt wurde. Die MHA-Wirksamkeit variierte in einem Bereich zwischen 62\% und 100\% in Abhängigkeit vom Met:Cys-Verhältnis und dem Gehalt an Met bzw. Cys in der Diät. Die Ergebnisse lassen vermuten, dass mit zunehmendem Anteil an Methionin sowie innerhalb des Methioninlevels ein zunehender Anteil an Cystein in der Diät, die Wirksamkeit von MHA relativ zu DLM senkte.

Tabelle 1: Wirksamkeit von MHA relativ zu DLM (100)

\begin{tabular}{llcccc}
\hline Versuch & Wachstumsperiode & $0,1 \%$ Met+Cys & $0,2 \%$ Met+Cys & $0,1 \%$ Met & $0,2 \%$ Met \\
\hline N-Bilanzversuch & $10 .-20 . \mathrm{LT}$ & 86 & 76 & 89 & 71 \\
& $25 .-35 . \mathrm{LT}$ & 89 & 100 & 93 & 68 \\
\multirow{2}{*}{ Wachstumsstudie } & $0 .-35 . \mathrm{LT}$ & 79 & 81 & 62 & 73 \\
\hline
\end{tabular}

Ableitungen zum täglichen Methioninbedarf

Die abgeleiteten Werte zum täglichen Methioninbedarf bezogen sich auf einen Rohproteinansatz von 6 - 10g/d (Starter) bzw. 12 - 20g/d (Grower) und lagen in einem Bereich von:

- 244 - $498 \mathrm{mg} / \mathrm{LM}_{\mathrm{kg}}{ }^{0,67}$ pro LT bei einer Met-Wirksamkeit von 157 (Starter, 10. - 21. LT)

- 230 - $500 \mathrm{mg} / \mathrm{LM}_{\mathrm{kg}}{ }^{0,67}$ pro LT bei einer Met-Wirksamkeit von 196 (Grower, 25. - 35. LT)

Danach benötigte ein Broiler mit einer mittleren Lebendmasse von 500g zur Realisierung eines täglichen Proteinansatzes von 6 - 10 mg/d eine Zufuhr von 154 - $313 \mathrm{mg} \mathrm{Met/d} \mathrm{und} \mathrm{ein}$ Broiler mit einer mittleren Lebendmasse von $1800 \mathrm{~g}$ zur Realisierung eines täglichen Proteinansatzes von 12 - $20 \mathrm{mg} / \mathrm{d}$ eine Zufuhr von $341-742 \mathrm{mg}$ Met/d. Bei einer täglichen Futteraufnahme von 50g bzw. 130g ergaben sich notwendige Aminosäurekonzentrationen im Futter von 0,26 - $0,57 \%$ Methionin bzw. 0,31 - 0,63\% Methionin. Für die Methioninbedarfswerte zeigte sich eine bestehende Abhängigkeit zum Met:Cys-Verhältnis bzw. Cys-Gehalt der Futtermischung. 


\section{$\underline{\text { Ableitungen zum idealen Aminosäurenverhältnis }}$}

N-Bilanz- und Wachstumsversuche zur Ermittlung der idealen Aminosäurenverhältnisse wurden durchgeführt. Aus den drei N-Bilanzversuchen ergab sich ein ideales Lys:Thr:Trp:Arg:Ile:Val-Verhältnis von 100:61:17:106:59:69 für Broiler in der Altersperiode 10. - 20. LT sowie ein ideales Lys:Thr:Trp:Arg:Ile:Val-Verhältnis von 100:65:17:106:65:82 für Broiler in der Altersperiode 25. - 35. LT. Die Ergebnisse bestätigten die schon für Lys:Thr bekannte Altersabhängigkeit. Neue Aspekte ergaben sich jedoch hinsichtlich Ile und Val, bei denen ebenfalls ein altersbedingter Anstieg relativ zum Lys beobachtet wurde.

Unter Mittelwertbildung der beiden Wachstumsversuche ergaben sich folgende Aminosäurenverhältnisse: Lys:Thr:Trp:Arg:Ile:Val von 100:62:18:95:68:72 für Broiler in der Altersperiode 0. - 21. LT und Lys:Thr:Trp:Arg:Ile:Val von 100:73:15:92:73:82 für Broiler in der Altersperiode 21. - 35. LT. 


\section{Summary}

Based on a verified nonlinear N-utilization model (GEBHARDT 1966, SAMADI und LIEBERT 2008), the objective of this investigation was to determine the amino acid efficiency of broiler chicken with regard to the amino acids methionine and cysteine and further to obtain new knowledge about ideal protein concept. N-Balance studies and growth trials with male Ross 308 broiler chicken, respectively, were carried out in two age periods (Starter and Grower). The complexity of this problem required the application of threecompartmental methodological approaches:

Experimental Complex I was designed to establish NMR (nitrogen maintenance requirement) and $\mathrm{NR}_{\max } \mathrm{T}$ (maximum theoretical $\mathrm{N}$ retention capacity).

Experimental Complex II: comparison of methionine efficiency of two different methionine sources (DL-Methionine (DLM) and 2-Hydroxy-4-(methylthio)butyrate (MHA)) and determination of the methionine requirement data

Experimental Complex III: determination of ideal amino acid ratio (lysine, threonine, tryptophan, arginine, isoleucine and valine)

The following results were obtained:

\section{$\underline{\text { NMR and NR }}$ max $\underline{T}$}

NMR was determined to be $295 \mathrm{mg} / \mathrm{BW}_{\mathrm{kg}}{ }^{0,67} / \mathrm{d}$ for Ross 308 broiler chicks (10. - 20. d) and $313 \mathrm{mg} / \mathrm{BW}_{\mathrm{kg}}{ }^{0,67} / \mathrm{d}$ for broiler chicks $(25$ - 35. d). These results were very similar for both age periods. In conclusion, the average of $\mathrm{NMR}=304 \mathrm{mg} / \mathrm{BW}_{\mathrm{kg}}{ }^{0,67}$ per day can be proposed as a "working value" for the NMR within the age periods. As $\mathrm{NR}_{\max } \mathrm{T}, 3991 \mathrm{mg} / \mathrm{BW}_{\mathrm{kg}}{ }^{0,67} / \mathrm{d}(10$. 20. d) and $3110 \mathrm{mg} / \mathrm{BW}_{\mathrm{kg}}{ }^{0,67} / \mathrm{d}(25 .-35$. d) were obtained. It was observed that the genetic potential for protein deposition of chicks was reduced with increasing age.

\section{Methionine efficiency}

Compared to the supplemented groups feed conversion ratio and daily body weight gain were significantly poorer in the basal diet group. Comparing the effects of DLM and MHA it was shown that DLM was superior MHA in each treatment (table 1), except the second supplementation grade in grower period. In this treatment a MHA bioefficiency of 100 was 
observed. The MHA efficiency data varied between $62 \%$ and $100 \%$ and were dependent on Met:Cys ratio and Met/Cys supply. The results of these studies suggest that increasing concentrations of methionine and decreasing concentrations of cysteine in diets with analog methionin level were resulted in decreasing MHA efficiency.

Table 1: Bioefficiency of MHA relative to DLM (100)

\begin{tabular}{lccccc}
\hline Experiment & Age period & $0.1 \%$ Met+Cys & $0.2 \%$ Met+Cys & $0.1 \%$ Met & $0.2 \%$ Met \\
\hline N balance study & $10 .-20 . \mathrm{d}$ & 86 & 76 & 89 & 71 \\
& $25 .-35 . \mathrm{d}$ & 89 & 100 & 93 & 68 \\
Growth trial & $0 .-35 . \mathrm{d}$ & 79 & 81 & 62 & 73 \\
\hline
\end{tabular}

\section{Calculated daily methionine requirement}

The calculated daily methionine requirement referred to a daily protein deposition of $6-10 \mathrm{~g} / \mathrm{d}$ (starter) and $12-20 \mathrm{~g} / \mathrm{d}$ (grower) were in the ranges of:

- 244 - $498 \mathrm{mg} \mathrm{Met} / \mathrm{BW}_{\mathrm{kg}}{ }^{0,67}$ at a methionine efficiency of 157 (starter, 10. - 21. d)

- 230 - $500 \mathrm{mg} \mathrm{Met} / \mathrm{BW}_{\mathrm{kg}}{ }^{0,67}$ at a methionine efficiency of 196 (grower, 25. - 35. d)

Accordingly, a broiler with a mean live weight of $500 \mathrm{~g}$ required a supply of $154-313 \mathrm{mg}$ Met/d (daily protein deposition of $6-10 \mathrm{~g} / \mathrm{d}$ ), and a broiler with a mean live weight of $1800 \mathrm{~g}$ required a supply of $341-742 \mathrm{mg}$ Met/d (daily protein deposition of $12-20 \mathrm{~g} / \mathrm{d}$ ). On the assumption of a daily feed intake of $50 \mathrm{~g}$ or $130 \mathrm{~g}$ the corresponding amino acid concentrations in the diet amounted to $0.26-0.57 \%$ methionine or to $0.31-0.63 \%$ methionine. The methionine requirement data confirmed a dependence on the Met:Cys ratio and Cys supply.

\section{Estimation of ideal amino acid ratio}

$\mathrm{N}$ balance studies and growth trials were carried out to evaluate ideal amino acid ratios. Derived from three $\mathrm{N}$ balance experiments, summarized ideal amino acid ratios were Lys:Thr:Trp:Arg:Ile:VAL = 100:61:17:106:59:69 for broiler $(10 .-20$. d) and Lys:Thr:Trp:Arg:Ile:VAL = 100:65:17:106:65:82 for broiler (25. - 35. d). The results confirmed the age dependent increase of Lys:Thr ratio. However, an age dependent increase of Lys: Ile and Lys:Val were also observed. The pattern of summarized amino acid ratios of the two growth trials, was as follows: Lys:Thr:Trp:Arg:Ile:VAL = 100:62:18:95:68:72 for broiler (10. - 20. day of age ) and Lys:Thr:Trp:Arg:Ile:VAL = 100:73:15:92:73:82 for broiler (25. - 35. day of age). 


\section{Literaturverzeichnis}

AHMAD, T. 2008. Dietary methionine requirement and availability for broiler chickens through indicator amino acid technique. Post-doctoral research programme. Department of Agricultural, Food and Nutritional Science University of Alberta.

AHMADI, H., A. GOLIAN. 2010. The integration of broiler chicken threonine responses data into neural network models. Poultry Sci. 89:2535-2541.

AJANG, O. A., S. PRIJONO, W. K. SMITH. 1993. Effect of dietary protein content on growth und body composition of fast und slow feathering broiler chickens. Br. Poultry Sci. 34:73-91.

ALMQUIST, H.J., C.R. GRAU. 1944. The amino acid requirements of the Chick. J. Nutrition. 28:325-331.

AUSTIC, R.E. 1994. Update on amino acid requirements and ratios for broiler. Proceedings of Maryland Nutrition Conference, College Park, M.D. 114-130.

AYASAN, T., F. OKAN, H. HIZLI. 2009. Threonine Requirement of Broiler from 22-42 Days. International Journal of Poultry Sci. 8: 862-865.

BAE, S.H., J.H. KIM, I.S. SHIN, I.K. HAN. 1999. Partition of amino acid requirements of broilers between maintenance and growth. 4. Threonine and glycine. Asian-Aust. J. Anim. Sci. 12: 381-387.

BAKER, D.H. 1995. Amino acid utilisation in swine and poultry. in Annual Biokyowa meeting. Toronto, Canada. 1-25.

BAKER, D.H. 1997. Ideal amino acid profiles for swine and poultry and their application in feed formulation. Biokyowa Technol. Rev.9: 1-24.

BAKER, D.H. 2003. Ideal amino patterns for broiler chicks. 223-236. in amino acids in Animal Nutrition, ed. D`Mello, J.P.F. CABI Publ. Wallingford. Oxon. UK.

BAKER, D.H., A.B. BATAL, T.M. PARR, N.R. AUGSPURGER, C.M. PARSONS. 2002. Ideal ratio (relative to lysine) of tryptophan, threonine, isoleucine and valine for chicks during the second and third week of life. Poultry Sci. 81: 485-494.

BAKER, D.H., K.P. BOEBEL. 1980. Utilisation of the D- and L- isomers of methionine and methionine hydroxy analogue as determined by chick bioassay. Journal of Nutrition. 110: 959-964.

BAKER, D.H., S.R. FERNANDEZ, D.M. WEBEL, C.M. PARSONS. 1996. Sulfur amino acid requirement and cystine replacement value of broiler chicks during the period 
three to six weeks posthatching. Poultry Sci. 75:737-742.

BAKER, D.H., Y. HAN. 1994. Ideal amino acid profile for chicks during the first three weeks posthatching. Poultry Science 73: 1441-1447.

BAKER, D.H., C.M. PARSONS, S. FERNANDEZ, S. AOYAGI, Y. HAN. 1993. Digestible amino acid requirements of broiler based upon ideal protein considerations. 22-32. in Proceedings of the Arkansas Nutrition Conference, Fayetteville, AR.

BAKER, D.H., K.R. ROBBINS, J.S. BUCK. 1979. Modification of the level of histidine and sodium bicarbonate in the Illinois crystalline amino acid diet. Poultry Sci. 58:749750.

BARBATO, G.F. 1992. Genetic architecture of carcass composition in chickens. Poultry Sci. 71:789-798.

BARBOUR, G., J.D. LATSHAW. 1992. Isoleucine requirement of broiler chicks as affected by the concentrations of leucine and valine in practical diets. Br. Poultry Sci. 33:561-568.

BARBUL, A., S.A. LAZAROU, D.T. EFRON, H.L. WASSERKRUG, G. EFRON. 1990. Arginine enhances wound healing and lymphocytes immune responses in humans. Surgery. 108:331-337.

BARBUL, A., H.L. WASSERKRUG, E. SEIFTER, G. RETTURA, S. M. LEVENSON, G. EFRON. 1980. Immunostimulatory effects of arginine in normal and injured rats. J. Surg. Res. 29:228-235.

BATEMAN, A., Z. LIU, D.A. ROLAND. 2005. Bioefficacy determination of Methionine hydroxy analog-free acid relative to DL-Methionine in Laying hen diets with limited methionine using different regression models. International J. of Poultry Sci. 4(9) $628-623$

BENEVENGA, N.J., M.J. GAHL, K.P. BLEMINGES.1993. Role of Protein synthesis in amino acid catabolism. J. Nutrition. 123:332-336.

BERTALANFFY, L.V. 1951. Stoffwechsel und Wachstum. in Theoretische Biologie. Band 2, Verlag A. Francke, Bern.

BERTRAM, H.L., J. SCHUTTE, E. VAN WEERDEN. 1989. Threonine requirement of young broilers. Arch. Geflügelk. 53:25-26.

BMELV. 2009. Bundesministerium für Ernährung, Landwirtschaft und Verbraucherschutz. Stat. Monatsberichte, Ref. 616. EU-Kommission.

BOEBEL, K.P., D.H. BAKER. 1982. Efficacy of calcium salt and free acid forms of methionine hydroxy analog for chicks. Poultry Sci. 61:1167-1175. 
BOORMAN, K.N., A.D. BURGESS. 1986. Responses to amino acids. in Fischer, C., K. N Boorman (Ed). Nutrient requirements of poultry and nutritional research. Butterworths. London. 99-123.

BOORMAN, A., T.R. WOOD, H.C. BALCK, E.G. ANDERSON, M.J. OESTERLING, M. WOMACK, W.C. ROSE. 1946. The role of arginine in growth with some observations on the effects of arginic acid. J. Biol. Chem. 166:585-594.

BREGENDAHL, K. 2008. Amino acid nutrition of modern laying hens. Proceedings of the 6th Mid-Atlantic Nutrition Conference.

BREGENDAHL, K., S.A.ROBERTS, B.KERR, D. HOEHLER. 2008. Ideal ratios of isoleucine, methionine, methionine plus cysteine, threonine, tryptophan, and valine relative to lysine for white leghorn-type laying hens of twenty-eight to thirty-four weeks of age. Poultry Sci. 87:744-758.

BUNCHASAK, C. 2009. Role of dietary methionine in poultry production. Japan Poultry Sci. Association. 46:169-179.

BUNCHASAK, C., N. KEAWARUN. 2006. Effect of methionine hydroxy analog-free acid on growth performance and chemical composition of liver of broiler chicks fed a corn-soybean based diet from 0 to 6 weeks of age. Animal Sci. Journal. 77: 95-102.

BUNCHASAK, C., T. SOOKSRIDANG, R. CHAIYAPIT. 2006. Effect of adding methionine hydroxyl analogue as methionine source at the commercial requirement recommendation on production performance and evidence of ascites syndrome of male broiler chicks fed corn-soybean based. International Journal of Poultry Sci. 5:744-752.

CHAMRUSPOLLERT, M., G.M. PESTI, R.I. BAKALLI. 2001. The influence of labile dietary methyl donors on the arginine requirement of young broiler chicks. Poultry Sci. 81:1142-1148.

CHAMRUSPOLlERT, M., G.M. PESTI, R.I. BAKALI. 2002. Determination of the methionine requirement of male and female broiler chicks using an indirect amino acid oxidation method. Poultry Sci. 81:1004-1013.

CHAMRUSPOLLERT, G., M. PESTI, R.I. BAKALLI. 2004a. Influence of temperature on the arginine and methionine requirements of young broiler chick. J. Appl. Poultry Res. 13:628-638.

CHAMRUSPOLLERT, G., M. PESTI, R. I. BAKALLI. 2004b. Chick responses to dietary arginine and methionine levels a different environmental temperature. Br. Poultry 45:93-100. 
CHRISTENSEN, A.C., J.O. ANDERSON. 1980. Factors affecting efficacy of methionine hydroxy analogue for chicks fed practical diets. Poultry Sci. 59:2485-2491.

CHUNG, T.K., D.H. BAKER. 1992. Ideal amino acid pattern for ten kilogram pigs. J. Anim. Sci. 70:3102-3111.

CHUNG E., P. GRIMINGER, H. FISCHER. 1973. The Lysine und Amino Acid Requirements at two Stages of Growth in Chicks. J. Nutr. 103:117-122

ÇIFTCI, I., N. CEYLAN. 2004. Effects of dietary threonine und crude protein on growth performance, carcass und meat composition of broiler chickens. Br. Poultry Sci. 45:280-289.

COLUMBUS, A. 1951. Die Variabilität der biologischen Eiweißwerigkeit unter verschiedenen Bedingungen, nach Stoffwechselversuchen an wachsenden Schweinen. Arch. Tierernährung. 1:84-128.

COON, C. 2004. The ideal amino acid requirement and profile for broilers layers, and broiler breeders. Technical Information of American Soybean Association. FE 153.

CORZO, A., M.T. KIDD. 2003. Arginin needs of chick and growing broiler. Interna. Journal of Poultry Sci. 2 (6):379-382.

CORZO, A., M.T. KIDD, M.D. KOTER, S.C. BURGESS. 2005. Assessment of dietary amino acid scarcity on growth and blood plasma proteome status of broiler chickens. Poultry Sci. 84:419-425.

CORZO, A., M.T. KIDD, G.T. PHARR, W.A. DOZIER, III, E.A. KOUTSOS. 2006. Immune and growth responses to dietary L-threonine of broilers raised in different litter conditions. Poultry Sci. 85(Suppl. 1):32. (Abstr.).

CORZO, A., M.T. KIDD, W.A. DOZIER III, G.T. PHARR, and E.A. KOUTSOS. 2007. Dietary threonine needs for growth and immunity of broilers raised under different litter conditions. J. Appl. Poultry Res. 13:593- 604.

CRESWELL, D., A.R. SWICK. 2001. Formulating with digestible amino acids. Part two. Asian Poultry Magazine. March/ April.

CVB. 1996. Aminozurenbehoefte van leghennen en leeskuikens. CVB-docomentatierapport nr. 18. Central Veevoederbureau, Lelyestad, The Netherlands.

D`MELLO, J.P.F., D. LEWIS. 1970a. Amino acid interaction in chick nutrition. 1. Interrelationship between lysine and agrinine. Br. Poultry Sci. 11:299-311.

D'MELLO, J.P.F., D. LEWIS. 1970b. Amino acid interaction in chick nutrition. 2. Interrelationship between leucine, isoleucine and valine. Br. Poultry Sci. 11:313323. 
D'MELLO, J.P.F. 1982. A comparison of two empirical methods of determining amino acid requirements. World`s Poultry Sci. J. 38:114-119.

D’MELLO, J.P.F. 1994a. Responses of growing poultry to amino acids. In: Amino acids in farm animal nutrition. CAB International, Wallingford, UK.

D'MELLO, J.P.F.1994b. Amino acid imbalances, antagonism and toxicities. in Amino acids in farm animal nutrition. CAB International, Wallingford, UK.

D'Mello, J.P.F. 2003. Amino acids in animal nutrition. CAB International; 2nd ed. Wallingford, UK.

DÄNICKE, S. 1993. Modellierung des Wachstums männlicher Broiler auf der Grundlage der Verwertungsgesetzmäßigkeiten des N-Stoffwechsels unter besonderer Berücksichtigung der Proteinqualität und des Konzeptes der Wirksamen Aminosäure. Dissertation, Martin-Luther-Universität Halle-Wittenberg.

DÄNICKE, S., H. JEROCH, W. KRACHT. 1998. Untersuchungen zum Einfluss eines thermischen Behandlungsverfahrens von Rapssaat auf die Proteinqualität für Broiler. Arch. Geflügelk. 62:163-168.

DÄNNER, E., W. BESSEI. 2003. Influence of supplementation with liquid DL-methionine hydroxy analogue-fee acid (Alimet) or DL-methionine on performance of broilers. J. Appl. Poultry Res. 12:101-105.

DE lA HIGUERA, M., A. GARZÓN, M.C. HIDAlGO, J. PERAGÓN, G. CARDENETE, J.A. LUPIÁÑEZ. 1998. Influence of temperature and dietary-protein supplementation either with free or coated lysine on the fractional protein-turnover rates in the white muscle of carp. Fish Physiol. Biochem. 18:85-95.

DEAN, W.F., H.M. SCOTT. 1965. The development of amino acid reference diet for the early growth of chicks. Poultry Sci. 44:803-808.

DEGUSSA. 2003. Amino acids recommendations for poultry. Degussa AG. Feed Additives Division. Frankfurt a. M. Germany.

DIBNER, J.J., F.J. IVEY. 1992. Capacity of the liver of the broiler chick for conversation of supplemental methionine activity to L-methionine. Poultry Sci. 71:700-708.

DIBNER, J.J., C.D. KNIGHT. 1984. Conversion of 2-hydroxy-4-(methylthio)butanoic acid to L-methionine in the chick: Astereospecific pathway. J. Nutr. 114:1716-1723.

DILGER, R.N., D.H. BAKER. 2008. Cyst(e)ine imbalance and its effect on methionine precursor utilisation in chicks. J. Anim. Sci. 86:1832-1840.

DOZIER, W. A., A. CORZO, M. T. KIDD, P. B. TILlMAN, S. L. BRANTON. 2009. Digestible lysine requirements of male and female broilers from fourteen to twenty- 
eight days of age. Poultry Sci. 88:1676-1682.

DREW, M.D., A.G. VAN KESSEL, D.D. MAENZ. 2003. Absorption of methionine and 2hydroxy-4-methylthiobutoanic acid in conventional and germ-free chickens. Poultry Sci. 82:1149- 1153.

EDWARDS, H.M. III, D.H. BAKER. 1999. Maintenance sulfur amino acid requirements of young chicks und efficiency of their use for accretion of whole body sulfur amino acids und protein. Poultry Science 78:1418-1423.

EDWARDS, H.M. III, D.H. BAKER, S.R. FERNANDEZ, C.M. PARSONS. 1997. Maintenance threonine requirement and efficiency of its use for accretion of wholebody threonine and protein in young chicks. Br. J. Nutr. 78:111-119.

EDWARDS, H.M. III, S.R. FERNANDEZ, D.H. BAKER. 1999. Maintenance lysine requirement und efficiency of using lysine for accretion of whole-body lysine und protein in young chicks. Poultry Science 78:1412-1417.

EDWARDS, H.M. III, S.R. FERNANDEG, C.M. PARSONS, D.H. BAKER. 1996. Maintenance lysine and threonine requirements of young chicks and efficiency of their utilization above maintenance. Poultry Sci. 75(Suppl):86.

EMMERT, J.L., H.M. EDWARDS III, D.H. BAKER. 2000. Protein and body weight accretion of chicks on diets with widely varying contents of soybean meal supplemented with its limiting amino acids. Br. Poultry Sci. 41: 204-213.

ESTEVE-GARCIA, E., R.E. AUSTIC. 1993. Performance, breast meat yield and abdominal fat deposition of male broiler chickens fed diets supplemented with DL-methionine or DL-methionine hydroxy analogue free acid. British Poultry Sci. 34:351-359.

FARRAN, M.T., O.P. THOMAS.1990. Dietary requirements of leucine, isoleucine and valine in male broilers during the starter period. Poultry Sci. 69: 757-762.

FATUFE, A.A., R. TIMMLER, M. RODEHUTSCORD. 2004. Response to lysine intake in composition of body weight gain und efficiency of lysine utilization of growing male chickens from two genotypes. Poultry Sci. 83:1314-1324.

FEATHERSTON, W.R., G.W. HORN. 1974. Studies on the utilisation of the alpha-hydroxy acid of methionine by chicks fed crystalline amino acid diets. Poultry Sci. 53:680686.

FINKELSTEIN, J.D., S.H. MUDD. 1967. Trans-sulfuration in Mammals. The methioninesparing effect of cystine. The J. Biol. Chem. Vol. 242:873-880.

FISCHER, C. 1998. Amino acid requirement of broiler breeders. Poultry Sci. 77:124-133.

FISCHER, H. 1972. Methods of protein evaluation: chick and other assays. Proc. Conf. The 
Chemistry, Biology und Physics of Protein evaluation. in Chung E., P. GRIMINGER, H. FISCHER. 1973. The lysine and amino acid requirements at two stages of growth in Chicks. J. Nutr. 103:117-122.

FLOCH, N. L.E., B. SEVE, Y. HENRY. 1993. Threonine dehydrogenase in growing pigs fed on threonine-deficient diets: effect of glutamic acid or protein addition. Proc. Nutr. Soc. . 52:171a.

FREEMAN, C. P. 1979. The tryptophan requirement of broiler chicks. Br. Poultry Sci. 20:2737.

FUKAGAWA, N.K. 2006. Sparing of methionine requirements: Evaluation of human data takes sulfur amino acids beyond protein. 5th amino acid assessment workshop. AMERICAN Society of Nutr. 1676S.

FULLER, M.F. 1994. Amino acid requirements for maintenance, body protein accretion and reproduction in pigs. In: Amino Acids in Farm Animal Nutrition (D’Mello, J.P.F., ed.), pp. 155-184. CAB Intl. Wallingford. Oxon. UK.

GEBHARDT, G. 1963. Die Bewertung des Futtereiweißes nach dem N-Bilanzverfahren an wachsenden Tieren. Habil.-Schrift., Martin-Luther-Universität Halle-Wittenberg.

GEBHARDT, G. 1966. Die Bewertung der Eiweißqualität von Nahrungs- und Futtermitteln mit Hilfe des N-Bilanzversuches. In: Hock, A.: Vergleichende Ernährungslehre des Menschen und seiner Haustiere. Gustav Fischer Verlag Jena, 323-348.

GEBHARDT, G. 1980. Eiweiß- und Aminosäureverwertung in Beziehung zum Stoffwechsel der limitierenden Aminosäure. Archiv für Tierernährung, 30:63-71.

GEBHARDT, G. 1988. Tierernährung. VEB. Deutscher Landwirtschaftsverlag Berlin.

GEBHARDT, G., F. LIEBERT, C. WECKE. 1977. Der leistungsabhängige Aminosäurenbedarf bei wachsenden Monogastiern. in: Karl-Marx-Universität Leipzig (Hrsg.): 125 Jahre Lehr- und Versuchsstation Leipzig-Möckern. Int. Tagung. 20. - 21. September. Leipzig, 107-125.

GFE - Ausschuss für Bedarfsnormen der Gesellschaft für Ernährungsphysiologie. 1999. Empfehlungen zur Energie- und Nährstoffversorgung der Legehennen und Masthühner (Broiler). DLGVerlags-GmbH, Frankfurt am Main.

GORDON, R.S., I.W. SIZER. 1965. Conversation of methionine hydroxy analog to methionine in chick. Poultry Sci. 44:673-678.

GOUS, R.M. 1998. Making progress in the nutrition of broilers. Poultry Sci. 77:111-117.

GOUS, R.M., T.R. MORRIS. 1985. Evaluation of diet dilution technique for measuring the response of broiler chickens to increasing concentrations of lysine. Br. Poultry Sci. 
26. $147-161$.

GRABER, G., D.H. BAKER. 1971. Sulfur amino acid nutrition of the growing chick: quantitative aspects concerning the efficacy of dietary methionine, cysteine and cystine. J. Anim. Sci. 33:1005-1011.

GRABER, G., D.H. BAKER. 1973. The essential nature of glycine and proline for growing chicks. Poultry Sci. 52:892-896.

GRABER, G., H.M. SCOTT, D.H. BAKER. 1971. Sulfur amino acid nutrition of the growing chick: effect of age on the capacity of cystine to spare dietary methionine. Poultry Sci. 50:1450-1455.

GRISONI, M.L., G. UZU, M. LARBIER, P.A. GERAET. 1991. Effect of dietary lysine level on lipogenesis in broiler. Reprod. Nutr. Dev. 31:683-690.

GRUBER, K., ROTH, F. X., M. KIRCHGESSNER. 1999. Das ideale Verhältnis von Aminosäuren im Broilerfutter. in: GfE. 1999. Empfehlungen zur Energie- und Nährstoffversorgung der Legehennen und Masthühner (Broiler). DLGVerlagsGmbH, Frankfurt am Main.

HALLE I., H. JEROCH, T. PAHLE, G. GEBHARDT. 1984. Zum Stickstofferhaltungsbedarf der Broilerelterntier-Legehenne. Archives of Animal Nutrition, 34:57 - 64.

HAN, Y., D.H. BAKER. 1991. Lysine requirement of fast and slow growing broiler chicks. Poultry Science. 70: 2108-2114.

HAN, Y. D.H. BAKER. 1993. Effects of excess methionine or lysine for broilers fed a cornsoybean meal diet. Poultry Sci. 72:1070-1074.

HAN, Y., D.H. BAKER. 1994. Digestible lysine requirement of male and female broiler chicks during period three to six weeks posthatching. Poultry Sci. 73:1739-1745.

HAN, Y., F. CASTANON, C.M. PARSON, D.H. BAKER. 1990. Absorption und bioavailability of DL-methionine hydroxy analog compared to DL-methionine. Poultry Sci. 69:281-287.

HARMS, R.H. A.R. ELDRED, B.L. DAMRON. 1976. The relative efficiency of DLmethionine and methionine hydroxy analogue-calcium (MHAC) in broiler diets. Poultry Sci. 55:1794-1797.

HARPER, A.E., N.J. BENEVENGA, R.M. WOHLHUETER. 1970. Effects of ingestion of disproportionate amounts of amino acids. Physiol. Rev. 50:428-558.

HARTER, J.M., D.H. BAKER. 1977. Sulfur amino acid activity of glutathione, DL-alphahydroxy-methionine, and alpha-keto-methionine in chicks. Proc. Soc. Exp. Biol. Med. 156:201-204. 
HEIMANN, W. 1976. Grundzüge der Lebensmittelchemie. Dr. Dietrich Steinkopff Verlag Darmstadt. 1976).

HOEHLER, D., D.M. HOOGE, 2003. Relative effectiveness of methionine sources in turkeys scientific and new commercial data. Int. J. Poultry Sci., 2:361-366.

HOEHLER, D., A. LEMME. 2005. Using SID. Feed International. November/ December

HOEHLER, D., A. LEMME, K. ROBERSON, K. TURNER. 2005. Impact of methionine sources on performance in turkeys. Journal of Applied Poultry Research 14:296305.

HOFFMANN, M. 1971. Die Stickstoffretention als Grundlage der Proteinbewertung und leistungsabhängiger Protein- und Aminosäurenbedarfsangaben für wachsendes Geflügel. Habil. Schrift. Karl-Marx-Universität Leipzig.

HOFFMANN, M., G. GEBHARDT. 1973. Die Ermittlung leistungsabhängiger Rohproteinund Aminosäurenangaben für Broiler auf der Grundlage der Stickstoffretention. Wiss. Z. Univ. Leipzig, Math-nat. wiss. R. 22:245-255.

HOFFMANN, L., M. KLEIN, R. SCHIEMANN. 1982. Untersuchungen zum Energieerhaltungsbedarf für den Proteinansatz an wachsenden Ratten und Broilern 4. Mitteilung Untersuchung zum Energiebedarf für den Proteinansatz in Broilern. Arch. Tierernährung. 32:513-530.

HURWITZ, S., D. SKLAN, I. BARTOV. 1978. New formal approaches to the determination of energy and amino acid requirements of chicks. Poultry Sci. 57:197-205.

HURWITZ, S., M. WEISELBERG, U. EISNER, I. BARTOV, M. REISENFELD, A. SHARVIT, S. BORNSTEIN. 1980. The energy requirements and performance of growing chickens and turkeys as affected by environmental temperature. Poultry Sci. 59:2290-2299.

HUYGHEBAERT, G. 1993. Comparison of DL-methionine and methionine hydroxyl analogue-free acid in broilers by using multi-exponential regression models. $\mathrm{Br}$. Poultry Sci. 34:351-359.

HUYGHEBAERT, G., M. PACK, G. DE GROOTE. 1994. Influence of protein concentration on the response of broilers to supplemental DL-methionine. Arch. Geflügelk. 58:2329.

HUYGHEBAERT, G., M. PACK. 1996. Effects of dietary protein content, addition of nonessential amino acid and dietary methionine to cysteine balance on responses to dietary sulphur-containing amino acid in broilers. Br. Poultry Sci. 37:623-639.

ISHIBASHI, T., M. KAMETAKA. 1985. Methionine requirements of chicken with various 
body weights. Agric. Biol. Chem. 49:3493-3500.

ISHIBASHI, T., Y. OHTA. 1999. Recent advances in amino acid nutrition for efficient poultry production. Review. Asian-Aust. J. Anim. Sci. 12: 1298-1309.

JAIS, C., F.X. ROTH, M. KIRCHGEBNER. 1995. Die Bestimmung des optimalen Verhältnisses zwischen den essenziellen Aminosäuren im Futter der Legehenne. Archiv für Geflügelkunde 59:292-302.

JANSMAN, A.J. M., C.A. KAN, J. WIEBENGA. 2003. Comparison of the biological efficacy of DL-methionine and hydroxyl-4- methylthiobutanoic acid (HMB) in pigs and poultry. Report no. 2209. ID-Lelystad. Anim. Sci. Group, Wageninger Univ. Res. Cent., The Netherlands.

JENSEN, L.S., C.L. WYATT, B.I. FRANCER. 1989. Sulphur amino acid requirement of broiler chickens from 3 to 6 weeks of age. Poultry Sci. 68:163-168.

JEROCH, H., S. GRAMZOW, S. DÄNICKE. 2004. Wachstum, Tierkörperzusammensetzung und chemische Zusammensetzung von weiblichen Puten der Herkunft BUT Big 6. in Jeroch, H. 2004. Bedarf und Versorgung von schweren Mastputen mit Rohprotein und Aminosäuren. Lohmann Information Okt.-Dez.

KALINOWSKI, A., E.T. MORAN, Jr., C.L. WYATT. 2003a. Methionine and cystine requirements of slow- and fast-feathering male broilers from zero to three weeks of age. Poultry Sci. 82:1423-1427.

KALINOWSKI, A., E.T. MORAN, Jr., C.L. WYATT. 2003b. Methionine and cysteine requirements of slow and fast feathering broiler males from three to six weeks of age. Poultry Sci. 82:1428-1437.

KANG, C.W., M. L. SUNDE, R.W. SWICK. 1985. Growth und protein turnover in the skeletal muscles of broiler chicks. Poultry Sci. 64:370-379.

KATZ, R.S., D.H. BAKER. 1975. Factors associated with utilization of the calcium salt of methionine hydroxy analogue by the young chick. Poultry Sci. 54: 584-591.

KAUSHIK, S.J., T. DOUDET, F. MÉDALE, P. AGUIRRE, D. BLANC. 1995. Protein and energy needs for maintenance and growth of Nile tilapia (Oreochromis niloticus). J. Appl. Ichthyol. 11:290-296.

KESHARVARZ. K., H.L. FULLER. 1971. Relationship of arginine and methionine in the nutrition of the chicks and the significant of creatine biosynthesis in their interaction. J. Nutr. 101:217-222.

KESHAVARZ, K., 1997. Investigations on the use of low-protein, amino acid-supplemented diets for poultry. Pages 155-166 in Proceedings Cornell Nutrition Conference for 
Feed Manufacturers, Rochester, NY.

KIDD, M.T. 2000. Nutritional consideration concerning threonine in broilers. World`s Poultry Sci. J. 56:139-151.

KIDD, M.T., A. CORZO, D. HOEHLER, B.J. KERR, S.J. BARBER, S.L. BRANTON. 2004.

Threonine needs of broiler chickens with different growth rates. Poultry Sci.

83:1368-1375.

KIDD, M.T., P.D. GERALD, J. HEGER, B. J. KERR. D. ROWE, K. SISTANI, D.J. BURNHAM. 2001. Threonine and crude protein responses in broiler chicks. Animal Feed Sci. and Techn. 94:57-64.

KIDD, M.T., B.J. KERR. 1996. L-threonine for poultry: A review. J. Appl. Poultry Res. $5: 358-367$.

KIDD, M.T., B.J. KERR. 1998. Dietary arginine and lysine ratios in large white Toms. Lack of interaction between arginine:lysine ratios and electrolyte balance. Poultry Sci. 77:864-869.

KIDD, M.T., B.J. KERR, J.P. ALLARD, S.K. RAO, J.T. HALLEY. 2000. Limiting amino acid responses in commercial broilers. J. Appl. Poultry Res. 9:223-233.

KIDD, M.T., B.J. KERR, N.B. ANTHONY. 1997. Dietary interactions between lysine and threonine in broilers. Poultry Sci. 76:608-614.

KIM, B.G., M.D. LINDEMANN, M. RADEMACHER, J.J. BRENNAN, G.L. CROMELL. 2006. Efficacy of DL-methionine hydroxy analog free acid and DL-methionine as methionine sources for pigs. J. Anim. Sci. 84:104-111.

KIRCHGESSNER, M., J. GERUM, D.A. ROTH-MAIER. 1978a. Zum Verwertung von Stickstoff und Energie bei 3-5 Wochen alten Mastküken mit unterschiedlichen Energie- und Eiweißgehalten im Futter. Arch. Geflügelk. 42:106-114.

KIRCHGESSNER, M., J. GERUM, D.A. ROTH-MAIER. 1978b. Zum energetischen Teilwirkungsgrad 2 Wochen alter Broiler mit unterschiedlicher Energie - und Eiweißversorgung. Arch. Geflügelk. 42:106-114.

KIRCHGESSNER, M., C. JAIS, F.X. ROTH. 1995. Das ideale Verhältnis zwischen Lysin, Methionin, Threonin, Tryptophan, Isoleucin und Arginin im Legehennenfutter. Journal of Animal Physiology and Animal Nutrition 73:190-201.

KIRCHGESSNER, M., O. VORECK. 1980. Zur Umsetzbarkeit der Futterenergie bei der Legehenne in Abhängigkeit von der Energie- und Proteinversorgung. Arch. Geflügelk. 44:61-66.

KLAIN, G.J., H.M. SCOTT, B.C. JOHNSON. 1960. The amino acid requirement of the 
growing chick fed a crystalline amino acid diet. Poultry Sci. 39:39-44.

KNIGHT D.C., C.A. ATWELL, C.W. WUELling, F.J. IVEY, J.J. DIBNER. 1998. The relative effectiveness of 2-hydroxy-4-(methylthio)butanoic acid and dl-methionine in young swine. Journal of Animal Science 76:781-787.

KNIGHT, C.D., J.J. DIBNER. 1984. Comparative absorption of 2-hydroxy-4(methylthio)butanoic acid and L-methionine in the broiler chick. J. Nutr. 114:21792186.

KÖHLER, R., M. HOFFMANN, G. GEBHARDT. 1970. Endogene Stickstoffausscheidung bei Broilern nach Verabreichung von $15 \mathrm{~N}$ markierten Kasein. Arch. Tierernährung 20:657-665.

KÖHLER, R., T. PAHLE, K. GRUHN, R. ZANDER, H. JEROCH, G. GEBHARDT. 1988. Zur Bestimmung von Proteinsyntheseraten des Gesamtkörpers wachsender Broiler. Arch. Anim. Nutr. 38:565-572.

LABADAN, M.C. Jr., K.N. HSU. R.E. AUSTIC. 2001. Lysine and arginine requirements of broiler chickens at two- to three week intervals to eight weeks of age. Poultry Sci. 80:599-606.

LARBIER, M., B. LECLERCQ. 1994. Nutrition and feeding of poultry. Übersetzt und herausgegeben von Wieseman, J. Nottingham University Press, Loughborough.

LECLERCQ, B. 1998. Specific effects of lysine on broiler production: comparison with threonine and valine. Poultry Sci. 77:118-123.

LECLERCQ. A. M., CHAQNEAU, T. COCHARD, S. HAMAOUI, M. LARBIERE. 1993. Comparative utilisation of sulphur-containing amino acids by genetically lean or fat chickens. Brit. Poultry Sci. 34:383-391.

LEESON, S., J. D. SUMMERS. 2001. Pages 100-175 in Nutrition of the Chicken. 4th ed. University Books, Guelph, Canada.

LEESON, S., T. WALSH. 2004. Feathering in commercial poultry I. Feather growth and composition. World`s Poultry Science Journal 60: März 2004.

LEITGEB, R., M. TSCHISCHEJ, F. HUTTERER, J. BARTELT. 2003. Einfluss der Rohproteinabsenkung und Arginin- und Valinergänzung im Alleinfutter auf die Mast- und Schlachtleistung von Masthühnern. Die Bodenkultur 54:187-193.

LEL. 2009. Landesanstalt für Entwicklung der Landwirtschaft und der Ländlichen Räume, Schwäbisch Gmünd. Agrarmärkte Jahresheft 2009.

LEMME, A. 2002. Comparing methionine sources - the physiological background. Poultry International. August. 
LEMME, A., D. HOEHLER, J.J. BRENNAN, P.F. MANNION. 2002. Relative effectiveness of methionine hydroxy analog compared to DL-methionine in broiler chickens. Poultry Sci. 81:838-845.

LIEBERT, F. 1978. Untersuchungen zur Verwertung von Stickstoff und limitierender Aminosäure sowie zu Methoden für die Bestimmung der limitierenden Aminosäure beim Broilerküken. Diss. (Promotion A), Karl-Marx-Universität Leipzig.

LIEBERT, F. 1995a. Methodische Untersuchungen zur Beurteilung von Lysinverwertungskennzahlen von Schweinen nach extremen Veränderungen von Proteinmenge und -zusammensetzung. Arch. Anim. Nutr. 48:319-327.

LIEBERT, F. 1995b. Untersuchungsergebnisse zur Lysinverwertung bei wachsenden Monogastriden unter besonderer Beachtung unterschiedlicher Lysinquellen. Arch. Anim. Nutr. 47:373-380.

LIEBERT, F., K. BENKENDORFF. 2007. Modeling lysine requirements of Oreochromis niloticus due to principles of the dilution technique. Aquaculture 267: 100-110.

LIEBERT, F., G. GEBHARDT. 1986. Ergebnisse zur Wirksamkeit und zum Bedarf an ausgewählten Aminosäuren beim wachsenden weiblichen Schwein. 1. Mitteilung: Lysin. Archives of Animal Nutrition. 36:1077-1086.

LIEBERT, F., G. GEBHARDT. 1980. Beziehung zwischen Lysinkonzentration und Kenndaten der Eiweiß- und Aminosäurenverwertung beim Broilerküken. Archives of Animal Nutrition 30:469-478.

LIEBERT, F., G. GEBHARDT. 1988a. Ergebnisse zur Wirksamkeit und zum Bedarf an ausgewählten Aminosäuren beim wachsenden weiblichen Schwein. 5. Mitteilung: Kombination von Proteinträgern zur Ableitung der Lysinwirksamkeit mit Hilfe des Differenzverfahrens. Archives of Animal Nutrition, 38:27-36.

LIEBERT, F., G. GEBHARDT. 1988b. Ergebnisse zur Wirksamkeit und zum Bedarf an ausgewählten Aminosäuren beim wachsenden weiblichen Schwein. 6. Mitteilung: Zusammenfassende Diskussion und Wertung sowie Anwendungsempfehlungen zur vorgestellten Methode. Archives of Animal Nutrition. 38:453-462.

LIEBERT, F., H. LE KHAC, G. GEBHARDT. 1987. Ergebnisse zur Wirksamkeit und zum Bedarf an ausgewählten Aminosäuren beim wachsendenweiblichen Schein. 4. Mitteilung: Kombinationen von Proteinträgern mit Lysin-, Methionin/Zystin- bzw. Threoninlimitanz. Arch. Anim. Nutr. 37:559-568.

LIEBERT, F., A. SÜNDER, K. MOHAMED. 2006. Assessment of nitrogen maintenance requirement and potential for protein deposition in juvenile Tilapia genotypes by 
application of an exponential nitrogen utilisation model. Aquaculture. 261:13461355.

LIEBERT, F., C. WECKE. 2010. Nitrogen losses per unit of nitrogen deposition as derived from modelling of protein utilisation depending on dietary quality parameters and age of growing barrows. $3^{\text {rd }}$ EAA International Symposium on Energy and Protein Metabolism and Nutrition. EAAP publ. No. 127: 443-444.

LIN, Y.F., A. HSU. 1994. Tryptophan requirement of country chicks in Taiwan. J. Chinese Society of Animal Sci. 23:121-126.

LINGENS, G., S. MOLNAR. 1996. Studies on metabolism of broilers by using ${ }^{14} \mathrm{C}$-labled DL-methionine and DL-methionine hydroxy analogue Ca-salt. Arch. Anim. Nutr. 49:113-124.

LITTEL, R.C., P.R. HENRY, A.J. Lewis, C.B. AMMERMAN. 1997. Estimation of relative bioavailability of nutrients using SAS procedures. J. Anim. Sci. 75:2672-2683.

LIU, Z., A. BATEMAN, M. BRYANT, A. ABEBE, D. ROLAND. 2004. Estimation of bioavailability of DL-methionine hydroxy analogue relative to DL-methionine in layers with exponential and slope ratio models. Poultry Sci. 83:1580-1586.

MACHLIN, L. J., R. S. GORDON. 1959. Equivalence of methionine hydroxy analog and methionine for chickens fed low protein diets. Poultry Sci. 38:650-652.

MACK, S., D. BERCOVICI, G. DEGROOTE, B. LECLERCQ, M. LIPPENS, M. PACK, J. B. SCHUTTE, S. VAN CAUWENBERGHE. 1999. Ideal amino acid profile and dietary lysine specification for broiler chicks of 20 to 40 days of age. Br. Poultry Sci. 40:257-265.

MAENZ, D.D., C.M. ENGELE-SCHAAN. 1996. Methionine and 2-Hydroxy-4Methylthiobutanoic acid are partially converted to nonabsorbed compounds during passage through the small intestine and heat exposure does not affect small intestinal absorption of methionine sources in broiler chicks. J. Nutr.126:1438 - 1444.

MARTIN-VENEGAS, R., P.A. GERAERT, R. FERRER. 2006. Conversion of Methionine Hydroxy Analogue DL-2_Hydroxy-(4-Methylthio) Butanoic Acid to Sulfur Containing Amino Acids in Chicken Small Intestine Poultry Sci. 85:1932-1938.

MARUYAMA, K., M.L. SUNDE, R.W. SWICK. 1978. Growth and muscle protein turnover in the chick. Biochem. J. 176:573-582.

MEG. 2010. Marktinfo Eier und Geflügel, Stuttgart.

MENDES, A.A., S.E. WATKINS, J.A. ENGLAND, D.A. SAHLE, A.L. WALDROUP, P.W. WALDROUP. 1997. Influence of dietary lysine levels and arginine:lysine ratios on 
performance of broiler exposed to heat or cold stress during the period of three to six weeks of age. Poultry Sci. 76:472-481.

MILES, R.D., F.A. CHAPMAN. 2010. The concept of ideal Protein in Formulation of aquaculture feeds. SFRC University of Florida. EDIS FA144.

MILLWARD, D.J., P.J. GARLICK, W.P.T. JAMES, P. SENDER, J.C. WATERLOW. 1976. Protein turnover . In: Cole, D.J.A. et al. (Eds.): Protein metabolism and nutrition EAAP-Publ. No. 16, Butterworths, London, 49-69.

MILNER, J.A., A.E. WAKELING, W.J. VISEK. 1974. Effect of arginine deficiency on growth and intermediary metabolism in rats. J. Nutr. 104:1681-1689.

MISCHERLICH，A. 1956. Ertragsgesetz. Akademie-Verlag, Berlin. Zit. Nach Gebhardt (1963) und (1966).

MITCHELL, H.H. 1924. A method of determining the biological value of protein. J. Biol. Chem. 58:873-903.

MOEHN, S., C.F. M. DE LANGE. 1998. The effect of body weight on the upper limit to protein deposition in a defined population of growing gilts. J. Anim. Sci. 76:124133.

MORRIS, T.R. 1983. The interpretation of response data from feeding trials. In: Haresign, W. (Ed.): Recent advances in animal nutrition. Butterworths, London, 13-23.

MORRIS, T.R., R.M. GOUS, S. ABEBE. 1992. Effects of dietary protein concentration on the response of growing chicks to methionine. Br. Poultry Sci. 33:795-803.

MÜLLER, A. 1987. Untersuchungenn zum Stickstoffumsatz männlicher Broiler. Dissertation, Karl Marx Univerität Leipzig.

MÜLLER, A. PAHLE, T. GEBHARDT, G. 1989. Parameter des N-Umsatzes männlicher Broiler der Herkunft Tera 82. Arch. Tierernähr. 39:901-910.

MURAMATSU, T., J.I. OKUMURA. 1979a. Nitrogen sparing action of dietary methionine and arginine in chicks fed a protein-free diet. Nutr. Reports Internationale 19:335342.

MURAMATSU, T., J.I. OKUMURA. 1979b. Nitrogen loss from individual tissues in chicks fed a protein-free diet with methionine plus arginine. Nutr. Reports Internationale 20:709-716.

MURAMATSU, T., J.I. OKUMURA. 1980. The nitrogen sparing effect of methionine in chicks receiving a protein-free diet supplemented with arginine: Effects of various methionine substitutes. Br. Poultry Sci. 21:273-280.

MURAMATZU, T., H. OHSHIMA, M. GOTO, S. MORI, J. OKUMURA. 1991. Growth 
prediction of young chicks: Do equal deficiencies of different essential amino acids produce equal growth responses? Br. Poultry Sci. 32:139-149.

MURAMATSU, T., H. YOKOTA, J. OKUMURA, I. TASAKI. 1984. Biological efficacy of liquid methionine and methionine hydroxy analog-free acid in chicks. Poultry Sci. 63:1453-1456.

NATIONAL RESEARCH COUNCIL (NRC). 1989. Nutrient Requirements of poultry, 8th rev. ed. National Academy Press, Washington, DC.

NATIONAL RESEARCH COUNCIL (NRC). 1994. Nutrient requirement of poultry. 9th revised Ed. National Academy Press. Washington, D. C.

NAUMANN, C.,R. BASSLER. 1976-1997. VDLUFA-Methodenbuch. Vol. III. Die chemischen Untersuchungen von Futtermitteln. VDLUFA-Verlag, Darmstadt, Germany.

NESHEIM, M.C., R.E. AUSTIC, S. WANG. 1972. Amino acids in avian nutrition. 4. Dietary factors influencing amino acid degradation. Poultry Sci. 51:28-35.

NIESS, E. 1978. Ursachen und Folgen von Aminosäureninbalanzen beim monogastrischen Nutztier. Kraftfutter 61: 686-690.

PAYNE, R.L., A. LEMME, H. SEKO, Y. HASHIMOTO, H. FUJISAKI, J. KORELESKI, S. SWIATKIEWICZ, W. SZCZUREK, H. ROSTAGNO. 2006. Bioavailability of methionine hydroxy analog-free acid relative to DL-methionine in broilers. Anim. Sci. J. 77:427-439.

PESTI, G.M., B. LECLERCQ, A.M. CHAGNEAU, T. COCHARD. 1996. Effects of the naked neck $(\mathrm{Na})$ gene on the sulphur-containing amino acid requirements of broilers. Poultry Sci. 75:375-380.

PESTI, G.M., N.J. BENEVENGA, A.E. HARPER, M.L. SUNDE. 1981. The effect of high dietary protein and nitrogen levels on the performed methyl group requirement and methionine- induced growth depression in chicks. Poultry Sci. 60:425-432.

PLUMSTEAD, P.W., H. ROMERO-SANCHEZ, N.D. PATON, J.W. SPEARS, J. BRAKE. 2007. Effects of dietary metabolizable energy and protein on early growth responses of broilers to dietary lysine. Poultry Sci. 86:2639-2648.

PROUDFOOT, F.G., H.W. HULAN. 1978. The interrelated effects of feeding diet combinations with different protein und energy levels to males und females of commercial genotypes. Can. J. Anim. Sci. 58:391-398.

RANGEL-LUGO, M., C. L. SU, R. E. AUSTIC. 1994. Threonine requirement and threonine imbalance in broiler chickens. Poultry Sci. 73:670-681. 
REEDS, P.J., A. CADENHEAD, M.F. FULLER, G.E. LOBLEY, J.D. Mc DONALD. 1980a. Protein turnover in growing pigs: Effect of age and foot intake. Br. J. Nutr. 43:445455.

REEDS, P.J., M.F. FULLER, A. CADENHEAD, G.E. LOBLEY. 1980b. The effects of dietary energy and protein on protein turnover and nitrogen balance in growing pigs. Proc. 3rd EAP-Symp. Protein Metabol. Nutr. Braunschweig. I:67-72.

REEDS, P.J., M.F. FULLER, A. CADENHEAD, G.E. LOBLEY, J.D. Mc DONALD. 1981. Effects of chances in the intakes of protein and non-protein energy on whole-body protein turnover in growing pigs. Br. J. Nutr. 45:539-546.

REIFSNYDER, D.H., C.T. YOUNG, E.E. JONES. 1984. The use of low protein liquid diets to_determine the methionine requirement and the efficacy of methionine hydroxyl analogue for the three week old pig. Journal of Nutrition 114:1705-1715.

RENDEN, J. A., M.T. MORAN, S.A. KINCAID. 1994. Lack of intersections between dietary lysine or stain cross and photoschedule for male broiler performance und carcass yield. Poultry Sci. 73:1651-1662.

RENDEN, J.A., S.F. BILGILI, S.A. KINCAID. 1992. Effects of photoschedule und strain cross on broiler performance und carcass yield. Poultry Sci. 71:1417-1426.

REZAEI, M., H. NASSIRI, J. MOGHADDAM, J. POUR REZA, H. KERMANSHAHI. 2004. The Effects of Dietary Protein and Lysine Levels on Broiler Performance, Carcass Characteristics and N Excretion. International Journal of Poultry Science 3 (2): $148-152$.

RHONE-POULENC. 1993. Rhodimet Nutrition Guide. 2nd ed. Rhone-Poulenc Animal Nutrition, Antony, France.

RIBEIR, A.M.L., A.M. PENZ Jr., R.G. TEETER. 2001. Effects of 2-hydroxy-4-(mthylthio) butanoic acid as DL-methionine on broiler performance and compensatory growth after exposure to two different environmental temperatures. J. Appl. Poultry Res. $10(4): 419-426$.

RIMBACH， M.G. 2002. Untersuchungen zum leistungsabhängigen Threoninbedarf männlicher Broiler auf der Grundlage von N-Bilanzmessungen und Wachstumstests. Diss. sc. agr., Göttingen, 181 pp.

RIMBACH, M.G , F. LIEBERT. 1999. N-metabolism parameter of current broiler chicken genotypes in different age period. Proc. Soc. Nutr. Physiol. 8:49.

RIMBACH, M.G., F. LIEBERT. 2000. Ergebnisse zum alterabhängigen Threoninbedarf aktueller Broilergenotypen. Proc. Soc. Nutr. Physiol. 9:106. 
ROBBINS, K.R. 1987. Threonine requirement of the broiler chick as affected by protein level and source. Poultry Sci. 66:1531-1534.

RODEHUTSCORD, M., M. PACK. 1999. Estimates of essential amino acids requirements from dose-response studies with rainbow trout and broiler chicken: Effect of mathematical model. Arch. Anim. Nutr. 52:223-244.

RÖMER A., H.J. ABEL. 1999. Effects of DL-methionine hydroxyanalogue (MHA) or DLmethionine (DL-Met) on N-retention in broiler chickens and pigs. Animal Feed Science and Technology 81:193-203.

ROSTAGNO, H.S., J. M.R. PUPA, M. PACK. 1995. Diet formulation for broilers based on total versus digestible amino acids. J. Appl. Poultry Res. 4: 293-299.

ROSTAGNO, H., L. PAE'Z, AND L. ALBINO. 2007. Nutrient requirements of broilers for optimum growth and lean mass. World's Poult. Sci. Assoc. France XVI Eur. Symp. Poult. Nutr., Strasbourg, France.

ROTH, F.X., K. GRUBER, M. KIRCHGESSNER. 2001. The ideal dietary amino acid pattern for broiler-chicks of age 7 to 28 days. Archiv für Geflügelk. 65:199-206.

ROTH, F.X., M. KIRCHGESSNER. 1989. Influence of the methionine:cysteine relationship in the feed on the performance of growing pigs. J. Anim. Physiol. a. Anim. Nutr. $61: 265-274$.

RUITZ-FERIA, C.A., M.T. KIDD, R.F. WIDEMAN JR. 2001. Plasma levels of arginine, ornitine, and urea and growth performance of broilers fed supplemental arginine during cool temperature exposure. Poultry Sci. 80:358-369.

SAMADI, F. LIEBERT. 2006a. Estimation of nitrogen maintenance requirement and potential for nitrogen deposition in fast growing chickens depending on age and sex. Poultry Sci. 85:1421-1429.

SAMADI, F. LIEBERT. 2006b. Modelling Threonine Requirement in Fast-Growing chickens - depending on age, sex, Deposition and Dietary Threonine Efficiency. Poultry Sci. 85:1961-1968.

SAMADI, F. LIEBERT. 2007a. Threonine Requirement of Slow-Growing Male Chickens Depends on Age und Dietary Efficiency of Threonine Utilization J. Poultry Sci. 44:63-72.

SAMADI, F. LIEBERT. 2007b. Lysine requirement of fast-growing chickens-Effects of age, sex, level or protein deposition und dietary lysine efficiency. J. Poultry Sci. 44:63-72.

SAMADI, F. LIEBERT. 2008. Modelling the optimal lysine to threonine ratio in growing 
chickens depending on age and efficiency of dietary amino acid utilisation. Br. Poultry Sci. 49(1):45-54.

SASSE, C.E., D.H. BAKER. 1974. Sulfur utilization by the chick with emphasis on the effect of inorganic sulfate on the cystine-methionine interrelationship. J. Nutr. 104:244251.

SAUER, N., K. EMRICH, H.P. PIEPHO, A. LEMME, M.S. REDSHAW, R. MOSENTHIN. 2008. Meta-analysis of the relative efficiency of Methionine-Hydroxy-AnalogueFree-Acid compared with DL-Methionine in broilers using nonlinear mixed models. Poultry Sci. 87:2023-2031.

SAUNDERSON, C.L. 1991. Metabolism of Methionine and its nutritional analogs. Poultry International 30:34-38.

SCHMIDT, E., N. SCHMIDT. 2004. Leitfaden Mikronährstoffe. S. 321-322. Urban \& Fischer Verlag. München.

SCHUTTE, J.B., J. DE JONG. 1996. Biological efficiency of DL-methionine hydroxy analog-free acid compared to DL-methionine in broiler chicks as determined by performance and breast meat yield. Agribiol. Res. 49:74-82.

SCHUTTE, J.B., J. DE JONG. 2004. Ideal amino acid profile for poultry. TNO Nutrition and Food Research Institute, Dept. of Animal Nutrition and Physiology (ILOB), F.O. Box 15, 6700 AA Wageningen, The Niederlande

SCHUTTE, J.B., M. PACK. 1995. Sulfur amino acid requirement of broiler chicks from fourteen to thirty eight days of age. 1. Performance and carcass yield. Poultry Sci. 74:480-487.

SCOTT, M.L., M.C. NESHEIM, R.J. YOUNG. 1969. Nutrition of the Chicken. M. L. Scott and Assoc., Ithaca, NY.

SCOTT, M.L., M.C. NESHEIM, R.J. YOUNG. 1982. Nutrition of the Chicken. 3rd ed. M. L. Scott and Assoc., Ithaca, NY.

SEBASTIAN, S., S.P. TOUCHBURN, E.R. CHAUEZ, P.C. LAGUE. 1997. Apparent digestibility of protein und amino acids in broiler chickens fed a corn-soybean diet supplemented with microbial phytase. Poultry Sci. 76:1760-1769.

SHELTON, J.L., I. MAVROMICHALIS, R.L. PAYNE, L.L. SOUTHERN, D.H. BAKER. 2003. Growth performance of different breed crosses of chicks fed diets with different protein und energy source. Poultry Sci. 82:272-278.

SHOVELLER, A.K., S. MOEHN, M.RADEMACHER, J.K. HTOO, R.O. BALL. 2009. Methionine-hydroxy analogue was found to be significantly less bioavailable 
compared to DL-methionine for protein deposition in growing pigs. Animal 4: 6164.

SI, J., C.A. FRITTS, D.J. BURNHAM, P.W. WALDROUP. 2001. Relationship of dietary lysine level to the concentration of all essential amino acids in broiler diets. Poultry Sci. 80:1472-1479.

SKLAN, D., Y. NOY. 2004. Catabolism und deposition of amino acids in growing chicks: Effect of dietary supply. Poultry Sci. 83:952-961.

SMITH R.E. 1966. The utilisation of L-methionine, DL-methionine, and methionine hydroxy analogue by the growing chicks. Poultry Sci. 45: 571-577.

SMITH, N.K. Jr., P. WALDROUP.1988. Investigations of threonine requirement of broiler chicks fed diets based on grain sorghum and soybean meal. Poultry Sci. 67:108-112.

STEINHARDT, H., M. KIRCHGESSNER. 1984. Untersuchungen zum Tryptophanbedarf von Broilern. Arch. Geflügelk. 48:150-155.

STERLING, K. G., G. M. PESTI, R. I. BALKALLI. 2003. Performance of broiler chicks fed various levels of dietary lysine und crude protein. Poultry Sci. 82:1939-1947.

STOCKLAND, W.L., R.J. MEADE, D.F. WASS, J.E. SOWERS. 1973. Influence of levels of methionine and cystine on the total sulfur amino acid requirement of the growing rat. J. Anim. Sci. 36:526-530.

SÜNDER, A., F. LIEBERT. 2005. Comparison of different methods for estimation of the Nmaintenance requirement (NMR) in different species based on N-rise balance experiments. Proc. Soc. Nutr. Physiol. 14:33.

TAMIR, H., S. RATNER. 1963. Enzymes of arginine metabolism in chicks. Arch. Biochem. Biophys. 102:249-258.

TEEKELL, R.A., C.E. RICHARDSON, A.B. WATTS. 1968. Dietary protein effects on urinary nitrogen components of the hen. Poultry Science 47:1260-1266.

THONG, H.T. 2003. Variability of lysine and threonine efficiency in feed proteins and implications on amino acid requirements of growing pigs of modern genotype. Diss. sc. agr., Göttingen, 183 pp.

THONG, H.T., F. LIEBERT. 2004a. Potential for protein deposition and threonine requirement of modern genotype borrows fed graded levels of protein with threonine as the limiting amino acids. Journal of Animal Physiology and Animal Nutrition. 88:196-203.

THONG, H.T., F. LIEBERT. 2004b. Amino acid requirement of growing pigs depending on amino acid efficiency and level of protein deposition. 1st communication:lysine. 
Archives of Animal Nutrition. 58:69-87.

TILLMAN, P.B., G.M. PESTI. 1985. Development of a basal diet to study broiler chicken responses to the sulfur-containing amino acid and sodium sulfate. Poultry Sci. 64:1350-1355.

UHLEMANN, H., S. POPPE. 1970. Vergleichende Untersuchungen über die NAusscheidungen unter verschiedenen Ernährungsbedingungen im Hinblick auf eine Verallgemeinerungsfähigkeit des N-Erhaltungsbedarfs. Archives of Animal Nutrition. 20:153 - 163 .

UNI, Z., Y. NOY, D. SKLAN. 1999. Posthatch development of small intestinal function in the poultry. Poultry Sci. 78:215-222.

VAN WEERDEN E.J., J.B. SCHUTTE, H.L. BERTRAM. 1992. Utilization of the polymers of methionine hydroxy analog free acid (MHA-FA) in broiler chicks. Archiv für Geflügelkunde 56:63-68.

VAN WEERDEN, E.J., J.B. SCHUTTE, H.L. BERTRAM. 1982. DL-methionine and DLMethionine Hydroxy analogue free acid (MHA_FA) in broiler chicks. Arch. für Geflügelk. 56:63-68.

VASQUEZ-ANON, M., E. SALEH, S. PEAK, T.HAMPTON, C. LOPEZ-COELLO, J. FIRMAN, C. KNIGHT. 2004. Effect of 2-hydroxy-4-(mthylthio)butanoic (HMB) and DL-methionine in sorghum-soybean meal diets on broiler performance. Poultry Sci. 83(suppl.1):118.

VAZQUEZ,M., G.M. PESTI. 1997. Estimation of the lysine requirement for broiler chicks for maximum body gain and feed efficiency. J. Appl. Poultry Res. 6:241-246.

VAZQUEZ-ANON, M., D. KRATZER, R. GONZALEZ-ESQUERRA, I. G. YI, C. D. KNIGHT. 2006. A multiple regression model approach to contrast the performance of 2-hydroxy-4-methylthio butanoic acid and DL-methionine supplementation tested in broiler experiments and reported in the literature. Poultry Sci. 85: 693-705.

VELU, J.G., D.H. BAKER, H.M. SCOTT. 1971. Protein and energy utilization of chicks fed graded levels of a balanced mixture of crystalline amino acids. J. Nutr. 101:12491256.

VIEIRA, S.L., A. LEMME, D.B. GOLDBERG, I. BRUGALLI. 2004. Responses of growing broilers to diets with increased sulfur amino acids to lysine ratios at two dietary protein levels. Poultry Sci. 83:1307-1313.

WALDROUP, P.W., C.J. CABRAY, J.R. BLACKMAN, Z.B. JOHNSON. 1979. Influence of copper sulfate on the methionine requirement of the young broiler chick. Nutr. Rep. 
Int. 20:303-308.

WALDROUP, P.W., C.J. MABRAY, J.R. BLACKMAN, P.J. SLAGTER, J.R. SHORT, Z.B. JOHNSON. 1981. Effectiveness of the free acid of methionine hydroxy analogue as a methionine supplement in broiler diets. Poultry Sci.. 60:438-443.

WALDRUP, P.W., J.A. ENGLAND, M.T. KIDD, B.J. KERR. 1998. Dietary arginine and lysine at Large white Toms. 1. Increasing arginine:lysine ratio does not improve performance when lysine levels are adequate. Poultry Sci. 77:1364-1370.

WANG, T.C., M.F. FULLER. 1989. The optimum dietary amino acid pattern for growing pigs. 1. Experiments by amino acid deletion, British Journal of Nutrition 62:77-89.

WEBEL, D.M., S.E. FERNANDEZ, C.M. PARSONS, D.H. BAKER. 1996. Digestible threonine requirement of broiler chickens during the period three to six and six to eight weeks post hatching. Poultry Sci. 75:1253-1257.

WEBEL, D.M., S.R. FERNANDEZ, C.M. PARSONS, D.H. BAKER. 1996. Digestible threonine requirement of broiler chickens during the period three to six and six to eight weeks posthatching. Poultry Sci., 75:1253-1257.

WEBEL, D.M., D.H. BAKER. 1999. Cystine is the first limiting amino acid for utilisation of endogenous amino acid in chicks fed a protein-free diet. Nutr. Res.19:569-577.

WECKE, C., G. GEBHARDT. 1982. Untersuchung zur Eiweißverwertung von lysinergänztem Gerstenprotein und zur Wirkungsmöglichkeit der limitierenden Aminosäure Lysin an wachsenden Schweinen. Arch. Tierernährung 32:221-228.

WECKE, C., F. LIEBERT. 2005. Prediction of the potential for protein deposition in growing und finishing pigs. Proc. Soc. Nutr. Physiol. 14:34.

WECKE, C., F. LIEBERT. 2009. Lysine requirement studies in modern genotype barrows dependent on age, protein deposition and dietary lysin efficiency. J.Anim. Phys. a. Anim. Nutr. 93 (3): 295-304.

WECKE, C., F. LIEBERT. 2010a. $\mathrm{N}$ excretion to $\mathrm{N}$ deposition ratios in growing pigs as derived from modelling of $\mathrm{N}$ excretion depending on dietary protein supply. Proc. Soc. Nutr. Physiol. 19: 97.

WECKE, C., F. LIEBERT. 2010b. Optimal dietary lysine to threonine ratio in pigs (30-110 $\mathrm{kg}$ BW) derived from observed dietary amino acid efficiency. J. Anim. Physiol. a. Anim. Nutr.: online, e277-e285.

WESSELING, B. 2003: Zur Wirksamkeit von Futteraminosäuren beim Schwein. Diss. sc. agr., Göttingen, 159 pp.

WHEELER, K. B., J. D. LATSHAW. 1981. Sulfur amino acid requirements and interactions 
in broilers during two growth periods. Poultry Sci. 60:228-236.

WIESEMÜLLER, W., 1984. Physiologische Grundlagen des Proteinbedarfes von Schweinen. Übers. Tierernähr. 85-118.

WIESEMÜLLER, W., S. POPPE. 1969. Biologischen Wert einiger Futterproteine beim Schwein. 1. Mitteilung: N-Bilanzversuche an Schweinen mit verschieden hohen Gehalten an Proteinträgern pflanzlicher Herkunft. Arch. Tierernähr. 19:157-169.

XIE, M., S.S. HOU, W. HUANG, L. ZHAO, J.Y. YU, W.Y. LI, Y.Y. WU. 2004. Interrelationship between methionine and cystine of early Peking ducklings. Poultry Sci. 83:1703-1708.

ZIMMERMAN, R.A., H.M. SCOTT. 1965. Interrelationship of plasma amino acid levels and weight gain in the chick as influenced by suboptimal und superoptimal dietary concentrations of single amino acids. J. Nutr. 87:13-18. 


\section{Tabellenanhang}

Tabelle A 1: Aminosäurengehalte der Futtermischungen (\% FS), Versuch 1 (Starterperiode)

\begin{tabular}{|c|c|c|c|c|c|c|}
\hline \multirow[b]{2}{*}{ Aminosäuren } & \multicolumn{5}{|c|}{ Futtermischungen } & \multirow[b]{2}{*}{ N6 } \\
\hline & N1 & N2 & N3 & N4 & N5 & \\
\hline Lys & 1,823 & 1,519 & 1,214 & 0,911 & 0,607 & 0,304 \\
\hline Met & 0,574 & 0,479 & 0,382 & 0,287 & 0,191 & 0,096 \\
\hline Cys & 0,661 & 0,551 & 0,440 & 0,331 & 0,220 & 0,110 \\
\hline Met + Cys & 1,236 & 1,030 & 0,822 & 0,618 & 0,412 & 0,206 \\
\hline Thr & 1,396 & 1,163 & 0,928 & 0,698 & 0,465 & 0,233 \\
\hline Trp & 0,395 & 0,329 & 0,263 & 0,197 & 0,131 & 0,066 \\
\hline Arg & 2,451 & 2,042 & 1,632 & 1,225 & 0,817 & 0,408 \\
\hline Ile & 1,624 & 1,353 & 1,081 & 0,812 & 0,541 & 0,271 \\
\hline Leu & 3,026 & 2,521 & 2,010 & 1,513 & 1,008 & 0,504 \\
\hline Val & 1,736 & 1,446 & 1,155 & 0,868 & 0,578 & 0,289 \\
\hline His & 0,982 & 0,819 & 0,654 & 0,491 & 0,327 & 0,164 \\
\hline Phe & 1,906 & 1,589 & 1,268 & 0,953 & 0,635 & 0,318 \\
\hline Phe + Tyr & 3,243 & 2,703 & 2,157 & 1,622 & 1,081 & 0,541 \\
\hline Pro & 1,686 & 1,405 & 1,119 & 0,843 & 0,562 & 0,281 \\
\hline Gly & 1,528 & 1,347 & 1,016 & 0,764 & 0,509 & 0,255 \\
\hline Ser & 1,906 & 1,588 & 1,268 & 0,953 & 0,635 & 0,318 \\
\hline
\end{tabular}

Tabelle A 2: Aminosäurengehalte (\% FS), Versuch 1 (Growerperiode)

\begin{tabular}{lcccccc}
\hline & \multicolumn{7}{c}{ Futtermischungen } \\
\cline { 2 - 7 } Aminosäuren & $\mathbf{N 1}$ & $\mathbf{N 2}$ & $\mathbf{N 3}$ & $\mathbf{N 4}$ & $\mathbf{N 5}$ & $\mathbf{N 6}$ \\
\hline Lys & 1,732 & 1,443 & 1,154 & 0,866 & 0,577 & 0,289 \\
Met & 0,546 & 0,455 & 0,364 & 0,273 & 0,182 & 0,091 \\
Cys & 0,628 & 0,524 & 0,419 & 0,314 & 0,209 & 0,105 \\
Met+ Cys & 1,174 & 0,978 & 0,783 & 0,587 & 0,391 & 0,196 \\
Thr & 1,326 & 1,105 & 0,884 & 0,663 & 0,442 & 0,221 \\
Trp & 0,375 & 0,312 & 0,250 & 0,187 & 0,125 & 0,062 \\
Arg & 2,328 & 1,940 & 1,552 & 1,164 & 0,776 & 0,388 \\
Ile & 1,542 & 1,285 & 1,028 & 0,771 & 0,514 & 0,257 \\
Leu & 2,874 & 2,395 & 1,916 & 1,437 & 0,958 & 0,479 \\
Val & 1,649 & 1,374 & 1,099 & 0,824 & 0,549 & 0,275 \\
His & 0,933 & 0,778 & 0,622 & 0,467 & 0,311 & 0,156 \\
Phe & 1,811 & 1,509 & 1,207 & 0,906 & 0,604 & 0,302 \\
Phe + Tyr & 3,081 & 2,567 & 2,054 & 1,541 & 1,027 & 0,514 \\
Pro & 1,602 & 1,335 & 1,068 & 0,801 & 0,534 & 0,267 \\
Gly & 1,451 & 1,209 & 0,967 & 0,726 & 0,484 & 0,242 \\
Ser & 1,811 & 1,509 & 1,207 & 0,905 & 0,603 & 0,302 \\
\hline
\end{tabular}


Tabelle A 3: Aminosäurengehalte der Futtermischungen (\% FS), Versuch 2 - 5 (Starterperiode)

\begin{tabular}{|c|c|c|c|c|c|c|c|c|c|c|}
\hline \multirow[b]{2}{*}{$\begin{array}{l}\text { Amino- } \\
\text { säuren }\end{array}$} & \multicolumn{5}{|c|}{ Versuch 2 und 3} & \multicolumn{5}{|c|}{ Versuch 4 und 5} \\
\hline & $\mathrm{NC}$ & $\mathrm{M}+\mathrm{C} \mathrm{I}$ & $\mathrm{M}+\mathrm{C}$ II & $\begin{array}{c}\mathrm{MHA}+ \\
\mathrm{C} \mathrm{I}\end{array}$ & $\begin{array}{c}\text { MHA+ } \\
\text { C II }\end{array}$ & $\mathrm{NC}$ & M I & M II & MHA I & MHA II \\
\hline Lys & $\begin{array}{c}1,249 * \\
(1,23)^{* *}\end{array}$ & $\begin{array}{r}1,249 \\
(1,25)\end{array}$ & $\begin{array}{l}1,249 \\
(1,24)\end{array}$ & $\begin{array}{l}1,249 \\
(1,24)\end{array}$ & $\begin{array}{l}1,249 \\
(1,26)\end{array}$ & $\begin{array}{l}1,225 \\
(1,38)\end{array}$ & $\begin{array}{l}1,225 \\
(1,22)\end{array}$ & $\begin{array}{l}1,225 \\
(1,22)\end{array}$ & $\begin{array}{l}1,225 \\
(1,23)\end{array}$ & $\begin{array}{l}1,225 \\
(1,24)\end{array}$ \\
\hline Met & $\begin{array}{l}0,250 \\
(0,24)\end{array}$ & $\begin{array}{r}0,348 \\
(0,34)\end{array}$ & $\begin{array}{l}0,447 \\
(0,43)\end{array}$ & $\begin{array}{l}0,350 \\
(0,34)\end{array}$ & $\begin{array}{l}0,450 \\
(0,45)\end{array}$ & $\begin{array}{l}0,244 \\
(0,24)\end{array}$ & $\begin{array}{l}0,343 \\
(0,33)\end{array}$ & $\begin{array}{l}0,441 \\
(0,43)\end{array}$ & $\begin{array}{l}0,345 \\
(0,36)\end{array}$ & $\begin{array}{l}0,445 \\
(0,46)\end{array}$ \\
\hline Cys & $\begin{array}{l}\mathbf{0 , 3 5 7} \\
(\mathbf{0 , 2 8})\end{array}$ & $\begin{array}{l}0,510 \\
(0,41)\end{array}$ & $\begin{array}{l}0,661 \\
(0,55)\end{array}$ & $\begin{array}{l}0,510 \\
(0,41)\end{array}$ & $\begin{array}{l}0,661 \\
(0,57)\end{array}$ & $\begin{array}{l}0,332 \\
(0,29)\end{array}$ & $\begin{array}{c}0,332 \\
(0,27)\end{array}$ & $\begin{array}{l}0,332 \\
(0,28)\end{array}$ & $\begin{array}{l}0,332 \\
(0,29)\end{array}$ & $\begin{array}{l}0,332 \\
(0,29)\end{array}$ \\
\hline $\begin{array}{l}\text { Met + } \\
\text { Cys }\end{array}$ & 0,606 & 0,858 & 1,107 & 0,860 & 1,111 & 0,576 & 0,676 & 0,773 & 0,677 & 0,777 \\
\hline Thr & $\begin{array}{l}0,802 \\
(0,77)\end{array}$ & $\begin{array}{l}0,802 \\
(0,78)\end{array}$ & $\begin{array}{r}0,802 \\
(0,78)\end{array}$ & $\begin{array}{l}0,802 \\
(0,78)\end{array}$ & $\begin{array}{l}0,802 \\
(0,78)\end{array}$ & $\begin{array}{l}0,780 \\
(0,83)\end{array}$ & $\begin{array}{l}0,780 \\
(0,76)\end{array}$ & $\begin{array}{l}0,780 \\
(0,76)\end{array}$ & $\begin{array}{l}0,780 \\
(0,79)\end{array}$ & $\begin{array}{l}0,780 \\
(0,79)\end{array}$ \\
\hline Trp & 0,212 & 0,212 & 0,212 & 0,212 & 0,212 & 0,466 & 0,466 & 0,466 & 0,466 & 0,466 \\
\hline Arg & $\begin{array}{l}1,304 \\
(1,30)\end{array}$ & $\begin{array}{l}1,304 \\
(1,31)\end{array}$ & $\begin{array}{l}1,304 \\
(1,30)\end{array}$ & $\begin{array}{l}1,304 \\
(1,30)\end{array}$ & $\begin{array}{l}1,304 \\
(1,32)\end{array}$ & $\begin{array}{l}1,278 \\
(1,44)\end{array}$ & $\begin{array}{l}1,278 \\
(1,28)\end{array}$ & $\begin{array}{l}1,278 \\
(1,29)\end{array}$ & $\begin{array}{l}1,278 \\
(1,31)\end{array}$ & $\begin{array}{l}1,278 \\
(1,32)\end{array}$ \\
\hline Ile & 0,839 & 0,839 & 0,839 & 0,839 & 0,839 & 0,833 & 0,833 & 0,833 & 0,833 & 0,833 \\
\hline Val & 0,973 & 0,973 & 0,973 & 0,973 & 0,973 & 0,963 & 0,963 & 0,963 & 0,963 & 0,963 \\
\hline His & 0,541 & 0,541 & 0,541 & 0,541 & 0,541 & 0,535 & 0,535 & 0,535 & 0,535 & 0,535 \\
\hline Leu & 1,525 & 1,525 & 1,525 & 1,525 & 1,525 & 1,508 & 1,508 & 1,508 & 1,508 & 1,508 \\
\hline Phe & 0,844 & 0,844 & 0,844 & 0,844 & 0,844 & 0,835 & 0,835 & 0,835 & 0,835 & 0,835 \\
\hline Tyr & 0,662 & 0,662 & 0,662 & 0,662 & 0,662 & 0,285 & 0,285 & 0,285 & 0,285 & 0,285 \\
\hline $\begin{array}{l}\text { Phe + } \\
\text { Tyr }\end{array}$ & 1,506 & 1,506 & 1,506 & 1,506 & 1,506 & 1,120 & 1,120 & 1,120 & 1,120 & 1,120 \\
\hline
\end{tabular}

* kalkuliert mittels Kalkulationsprogramm Hybrimin ${ }^{\circledR}$ (Ver. 3.9.) basierend auf analysierte Einzelkomponenten **Analysierte Werte

Tabelle A 4: Aminosäurengehalte der Futtermischungen (\% FS), Versuch 2 - 5 (Growerperiode)

\begin{tabular}{|c|c|c|c|c|c|c|c|c|c|c|}
\hline \multirow[b]{2}{*}{$\begin{array}{l}\text { Amino- } \\
\text { säuren }\end{array}$} & \multicolumn{4}{|c|}{ Versuch 2 und 3} & \multirow[b]{2}{*}{$\begin{array}{c}\text { MHA+ } \\
\text { C II }\end{array}$} & \multicolumn{5}{|c|}{ Versuch 4 und 5} \\
\hline & $\mathrm{NC}$ & $\mathrm{M}+\mathrm{C} \mathrm{I}$ & $\mathrm{M}+\mathrm{C}$ II & $\begin{array}{c}\mathrm{MHA}^{+} \\
\mathrm{C} \mathrm{I}\end{array}$ & & $\mathrm{NC}$ & M I & M II & MHA I & MHA II \\
\hline Lys & $\begin{array}{c}1,149 * \\
(1,23)^{* *}\end{array}$ & $\begin{array}{l}1,149 \\
(1,25)\end{array}$ & $\begin{array}{l}1,149 \\
(1,24)\end{array}$ & $\begin{array}{l}1,149 \\
(1,24)\end{array}$ & $\begin{array}{l}1,149 \\
(1,26)\end{array}$ & $\begin{array}{l}1,127 \\
(1,13)\end{array}$ & $\begin{array}{l}1,127 \\
(1,14)\end{array}$ & $\begin{array}{l}1,127 \\
(1,12)\end{array}$ & $\begin{array}{l}1,127 \\
(1,12)\end{array}$ & $\begin{array}{l}1,127 \\
(1,12)\end{array}$ \\
\hline Met & $\begin{array}{l}0,230 \\
(0,23)\end{array}$ & $\begin{array}{l}0,328 \\
(0,33)\end{array}$ & $\begin{array}{l}0,427 \\
(0,41)\end{array}$ & $\begin{array}{l}0,330 \\
(0,33)\end{array}$ & $\begin{array}{l}0,430 \\
(0,44)\end{array}$ & $\begin{array}{l}0,225 \\
(0,24)\end{array}$ & $\begin{array}{l}0,323 \\
(0,34)\end{array}$ & $\begin{array}{l}0,422 \\
(0,42)\end{array}$ & $\begin{array}{l}0,325 \\
(0,33)\end{array}$ & $\begin{array}{l}0,425 \\
(0,44)\end{array}$ \\
\hline Cys & $\begin{array}{l}0,328 \\
(0,26)\end{array}$ & $\begin{array}{l}0,481 \\
(0,40)\end{array}$ & $\begin{array}{l}0,632 \\
(0,54)\end{array}$ & $\begin{array}{l}0,481 \\
(0,41)\end{array}$ & $\begin{array}{l}0,632 \\
(0,53)\end{array}$ & $\begin{array}{l}0,305 \\
(0,27)\end{array}$ & $\begin{array}{l}0,305 \\
(0,27)\end{array}$ & $\begin{array}{l}0,305 \\
(0,28)\end{array}$ & $\begin{array}{l}0,305 \\
(0,25)\end{array}$ & $\begin{array}{l}0,305 \\
(0,25)\end{array}$ \\
\hline $\begin{array}{l}\text { Met + } \\
\text { Cys }\end{array}$ & $\begin{array}{l}0,558 \\
(0,49)\end{array}$ & $\begin{array}{l}0,809 \\
(0,73)\end{array}$ & $\begin{array}{l}1,059 \\
(0,95)\end{array}$ & $\begin{array}{l}\mathbf{0 , 8 1 1} \\
(0,74)\end{array}$ & $\begin{array}{l}1,062 \\
(0,97)\end{array}$ & $\begin{array}{l}0,530 \\
(0,51)\end{array}$ & $\begin{array}{l}0,628 \\
(0,61)\end{array}$ & $\begin{array}{l}\mathbf{0 , 7 2 7} \\
(0,70)\end{array}$ & $\begin{array}{l}0,63 \\
(0,58)\end{array}$ & $\begin{array}{l}0,73 \\
(0,69)\end{array}$ \\
\hline Thr & $\begin{array}{l}\mathbf{0 , 7 3 8} \\
(0,72)\end{array}$ & $\begin{array}{l}0,738 \\
(0,71)\end{array}$ & $\begin{array}{l}0,738 \\
(0,71)\end{array}$ & $\begin{array}{l}0,738 \\
(0,71)\end{array}$ & $\begin{array}{l}0,738 \\
(0,72)\end{array}$ & $\begin{array}{l}0,718 \\
(0,73)\end{array}$ & $\begin{array}{l}\mathbf{0 , 7 1 8} \\
(0,72)\end{array}$ & $\begin{array}{l}\mathbf{0 , 7 1 8} \\
(0,73)\end{array}$ & $\begin{array}{l}\mathbf{0 , 7 1 8} \\
(0,70)\end{array}$ & $\begin{array}{l}\mathbf{0 , 7 1 8} \\
(0,69)\end{array}$ \\
\hline Trp & 0,195 & 0,195 & 0,195 & 0,195 & 0,195 & 0,428 & 0,428 & 0,428 & 0,428 & 0,428 \\
\hline Arg & $\begin{array}{l}1,200 \\
(1,30)\end{array}$ & $\begin{array}{l}1,200 \\
(1,31)\end{array}$ & $\begin{array}{l}1,200 \\
(1,30)\end{array}$ & $\begin{array}{l}1,200 \\
(1,30)\end{array}$ & $\begin{array}{l}1,200 \\
(1,32)\end{array}$ & $\begin{array}{l}1,176 \\
(1,22)\end{array}$ & $\begin{array}{l}1,176 \\
(1,21)\end{array}$ & $\begin{array}{l}1,176 \\
(1,18)\end{array}$ & $\begin{array}{l}1,176 \\
(1,17)\end{array}$ & $\begin{array}{l}1,176 \\
(1,17)\end{array}$ \\
\hline Ile & 0,771 & 0,771 & 0,771 & 0,771 & 0,771 & 0,766 & 0,766 & 0,766 & 0,766 & 0,766 \\
\hline Val & 0,895 & 0,895 & 0,895 & 0,895 & 0,895 & 0,886 & 0,886 & 0,886 & 0,886 & 0,886 \\
\hline His & 0,498 & 0,498 & 0,498 & 0,498 & 0,498 & 0,492 & 0,492 & 0,492 & 0,492 & 0,492 \\
\hline Leu & 1,403 & 1,403 & 1,403 & 1,403 & 1,403 & 1,387 & 1,387 & 1,387 & 1,387 & 1,387 \\
\hline Phe & 0,776 & 0,776 & 0,776 & 0,776 & 0,776 & 0,768 & 0,768 & 0,768 & 0,768 & 0,768 \\
\hline Tyr & 0,609 & 0,609 & 0,609 & 0,609 & 0,609 & 0,262 & 0,262 & 0,262 & 0,262 & 0,262 \\
\hline $\begin{array}{l}\text { Phe + } \\
\text { Tyr }\end{array}$ & 1,385 & 1,385 & 1,385 & 1,385 & 1,385 & 1,03 & 1,030 & 1,030 & 1,030 & 1,030 \\
\hline
\end{tabular}

* kalkuliert mittels Kalkulationsprogramm Hybrimin ${ }^{\circledR}$ (Ver. 3.9.) basierend auf analysierte Einzelkomponenten **Analysierte Werte

Tabelle A 5: Aminosäurengehalte der Basalmischung (\% FS), Versuch 6 - 10 


\begin{tabular}{lccccccc}
\hline & \multicolumn{3}{c}{ Starterperiode } & & \multicolumn{3}{c}{ Growerperiode } \\
\cline { 2 - 3 } \cline { 6 - 7 } Versuch & 6 und 7 & 8 & 9 und 10 & & 6 und 7 & 8 & 9 und 10 \\
\hline Lys & $\mathbf{1 , 2 5}$ & $\mathbf{1 , 3 5}$ & $\mathbf{1 , 3 5}$ & & $\mathbf{1 , 1 5}$ & $\mathbf{1 , 2 5}$ & $\mathbf{1 , 2 5}$ \\
Met & $\mathbf{0 , 5 0}$ & $\mathbf{0 , 5 4}$ & $\mathbf{0 , 5 4}$ & & $\mathbf{0 , 4 6}$ & $\mathbf{0 , 5}$ & $\mathbf{0 , 5 0}$ \\
Cys & $\mathbf{0 , 4 4}$ & $\mathbf{0 , 4 7}$ & $\mathbf{0 , 4 6}$ & & $\mathbf{0 , 4 1}$ & $\mathbf{0 , 4 4}$ & $\mathbf{0 , 4 3}$ \\
Met + Cys & $\mathbf{0 , 9 4}$ & $\mathbf{1 , 0 1}$ & $\mathbf{1 , 0 0}$ & & $\mathbf{0 , 8 6}$ & $\mathbf{0 , 9 3}$ & $\mathbf{0 , 9 3}$ \\
Thr & $\mathbf{0 , 8 1}$ & $\mathbf{0 , 9 0}$ & $\mathbf{0 , 9 0}$ & & $\mathbf{0 , 7 5}$ & $\mathbf{0 , 8 3}$ & $\mathbf{0 , 8 3}$ \\
Trp & $\mathbf{0 , 2 3}$ & $\mathbf{0 , 2 5}$ & $\mathbf{0 , 2 6}$ & & $\mathbf{0 , 2 1}$ & $\mathbf{0 , 2 3}$ & $\mathbf{0 , 2 4}$ \\
Arg & $\mathbf{1 , 3 1}$ & $\mathbf{1 , 4 3}$ & $\mathbf{1 , 4 2}$ & & $\mathbf{1 , 2 1}$ & $\mathbf{1 , 3 3}$ & $\mathbf{1 , 3 1}$ \\
Ile & $\mathbf{0 , 8 4}$ & $\mathbf{0 , 9 3}$ & $\mathbf{0 , 9 3}$ & & $\mathbf{0 , 7 7}$ & $\mathbf{0 , 8 6}$ & $\mathbf{0 , 8 6}$ \\
Val & $\mathbf{1 , 0 2}$ & $\mathbf{1 , 1 0}$ & $\mathbf{1 , 1 1}$ & & $\mathbf{0 , 9 4}$ & $\mathbf{1 , 0 2}$ & $\mathbf{1 , 0 3}$ \\
His & $\mathbf{0 , 6 6}$ & $\mathbf{0 , 7 1}$ & $\mathbf{0 , 6 9}$ & & $\mathbf{0 , 6 0}$ & $\mathbf{0 , 6 6}$ & $\mathbf{0 , 6 4}$ \\
Leu & $\mathbf{1 , 7 6}$ & $\mathbf{1 , 9 3}$ & $\mathbf{1 , 8 5}$ & & $\mathbf{1 , 6 2}$ & $\mathbf{1 , 7 9}$ & $\mathbf{1 , 7 2}$ \\
Phe & $\mathbf{0 , 9 4}$ & $\mathbf{1 , 0 2}$ & $\mathbf{1 , 0 3}$ & & $\mathbf{0 , 8 7}$ & $\mathbf{0 , 9 4}$ & $\mathbf{0 , 9 5}$ \\
Tyr & $\mathbf{0 , 7 1}$ & $\mathbf{0 , 8 1}$ & $\mathbf{0 , 8 0}$ & & $\mathbf{0 , 6 5}$ & $\mathbf{0 , 7 5}$ & $\mathbf{0 , 7 4}$ \\
Phe + Tyr & $\mathbf{1 , 6 5}$ & $\mathbf{1 , 8 3}$ & $\mathbf{1 , 8 3}$ & & $\mathbf{1 , 5 2}$ & $\mathbf{1 , 6 9}$ & $\mathbf{1 , 6 9}$ \\
\hline
\end{tabular}

Tabelle A 6: Aminosäurenmuster der Basalmischungen (Lys = 100), Untersuchungskomplex III

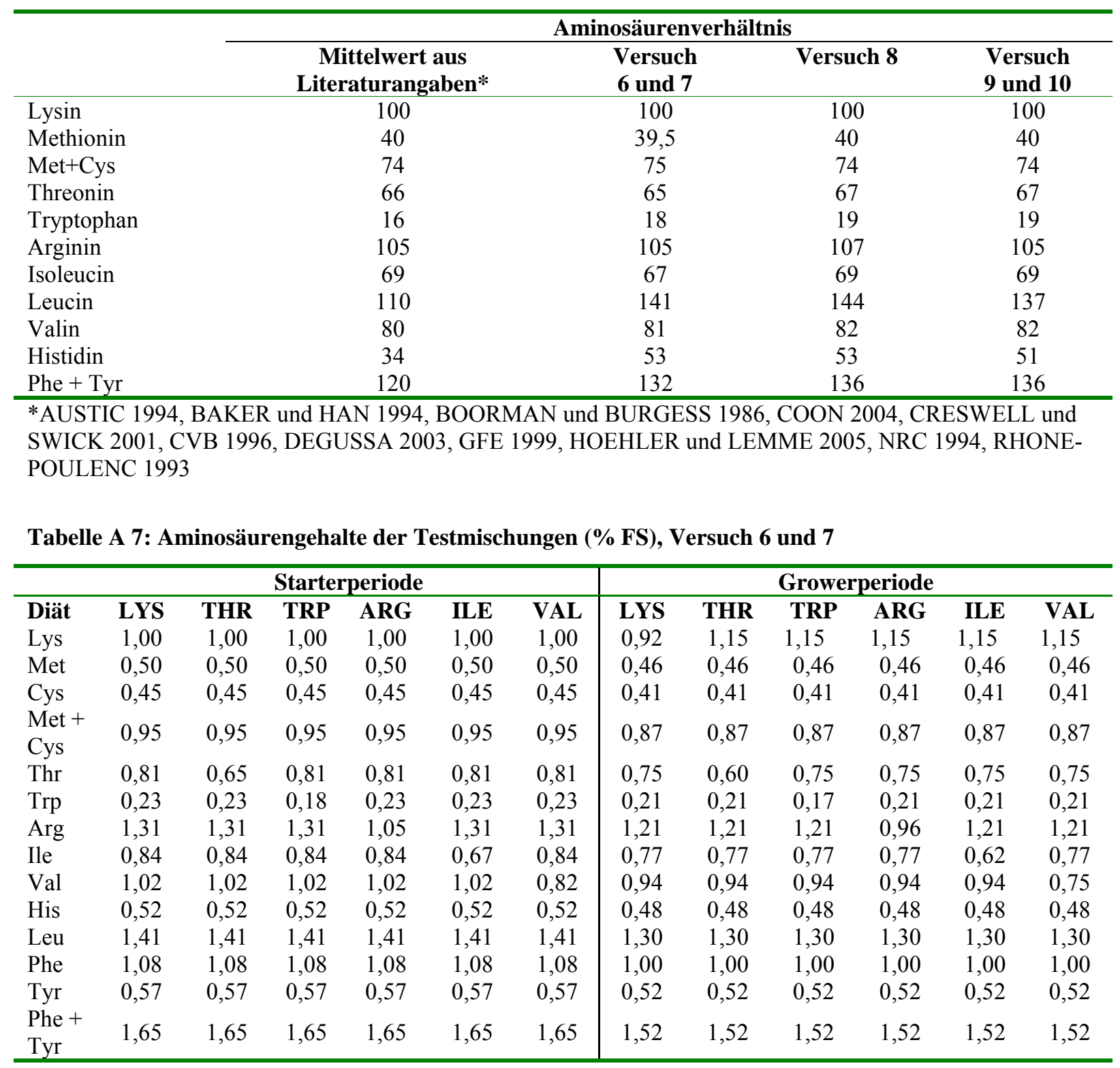

Tabelle A 8: Aminosäurengehalte der Testmischungen (\% FS), Versuch 8 


\begin{tabular}{|c|c|c|c|c|c|c|c|c|c|c|c|c|}
\hline & \multicolumn{6}{|c|}{ Starterperiode } & \multicolumn{6}{|c|}{ Growerperiode } \\
\hline Diät & LYS & THR & TRP & ARG & ILE & VAL & LYS & THR & TRP & ARG & ILE & VAL \\
\hline Lys & 1,08 & 1,35 & 1,35 & 1,35 & 1,35 & 1,35 & 1,00 & 1,25 & 1,25 & 1,25 & 1,25 & 1,25 \\
\hline Met & 0,54 & 0,54 & 0,54 & 0,54 & 0,54 & 0,54 & 0,50 & 0,50 & 0,50 & 0,50 & 0,50 & 0,50 \\
\hline Cys & 0,48 & 0,48 & 0,48 & 0,48 & 0,48 & 0,48 & 0,44 & 0,44 & 0,44 & 0,44 & 0,44 & 0,44 \\
\hline $\begin{array}{l}\text { Met }+ \\
\text { Cys }\end{array}$ & 1,02 & 1,02 & 1,02 & 1,02 & 1,02 & 1,02 & 0,94 & 0,94 & 0,94 & 0,94 & 0,94 & 0,94 \\
\hline Thr & 0,89 & 0,72 & 0,89 & 0,89 & 0,89 & 0,89 & 0,82 & 0,66 & 0,82 & 0,82 & 0,82 & 0,82 \\
\hline Trp & 0,25 & 0,25 & 0,20 & 0,25 & 0,25 & 0,25 & 0,20 & 0,20 & 0,19 & 0,20 & 0,20 & 0,20 \\
\hline Arg & 1,42 & 1,42 & 1,42 & 1,15 & 1,42 & 1,42 & 1,31 & 1,31 & 1,31 & 1,06 & 1,31 & 1,31 \\
\hline Ile & 0,93 & 0,93 & 0,93 & 0,93 & 0,74 & 0,93 & 0,86 & 0,86 & 0,86 & 0,86 & 0,69 & 0,86 \\
\hline Val & 1,08 & 1,08 & 1,08 & 1,08 & 1,08 & 0,88 & 1,00 & 1,00 & 1,00 & 1,00 & 1,00 & 0,81 \\
\hline His & 0,57 & 0,57 & 0,57 & 0,57 & 0,57 & 0,57 & 0,53 & 0,53 & 0,53 & 0,53 & 0,53 & 0,53 \\
\hline Leu & 1,54 & 1,54 & 1,54 & 1,54 & 1,54 & 1,54 & 1,43 & 1,43 & 1,43 & 1,43 & 1,43 & 1,43 \\
\hline Phe & 0,97 & 0,97 & 0,97 & 0,97 & 0,97 & 0,97 & 0,90 & 0,90 & 0,90 & 0,90 & 0,90 & 0,90 \\
\hline Tyr & 0,65 & 0,65 & 0,65 & 0,65 & 0,65 & 0,65 & 0,60 & 0,60 & 0,60 & 0,60 & 0,60 & 0,60 \\
\hline $\begin{array}{l}\text { Phe + } \\
\text { Tyr }\end{array}$ & 1,62 & 1,62 & 1,62 & 1,62 & 1,62 & 1,62 & 1,50 & 1,50 & 1,50 & 1,50 & 1,50 & 1,50 \\
\hline
\end{tabular}

Tabelle A 9: Aminosäurengehalte der Testmischungen (\% FS), Versuch 9 und 10

\begin{tabular}{|c|c|c|c|c|c|c|c|c|c|c|c|c|}
\hline \multirow[b]{2}{*}{ Diät } & \multicolumn{6}{|c|}{ Starterperiode } & \multicolumn{6}{|c|}{ Growerperiode } \\
\hline & LYS & THR & TRP & ARG & ILE & VAL & LYS & THR & TRP & ARG & ILE & VAL \\
\hline Lys & 1,08 & 1,35 & 1,35 & 1,35 & 1,35 & 1,35 & 1,00 & 1,25 & 1,25 & 1,25 & 1,25 & 1,25 \\
\hline Met & 0,54 & 0,54 & 0,54 & 0,54 & 0,54 & 0,54 & 0,50 & 0,50 & 0,50 & 0,50 & 0,50 & 0,50 \\
\hline Cys & 0,46 & 0,46 & 0,46 & 0,46 & 0,46 & 0,46 & 0,43 & 0,43 & 0,43 & 0,43 & 0,43 & 0,43 \\
\hline $\begin{array}{l}\text { Met + } \\
\text { Cys }\end{array}$ & 1,00 & 1,00 & 1,00 & 1,00 & 1,00 & 1,00 & 0,93 & 0,93 & 0,93 & 0,93 & 0,93 & 0,93 \\
\hline Thr & 0,89 & 0,72 & 0,89 & 0,89 & 0,89 & 0,89 & 0,82 & 0,67 & 0,82 & 0,82 & 0,82 & 0,82 \\
\hline $\operatorname{Trp}$ & 0,22 & 0,22 & 0,20 & 0,22 & 0,22 & 0,22 & 0,20 & 0,20 & 0,19 & 0,20 & 0,20 & 0,20 \\
\hline Arg & 1,42 & 1,42 & 1,42 & 1,12 & 1,42 & 1,42 & 1,31 & 1,31 & 1,31 & 1,04 & 1,31 & 1,31 \\
\hline Ile & 0,93 & 0,93 & 0,93 & 0,93 & 0,65 & 0,93 & 0,86 & 0,86 & 0,86 & 0,86 & 0,60 & 0,86 \\
\hline Val & 1,08 & 1,08 & 1,08 & 1,08 & 1,08 & 0,78 & 1,03 & 1,00 & 1,00 & 1,00 & 1,00 & 0,72 \\
\hline His & 0,55 & 0,55 & 0,55 & 0,55 & 0,55 & 0,55 & 0,51 & 0,51 & 0,51 & 0,51 & 0,51 & 0,51 \\
\hline Leu & 1,48 & 1,48 & 1,48 & 1,48 & 1,48 & 1,48 & 1,37 & 1,37 & 1,37 & 1,37 & 1,37 & 1,37 \\
\hline Phe & 0,98 & 0,98 & 0,98 & 0,98 & 0,98 & 0,98 & 0,95 & 0,95 & 0,95 & 0,95 & 0,95 & 0,95 \\
\hline Tyr & 0,64 & 0,64 & 0,64 & 0,64 & 0,64 & 0,64 & 0,74 & 0,59 & 0,59 & 0,59 & 0,59 & 0,59 \\
\hline $\begin{array}{l}\text { Phe + } \\
\text { Tyr }\end{array}$ & 1,62 & 1,62 & 1,62 & 1,62 & 1,62 & 1,62 & 1,50 & 1,50 & 1,50 & 1,50 & 1,50 & 1,50 \\
\hline
\end{tabular}


Tabelle A 10: Mittlere Lebendmasse, TS-Aufnahme, N-Ausscheidung (NEX), N-Aufnahme und NDeposition (ND) im Versuchs 1, Starterperiode

\begin{tabular}{|c|c|c|c|c|c|c|c|}
\hline $\begin{array}{l}\text { Diät } \\
\text { (XP) }\end{array}$ & SP & $\begin{array}{c}\text { Tier- } \\
\text { nr. }\end{array}$ & $\begin{array}{l}\text { Mittlere } \\
\text { LM (kg) }\end{array}$ & $\begin{array}{c}\text { TS- } \\
\text { Aufnahme } \\
\text { (g/Tag) }\end{array}$ & $\begin{array}{c}\text { NEX } \\
\left(\mathrm{mg} / \mathrm{LM}_{\mathrm{kg}}{ }^{0,67}\right)\end{array}$ & $\begin{array}{l}\text { N-Aufnahme } \\
\left(\mathrm{mg}^{-} \mathbf{L M}_{\mathrm{kg}}{ }^{0,67}\right)\end{array}$ & $\begin{array}{c}\mathrm{ND} \\
\left(\mathrm{mg} / \mathrm{LM}_{\mathrm{kg}}{ }^{0,67}\right)\end{array}$ \\
\hline \multirow[t]{14}{*}{ N1 $(36,7 \%)$} & I & 1 & 0,2133 & 23,745 & 2016,4 & 4254,2 & 2237,7 \\
\hline & I & 2 & Ausreißer & & & & \\
\hline & I & 3 & Ausfalltier & & & & \\
\hline & I & 4 & Ausreißer & & & & \\
\hline & I & 5 & Ausreißer & & & & \\
\hline & I & 6 & 0,2390 & 28,007 & 2478,1 & 4650,1 & 2172,1 \\
\hline & II & 1 & 0,3339 & 32,726 & 2041,3 & 4342,4 & 2301,1 \\
\hline & II & 2 & 0,3951 & 38,510 & 2051,2 & 4565,0 & 2513,8 \\
\hline & II & 3 & Ausfalltier & & & & \\
\hline & II & 4 & 0,3150 & 30,747 & 1865,2 & 4242,3 & 2377,0 \\
\hline & II & 5 & 0,3537 & 36,226 & 2438,2 & 4624,9 & 2186,7 \\
\hline & II & 6 & 0,3875 & 41,097 & 1911,9 & 4936,0 & 3024,1 \\
\hline & & MW & 0,3196 & 33,008 & 2114,6 & 4516,4 & 2401,8 \\
\hline & & SD & $\mathbf{0 , 0 7}$ & 6,08 & 244,70 & 252,40 & 299,00 \\
\hline \multirow{14}{*}{ N2 (30,6\%) } & $\mathrm{I}$ & 1 & 0,2340 & 27,292 & 1826,3 & 3815,3 & 1988,9 \\
\hline & I & 2 & 0,2754 & 34,681 & 2269,1 & 4346,8 & 2077,7 \\
\hline & I & 3 & 0,2610 & 27,142 & 2287,7 & 3526,5 & 1238,8 \\
\hline & I & 4 & 0,2430 & 33,776 & 2010,1 & 4603,8 & 2593,7 \\
\hline & $\mathrm{I}$ & 5 & 0,2372 & 28,951 & 2061,8 & 4011,0 & 1949,2 \\
\hline & I & 6 & 0,2102 & 26,388 & 2006,3 & 3964,3 & 1958,0 \\
\hline & II & 1 & 0,3843 & 39,205 & 1984,0 & 3930,7 & 1946,7 \\
\hline & II & 2 & 0,4307 & 40,712 & 1533,8 & 3782,0 & 2248,2 \\
\hline & II & 3 & 0,4217 & 40,712 & 1900,8 & 3835,9 & 1935,1 \\
\hline & II & 4 & 0,3821 & 40,562 & 2162,8 & 4082,8 & 1920,0 \\
\hline & II & 5 & 0,3834 & 39,205 & 2141,5 & 3936,8 & 1795,3 \\
\hline & II & 6 & 0,3330 & 31,514 & 2085,3 & 3478,0 & 1392,7 \\
\hline & & MW & 0,3163 & 34,178 & 2022,5 & 3942,8 & 1920,4 \\
\hline & & SD & 0,08 & 5,79 & 205,53 & 311,58 & 350,57 \\
\hline \multirow[t]{14}{*}{ N3 $(24,4 \%)$} & I & 1 & 0,1535 & 13,283 & 910,1 & 1958,9 & 1048,8 \\
\hline & I & 2 & 0,2493 & 31,999 & 1489,3 & 3409,3 & 1920,0 \\
\hline & I & 3 & 0,2502 & 30,943 & 1785,9 & 3288,8 & 1502,9 \\
\hline & $\mathrm{I}$ & 4 & 0,2538 & 28,226 & 1529,6 & 2971,5 & 1441,8 \\
\hline & I & 5 & 0,2003 & 22,792 & 1063,9 & 2812,3 & 1748,4 \\
\hline & I & 6 & 0,2651 & 31,094 & 1749,7 & 3179,6 & 1430,0 \\
\hline & II & 1 & 0,2061 & 26,113 & 1142,0 & 3160,5 & 2018,4 \\
\hline & II & 2 & 0,3983 & 40,603 & 1520,2 & 3160,7 & 1640,5 \\
\hline & II & 3 & 0,3843 & 40,754 & 1677,0 & 3249,2 & 1572,1 \\
\hline & II & 4 & 0,3965 & 39,546 & 1597,2 & 3087,8 & 1490,7 \\
\hline & II & 5 & 0,3159 & 33,509 & 1216,1 & 3046,4 & 1830,3 \\
\hline & II & 6 & 0,4185 & 39,697 & 1239,0 & 2989,2 & 1750,2 \\
\hline & & MW & 0,291 & 31,547 & 1410,0 & 3026,2 & 1616,0 \\
\hline & & SD & 0,09 & 8,27 & 286,74 & 371,55 & 261,54 \\
\hline \multirow[t]{13}{*}{ N4 (18,3\%) } & I & 1 & 0,2070 & 28,762 & 840,5 & 2599,9 & 1759,3 \\
\hline & I & 2 & 0,2169 & 30,076 & 902,9 & 2634,9 & 1732,0 \\
\hline & I & 3 & 0,2129 & 31,828 & 1251,7 & 2823,8 & 1572,1 \\
\hline & I & 5 & 0,1715 & 20,002 & 793,1 & 2051,3 & 1258,2 \\
\hline & I & 6 & 0,2034 & 25,550 & 1038,8 & 2336,8 & 1298,0 \\
\hline & II & 1 & 0,2930 & 29,346 & 831,7 & 2102,0 & 1270,2 \\
\hline & II & 2 & 0,3290 & 35,770 & 1033,8 & 2370,7 & 1336,9 \\
\hline & II & 3 & 0,3339 & 39,274 & 1208,7 & 2577,0 & 1368,3 \\
\hline & II & 4 & 0,3272 & 36,354 & 1002,9 & 2418,3 & 1415,4 \\
\hline & II & 5 & 0,2394 & 26,864 & 871,7 & 2202,9 & 1331,2 \\
\hline & II & 6 & 0,2988 & 32,558 & 990,3 & 2301,4 & 1311,1 \\
\hline & & MW & 0,2575 & 30,58 & 978,7 & 2401,7 & 1423 \\
\hline & & SD & 0,06 & 5,45 & 150,74 & 238,79 & 181,2 \\
\hline
\end{tabular}




\begin{tabular}{|c|c|c|c|c|c|c|c|}
\hline $\begin{array}{l}\text { Diät } \\
\text { (XP) }\end{array}$ & SP* & $\begin{array}{l}\text { Tier- } \\
\text { nr. }\end{array}$ & $\begin{array}{l}\text { Mittlere } \\
\text { LM (kg) }\end{array}$ & $\begin{array}{c}\text { TS- } \\
\text { Aufnahme } \\
\text { (g/Tag) }\end{array}$ & $\begin{array}{c}\mathrm{NEX} \\
\left(\mathrm{mg} / \mathrm{LM}_{\mathrm{kg}}{ }^{0,67}\right)\end{array}$ & $\begin{array}{l}\text { N-Aufnahme } \\
\left(\mathrm{mg} / \mathrm{LM}_{\mathrm{kg}}{ }^{0,67}\right)\end{array}$ & $\begin{array}{c}\text { ND } \\
\left(\mathrm{mg} / \mathrm{LM}_{\mathrm{kg}}{ }^{0,67}\right)\end{array}$ \\
\hline \multirow[t]{14}{*}{ N5 $(12,2 \%)$} & $\mathrm{I}$ & 1 & 0,1697 & 19,643 & 560,9 & 1347,6 & 786,7 \\
\hline & I & 2 & 0,1728 & 20,662 & 506,6 & 1400,1 & 893,5 \\
\hline & I & 3 & 0,1751 & 22,408 & 551,1 & 1505,4 & 954,2 \\
\hline & I & 4 & 0,1665 & 22,117 & 576,1 & 1536,5 & 960,4 \\
\hline & I & 5 & 0,1413 & 14,696 & 602,9 & 1139,6 & 536,8 \\
\hline & I & 6 & 0,1679 & 22,117 & 464,5 & 1528,2 & 1063,7 \\
\hline & II & 1 & 0,2232 & 25,463 & 526,2 & 1453,6 & 927,4 \\
\hline & II & 2 & 0,2169 & 20,516 & 496,2 & 1193,9 & 697,7 \\
\hline & II & 3 & 0,2295 & 27,064 & 583,1 & 1516,5 & 933,3 \\
\hline & II & 4 & 0,2264 & 25,172 & 625,7 & 1423,6 & 797,9 \\
\hline & II & 5 & 0,1746 & 16,442 & 547,2 & 1106,5 & 559,3 \\
\hline & II & 6 & 0,2255 & 28,373 & 508,1 & 1608,9 & 1100,8 \\
\hline & & MW & 0,1908 & 22,056 & 545,7 & 1396,7 & 851,0 \\
\hline & & SD & 0,03 & 4,07 & 47,28 & 166,75 & 180,65 \\
\hline \multirow[t]{14}{*}{ N6 $(6,1 \%)$} & I & 1 & 0,0968 & 6,818 & 228,4 & 339,8 & 111 \\
\hline & I & 2 & 0,1188 & 10,302 & 330,6 & 447,5 & 117 \\
\hline & I & 3 & 0,1004 & 7,272 & 305,2 & 353,7 & 48 \\
\hline & I & 4 & 0,1062 & 9,545 & 371,9 & 446,9 & 75 \\
\hline & I & 5 & 0,1035 & 9,242 & 397,5 & 440,3 & 43 \\
\hline & I & 6 & 0,1035 & 8,787 & 355,4 & 418,6 & 63 \\
\hline & II & 1 & 0,0873 & 4,394 & 273,5 & 234,6 & -39 \\
\hline & II & 2 & 0,1116 & 6,060 & 326,7 & 274,5 & -52 \\
\hline & II & 3 & 0,0941 & 5,151 & 369,6 & 261,7 & -108 \\
\hline & II & 4 & 0,0986 & 6,363 & 323,6 & 313,3 & -10 \\
\hline & II & 5 & 0,0900 & 5,909 & 336,8 & 309,1 & -28 \\
\hline & II & 6 & 0,1004 & 6,666 & 404,1 & 324,2 & -80 \\
\hline & & MW & 0,101 & 7,209 & 335,3 & 347,0 & 11,7 \\
\hline & & SD & $\mathbf{0 , 0 1}$ & 1,86 & 50,40 & 75,20 & 74,70 \\
\hline
\end{tabular}

$* \mathrm{SP}=$ Sammelperiode 
Tabelle A 11: Mittlere Lebendmasse, TS-Aufnahme, N-Ausscheidung (NEX), N-Aufnahme und NDeposition (ND) im Versuchs 1, Growerperiode

\begin{tabular}{|c|c|c|c|c|c|c|c|}
\hline $\begin{array}{l}\text { Diät } \\
\text { (XP) }\end{array}$ & SP & $\begin{array}{l}\text { Tier- } \\
\text { nr. }\end{array}$ & $\begin{array}{l}\text { Mittlere } \\
\text { LM (kg) }\end{array}$ & $\begin{array}{c}\text { TS- } \\
\text { Aufnahme } \\
\text { (g/Tag) }\end{array}$ & $\begin{array}{c}\text { NEX } \\
\left(\mathrm{mg}^{\mathrm{L}} \mathrm{M}_{\mathrm{kg}}{ }^{0,67}\right)\end{array}$ & $\begin{array}{l}\text { N-Aufnahme } \\
\left(\mathrm{mg}^{\mathrm{L}} \mathrm{M}_{\mathrm{kg}}{ }^{0,67}\right)\end{array}$ & $\begin{array}{c}\text { ND } \\
\left(\mathrm{mg} / \mathrm{LM}_{\mathrm{kg}}{ }^{0,67}\right)\end{array}$ \\
\hline \multirow[t]{14}{*}{ N1 $(36,7 \%)$} & $\mathrm{I}$ & 1 & 0,9244 & 65,435 & 2243,6 & 4160,4 & 1916,8 \\
\hline & I & 2 & 0,9686 & 68,807 & 2140,1 & 4240,1 & 2100,0 \\
\hline & I & 3 & 0,6939 & 43,215 & 1692,7 & 3329,8 & 1637,1 \\
\hline & I & 4 & Ausreißer & & & & \\
\hline & I & 5 & Ausfalltier & & & & \\
\hline & I & 6 & Ausfalltier & & & & \\
\hline & II & 1 & 1,3588 & 86,583 & 2301,8 & 4252,8 & 1951,0 \\
\hline & II & 2 & 1,3921 & 89,495 & 2344,0 & 4325,1 & 1981,2 \\
\hline & II & 3 & 1,0521 & 75,243 & 2193,2 & 4386,8 & 2193,6 \\
\hline & II & 4 & 1,2723 & 82,446 & 2376,0 & 4232,0 & 1856,1 \\
\hline & II & 5 & Ausfalltier & & & & \\
\hline & II & 6 & Ausfalltier & & & & \\
\hline & & MW & 1,0946 & 73,032 & 2184,5 & 4132,4 & 1948,0 \\
\hline & & SD & 0,26 & 15,88 & 232,13 & 361,23 & 178,24 \\
\hline \multirow[t]{14}{*}{ N2 $(30,6 \%)$} & I & 1 & 0,9934 & 66,046 & 1514,8 & 3322,9 & 1808,1 \\
\hline & I & 2 & 0,9910 & 69,724 & 1876,1 & 3513,7 & 1637,6 \\
\hline & I & 3 & 1,1035 & 70,184 & 1706,9 & 3291,0 & 1584,1 \\
\hline & I & 4 & 1,0727 & 70,490 & 1851,1 & 3368,7 & 1517,6 \\
\hline & I & 5 & 1,0176 & 66,046 & 1525,8 & 3269,8 & 1743,9 \\
\hline & I & 6 & 0,9015 & 70,031 & 1800,1 & 3760,3 & 1960,2 \\
\hline & II & 1 & 1,4211 & 86,734 & 1651,2 & 3432,9 & 1781,8 \\
\hline & II & 2 & 1,4115 & 91,637 & 1767,8 & 3643,7 & 1875,9 \\
\hline & II & 3 & 1,4968 & 91,637 & 1700,0 & 3503,2 & 1803,2 \\
\hline & II & 4 & 1,4617 & 91,944 & 1872,7 & 3571,2 & 1698,6 \\
\hline & II & 5 & 1,4157 & 90,105 & 1994,4 & 3575,6 & 1581,2 \\
\hline & II & 6 & 1,3334 & 91,637 & 1957,4 & 3785,2 & 1827,8 \\
\hline & & MW & 1,2183 & 79,685 & 1768,2 & 3503,2 & 1735,0 \\
\hline & & SD & 0,22 & 11,59 & 154,47 & 173,32 & 133,47 \\
\hline \multirow[t]{14}{*}{ N3 $(24,4 \%)$} & I & 1 & 1,0358 & 68,253 & 1218,8 & 2925,4 & 1706,6 \\
\hline & I & 2 & 1,0430 & 69,615 & 1303,4 & 2969,8 & 1666,5 \\
\hline & I & 3 & Ausfalltier & & & & \\
\hline & I & 4 & Ausreißer & & & & \\
\hline & I & 5 & 1,0212 & 69,615 & 1073,7 & 3012,1 & 1938,4 \\
\hline & I & 6 & 1,1162 & 69,615 & 1356,7 & 2837,9 & 1481,2 \\
\hline & II & 1 & 1,3225 & 76,425 & 1244,7 & 2780,9 & 1536,1 \\
\hline & II & 2 & 1,4248 & 90,651 & 1348,1 & 3138,0 & 1789,9 \\
\hline & II & 3 & Ausfalltier & & & & \\
\hline & II & 4 & 1,4012 & 75,971 & 1386,0 & 2659,4 & 1273,4 \\
\hline & II & 5 & 1,3939 & 90,802 & 1270,8 & 3189,6 & 1918,8 \\
\hline & II & 6 & 1,4526 & 90,802 & 1397,0 & 3102,7 & 1705,7 \\
\hline & & MW & 1,246 & 77,972 & 1288,8 & 2957,3 & 1668,5 \\
\hline & & SD & 0,19 & 10,00 & 101,82 & 175,39 & 212,66 \\
\hline \multirow[t]{13}{*}{ N4 (18,3\%) } & I & 1 & 1,0503 & 69,269 & 954,5 & 2230,9 & 1276,4 \\
\hline & I & 2 & 1,0237 & 66,838 & 942,3 & 2190,0 & 1247,7 \\
\hline & I & 3 & 1,0521 & 69,877 & 1012,9 & 2247,9 & 1235,0 \\
\hline & I & 4 & Ausfalltier & & & & \\
\hline & I & 5 & 1,0696 & 57,724 & 860,1 & 1836,5 & 976,4 \\
\hline & I & 6 & Ausfalltier & & & & \\
\hline & II & 1 & 1,2590 & 67,750 & 696,1 & 1932,5 & 1236,4 \\
\hline & II & 2 & 1,2257 & 68,813 & 789,9 & 1998,3 & 1208,5 \\
\hline & II & 3 & 1,3352 & 87,801 & 1004,1 & 2407,7 & 1403,6 \\
\hline & II & 4 & Ausfalltier & & & & \\
\hline & II & 5 & 1,1664 & 48,914 & 698,9 & 1468,4 & 769,6 \\
\hline & II & 6 & Ausfalltier & & & & \\
\hline & & MW & 1,1478 & 67,123 & 869,8 & 2039,0 & 1169,2 \\
\hline
\end{tabular}




\begin{tabular}{|c|c|c|c|c|c|c|c|}
\hline $\begin{array}{l}\text { Diät } \\
\text { (XP) }\end{array}$ & SP* & $\begin{array}{c}\text { SD } \\
\text { Tier- } \\
\text { nr. }\end{array}$ & $\begin{array}{c}\text { 0,12 } \\
\text { Mittlere } \\
\text { LM (kg) }\end{array}$ & $\begin{array}{c}11,10 \\
\text { TS- } \\
\text { Aufnahme } \\
\text { (g/Tag) }\end{array}$ & $\begin{array}{c}129,19 \\
\text { NEX } \\
\left(\mathrm{mg} / \mathrm{LM}_{\mathrm{kg}}{ }^{0,67}\right)\end{array}$ & $\begin{array}{c}\text { 297,31 } \\
\text { N-Aufnahme } \\
\text { (mg/LM }_{\text {kg }}{ }^{0,67} \text { ) }\end{array}$ & $\begin{array}{c}199,95 \\
\text { ND } \\
\left(\mathrm{mg} / \mathrm{LM} \mathbf{k g}^{0,67}\right)\end{array}$ \\
\hline \multirow[t]{14}{*}{ N5 $(12,2 \%)$} & $\mathrm{I}$ & 1 & 0,9420 & 62,170 & 604,2 & 1533,0 & 928,8 \\
\hline & I & 2 & 1,0231 & 70,407 & 756,6 & 1642,7 & 886,2 \\
\hline & I & 3 & 1,0303 & 71,495 & 802,7 & 1660,2 & 857,6 \\
\hline & I & 4 & 1,0394 & 71,495 & 719,2 & 1650,5 & 931,3 \\
\hline & I & 5 & 1,0430 & 71,495 & 731,5 & 1646,7 & 915,2 \\
\hline & I & 6 & 0,9759 & 70,252 & 682,3 & 1691,8 & 1009,5 \\
\hline & II & 1 & 1,0448 & 50,979 & 516,2 & 1172,8 & 656,6 \\
\hline & II & 2 & 1,2142 & 78,178 & 658,1 & 1626,2 & 968,2 \\
\hline & II & 3 & 1,2179 & 83,152 & 661,9 & 1726,2 & 1064,4 \\
\hline & II & 4 & Ausreißer & & & & \\
\hline & II & 5 & 1,2300 & 84,861 & 656,1 & 1750,1 & 1094,0 \\
\hline & II & 6 & 1,1664 & 79,422 & 600,7 & 1697,2 & 1096,5 \\
\hline & & MW & 1,0843 & 72,173 & 671,7 & 1618,0 & 946,2 \\
\hline & & SD & 0,10 & 9,63 & 80,38 & 158,33 & 126,37 \\
\hline \multirow[t]{14}{*}{ N6 (6,1\%) } & I & 1 & 0,7460 & 18,806 & 397,3 & 279,7 & $-117,5$ \\
\hline & I & 2 & 0,7466 & 28,443 & 481,1 & 422,8 & $-58,3$ \\
\hline & I & 3 & Ausfalltier & & & & \\
\hline & I & 4 & 0,7169 & 19,117 & 421,2 & 292,0 & $-129,2$ \\
\hline & I & 5 & Ausreißer & & & & \\
\hline & I & 6 & 0,6970 & 17,407 & 386,6 & 271,0 & $-115,6$ \\
\hline & II & 1 & 0,6595 & 10,103 & 313,5 & 163,2 & $-150,3$ \\
\hline & II & 2 & 0,6716 & 18,495 & 366,9 & 295,2 & $-71,8$ \\
\hline & II & 3 & Ausfalltier & & & & \\
\hline & II & 4 & 0,6419 & 11,035 & 255,9 & 181,5 & $-74,4$ \\
\hline & II & 5 & 0,6915 & 13,833 & 266,6 & 216,5 & $-50,1$ \\
\hline & II & 6 & 0,6123 & 11,657 & 321,1 & 197,9 & $-123,2$ \\
\hline & & MW & 0,687 & 16,544 & 356,7 & 257,8 & $-98,9$ \\
\hline & & SD & 0,05 & 5,71 & 73,89 & 79,46 & 35,6 \\
\hline
\end{tabular}

*SP = Sammelperiode 
Tabelle A 12: Mittlere Lebendmasse, TS-Aufnahme, N-Aufnahme, N-Ausscheidung (NEX), N-Deposition (ND) und Proteinqualität (b) im Versuchs 2, Starterperiode

\begin{tabular}{|c|c|c|c|c|c|c|c|c|}
\hline Diät & $\mathrm{SP}^{*}$ & $\begin{array}{c}\text { Tier- } \\
\text { nr. }\end{array}$ & $\begin{array}{l}\text { Mittlere } \\
\text { LM (kg) }\end{array}$ & $\begin{array}{c}\text { TS- } \\
\text { Aufnahme } \\
\text { (g/Tag) }\end{array}$ & $\begin{array}{l}\text { N-Aufnahme } \\
\left(\mathrm{mg} / \mathrm{LM}_{\mathrm{kg}}^{0,67}\right)\end{array}$ & $\begin{array}{c}\mathrm{NEX} \\
\left(\mathrm{mg} / \mathrm{LM}_{\mathrm{kg}}{ }^{0,67}\right)\end{array}$ & $\begin{array}{c}\mathrm{ND} \\
(\mathrm{mg} / \mathrm{LM} \\
\mathrm{kg}\end{array}$ & $\begin{array}{c}b \\
\left(b^{*} 10^{6}\right)\end{array}$ \\
\hline \multirow[t]{18}{*}{$\mathrm{NC}$} & I & 1 & 0,3525 & 45,619 & 3029,0 & 1400,8 & 1628,3 & 218,5 \\
\hline & I & 2 & 0,3835 & 50,234 & 3152,3 & 1416,6 & 1735,7 & 227,0 \\
\hline & I & 3 & 0,3765 & 52,882 & 3359,7 & 1535,6 & 1824,1 & 226,8 \\
\hline & I & 4 & 0,4160 & 63,096 & 3749,4 & 1655,6 & 2093,8 & 244,9 \\
\hline & I & 5 & 0,4075 & 54,093 & 3259,1 & 1482,4 & 1776,8 & 226,1 \\
\hline & I & 6 & 0,3725 & 49,024 & 3136,9 & 1256,2 & 1880,7 & 252,7 \\
\hline & I & 7 & 0,4120 & 61,280 & 3665,1 & 1764,8 & 1900,4 & 219,3 \\
\hline & I & 8 & 0,2600 & 29,354 & 2389,9 & 1097,1 & 1292,8 & 213,8 \\
\hline & II & 1 & 0,5050 & 57,573 & 3004,4 & 1336,0 & 1668,5 & 226,9 \\
\hline & II & 2 & 0,5425 & 59,616 & 2965,3 & 1254,9 & 1710,4 & 237,0 \\
\hline & II & 3 & 0,5645 & 67,484 & 3268,4 & 1531,7 & 1736,7 & 219,1 \\
\hline & II & 4 & 0,6580 & 81,253 & 3551,2 & 1405,4 & 2145,8 & 267,9 \\
\hline & II & 5 & 0,6350 & 72,931 & 3264,4 & 1504,5 & 1759,9 & 223,0 \\
\hline & II & 6 & 0,5365 & 61,809 & 3097,4 & 1261,3 & 1836,1 & 248,1 \\
\hline & II & 7 & 0,6600 & 75,125 & 3276,7 & 1588,2 & 1688,5 & 211,1 \\
\hline & II & 8 & 0,3700 & 47,738 & 3068,4 & 1218,7 & 1849,7 & 252,8 \\
\hline & & MW & 0,4658 & 58,069 & 3202,4 & 1419,4 & 1783,0 & 232,2 \\
\hline & & SD & 0,12 & 12,81 & 316,02 & 177,24 & 192,70 & 16,48 \\
\hline \multirow[t]{16}{*}{$\mathrm{M}+\mathrm{C} \mathrm{I}$} & I & 1 & 0,5235 & 70,757 & 3638,0 & 995,8 & 2642,2 & 368,4 \\
\hline & I & 2 & 0,4925 & 65,081 & 3485,9 & 1016,3 & 2469,6 & 340,6 \\
\hline & I & 3 & 0,5260 & 73,405 & 3762,2 & 1128,6 & 2633,6 & 354,1 \\
\hline & I & 4 & 0,5310 & 75,676 & 3854,0 & 1392,7 & 2461,4 & 306,3 \\
\hline & I & 5 & 0,5110 & 74,616 & 3899,1 & 1288,9 & 2610,2 & 336,0 \\
\hline & I & 6 & 0,5010 & 74,616 & 3951,0 & 1394,4 & 2556,6 & 319,3 \\
\hline & I & 7 & 0,5060 & 75,600 & 3976,6 & 1539,3 & 2437,3 & 292,0 \\
\hline & II & 1 & 0,8780 & 103,297 & 3755,9 & 1167,6 & 2588,3 & 343,4 \\
\hline & II & 2 & 0,7940 & 85,892 & 3340,7 & 965,7 & 2375,1 & 333,0 \\
\hline & II & 3 & 0,8785 & 99,741 & 3625,2 & 1079,6 & 2545,6 & 345,3 \\
\hline & II & 4 & 0,8790 & 97,016 & 3524,9 & 1388,0 & 2136,8 & 268,3 \\
\hline & II & 5 & 0,8650 & 94,897 & 3485,2 & 1305,0 & 2180,1 & 279,5 \\
\hline & II & 6 & 0,8495 & 100,724 & 3744,3 & 1225,7 & 2518,5 & 328,1 \\
\hline & II & 7 & 0,8535 & 103,524 & 3836,2 & 1328,6 & 2507,6 & 317,8 \\
\hline & & MW & 0,6849 & 85,346 & 3705,7 & 1229,7 & 2475,9 & 323,7 \\
\hline & & SD & 0,18 & 13,89 & 194,37 & 175,45 & 154,86 & 28,70 \\
\hline \multirow[t]{16}{*}{$\mathrm{M}+\mathrm{C}$ II } & I & 1 & 0,4870 & 58,776 & 3200,9 & 823,8 & 2377,1 & 348,1 \\
\hline & I & 2 & 0,5100 & 65,399 & 3453,1 & 942,5 & 2510,7 & 353,8 \\
\hline & I & 3 & 0,4805 & 65,173 & 3581,4 & 1074,2 & 2507,2 & 340,3 \\
\hline & I & 4 & 0,4245 & 59,303 & 3540,9 & 1226,8 & 2314,1 & 301,4 \\
\hline & I & 5 & 0,5020 & 69,086 & 3686,7 & 1139,2 & 2547,5 & 340,0 \\
\hline & I & 6 & 0,5000 & 65,173 & 3487,2 & 1013,6 & 2473,6 & 341,4 \\
\hline & I & 7 & 0,5085 & 68,409 & 3619,2 & 873,1 & 2746,1 & 399,2 \\
\hline & II & 1 & 0,7775 & 76,838 & 3058,6 & 701,8 & 2356,7 & 359,2 \\
\hline & II & 2 & 0,8520 & 87,600 & 3279,6 & 816,0 & 2463,7 & 360,5 \\
\hline & II & 3 & 0,7755 & 81,203 & 3237,9 & 1178,3 & 2059,6 & 277,1 \\
\hline & II & 4 & 0,7200 & 96,330 & 4037,0 & 1306,0 & 2731,0 & 354,0 \\
\hline & II & 5 & 0,8260 & 98,437 & 3762,7 & 1302,6 & 2460,0 & 313,5 \\
\hline & II & 6 & 0,8295 & 92,341 & 3519,7 & 905,2 & 2614,5 & 373,3 \\
\hline & II & 7 & 0,8680 & 99,415 & 3675,9 & 933,9 & 2742,0 & 391,9 \\
\hline & & MW & 0,6472 & 77,392 & 3510,0 & 1016,9 & 2493,1 & 346,7 \\
\hline & & SD & 0,17 & 14,92 & 255,49 & 191,37 & 187,091 & 32,92 \\
\hline
\end{tabular}

$* \mathrm{SP}=$ Sammelperiode 


\begin{tabular}{|c|c|c|c|c|c|c|c|c|}
\hline Diät & $\mathrm{SP}^{*}$ & $\begin{array}{l}\text { Tier- } \\
\text { nr. }\end{array}$ & $\begin{array}{l}\text { Mittlere } \\
\text { LM (kg) }\end{array}$ & $\begin{array}{c}\text { TS- } \\
\text { Aufnahme } \\
\text { (g/Tag) }\end{array}$ & $\begin{array}{l}\text { N-Aufnahme } \\
\left(\mathrm{mg} / \mathrm{LM}_{\mathrm{kg}}{ }^{0,67}\right)\end{array}$ & $\begin{array}{c}\text { NEX } \\
\left(\mathrm{mg}^{\mathrm{L}} \mathrm{M}_{\mathrm{kg}}{ }^{0,67}\right)\end{array}$ & $\begin{array}{c}\text { ND } \\
\left(\mathrm{mg} / \mathrm{L} \mathbf{M}_{\mathrm{kg}}{ }^{0,67}\right)\end{array}$ & $\begin{array}{c}\text { b } \\
\left(b^{*} 10^{6}\right)\end{array}$ \\
\hline \multirow{16}{*}{$\begin{array}{c}\mathrm{MHA}+\mathrm{C} \\
\mathrm{I}\end{array}$} & I & 1 & 0,4970 & 67,291 & 3590,5 & 1141,2 & 2449,3 & 326,1 \\
\hline & I & 2 & 0,5150 & 74,005 & 3855,7 & 1321,9 & 2533,8 & 322,0 \\
\hline & I & 3 & 0,5080 & 71,105 & 3738,8 & 1167,6 & 2571,2 & 340,9 \\
\hline & I & 4 & 0,5170 & 73,776 & 3833,8 & 1355,3 & 2478,6 & 311,6 \\
\hline & I & 5 & 0,4945 & 68,435 & 3663,9 & 1233,3 & 2430,6 & 315,5 \\
\hline & I & 6 & 0,4895 & 69,427 & 3742,4 & 1201,6 & 2540,8 & 333,4 \\
\hline & I & 7 & 0,4600 & 62,179 & 3494,3 & 1185,8 & 2308,5 & 304,2 \\
\hline & II & 1 & 0,7790 & 78,506 & 3099,8 & 1044,9 & 2054,9 & 288,5 \\
\hline & II & 2 & 0,8600 & 104,522 & 3862,4 & 1439,9 & 2422,4 & 297,6 \\
\hline & II & 3 & 0,8460 & 89,950 & 3360,6 & 1012,4 & 2348,3 & 325,0 \\
\hline & II & 4 & 0,8660 & 102,996 & 3788,3 & 1367,0 & 2421,3 & 303,1 \\
\hline & II & 5 & 0,8105 & 95,596 & 3675,6 & 1396,9 & 2278,7 & 283,4 \\
\hline & II & 6 & 0,8025 & 88,043 & 3407,8 & 1185,6 & 2222,2 & 294,1 \\
\hline & \multirow[t]{3}{*}{ II } & 7 & 0,7595 & 96,359 & 3869,9 & 1421,2 & 2448,6 & 302,4 \\
\hline & & MW & 0,6575 & 81,585 & 3641,7 & 1248,2 & 2393,5 & 310,6 \\
\hline & & SD & $\mathbf{0 , 1 7}$ & 14,28 & 228,36 & 137,27 & 140,28 & 17,26 \\
\hline MHA+ & I & 1 & 0,4605 & 52,402 & 2976,1 & 743,5 & 2232,6 & 339,2 \\
\hline \multirow[t]{15}{*}{ C II } & I & 2 & 0,4890 & 62,943 & 3433,9 & 940,3 & 2493,6 & 351,6 \\
\hline & I & 3 & 0,4745 & 65,846 & 3665,4 & 1296,4 & 2369,0 & 302,3 \\
\hline & I & 4 & 0,4265 & 49,193 & 2941,3 & 762,1 & 2179,2 & 330,9 \\
\hline & I & 5 & 0,4615 & 56,144 & 3184,1 & 740,9 & 2443,2 & 366,2 \\
\hline & I & 6 & 0,4045 & 50,797 & 3146,9 & 913,3 & 2233,6 & 321,0 \\
\hline & I & 7 & 0,4560 & 53,471 & 3056,9 & 787,3 & 2269,6 & 338,7 \\
\hline & II & 1 & 0,7375 & 76,922 & 3186,6 & 842,4 & 2344,2 & 341,8 \\
\hline & II & 2 & 0,7945 & 82,727 & 3260,3 & 934,2 & 2326,1 & 330,0 \\
\hline & II & 3 & 0,7780 & 91,130 & 3642,3 & 1367,0 & 2275,3 & 285,3 \\
\hline & II & 4 & 0,6720 & 72,109 & 3179,3 & 993,1 & 2186,2 & 307,6 \\
\hline & II & 5 & 0,7335 & 67,679 & 2813,9 & 562,0 & 2251,9 & 363,5 \\
\hline & II & 6 & 0,6820 & 82,804 & 3614,8 & 1238,0 & 2376,8 & 308,1 \\
\hline & \multirow[t]{3}{*}{ II } & 7 & 0,6805 & 65,998 & 2885,4 & 832,4 & 2053,0 & 309,5 \\
\hline & & MW & 0,5893 & 66,440 & 3213,4 & 925,2 & 2288,2 & 328,3 \\
\hline & & SD & 0,15 & 13,34 & 281,40 & 231,36 & 114,57 & 23,85 \\
\hline
\end{tabular}

*SP = Sammelperiode 
Tabelle A 13: Mittlere Lebendmasse, TS-Aufnahme, N-Aufnahme, N-Ausscheidung (NEX), N-Deposition (ND) und Proteinqualität (b) im Versuchs 2, Growerperiode

\begin{tabular}{|c|c|c|c|c|c|c|c|c|}
\hline Diät & $\mathbf{S P}^{*}$ & $\begin{array}{c}\text { Tier- } \\
\text { nr. }\end{array}$ & $\begin{array}{l}\text { Mittlere } \\
\text { LM (kg) }\end{array}$ & $\begin{array}{c}\text { TS-Aufnahme } \\
\text { (g/Tag) }\end{array}$ & $\begin{array}{l}\text { N-Aufnahme } \\
\left.\text { (mg/LM }{ }_{k g}{ }^{0,67}\right)\end{array}$ & $\begin{array}{c}\text { NEX } \\
\left(\mathrm{mg}^{0} / \mathrm{LM}_{\mathrm{kg}}{ }^{0,67}\right)\end{array}$ & $\begin{array}{c}\mathrm{ND} \\
\left(\mathrm{mg} / \mathrm{LM}_{\mathrm{kg}}{ }^{0,67}\right)\end{array}$ & $\begin{array}{c}b \\
\left(b^{*} 10^{6}\right)\end{array}$ \\
\hline \multirow[t]{18}{*}{$\mathrm{NC}$} & I & 1 & 1,4920 & 144,588 & 3335,3 & 1693,7 & 1641,7 & 294,6 \\
\hline & I & 2 & 1,4335 & 120,784 & 2861,9 & 1542,8 & 1319,1 & 257,8 \\
\hline & I & 3 & 1,5355 & 147,462 & 3336,7 & 1715,3 & 1621,4 & 289,3 \\
\hline & I & 4 & 1,4765 & 125,648 & 2918,8 & 1554,0 & 1364,8 & 263,5 \\
\hline & I & 5 & 1,2815 & 89,980 & 2298,3 & 1114,1 & 1184,2 & 283,3 \\
\hline & I & 6 & 1,3765 & 118,058 & 2874,4 & 1590,5 & 1283,9 & 248,6 \\
\hline & I & 7 & 1,4980 & 140,756 & 3238,2 & 1782,4 & 1455,8 & 257,7 \\
\hline & I & 8 & Ausreißer & & & & & \\
\hline & II & 1 & 1,8605 & 162,569 & 3234,6 & 1642,1 & 1592,5 & 291,0 \\
\hline & II & 2 & 1,6695 & 126,975 & 2716,5 & 1324,7 & 1391,8 & 290,1 \\
\hline & II & 3 & 1,9355 & 170,086 & 3295,7 & 1657,2 & 1638,5 & 297,3 \\
\hline & II & 4 & 1,7785 & 143,998 & 2952,9 & 1546,0 & 1407,0 & 270,5 \\
\hline & II & 5 & 1,4725 & 96,908 & 2255,2 & 1216,0 & 1039,3 & 250,7 \\
\hline & II & 6 & 1,6340 & 130,881 & 2840,7 & 1464,7 & 1376,0 & 273,5 \\
\hline & II & 7 & 1,8850 & 179,003 & 3530,5 & 1803,8 & 1726,6 & 299,7 \\
\hline & II & 8 & 1,5665 & 136,186 & 3040,6 & 1332,8 & 1707,8 & 342,4 \\
\hline & & MW & 1,5930 & 135,592 & 2982,0 & 1532,0 & 1450,0 & 280,7 \\
\hline & & SD & 0,20 & 24,52 & 368,36 & 205,29 & 201,26 & 24,40 \\
\hline \multirow[t]{16}{*}{$\mathrm{M}+\mathrm{C} \mathrm{I}$} & I & 1 & 1,5460 & 148,051 & 3368,5 & 1233,9 & 2134,6 & 455,1 \\
\hline & I & 2 & 1,4945 & 141,521 & 3293,9 & 978,6 & 2315,3 & 560,6 \\
\hline & I & 3 & 1,5540 & 147,610 & 3346,9 & 1108,1 & 2238,8 & 508,4 \\
\hline & I & 4 & 1,5415 & 146,877 & 3348,4 & 1150,2 & 2198,1 & 487,5 \\
\hline & I & 5 & 1,5450 & 144,529 & 3289,8 & 929,8 & 2360,0 & 590,3 \\
\hline & I & 6 & 1,5560 & 138,660 & 3141,3 & 970,6 & 2170,7 & 505,6 \\
\hline & I & 7 & 1,6105 & 143,722 & 3181,7 & 835,5 & 2346,2 & 600,8 \\
\hline & II & 1 & 2,0410 & 180,698 & 3413,2 & 1246,0 & 2167,2 & 463,7 \\
\hline & II & 2 & 2,0545 & 172,334 & 3240,9 & 997,9 & 2242,9 & 527,3 \\
\hline & II & 3 & 2,0840 & 181,138 & 3374,0 & 1123,9 & 2250,1 & 510,3 \\
\hline & II & 4 & 2,0690 & 177,690 & 3325,9 & 1125,5 & 2200,4 & 492,0 \\
\hline & II & 5 & 2,0760 & 170,574 & 3185,4 & 985,6 & 2199,8 & 513,3 \\
\hline & II & 6 & 2,0375 & 156,634 & 2962,1 & 872,2 & 2089,8 & 495,8 \\
\hline & II & 7 & 2,1130 & 163,164 & 3011,2 & 909,6 & 2101,6 & 493,2 \\
\hline & & MW & 1,8088 & 158,086 & 3248,8 & 1033,4 & 2215,4 & 514,6 \\
\hline & & SD & 0,27 & 15,67 & 137,30 & 130,98 & 83,60 & 42,76 \\
\hline \multirow[t]{16}{*}{$\mathrm{M}+\mathrm{C}$ II } & I & 1 & 1,5930 & 148,082 & 3335,0 & 1078,5 & 2256,6 & 519,8 \\
\hline & I & 2 & 1,6090 & 149,487 & 3344,2 & 1235,6 & 2108,6 & 447,0 \\
\hline & I & 3 & 1,6010 & 138,836 & 3116,3 & 948,8 & 2167,5 & 508,1 \\
\hline & I & 4 & 1,6420 & 142,608 & 3147,2 & 873,9 & 2273,3 & 560,6 \\
\hline & I & 5 & 1,6230 & 148,747 & 3308,4 & 1002,6 & 2305,9 & 552,4 \\
\hline & I & 6 & 1,6030 & 142,238 & 3190,0 & 812,5 & 2377,5 & 621,4 \\
\hline & I & 7 & 1,6605 & 152,668 & 3344,0 & 1168,2 & 2175,9 & 477,4 \\
\hline & II & 1 & 2,1340 & 172,195 & 3188,2 & 1092,9 & 2095,2 & 463,0 \\
\hline & II & 2 & 2,1210 & 165,612 & 3078,9 & 1006,2 & 2072,7 & 469,3 \\
\hline & II & 3 & 2,1160 & 161,174 & 3001,1 & 958,0 & 2043,2 & 468,3 \\
\hline & II & 4 & 2,1695 & 169,458 & 3103,0 & 877,3 & 2225,8 & 541,1 \\
\hline & II & 5 & 2,1825 & 175,967 & 3209,4 & 692,5 & 2516,9 & 740,2 \\
\hline & II & 6 & 2,1365 & 167,165 & 3092,6 & 897,6 & 2195,0 & 526,2 \\
\hline & II & 7 & 2,2100 & 179,591 & 3248,1 & 956,6 & 2291,5 & 553,9 \\
\hline & & MW & 1,8858 & 158,130 & 3193,3 & 971,5 & 2221,8 & 532,0 \\
\hline & & SD & 0,28 & 13,62 & 110,42 & 142,70 & 128,86 & 76,88 \\
\hline
\end{tabular}

\footnotetext{
$* \mathrm{SP}=$ Sammelperiode
} 


\begin{tabular}{|c|c|c|c|c|c|c|c|c|}
\hline Diät & $\mathbf{S P}^{*}$ & $\begin{array}{c}\text { Tier- } \\
\text { nr. }\end{array}$ & $\begin{array}{l}\text { Mittlere } \\
\text { LM (kg) }\end{array}$ & $\begin{array}{c}\text { TS- } \\
\text { Aufnahme } \\
\text { (g/Tag) }\end{array}$ & $\begin{array}{l}\text { N-Aufnahme } \\
\left(\mathrm{mg}^{-} \mathbf{L M}_{\mathrm{kg}}{ }^{0,67}\right)\end{array}$ & $\begin{array}{c}\text { NEX } \\
\left(\mathrm{mg}^{0, \mathrm{LM}_{\mathrm{kg}}}{ }^{0,67}\right)\end{array}$ & $\begin{array}{c}\mathrm{ND} \\
\left(\mathrm{mg} / \mathrm{L} \mathrm{M}_{\mathrm{kg}}{ }^{0,67}\right)\end{array}$ & $\begin{array}{c}b \\
\left(b^{*} 10^{6}\right)\end{array}$ \\
\hline MHA+ & I & 1 & 1,4710 & 144,303 & 3402,9 & 1077,6 & 2325,2 & 548,7 \\
\hline \multirow[t]{15}{*}{ C I } & I & 2 & 1,4785 & 135,022 & 3173,2 & 1012,7 & 2160,5 & 495,5 \\
\hline & I & 3 & 1,4835 & 149,828 & 3513,2 & 1351,3 & 2161,9 & 448,2 \\
\hline & I & 4 & 1,5745 & 151,154 & 3405,7 & 1353,2 & 2052,5 & 416,3 \\
\hline & I & 5 & 1,5695 & 141,651 & 3198,4 & 931,3 & 2267,1 & 548,0 \\
\hline & I & 6 & 1,5380 & 146,218 & 3346,7 & 1222,4 & 2124,2 & 453,5 \\
\hline & I & 7 & Ausreißer & & & & & \\
\hline & II & 1 & 1,9685 & 163,087 & 3163,9 & 1014,2 & 2149,6 & 491,7 \\
\hline & II & 2 & 1,9745 & 159,257 & 3083,3 & 906,6 & 2176,7 & 518,2 \\
\hline & II & 3 & 1,9905 & 172,663 & 3324,8 & 1187,9 & 2136,9 & 462,1 \\
\hline & II & 4 & 2,0790 & 176,493 & 3300,9 & 1260,2 & 2040,7 & 424,8 \\
\hline & II & 5 & 2,0550 & 165,518 & 3119,8 & 955,7 & 2164,1 & 505,8 \\
\hline & II & 6 & 2,0880 & 177,009 & 3301,0 & 1122,7 & 2178,3 & 484,8 \\
\hline & \multirow[t]{3}{*}{ II } & 7 & 2,0530 & 178,630 & 3369,2 & 1065,4 & 2303,7 & 541,2 \\
\hline & & MW & 1,7941 & 158,526 & 3284,8 & 1112,4 & 2172,4 & 487,6 \\
\hline & & SD & 0,27 & 14,89 & 127,85 & 152,07 & 84,54 & 44,73 \\
\hline MHA+ & I & 1 & 1,6775 & 148,885 & 3254,8 & 986,9 & 2267,9 & 539,0 \\
\hline \multirow[t]{15}{*}{ C II } & I & 2 & 1,5950 & 149,182 & 3373,4 & 998,7 & 2374,7 & 585,6 \\
\hline & I & 3 & 1,5915 & 150,591 & 3410,2 & 919,6 & 2490,6 & 671,1 \\
\hline & I & 4 & 1,5915 & 155,040 & 3511,0 & 997,7 & 2513,3 & 673,1 \\
\hline & I & 5 & 1,5530 & 144,659 & 3330,1 & 953,8 & 2376,3 & 594,3 \\
\hline & I & 6 & 1,6080 & 149,404 & 3360,1 & 981,9 & 2378,2 & 590,4 \\
\hline & I & 7 & 1,5765 & 147,551 & 3362,7 & 934,8 & 2427,9 & 626,6 \\
\hline & II & 1 & 2,2825 & 179,730 & 3196,6 & 807,9 & 2388,7 & 628,3 \\
\hline & II & 2 & 2,0990 & 171,055 & 3218,0 & 937,3 & 2280,7 & 552,7 \\
\hline & II & 3 & 2,1595 & 178,989 & 3303,7 & 960,8 & 2342,9 & 576,5 \\
\hline & II & 4 & 2,0460 & 153,260 & 2933,1 & 1062,6 & 1870,4 & 409,6 \\
\hline & II & 5 & 2,0955 & 174,688 & 3290,0 & 1199,6 & 2090,5 & 446,6 \\
\hline & II & 6 & 2,1395 & 176,542 & 3279,0 & 968,9 & 2310,0 & 559,9 \\
\hline & \multirow[t]{3}{*}{ II } & 7 & 2,0790 & 167,051 & 3162,9 & 908,5 & 2254,4 & 546,8 \\
\hline & & MW & 1,8639 & 160,473 & 3284,7 & 972,8 & 2311,9 & 571,5 \\
\hline & & SD & 0,28 & 13,33 & 136,07 & 87,02 & 165,34 & 74,20 \\
\hline
\end{tabular}

*SP $=$ Sammelperiode 
Tabelle A 14: Ganzkörperanalyse, Versuch 3 (1. LT)

\begin{tabular}{cccccc}
\hline Null-Tiere & \% TS & \% XA & \% N & \% XP & \% XL \\
& & in TS & In TS & in TS & in TS \\
\hline 1 & 23,35 & 8,2398 & 10,54 & 65,87 & 25,89 \\
2 & 23,47 & 8,2533 & 10,84 & 67,75 & 24,00 \\
3 & 22,85 & 8,46 & 11,19 & 69,93 & 21,61 \\
MW & $\mathbf{2 3 , 2 2}$ & $\mathbf{8 , 3 2}$ & $\mathbf{1 0 , 8 6}$ & $\mathbf{6 7 , 8 5}$ & $\mathbf{2 3 , 8 3}$ \\
SD & $\mathbf{0 , 3 3}$ & $\mathbf{0 , 1 2}$ & $\mathbf{0 , 3 3}$ & $\mathbf{2 , 0 3}$ & $\mathbf{2 , 1 5}$ \\
\hline
\end{tabular}

Tabelle A 15: Ganzkörperanalyse, Versuch 3 (35. LT)

\begin{tabular}{|c|c|c|c|c|c|c|}
\hline Diät & Tiernummer & $\%$ TS & $\begin{array}{l}\% \mathrm{XA} \\
\text { in TS }\end{array}$ & $\begin{array}{c}\% \mathrm{~N} \\
\text { in TS }\end{array}$ & $\begin{array}{l}\% \mathrm{XP} \\
\text { in TS }\end{array}$ & $\begin{array}{l}\% \mathrm{XL} \\
\text { in TS }\end{array}$ \\
\hline \multirow[t]{6}{*}{$\mathrm{NC}$} & 1 & 31,96 & 8,78 & 8,94 & 55,88 & 35,34 \\
\hline & 2 & 34,55 & 8,54 & 8,37 & 52,31 & 39,15 \\
\hline & 3 & 29,06 & 7,80 & 10,19 & 63,68 & 28,51 \\
\hline & 4 & 32,49 & 7,63 & 8,80 & 54,97 & 37,40 \\
\hline & MW & 32,02 & 8,19 & 9,07 & 56,71 & 35,10 \\
\hline & SD & 2,26 & 0,56 & 0,78 & 4,89 & 4,66 \\
\hline \multirow[t]{7}{*}{$\mathrm{M}+\mathrm{C} \mathrm{I}$} & 1 & 34,71 & 6,92 & 8,43 & 52,70 & 40,38 \\
\hline & 2 & 34,86 & 7,43 & 8,52 & 53,25 & 39,32 \\
\hline & 3 & 37,12 & 7,08 & 8,45 & 52,84 & 40,08 \\
\hline & 4 & 37,86 & 5,51 & 7,75 & 48,42 & 46,07 \\
\hline & 5 & 34,43 & 7,61 & 8,65 & 54,08 & 38,31 \\
\hline & MW & 35,80 & 6,91 & 8,36 & 52,26 & 40,83 \\
\hline & SD & 1,57 & 0,83 & 0,35 & 2,21 & 3,04 \\
\hline \multirow{7}{*}{$\mathrm{M}+\mathrm{C}$ II } & 1 & 34,22 & 7,31 & 8,64 & 53,99 & 38,70 \\
\hline & 2 & 37,15 & 6,45 & 7,75 & 48,46 & 45,09 \\
\hline & 3 & 35,64 & 6,24 & 8,46 & 52,87 & 40,89 \\
\hline & 4 & 34,81 & 7,10 & 8,68 & 54,24 & 38,66 \\
\hline & & 35,82 & 7,01 & 8,41 & 52,57 & 40,42 \\
\hline & MW & 35,53 & 6,82 & 8,39 & 52,43 & 40,75 \\
\hline & SD & 1,11 & 0,45 & 0,37 & 2,33 & 2,62 \\
\hline \multirow[t]{7}{*}{$\mathrm{MHA}+\mathrm{C} \mathrm{I}$} & 1 & 37,24 & 6,68 & 7,57 & 47,31 & 46,01 \\
\hline & 2 & 36,64 & 7,43 & 8,20 & 51,26 & 41,31 \\
\hline & 3 & 33,56 & 7,58 & 8,89 & 55,56 & 36,86 \\
\hline & 4 & 35,32 & 6,81 & 8,40 & 52,52 & 40,67 \\
\hline & 5 & 35,12 & 7,34 & 8,65 & 54,06 & 38,61 \\
\hline & MW & 35,58 & 7,17 & 8,34 & 52,14 & 40,69 \\
\hline & SD & 1,43 & 0,40 & 0,50 & 3,15 & 3,45 \\
\hline \multirow[t]{7}{*}{$\mathrm{MHA}+\mathrm{C}$ II } & 1 & 33,64 & 7,30 & 9,14 & 57,11 & 35,59 \\
\hline & 2 & 36,06 & 6,88 & 8,30 & 51,86 & 41,26 \\
\hline & 3 & 34,69 & 7,13 & 8,60 & 53,77 & 39,10 \\
\hline & 4 & 35,84 & 7,02 & 8,55 & 53,44 & 39,54 \\
\hline & 5 & 33,89 & 6,57 & 8,76 & 54,75 & 38,68 \\
\hline & MW & 34,82 & 6,98 & 8,67 & 54,19 & 38,83 \\
\hline & SD & 1,10 & 0,28 & 0,31 & 1,94 & 2,06 \\
\hline
\end{tabular}


Tabelle A 16: Anfangs-, Endmasse, Futteraufnahme, Zuwachs und Futteraufwand, Versuch 3

\begin{tabular}{|c|c|c|c|c|c|c|}
\hline Diät & Box & $\begin{array}{l}\text { Anfangs- } \\
\text { masse (g) }\end{array}$ & $\begin{array}{c}\text { Endmasse } \\
\text { (g) }\end{array}$ & $\begin{array}{c}\text { Futterauf- } \\
\text { nahme (g/d) }\end{array}$ & $\begin{array}{c}\text { Zuwachs } \\
\text { (g/d) }\end{array}$ & $\begin{array}{c}\text { Futteraufwand } \\
(\mathrm{g} / \mathrm{g})\end{array}$ \\
\hline \multicolumn{7}{|c|}{ Starterperiode $(1 .-3$. Woche $)$} \\
\hline \multirow[t]{6}{*}{$\mathrm{NC}$} & 1 & 55,00 & 371,90 & 38,23 & 15,09 & 2,53 \\
\hline & 2 & 55,13 & 347,30 & 35,92 & 13,91 & 2,58 \\
\hline & 3 & 54,38 & 334,60 & 34,59 & 13,34 & 2,59 \\
\hline & 4 & 54,00 & 340,10 & 32,64 & 13,62 & 2,40 \\
\hline & MW & 54,63 & 348,48 & 35,35 & 13,99 & 2,53 \\
\hline & SD & 0,50 & 16,5 & 2,35 & 0,77 & 0,09 \\
\hline \multirow[t]{7}{*}{$\mathrm{M}+\mathrm{C} \mathrm{I}$} & 1 & 54,63 & 1047,30 & 70,43 & 47,27 & 1,49 \\
\hline & 2 & 55,50 & 1043,90 & 69,58 & 47,07 & 1,48 \\
\hline & 3 & 55,50 & 1079,40 & 69,92 & 48,76 & 1,43 \\
\hline & 4 & 56,75 & 1129,80 & 74,19 & 51,10 & 1,45 \\
\hline & 5 & 54,75 & 1092,00 & 71,98 & 49,39 & 1,46 \\
\hline & MW & 55,43 & 1078,48 & 71,22 & 48,72 & 1,46 \\
\hline & SD & 0,85 & 35,30 & 1,90 & 1,65 & 0,02 \\
\hline \multirow[t]{7}{*}{$\mathrm{M}+\mathrm{C}$ II } & 1 & 56,10 & 1093,80 & 68,13 & 49,41 & 1,38 \\
\hline & 2 & 54,50 & 1133,20 & 74,14 & 51,37 & 1,44 \\
\hline & 3 & 54,90 & 1144,90 & 73,09 & 51,90 & 1,41 \\
\hline & 4 & 55,00 & 1211,40 & 75,23 & 55,07 & 1,37 \\
\hline & 5 & 54,60 & 1163,70 & 75,96 & 52,81 & 1,44 \\
\hline & MW & 55,02 & 1149,40 & 73,31 & 52,11 & 1,41 \\
\hline & SD & 0,64 & 43,08 & 3,09 & 2,07 & 0,03 \\
\hline \multirow[t]{7}{*}{$\mathrm{MHA}+\mathrm{C} \mathrm{I}$} & 1 & 55,30 & 924,10 & 65,41 & 41,37 & 1,58 \\
\hline & 2 & 57,10 & 1020,10 & 69,80 & 45,86 & 1,52 \\
\hline & 3 & 55,10 & 1007,70 & 70,42 & 45,36 & 1,55 \\
\hline & 4 & 48,00 & 1036,40 & 70,55 & 47,07 & 1,50 \\
\hline & 5 & 55,80 & 998,90 & 69,50 & 44,91 & 1,55 \\
\hline & MW & 54,26 & 997,44 & 69,14 & 44,91 & 1,54 \\
\hline & SD & 3,59 & 43,35 & 2,13 & 2,14 & 0,03 \\
\hline \multirow{7}{*}{$\mathrm{MHA}+\mathrm{C}$ II } & 1 & 54,00 & 986,50 & 66,06 & 44,40 & 1,49 \\
\hline & 2 & 55,13 & 958,44 & 67,06 & 43,02 & 1,56 \\
\hline & 3 & 54,63 & 1018,80 & 67,45 & 45,91 & 1,47 \\
\hline & 4 & 56,63 & 1020,00 & 71,45 & 45,88 & 1,56 \\
\hline & 5 & 55,13 & 1004,60 & 68,06 & 45,21 & 1,51 \\
\hline & MW & 55,10 & 997,67 & 68,02 & 44,88 & 1,52 \\
\hline & SD & $\mathbf{0 , 9 7}$ & 25,8 & 2,05 & 1,21 & 0,04 \\
\hline
\end{tabular}




\begin{tabular}{|c|c|c|c|c|c|c|}
\hline Diät & Box & $\begin{array}{l}\text { Anfangs- } \\
\text { masse (g) }\end{array}$ & $\begin{array}{c}\text { Endmasse } \\
\text { (g) }\end{array}$ & $\begin{array}{c}\text { Futterauf- } \\
\text { nahme (g/d) }\end{array}$ & $\begin{array}{c}\text { Zuwachs } \\
\text { (g/d) }\end{array}$ & $\begin{array}{c}\text { Futteraufwand } \\
(\mathrm{g} / \mathrm{g})\end{array}$ \\
\hline \multicolumn{7}{|c|}{ Growerperiode (3. - 5. Woche) } \\
\hline \multirow[t]{6}{*}{$\mathrm{NC}$} & 1 & 371,90 & 723,00 & 90,9 & 25,08 & 3,62 \\
\hline & 2 & 347,30 & 704,20 & 86,5 & 25,49 & 3,39 \\
\hline & 3 & 334,60 & 653,00 & 100,2 & 22,74 & 4,40 \\
\hline & 4 & 340,10 & 746,60 & 94,4 & 29,04 & 3,25 \\
\hline & MW & 348,48 & 706,70 & 92,98 & 25,59 & 3,67 \\
\hline & SD & 16,5 & 39,78 & 5,79 & 2,60 & 0,51 \\
\hline \multirow[t]{7}{*}{$\mathrm{M}+\mathrm{C} \mathrm{I}$} & 1 & 1047,30 & 2637,33 & 185,3 & 113,57 & 1,63 \\
\hline & 2 & 1043,90 & 2400,00 & 188,5 & 96,86 & 1,95 \\
\hline & 3 & 1079,40 & 2518,80 & 181,4 & 102,81 & 1,76 \\
\hline & 4 & 1129,80 & 2533,90 & 186,4 & 100,29 & 1,86 \\
\hline & 5 & 1092,00 & 2371,80 & 183,3 & 91,41 & 2,00 \\
\hline & MW & 1078,48 & 2492,37 & 184,97 & 100,99 & 1,84 \\
\hline & SD & 35,30 & 107,83 & 2,73 & 8,23 & 0,15 \\
\hline \multirow[t]{7}{*}{$\mathrm{M}+\mathrm{C}$ II } & 1 & 1093,80 & 2600,30 & 184,63 & 107,61 & 1,72 \\
\hline & 2 & 1133,20 & 2621,80 & 182,06 & 106,33 & 1,71 \\
\hline & 3 & 1144,90 & 2748,10 & 191,66 & 114,51 & 1,67 \\
\hline & 4 & 1211,40 & 2803,70 & 195,08 & 113,74 & 1,72 \\
\hline & 5 & 1163,70 & 2765,00 & 198,06 & 114,38 & 1,73 \\
\hline & MW & 1149,40 & 2707,78 & 190,30 & 111,31 & 1,71 \\
\hline & SD & 43,08 & 90,89 & 6,80 & 4,00 & 0,02 \\
\hline \multirow[t]{7}{*}{$\mathrm{MHA}+\mathrm{C} \mathrm{I}$} & 1 & 924,10 & 2242,10 & 171,05 & 94,14 & 1,82 \\
\hline & 2 & 1020,10 & 2365,40 & 173,93 & 96,09 & 1,81 \\
\hline & 3 & 1007,70 & 1899,00 & 148,92 & 63,66 & 2,34 \\
\hline & 4 & 1036,40 & 2180,30 & 159,37 & 81,71 & 1,95 \\
\hline & 5 & 998,90 & 2130,10 & 181,22 & 80,80 & 2,24 \\
\hline & MW & 997,44 & 2163,38 & 166,90 & 83,28 & 2,03 \\
\hline & SD & 43,35 & 171,97 & 12,76 & 13,00 & 0,25 \\
\hline \multirow[t]{7}{*}{$\mathrm{MHA}+\mathrm{C} \mathrm{II}$} & 1 & 986,50 & 2315,30 & 161,24 & 94,91 & 1,70 \\
\hline & 2 & 958,44 & 2514,43 & 168,16 & 111,14 & 1,51 \\
\hline & 3 & 1018,80 & 2478,89 & 172,52 & 104,29 & 1,65 \\
\hline & 4 & 1020,00 & 2545,71 & 191,69 & 108,98 & 1,76 \\
\hline & 5 & 1004,60 & 2355,90 & 175,92 & 96,52 & 1,82 \\
\hline & MW & 997,67 & 2442,05 & 173,91 & 103,17 & 1,69 \\
\hline & SD & 25,8 & 101,03 & 11,36 & 7,26 & 0,12 \\
\hline
\end{tabular}


Tabelle A 17: Mittlere Lebendmasse, TS-Aufnahme, N-Aufnahme, N-Ausscheidung (NEX), N-Deposition (ND) und Proteinqualität (b) im Versuchs 4, Starterperiode

\begin{tabular}{|c|c|c|c|c|c|c|c|c|}
\hline Diät & SP* & $\begin{array}{c}\text { Tier- } \\
\text { nr. }\end{array}$ & $\begin{array}{l}\text { Mittlere } \\
\text { LM (kg) }\end{array}$ & $\begin{array}{c}\text { TS-Aufnahme } \\
\text { (g/Tag) }\end{array}$ & $\begin{array}{l}\text { N-Aufnahme } \\
\left(\mathrm{mg} / \mathrm{LM}_{\mathrm{kg}}{ }^{0,67}\right)\end{array}$ & $\begin{array}{c}\mathrm{NEX} \\
\left(\mathrm{mg} / \mathrm{LM}_{\mathrm{kg}}{ }^{0,67}\right)\end{array}$ & $\begin{array}{c}\text { ND } \\
\left(\mathrm{mg} / \mathrm{LM}_{\mathrm{kg}}{ }^{0,67}\right)\end{array}$ & $\begin{array}{c}\text { b } \\
\left(b^{*} 10^{6}\right)\end{array}$ \\
\hline \multirow[t]{18}{*}{$\mathrm{NC}$} & I & 1 & 0,3555 & 51,867 & 3370,5 & 1817,2 & 1553,3 & 185,8 \\
\hline & I & 2 & 0,2705 & 40,851 & 3187,9 & 1668,7 & 1519,2 & 191,5 \\
\hline & I & 3 & 0,2920 & 36,108 & 2677,0 & 1066,3 & 1610,8 & 244,1 \\
\hline & I & 4 & 0,2290 & 26,469 & 2309,4 & 835,1 & 1474,4 & 255,4 \\
\hline & I & 5 & 0,3210 & 46,665 & 3247,1 & 1479,2 & 1767,8 & 225,5 \\
\hline & I & 6 & 0,2925 & 40,545 & 3002,6 & 1228,2 & 1774,3 & 245,0 \\
\hline & I & 7 & 0,2560 & 32,895 & 2663,6 & 1121,1 & 1542,5 & 233,2 \\
\hline & I & 8 & 0,2970 & 41,004 & 3005,7 & 1433,5 & 1572,1 & 211,3 \\
\hline & II & 1 & 0,5170 & 58,599 & 2962,9 & 1469,4 & 1493,5 & 202,0 \\
\hline & II & 2 & 0,3895 & 46,971 & 2871,1 & 1576,9 & 1294,2 & 178,2 \\
\hline & II & 3 & 0,4475 & 54,315 & 3025,2 & 1594,2 & 1431,0 & 188,6 \\
\hline & II & 4 & 0,2895 & 44,217 & 3297,2 & 1716,2 & 1581,0 & 193,9 \\
\hline & II & 5 & 0,4575 & 52,326 & 2871,5 & 1467,8 & 1403,7 & 194,5 \\
\hline & II & 6 & 0,3980 & 46,206 & 2783,8 & 1279,7 & 1504,0 & 216,7 \\
\hline & II & 7 & 0,3285 & 29,376 & 2012,7 & 947,4 & 1065,3 & 208,8 \\
\hline & II & 8 & 0,3990 & 42,840 & 2576,7 & 1425,3 & 1151,4 & 176,0 \\
\hline & & MW & 0,3463 & 43,204 & 2866,5 & 1382,9 & 1483,7 & 209,4 \\
\hline & & SD & 0,08 & 8,95 & 362,15 & 281,08 & 189,64 & 25,02 \\
\hline \multirow[t]{16}{*}{ M I } & I & 1 & 0,4385 & 125,400 & 4088,157 & 1649,7 & 2438,4 & 284,2 \\
\hline & I & 2 & 0,4385 & 113,407 & 3697,190 & 1053,1 & 2644,1 & 363,0 \\
\hline & I & 3 & 0,4145 & 116,141 & 3786,326 & 1099,5 & 2686,9 & 365,5 \\
\hline & I & 4 & 0,4315 & 120,171 & 3917,688 & 1326,8 & 2590,9 & 329,9 \\
\hline & I & 5 & 0,4720 & 116,883 & 3810,499 & 1474,9 & 2335,6 & 284,2 \\
\hline & I & 6 & 0,4460 & 129,654 & 4226,840 & 1212,1 & 3014,8 & 421,4 \\
\hline & I & 7 & 0,4110 & 113,808 & 3710,260 & 1598,8 & 2111,5 & 250,5 \\
\hline & II & 1 & 0,7585 & 115,399 & 3762,121 & 1512,3 & 2249,8 & 271,5 \\
\hline & II & 2 & 0,7515 & 115,573 & 3767,791 & 1276,8 & 2491,0 & 319,8 \\
\hline & II & 3 & 0,6885 & 115,233 & 3756,710 & 1472,3 & 2284,4 & 278,4 \\
\hline & II & 4 & 0,7075 & 108,609 & 3540,767 & 1593,0 & 1947,8 & 234,6 \\
\hline & II & 5 & 0,7830 & 117,210 & 3821,161 & 1639,5 & 2181,7 & 255,2 \\
\hline & II & 6 & 0,7630 & 115,122 & 3753,105 & 1691,8 & 2061,3 & 239,3 \\
\hline & II & 7 & 0,7210 & 112,100 & 3654,574 & 1300,9 & 2353,7 & 300,0 \\
\hline & & MW & 0,5875 & 116,765 & 3807 & 1421,5 & 2385,1 & 299,8 \\
\hline & & SD & 0,16 & 5,33 & 173,81 & 210,30 & 284,91 & 54,41 \\
\hline \multirow[t]{16}{*}{ M II } & I & 1 & 0,4385 & 63,220 & 3592,0 & 1205,4 & 2386,5 & 312,2 \\
\hline & I & 2 & 0,4040 & 61,564 & 3695,3 & 892,4 & 2802,9 & 407,9 \\
\hline & I & 3 & 0,4350 & 63,521 & 3628,5 & 992,1 & 2636,4 & 367,8 \\
\hline & I & 4 & 0,4225 & 60,059 & 3498,4 & 868,7 & 2629,7 & 379,7 \\
\hline & I & 5 & 0,4480 & 74,057 & 4147,7 & 1471,4 & 2676,4 & 331,1 \\
\hline & I & 6 & 0,4770 & 72,552 & 3896,2 & 1339,5 & 2556,7 & 323,8 \\
\hline & I & 7 & 0,4305 & 61,865 & 3558,6 & 670,5 & 2888,1 & 452,0 \\
\hline & II & 1 & 0,7500 & 88,959 & 3527,8 & 1291,4 & 2236,3 & 286,9 \\
\hline & II & 2 & 0,6880 & 89,260 & 3750,4 & 1188,9 & 2561,4 & 337,5 \\
\hline & II & 3 & 0,7300 & 93,174 & 3762,4 & 1249,9 & 2512,6 & 325,1 \\
\hline & II & 4 & 0,6975 & 91,217 & 3797,5 & 974,1 & 2823,5 & 403,1 \\
\hline & II & 5 & 0,7915 & 98,592 & 3771,2 & 1352,0 & 2419,2 & 304,1 \\
\hline & II & 6 & 0,8395 & 101,001 & 3713,9 & 1250,4 & 2463,6 & 318,4 \\
\hline & II & 7 & 0,7490 & 95,130 & 3775,9 & 893,8 & 2882,1 & 424,0 \\
\hline & & MW & 0,5929 & 79,584 & 3722,6 & 1117,2 & 2605,4 & 355,3 \\
\hline & & SD & 0,167 & 15,66 & 167,77 & 233,13 & 196,41 & 50,55 \\
\hline
\end{tabular}




\begin{tabular}{|c|c|c|c|c|c|c|c|c|}
\hline Diät & SP* & $\begin{array}{c}\text { Tier- } \\
\text { nr. }\end{array}$ & $\begin{array}{l}\text { Mittlere } \\
\text { LM (kg) }\end{array}$ & $\begin{array}{c}\text { TS-Aufnahme } \\
\text { (g/Tag) }\end{array}$ & $\begin{array}{l}\text { N-Aufnahme } \\
\left(\mathrm{mg}^{\prime} \mathbf{L M}_{\mathrm{kg}}{ }^{0,67}\right)\end{array}$ & $\begin{array}{c}\text { NEX } \\
\left(\mathrm{mg}^{\mathrm{L}} \mathrm{LM}_{\mathrm{kg}}{ }^{0,67}\right)\end{array}$ & $\begin{array}{c}\text { ND } \\
\left(\mathrm{mg} / \mathrm{LM}_{\mathrm{kg}}{ }^{0,67}\right)\end{array}$ & $\begin{array}{c}\text { B } \\
\left(b^{*} 10^{6}\right)\end{array}$ \\
\hline \multirow[t]{16}{*}{ MHA I } & I & 1 & 0,3985 & 64,172 & 3884,2 & 1319,9 & 2564,4 & 326,5 \\
\hline & I & 2 & 0,4525 & 70,665 & 3928,1 & 1133,5 & 2794,6 & 381,3 \\
\hline & I & 3 & 0,4360 & 71,873 & 4095,9 & 2256,1 & 1839,8 & 188,1 \\
\hline & I & 4 & 0,4275 & 68,400 & 3949,8 & 1445,0 & 2504,8 & 308,0 \\
\hline & I & 5 & 0,4500 & 73,836 & 4119,6 & 1235,7 & 2883,9 & 389,2 \\
\hline & I & 6 & 0,3930 & 61,303 & 3745,3 & 1005,7 & 2739,6 & 384,0 \\
\hline & I & 7 & Ausreißer & & & & & \\
\hline & II & 1 & 0,6405 & 92,257 & 4063,3 & 1546,8 & 2516,4 & 301,9 \\
\hline & II & 2 & 0,7475 & 98,448 & 3909,6 & 1200,3 & 2709,3 & 359,8 \\
\hline & II & 3 & 0,6910 & 97,240 & 4070,4 & 1827,7 & 2242,7 & 249,7 \\
\hline & II & 4 & 0,7460 & 99,656 & 3962,9 & 1646,1 & 2316,7 & 269,8 \\
\hline & II & 5 & 0,7410 & 95,881 & 3830,0 & 1605,5 & 2224,5 & 262,1 \\
\hline & II & 6 & 0,6555 & 96,938 & 4203,7 & 1114,8 & 3088,9 & 451,5 \\
\hline & II & 7 & 0,7630 & 99,354 & 3891,7 & 1822,6 & 2069,1 & 232,0 \\
\hline & & MW & 0,5802 & 83,848 & 3973,4 & 1473,8 & 2499,6 & 315,7 \\
\hline & & SD & 0,15 & 15,33 & 129,41 & 357,20 & 351,65 & 75,14 \\
\hline \multirow[t]{16}{*}{ MHA II } & I & 1 & Ausreißer & & & & & \\
\hline & I & 2 & 0,4020 & 58,650 & 3548,5 & 880,8 & 2667,6 & 384,6 \\
\hline & I & 3 & 0,3780 & 62,259 & 3925,4 & 1253,3 & 2672,2 & 348,8 \\
\hline & I & 4 & 0,3940 & 62,861 & 3854,8 & 1278,4 & 2576,4 & 331,8 \\
\hline & I & 5 & 0,3830 & 60,605 & 3787,6 & 1168,2 & 2619,5 & 348,2 \\
\hline & I & 6 & 0,4145 & 55,191 & 3271,4 & 911,8 & 2359,6 & 336,5 \\
\hline & I & 7 & 0,4510 & 64,816 & 3630,7 & 868,4 & 2762,2 & 402,8 \\
\hline & II & 1 & 0,7130 & 77,298 & 3185,7 & 1076,4 & 2109,2 & 291,3 \\
\hline & II & 2 & 0,6920 & 80,907 & 3401,9 & 936,4 & 2465,5 & 348,0 \\
\hline & II & 3 & 0,6520 & 82,411 & 3606,1 & 1461,9 & 2144,2 & 263,6 \\
\hline & II & 4 & 0,6775 & 82,110 & 3501,8 & 1209,7 & 2292,1 & 300,2 \\
\hline & II & 5 & 0,6345 & 69,779 & 3109,5 & 1020,4 & 2089,2 & 294,4 \\
\hline & II & 6 & 0,6615 & 71,734 & 3108,6 & 1158,4 & 1950,2 & 267,6 \\
\hline & II & 7 & 0,7740 & 87,524 & 3414,1 & 910,7 & 2503,4 & 356,0 \\
\hline & & MW & 0,5559 & 70,473 & 3488,2 & 1087,3 & 2400,9 & 328,8 \\
\hline & & SD & 0,15 & 10,62 & 272,67 & 185,04 & 263,52 & 42,76 \\
\hline
\end{tabular}

*SP = Sammelperiode 
Tabelle A 18: Mittlere Lebendmasse, TS-Aufnahme, N-Aufnahme, N-Ausscheidung (NEX), N-Deposition (ND) und Proteinqualität (b) im Versuchs 4, Growerperiode

\begin{tabular}{|c|c|c|c|c|c|c|c|}
\hline Diät & Box & $\begin{array}{l}\text { Mittlere } \\
\text { LM (kg) }\end{array}$ & $\begin{array}{c}\text { TS-Aufnahme } \\
\text { (g/Tag) }\end{array}$ & $\begin{array}{l}\text { N-Aufnahme } \\
\left(\mathrm{mg} \mathrm{LM}_{\mathrm{kg}}{ }^{0,67}\right)\end{array}$ & $\begin{array}{c}\text { NEX } \\
\left(\mathrm{mg} / \mathrm{LM}_{\mathrm{kg}}{ }^{0,67}\right)\end{array}$ & $\begin{array}{c}\text { ND } \\
\left(\mathrm{mg} / \mathrm{LM}_{\mathrm{kg}}{ }^{0,67}\right)\end{array}$ & $\begin{array}{c}b \\
\left(b^{*} 10^{6}\right)\end{array}$ \\
\hline \multirow[t]{18}{*}{$\mathrm{NC}$} & 1 & 0,6620 & 38,388 & 1501,5 & 888,2 & 613,3 & 232,8 \\
\hline & 2 & 0,8645 & 88,459 & 2893,4 & 1324,8 & 1568,7 & 318,5 \\
\hline & 3 & 0,6950 & 46,278 & 1752,0 & 1125,7 & 626,3 & 202,9 \\
\hline & 4 & 0,5775 & 56,747 & 2432,2 & 1266,7 & 1165,5 & 263,0 \\
\hline & 5 & 1,0540 & 99,232 & 2842,2 & 1351,9 & 1490,2 & 302,7 \\
\hline & 6 & 0,8495 & 61,147 & 2023,7 & 1267,0 & 756,7 & 206,1 \\
\hline & 7 & 1,0505 & 105,301 & 3022,7 & 1322,8 & 1700,0 & 342,0 \\
\hline & 8 & 0,9325 & 62,058 & 1929,5 & 1273,7 & 655,7 & 191,3 \\
\hline & 9 & 0,7105 & 37,477 & 1398,1 & 866,2 & 531,8 & 223,9 \\
\hline & 10 & 0,9745 & 103,632 & 3128,3 & 1061,3 & 2067,0 & 459,4 \\
\hline & 11 & 0,7480 & 46,733 & 1684,3 & 901,3 & 782,9 & 255,3 \\
\hline & 12 & 0,7390 & 75,713 & 2751,0 & 996,9 & 1754,1 & 394,1 \\
\hline & 13 & 1,3185 & 113,343 & 2794,1 & 1323,7 & 1470,4 & 302,5 \\
\hline & 14 & 0,9895 & 57,658 & 1722,8 & 1121,9 & 600,9 & 199,6 \\
\hline & 15 & 1,2245 & 128,212 & 3321,2 & 1287,4 & 2033,9 & 419,5 \\
\hline & 16 & 1,0435 & 63,575 & 1833,2 & 1117,5 & 715,7 & 216,7 \\
\hline & MW & 0,9021 & 73,997 & 2314,4 & 1156,1 & 1158,3 & 283,1 \\
\hline & SD & 0,21 & 28,62 & 645,73 & 170,66 & 556,81 & 84,41 \\
\hline \multirow[t]{15}{*}{ M I } & 1 & 1,0400 & 98,958 & 2872,6 & 1373,0 & 1499,6 & 301,9 \\
\hline & 2 & 1,2655 & 123,141 & 3134,2 & 1382,4 & 1751,8 & 345,2 \\
\hline & 3 & 1,3420 & 126,701 & 3100,5 & 1447,2 & 1653,3 & 320,1 \\
\hline & 4 & 0,8865 & 94,655 & 3058,0 & 1200,0 & 1858,1 & 388,5 \\
\hline & 5 & 1,0810 & 106,672 & 3017,4 & 1169,4 & 1848,0 & 390,2 \\
\hline & 6 & 1,1530 & 114,832 & 3110,9 & 1427,0 & 1683,9 & 327,7 \\
\hline & 7 & 1,2235 & 122,102 & 3178,9 & 1304,7 & 1874,2 & 379,1 \\
\hline & 8 & 1,3630 & 124,031 & 3003,7 & 1350,9 & 1652,8 & 330,3 \\
\hline & 9 & 1,6105 & 129,223 & 2798,5 & 1368,4 & 1430,1 & 291,4 \\
\hline & 10 & 1,7815 & 134,416 & 2720,6 & 1422,9 & 1297,7 & 266,0 \\
\hline & 11 & 1,1100 & 111,123 & 3088,0 & 1042,4 & 2045,7 & 456,2 \\
\hline & 12 & 1,5705 & 144,653 & 3185,9 & 1539,2 & 1646,7 & 309,7 \\
\hline & 13 & 1,6630 & 144,950 & 3072,3 & 1064,8 & 2007,5 & 442,6 \\
\hline & MW & 1,3146 & 121,189 & 3026,3 & 1314,8 & 1711,5 & 349,9 \\
\hline & SD & 0,27 & 15,68 & 144,20 & 151,51 & 218,83 & 57,75 \\
\hline \multirow[t]{15}{*}{ M II } & 1 & 1,2575 & 128,000 & 3283,0 & 1441,5 & 1841,4 & 356,6 \\
\hline & 2 & 1,2475 & 127,702 & 3292,9 & 1298,7 & 1994,2 & 407,9 \\
\hline & 3 & 1,1675 & 115,363 & 3109,8 & 964,8 & 2145,1 & 498,0 \\
\hline & 4 & 1,2320 & 115,066 & 2992,0 & 945,7 & 2046,3 & 471,1 \\
\hline & 5 & 0,9840 & 94,402 & 2853,7 & 895,0 & 1958,7 & 455,7 \\
\hline & 5 & 1,0435 & 98,713 & 2868,9 & 979,3 & 1889,6 & 425,9 \\
\hline & 6 & 1,6720 & 152,529 & 3232,3 & 971,7 & 2260,6 & 538,6 \\
\hline & 7 & 1,7720 & 172,004 & 3505,9 & 1393,5 & 2112,4 & 428,0 \\
\hline & 8 & 1,7520 & 159,665 & 3279,2 & 1058,2 & 2221,1 & 509,5 \\
\hline & 9 & 1,6375 & 141,082 & 3031,8 & 1083,2 & 1948,6 & 425,0 \\
\hline & 10 & 1,6580 & 138,109 & 2943,3 & 1075,3 & 1868,0 & 407,2 \\
\hline & 11 & 1,2590 & 89,793 & 2301,2 & 784,1 & 1517,1 & 382,8 \\
\hline & 12 & 1,3730 & 119,823 & 2897,6 & 1058,2 & 1839,3 & 403,3 \\
\hline & MW & 1,3889 & 127,096 & 3045,5 & 1073,0 & 1972,5 & 439,2 \\
\hline & SD & 0,27 & 25,24 & 300,08 & 194,12 & 195,97 & 52,73 \\
\hline
\end{tabular}




\begin{tabular}{|c|c|c|c|c|c|c|c|}
\hline Diät & Box & $\begin{array}{l}\text { Mittlere } \\
\text { LM (kg) }\end{array}$ & $\begin{array}{l}\text { TS-Aufnahme } \\
\text { (g/Tag) }\end{array}$ & $\begin{array}{c}\text { N-Aufnahme } \\
\text { (mg/LM }_{\text {kg }} \text { (m,67 } \\
\text { ) }\end{array}$ & $\begin{array}{c}\text { NEX } \\
\left(\mathrm{mg}^{\mathrm{L}} \mathbf{M}_{\mathrm{kg}}{ }^{0,67}\right)\end{array}$ & $\begin{array}{c}\text { ND } \\
\left(\mathrm{mg} / \mathrm{LM} \mathbf{k g}^{0,67}\right)\end{array}$ & $\begin{array}{c}b \\
\left(b^{*} 10^{6}\right)\end{array}$ \\
\hline \multirow[t]{16}{*}{ MHA I } & 1 & 1,2075 & 119,763 & 3153,4 & 1356,2 & 1797,2 & 357,0 \\
\hline & 2 & 1,0475 & 110,699 & 3206,0 & 1419,1 & 1786,9 & 348,0 \\
\hline & 3 & 0,9005 & 76,821 & 2462,0 & 1105,3 & 1356,8 & 310,2 \\
\hline & 4 & 1,0195 & 106,539 & 3142,0 & 1339,4 & 1802,6 & 360,0 \\
\hline & 5 & 0,9770 & 92,868 & 2818,1 & 1323,4 & 1494,7 & 306,4 \\
\hline & 6 & 0,9775 & 93,611 & 2839,7 & 1281,4 & 1558,3 & 321,6 \\
\hline & 7 & 0,9525 & 82,913 & 2559,2 & 1073,9 & 1485,4 & 334,7 \\
\hline & 8 & 1,6410 & 153,196 & 3284,3 & 1336,2 & 1948,1 & 392,1 \\
\hline & 9 & 1,3825 & 118,723 & 2855,0 & 1221,8 & 1633,2 & 341,6 \\
\hline & 10 & 1,1050 & 87,371 & 2441,4 & 989,2 & 1452,2 & 340,7 \\
\hline & 11 & 1,3775 & 126,747 & 3055,4 & 1388,2 & 1667,2 & 328,8 \\
\hline & 12 & 1,2240 & 112,482 & 2934,9 & 1304,9 & 1630,0 & 331,3 \\
\hline & 13 & 1,2020 & 110,848 & 2927,6 & 1378,8 & 1548,8 & 309,4 \\
\hline & 14 & 1,1700 & 92,720 & 2493,5 & 962,0 & 1531,5 & 357,8 \\
\hline & MW & 1,1560 & 106,093 & 2869,5 & 1248,6 & 1620,9 & 338,5 \\
\hline & SD & 0,21 & 20,25 & 287,31 & 152,94 & 164,26 & 23,67 \\
\hline \multirow[t]{16}{*}{ MHA II } & 1 & 1,0145 & 88,149 & 2623,7 & 993,6 & 1630,1 & 370,7 \\
\hline & 2 & 1,1950 & 121,317 & 3235,7 & 1184,2 & 2051,5 & 437,7 \\
\hline & 3 & 1,1295 & 110,261 & 3054,0 & 991,9 & 2062,2 & 468,4 \\
\hline & 4 & 1,1025 & 121,765 & 3427,8 & 1496,7 & 1931,1 & 370,0 \\
\hline & 5 & 1,2215 & 118,030 & 3102,1 & 1005,1 & 2097,1 & 476,6 \\
\hline & 6 & 1,2650 & 128,937 & 3310,3 & 1429,4 & 1880,9 & 366,3 \\
\hline & 7 & 1,3740 & 143,130 & 3476,7 & 1324,3 & 2152,4 & 448,6 \\
\hline & 8 & 1,3885 & 129,235 & 3117,2 & 1071,0 & 2046,2 & 452,1 \\
\hline & 9 & 1,5610 & 134,465 & 2998,6 & 1269,5 & 1729,1 & 353,7 \\
\hline & 10 & 1,5020 & 127,144 & 2909,5 & 1175,2 & 1734,3 & 366,2 \\
\hline & 11 & 1,5225 & 142,383 & 3228,7 & 1411,3 & 1817,4 & 355,0 \\
\hline & 12 & 1,6625 & 142,831 & 3053,5 & 1043,2 & 2010,4 & 446,4 \\
\hline & 13 & 1,6840 & 151,796 & 3217,3 & 1425,2 & 1792,2 & 348,4 \\
\hline & 14 & 1,8400 & 157,622 & 3148,3 & 1379,9 & 1768,4 & 348,7 \\
\hline & MW & 1,3902 & 129,790 & 3136,0 & 1228,6 & 1907,4 & 400,6 \\
\hline & SD & 0,25 & 17,94 & 215,65 & 184,65 & 164,35 & 50,17 \\
\hline
\end{tabular}

Tabelle A 19: Ganzkörperanalyse, Versuch 5 (1. LT)

\begin{tabular}{cccccc}
\hline \multirow{2}{*}{ Null-Tiere } & \% TS & $\begin{array}{c}\text { \% XA } \\
\text { in TS }\end{array}$ & $\begin{array}{c}\text { \% N } \\
\text { in TS }\end{array}$ & $\begin{array}{c}\text { \% XP } \\
\text { in TS }\end{array}$ & $\begin{array}{c}\text { \% XL } \\
\text { in TS }\end{array}$ \\
\hline 1 & 21,21 & 8,95 & 11,38 & 71,11 & 19,94 \\
2 & 21,33 & 8,96 & 11,53 & 72,07 & 18,97 \\
3 & 21,68 & 8,91 & 11,36 & 71,01 & 20,08 \\
MW & $\mathbf{2 1 , 4 1}$ & $\mathbf{8 , 9 4}$ & $\mathbf{1 1 , 4 2}$ & $\mathbf{7 1 , 4 0}$ & $\mathbf{1 9 , 6 7}$ \\
SD & $\mathbf{0 , 2 4}$ & $\mathbf{0 , 0 3}$ & $\mathbf{0 , 0 9}$ & $\mathbf{0 , 5 8}$ & $\mathbf{0 , 6 0}$ \\
\hline
\end{tabular}


Tabelle A 20: Ganzkörperanalyse, Versuch 5 (35. LT)

\begin{tabular}{|c|c|c|c|c|c|c|}
\hline Diät & Tiernummer & $\%$ TS & $\begin{array}{l}\% \mathrm{XA} \\
\text { in TS }\end{array}$ & $\begin{array}{c}\% \mathrm{~N} \\
\text { in TS }\end{array}$ & $\begin{array}{l}\text { \% XP } \\
\text { in TS }\end{array}$ & $\begin{array}{l}\% \mathrm{XI} \\
\text { in TS }\end{array}$ \\
\hline \multirow[t]{6}{*}{$\mathrm{NC}$} & 1 & 32,25 & 9,27 & 8,87 & 55,42 & 35,31 \\
\hline & 2 & 31,89 & 9,92 & 9,30 & 58,15 & 31,94 \\
\hline & 3 & 32,43 & 10,21 & 9,05 & 56,53 & 33,26 \\
\hline & 4 & 33,74 & 9,69 & 8,69 & 54,30 & 36,02 \\
\hline & MW & 32,58 & 9,77 & 8,98 & 56,10 & 34,13 \\
\hline & SD & $\mathbf{0 , 8 0}$ & 0,40 & 0,26 & 1,64 & 1,87 \\
\hline \multirow[t]{7}{*}{ M I } & 1 & 35,22 & 7,40 & 7,83 & 48,95 & 43,65 \\
\hline & 2 & 35,55 & 7,41 & 8,59 & 53,71 & 38,88 \\
\hline & 3 & 35,50 & 6,38 & 8,10 & 50,65 & 42,97 \\
\hline & 4 & 34,24 & 8,00 & 8,61 & 53,79 & 38,21 \\
\hline & 5 & 35,41 & 7,30 & 8,47 & 52,92 & 39,78 \\
\hline & MW & 35,18 & 7,30 & 8,32 & 52,01 & 40,70 \\
\hline & SD & 0,54 & 0,58 & 0,34 & 2,13 & 2,46 \\
\hline \multirow[t]{7}{*}{ M II } & 1 & 35,59 & 6,97 & 8,16 & 50,97 & 42,06 \\
\hline & 2 & 37,12 & 6,96 & 8,03 & 50,22 & 42,82 \\
\hline & 3 & 36,37 & 7,35 & 8,17 & 51,07 & 41,57 \\
\hline & 4 & 33,77 & 7,55 & 8,83 & 55,18 & 37,26 \\
\hline & & 34,82 & 7,81 & 8,61 & 53,79 & 38,40 \\
\hline & MW & 35,53 & 7,33 & 8,36 & 52,25 & 40,42 \\
\hline & SD & 1,31 & 0,37 & 0,34 & 2,13 & 2,44 \\
\hline \multirow[t]{7}{*}{ MHA I } & 1 & 33,08 & 8,54 & 8,66 & 54,11 & 37,34 \\
\hline & 2 & 36,03 & 7,22 & 7,96 & 49,75 & 43,03 \\
\hline & 3 & 35,65 & 8,26 & 8,18 & 51,12 & 40,62 \\
\hline & 4 & 35,08 & 7,65 & 8,35 & 52,21 & 40,14 \\
\hline & 5 & 35,19 & 8,31 & 8,10 & 50,62 & 41,07 \\
\hline & MW & 35,01 & 8,00 & 8,25 & 51,56 & 40,44 \\
\hline & SD & 1,14 & 0,55 & 0,27 & 1,68 & 2,05 \\
\hline \multirow{7}{*}{ MHA II } & 1 & 35,88 & 7,14 & 7,99 & 49,95 & 42,91 \\
\hline & 2 & 34,55 & 7,39 & 8,29 & 51,80 & 40,81 \\
\hline & 3 & 35,92 & 7,42 & 8,26 & 51,63 & 40,94 \\
\hline & 4 & 35,41 & 7,49 & 8,54 & 53,36 & 39,16 \\
\hline & 5 & 36,42 & 7,44 & 7,95 & 49,66 & 42,91 \\
\hline & MW & 35,64 & 7,38 & 8,20 & 51,28 & 41,35 \\
\hline & SD & 0,70 & 0,13 & 0,24 & 1,51 & 1,59 \\
\hline
\end{tabular}

Tabelle A 21: Anfangs-, Endmasse, Futteraufnahme, Zuwachs und Futteraufwand, Versuch 5

\begin{tabular}{|c|c|c|c|c|c|c|}
\hline Diät & $\begin{array}{c}\text { Tier- } \\
\text { nr. }\end{array}$ & $\begin{array}{c}\text { Anfangsmasse } \\
\text { (g) }\end{array}$ & $\begin{array}{c}\text { Endmasse } \\
\text { (g) }\end{array}$ & $\begin{array}{c}\text { Futterauf- } \\
\text { nahme (g/d) }\end{array}$ & $\begin{array}{c}\text { Zuwachs } \\
\text { (g/d) }\end{array}$ & $\begin{array}{c}\text { Futteraufwand } \\
(\mathrm{g} / \mathrm{g})\end{array}$ \\
\hline \multicolumn{7}{|c|}{ Starterperiode (1 - 3 Woche) } \\
\hline \multirow[t]{6}{*}{$\mathrm{NC}$} & 1 & 48,89 & 332,22 & 32,77 & 13,49 & 2,43 \\
\hline & 2 & 48,67 & 349,67 & 34,61 & 14,33 & 2,41 \\
\hline & 3 & 48,56 & 321,67 & 29,10 & 13,01 & 2,24 \\
\hline & 4 & 48,56 & 385,67 & 37,67 & 16,05 & 2,35 \\
\hline & MW & 48,67 & 347,31 & 33,54 & 14,22 & 2,36 \\
\hline & SD & 0,16 & 28,06 & 3,58 & 1,34 & 0,09 \\
\hline \multirow[t]{7}{*}{ M I } & 1 & 48,22 & 735,44 & 53,31 & 32,72 & 1,63 \\
\hline & 2 & 49,00 & 653,67 & 48,43 & 28,79 & 1,68 \\
\hline & 3 & 49,00 & 745,22 & 55,01 & 33,15 & 1,66 \\
\hline & 4 & 48,44 & 657,44 & 49,55 & 29,00 & 1,71 \\
\hline & 5 & 48,56 & 782,88 & 56,45 & 34,97 & 1,61 \\
\hline & MW & 48,64 & 714,93 & 52,55 & 31,73 & 1,66 \\
\hline & SD & 0,35 & 57,04 & 3,46 & 2,72 & 0,04 \\
\hline
\end{tabular}




\begin{tabular}{|c|c|c|c|c|c|c|}
\hline Diät & $\begin{array}{c}\text { Tier- } \\
\text { nr. }\end{array}$ & $\begin{array}{c}\text { Anfangsmasse } \\
\text { (g) }\end{array}$ & $\begin{array}{c}\text { Endmasse } \\
\text { (g) }\end{array}$ & $\begin{array}{c}\text { Futterauf- } \\
\text { nahme (g/d) }\end{array}$ & $\begin{array}{c}\text { Zuwachs } \\
\text { (g/d) }\end{array}$ & $\begin{array}{c}\text { Futteraufwand } \\
(\mathrm{g} / \mathrm{g})\end{array}$ \\
\hline \multirow[t]{7}{*}{ M II } & 1 & 48,67 & 1024,11 & 65,58 & 46,45 & 1,41 \\
\hline & 2 & 48,56 & 1029,00 & 63,70 & 46,69 & 1,36 \\
\hline & 3 & 48,44 & 971,00 & 62,49 & 43,93 & 1,42 \\
\hline & 4 & 48,56 & 939,78 & 61,88 & 42,44 & 1,46 \\
\hline & 5 & 48,44 & 992,88 & 67,06 & 44,97 & 1,49 \\
\hline & MW & 48,53 & 991,35 & 64,14 & 44,90 & 1,43 \\
\hline & SD & 0,09 & 37,31 & 2,16 & 1,77 & 0,05 \\
\hline \multirow[t]{7}{*}{ MHA I } & 1 & 48,56 & 613,89 & 46,52 & 26,92 & 1,73 \\
\hline & 2 & 48,78 & 711,56 & 52,83 & 31,56 & 1,67 \\
\hline & 3 & 48,44 & 664,78 & 50,36 & 29,35 & 1,72 \\
\hline & 4 & 48,56 & 673,44 & 50,91 & 29,76 & 1,71 \\
\hline & 5 & 48,56 & 629,13 & 50,69 & 27,65 & 1,83 \\
\hline & MW & 48,58 & 658,56 & 50,26 & 29,05 & 1,73 \\
\hline & SD & 0,12 & 38,51 & 2,30 & 1,83 & 0,06 \\
\hline \multirow[t]{8}{*}{ MHA II } & 1 & 48,78 & 998,67 & 66,63 & 45,23 & 1,47 \\
\hline & 2 & 48,88 & 891,63 & 61,50 & 40,13 & 1,53 \\
\hline & 3 & 48,67 & 985,00 & 64,26 & 44,59 & 1,44 \\
\hline & 4 & 48,67 & 931,44 & 58,33 & 42,04 & 1,39 \\
\hline & 5 & 48,89 & 946,44 & 61,54 & 42,74 & 1,44 \\
\hline & MW & 48,78 & 950,64 & 62,45 & 42,95 & 1,45 \\
\hline & SD & 0,11 & 42,88 & 3,14 & 2,04 & 0,05 \\
\hline & \multicolumn{5}{|c|}{ Growerperiode (3. - 5. Woche) } & \\
\hline \multirow[t]{6}{*}{$\mathrm{NC}$} & 1 & 517,33 & 688 & 98,6 & 25,41 & 3,88 \\
\hline & 2 & 548,88 & 769,75 & 100,3 & 30,01 & 3,34 \\
\hline & 3 & 551,89 & 734,11 & 101,8 & 29,46 & 3,46 \\
\hline & 4 & 591,67 & 786,33 & 108,4 & 28,62 & 3,79 \\
\hline & MW & 552,44 & 744,55 & 102,28 & 28,37 & 3,62 \\
\hline & SD & 30,47 & 43,54 & 4,29 & 2,06 & 0,26 \\
\hline \multirow{7}{*}{ M I } & 1 & 1126,11 & 1591,22 & 131,9 & 61,13 & 2,16 \\
\hline & 2 & 1037,67 & 1420,44 & 127,8 & 54,77 & 2,33 \\
\hline & 3 & 1205,67 & 1692,44 & 146,7 & 67,66 & 2,17 \\
\hline & 4 & 1026,67 & 1393,86 & 128,1 & 52,60 & 2,44 \\
\hline & 5 & 1243,57 & 1724,43 & 141,9 & 67,25 & 2,11 \\
\hline & MW & 1127,94 & 1564,48 & 135,28 & 60,7 & 2,24 \\
\hline & SD & 97,24 & 152,09 & 8,56 & 6,9 & 0,14 \\
\hline \multirow[t]{7}{*}{ M II } & 1 & 1703,11 & 2431,89 & 179,2 & 100,56 & 1,78 \\
\hline & 2 & 1684,5 & 2461,25 & 181,1 & 102,30 & 1,77 \\
\hline & 3 & 1653,11 & 2449,67 & 179,7 & 105,62 & 1,7 \\
\hline & 4 & 1555,11 & 2277,56 & 166,8 & 95,56 & 1,75 \\
\hline & 5 & 1622 & 2369,5 & 171,3 & 98,33 & 1,74 \\
\hline & MW & 1643,57 & 2397,97 & 175,62 & 100,47 & 1,75 \\
\hline & SD & 58,31 & 76,05 & 6,24 & 3,83 & 0,03 \\
\hline \multirow[t]{7}{*}{ MHA I } & 1 & 955,56 & 1341,22 & 126,4 & 51,95 & 2,43 \\
\hline & 2 & 1068,33 & 1485,44 & 133,5 & 55,28 & 2,42 \\
\hline & 3 & 989,78 & 1426,11 & 140,3 & 54,38 & 2,58 \\
\hline & 4 & 950,67 & 1299,11 & 131,1 & 44,69 & 2,93 \\
\hline & 5 & 916 & 1307,86 & 132,7 & 48,48 & 2,74 \\
\hline & MW & 976,07 & 1371,95 & 132,80 & 50,96 & 2,62 \\
\hline & SD & 57,82 & 80,89 & 5,01 & 4,38 & 0,22 \\
\hline \multirow{7}{*}{ MHA II } & 1 & 1646,56 & 2447,78 & 191,8 & 103,51 & 1,85 \\
\hline & 2 & 1411,25 & 2095,13 & 166,4 & 85,96 & 1,94 \\
\hline & 3 & 1677,88 & 2441,63 & 183 & 104,04 & 1,76 \\
\hline & 4 & 1502,33 & 2204,11 & 170,7 & 90,90 & 1,88 \\
\hline & 5 & 1517,11 & 2194,33 & 170,8 & 89,13 & 1,92 \\
\hline & MW & 1551,03 & 2276,60 & 176,54 & 94,71 & 1,87 \\
\hline & SD & 109,86 & 159,29 & 10,54 & 8,46 & $\mathbf{0 , 0 7}$ \\
\hline
\end{tabular}


Tabelle A 22: Mittlere Lebendmasse, TS-Aufnahme, N-Aufnahme, N-Deposition (ND) und Proteinqualität (b), Versuch 6, Starterperiode

\begin{tabular}{|c|c|c|c|c|c|c|c|}
\hline Diät & $\mathbf{S P}^{*}$ & Tiernr. & $\begin{array}{l}\text { Mittlere } \\
\text { LM (kg) }\end{array}$ & $\begin{array}{c}\text { TS-Aufnahm } \\
\text { (g/Tag) }\end{array}$ & $\begin{array}{l}\text { N-Aufnahme } \\
\left(\mathrm{mg}^{2} \mathrm{LM}_{\mathrm{kg}}{ }^{0,67}\right)\end{array}$ & $\begin{array}{c}\mathrm{ND} \\
\left(\mathrm{mg} / \mathrm{LM}_{\mathrm{kg}}{ }^{0,67}\right)\end{array}$ & $\begin{array}{c}b \\
\left(b^{*} 10^{6}\right)\end{array}$ \\
\hline \multirow[t]{12}{*}{$\mathrm{BC}$} & I & 1 & 0,4515 & 51,801 & 3653,3 & 2446,5 & 319,9 \\
\hline & I & 2 & 0,4430 & 50,977 & 3641,3 & 2560,3 & 347,3 \\
\hline & I & 3 & 0,4665 & 51,950 & 3584,5 & 2492,5 & 336,5 \\
\hline & I & 4 & 0,4055 & 44,764 & 3392,7 & 2421,3 & 338,5 \\
\hline & I & 5 & 0,4470 & 52,100 & 3699,1 & 2499,8 & 327,8 \\
\hline & II & 1 & 0,6895 & 60,409 & 3208,1 & 2277,0 & 324,3 \\
\hline & II & 2 & 0,6845 & 61,083 & 3259,8 & 2216,8 & 306,4 \\
\hline & II & 3 & 0,7085 & 61,382 & 3201,0 & 2211,0 & 310,8 \\
\hline & II & 4 & Ausreißer & & & & \\
\hline & II & 5 & 0,6925 & 61,382 & 3250,4 & 2141,5 & 291,9 \\
\hline & & MW & 0,5543 & 55,094 & 3432,2 & 2363,0 & 322,6 \\
\hline & & SD & 0,13 & 6,09 & 210,67 & 6,45 & 17,48 \\
\hline \multirow[t]{12}{*}{ LYS } & I & 1 & 0,3505 & 42,981 & 3274,5 & 2052,1 & 272,6 \\
\hline & I & 2 & 0,3525 & 39,418 & 2991,6 & 1904,6 & 269,4 \\
\hline & I & 3 & 0,3205 & 38,23 & 3092,5 & 1955,8 & 270,1 \\
\hline & I & 4 & Ausfalltier & & & & \\
\hline & I & 5 & 0,2238 & 25,017 & 2574,5 & 1723,5 & 275,5 \\
\hline & II & 1 & 0,546 & 53,3 & 3017,2 & 1885,9 & 263,7 \\
\hline & II & 2 & 0,524 & 45,802 & 2665,2 & 1814,4 & 283,9 \\
\hline & II & 3 & 0,482 & 44,985 & 2768,4 & 1724,6 & 256,4 \\
\hline & II & 4 & Ausfalltier & & & & \\
\hline & II & 5 & Ausreißer & & & & \\
\hline & & MW & 0,400 & 41,390 & 2912,0 & 1866,000 & 270,2 \\
\hline & & SD & 0,12 & 8,74 & 250,59 & 120,669 & 8,70 \\
\hline \multirow{12}{*}{ THR } & I & 1 & 0,3843 & 47,856 & 3457,6 & 2088,1 & 264,5 \\
\hline & I & 2 & Ausreißer & & & & \\
\hline & I & 3 & 0,4395 & 52,664 & 3477,4 & 2305,6 & 305,1 \\
\hline & I & 4 & 0,316 & 33,655 & 2771,9 & 1903,6 & 290,6 \\
\hline & I & 5 & Ausfalltier & & & & \\
\hline & II & 1 & 0,6213 & 60,431 & 3164,4 & 2052,7 & 282,1 \\
\hline & II & 2 & 0,691 & 60,505 & 2950,3 & 2149,0 & 323,2 \\
\hline & II & 3 & 0,659 & 60,653 & 3053,0 & 2074,7 & 296,9 \\
\hline & II & 4 & 0,5125 & 49,78 & 2965,4 & 1944,7 & 279,5 \\
\hline & II & 5 & Ausfalltier & & & & \\
\hline & & MW & 0,5186 & 52,22 & 3120,0 & 2074,0 & 291,7 \\
\hline & & SD & 0,15 & $\mathbf{9 , 8 1}$ & 265,22 & 132,71 & 19,07 \\
\hline \multirow[t]{12}{*}{ TRP } & I & 1 & 0,3813 & 50,775 & 3700,4 & 2255,8 & 277,1 \\
\hline & I & 2 & Ausreißer & & & & \\
\hline & I & 3 & 0,414 & 51,817 & 3573,5 & 2384,7 & 313,4 \\
\hline & I & 4 & Ausreißer & & & & \\
\hline & I & 5 & 0,4048 & 51,222 & 3586,3 & 2491,6 & 336,2 \\
\hline & II & 1 & Ausfalltier & & & & \\
\hline & II & 2 & 0,682 & 57,997 & 2862,7 & 2151,7 & 333,7 \\
\hline & $\mathrm{Ii}$ & 3 & 0,6625 & 61,049 & 3072,5 & 2097,3 & 299,6 \\
\hline & $\mathrm{Ii}$ & 4 & 0,6615 & 61,049 & 3075,6 & 1980,1 & 276,2 \\
\hline & II & 5 & 0,4875 & 61,049 & 3773,5 & 2565,3 & 336,3 \\
\hline & & MW & 0,528 & 56,423 & 3377,8 & 2275,2 & 310,36 \\
\hline & & SD & 0,14 & 4,95 & 363,38 & 215,01 & 26,72 \\
\hline
\end{tabular}

*SP=Sammelperiode 


\begin{tabular}{|c|c|c|c|c|c|c|c|}
\hline Diät & SP* & Tiernr. & $\begin{array}{l}\text { Mittlere } \\
\text { LM (kg) }\end{array}$ & $\begin{array}{c}\text { TS- } \\
\text { Aufnahme } \\
\text { (g/Tag) }\end{array}$ & $\begin{array}{l}\text { N-Aufnahme } \\
\left(\mathrm{mg}^{0, \mathrm{LM}_{\mathrm{kg}}}{ }^{0,67}\right)\end{array}$ & $\begin{array}{c}\text { ND } \\
\left(\mathrm{mg} / \mathrm{LM}_{\mathrm{kg}}{ }^{0,67}\right)\end{array}$ & $\begin{array}{c}b \\
\left(b^{*} 10^{6}\right)\end{array}$ \\
\hline \multirow[t]{12}{*}{ ARG } & I & 1 & 0,46 & 53,323 & 3348,7 & 2344,7 & 325,4 \\
\hline & I & 2 & 0,4725 & 53,249 & 3284,5 & 2123,7 & 285,3 \\
\hline & I & 3 & 0,475 & 52,432 & 3222,7 & 2149,1 & 295,9 \\
\hline & I & 4 & 0,4525 & 53,026 & 3366,9 & 2299,4 & 313,8 \\
\hline & I & 5 & 0,4658 & 51,69 & 3219,1 & 2228,8 & 312,8 \\
\hline & II & 1 & 0,679 & 60,899 & 2946,1 & 1945,1 & 281,4 \\
\hline & II & 2 & 0,6925 & 60,824 & 2904,0 & 1806,3 & 259,1 \\
\hline & II & 3 & 0,6905 & 60,899 & 2913,2 & 1862,1 & 268,6 \\
\hline & II & 4 & 0,674 & 60,899 & 2960,8 & 1836,9 & 259,7 \\
\hline & II & 5 & 0,6838 & 60,75 & 2925,3 & 1899,2 & 274,5 \\
\hline & & MW & 0,575 & 56,80 & 3109,1 & 2049,5 & 287,65 \\
\hline & & SD & 0,12 & 430 & 195,0 & 202,873 & 23,54 \\
\hline \multirow[t]{12}{*}{ ILE } & I & 1 & 0,4515 & 50,592 & 3281,4 & 2344,7 & 332,1 \\
\hline & I & 2 & 0,4915 & 53,568 & 3282,3 & 2297,3 & 321,4 \\
\hline & I & 3 & 0,4988 & 53,27 & 3232,2 & 2349,9 & 338,3 \\
\hline & I & 4 & 0,479 & 53,568 & 3339,4 & 2496,4 & 362,2 \\
\hline & I & 5 & 0,488 & 53,568 & 3298,1 & 2300,7 & 320,6 \\
\hline & II & 1 & 0,682 & 61,008 & 3001,5 & 2132,6 & 314,2 \\
\hline & II & 2 & 0,7125 & 61,008 & 2914,8 & 2023,6 & 300,2 \\
\hline & II & 3 & 0,7358 & 61,008 & 2852,8 & 2111,7 & 325,8 \\
\hline & II & 4 & 0,715 & 61,008 & 2908,0 & 2056,4 & 307,8 \\
\hline & II & 5 & 0,72 & 61,008 & 2894,5 & 2043,5 & 306,5 \\
\hline & & MW & 0,597 & 56,961 & 3100,4 & 2215,8 & 322,9 \\
\hline & & SD & 0,123 & 4,35 & 201,05 & 162,12 & 18,17 \\
\hline \multirow[t]{12}{*}{ VAL } & I & 1 & 0,4753 & 53,101 & 3322,4 & 2369,6 & 333,6 \\
\hline & I & 2 & 0,425 & 49,165 & 3315,3 & 2397,3 & 340,7 \\
\hline & I & 3 & 0,4828 & 53,026 & 3283,1 & 2413,3 & 347,9 \\
\hline & I & 4 & Ausreißer & & & & \\
\hline & I & 5 & 0,4888 & 51,987 & 3192,2 & 2207,9 & 311,0 \\
\hline & II & 1 & 0,6973 & 60,899 & 2947,3 & 1933,8 & 279,1 \\
\hline & II & 2 & 0,6625 & 60,899 & 3050,0 & 2128,1 & 308,2 \\
\hline & II & 3 & 0,7183 & 60,899 & 2889,3 & 1999,6 & 298,0 \\
\hline & II & 4 & 0,6865 & 60,899 & 2978,1 & 2106,5 & 311,0 \\
\hline & II & 5 & 0,7253 & 60,899 & 2870,6 & 1972,2 & 294,3 \\
\hline & & MW & 0,5957 & 56,864 & 3094,1 & 2169,9 & 313,8 \\
\hline & & SD & 0,12 & 4,92 & 185,37 & 187,60 & 22,80 \\
\hline
\end{tabular}

$* \mathrm{SP}=$ Sammelperiode 
Tabelle A 23: Mittlere Lebendmasse, TS-Aufnahme, N-Aufnahme, N-Deposition (ND) und Proteinqualität (b), Versuch 6, Growerperiode

\begin{tabular}{|c|c|c|c|c|c|c|c|}
\hline Diät & SP* & $\mathbf{n}$ & $\begin{array}{l}\text { Mittlere } \\
\text { LM (kg) }\end{array}$ & $\begin{array}{c}\text { TS-Aufnahme } \\
\text { (g/Tag) }\end{array}$ & $\begin{array}{l}\text { N-Aufnahme } \\
\left(\mathrm{mg}_{\mathbf{L}} \mathbf{L M}_{\mathrm{kg}}{ }^{0,67}\right)\end{array}$ & $\begin{array}{c}\text { ND } \\
\left(\mathrm{mg} / \mathrm{LM}_{\mathrm{kg}}{ }^{0,67}\right)\end{array}$ & $\begin{array}{c}b \\
\left(b^{*} 10^{6}\right)\end{array}$ \\
\hline \multirow[t]{12}{*}{$\mathrm{BC}$} & I & 1 & 1,2345 & 87,919 & 2891,6 & 1896,7 & 425,3 \\
\hline & I & 2 & 1,0055 & 84,411 & 3185,3 & 2221,4 & 524,8 \\
\hline & I & 3 & Ausfalltier & & & & \\
\hline & I & 4 & Ausfalltier & & & & \\
\hline & I & 5 & 1,2505 & 88,358 & 2881,1 & 2007,3 & 471,9 \\
\hline & II & 1 & 1,5755 & 101,805 & 2843,5 & 1795,7 & 395,4 \\
\hline & II & 2 & Ausfalltier & & & & \\
\hline & II & 3 & Ausfalltier & & & & \\
\hline & II & 4 & Ausreißer & & & & \\
\hline & II & 5 & 1,5940 & 101,878 & 2823,4 & 1902,3 & 437,7 \\
\hline & & MW & 1,332 & 92,874 & 2924,8 & 1964,7 & 451,0 \\
\hline & & SD & 0,25 & 8,33 & 148,12 & 161,870 & 49,53 \\
\hline \multirow[t]{12}{*}{ LYS } & I & 1 & 1,2595 & 87,672 & 2596,0 & 1672,6 & 388,8 \\
\hline & I & 2 & 1,2815 & 87,966 & 2574,6 & 1651,2 & 384,8 \\
\hline & I & 3 & 1,373 & 89,584 & 2503,6 & 1522,7 & 353,6 \\
\hline & I & 4 & 1,314 & 89,069 & 2563,5 & 1726,5 & 412,8 \\
\hline & I & 5 & 1,4995 & 100,102 & 2637,1 & 1747,3 & 408,6 \\
\hline & II & 1 & 1,552 & 101,646 & 2616,8 & 1683,0 & 389,3 \\
\hline & II & 2 & 1,596 & 102,823 & 2598,0 & 1557,9 & 351,4 \\
\hline & II & 3 & 1,666 & 102,97 & 2527,9 & 1539,1 & 355,3 \\
\hline & II & 4 & 1,616 & 101,867 & 2552,4 & 1732,5 & 416,7 \\
\hline & II & 5 & Ausreißer & & & & \\
\hline & & MW & 1,462 & 95,967 & 2574,4 & 1648,1 & 384,589 \\
\hline & & SD & 0,157 & 7,08 & 42,61 & 87,01 & 25,89 \\
\hline \multirow[t]{12}{*}{ THR } & I & 1 & 1,322 & 88,838 & 2568,2 & 1743,7 & 418,3 \\
\hline & I & 2 & 1,2085 & 86,177 & 2645,7 & 1749,7 & 408,2 \\
\hline & I & 3 & 1,183 & 82,630 & 2573,3 & 1801,4 & 439,1 \\
\hline & I & 4 & 1,094 & 69,991 & 2297,0 & 1670,1 & 438,5 \\
\hline & I & 5 & Ausreißer & & & & \\
\hline & II & 1 & 1,6435 & 102,511 & 2561,3 & 1702,8 & 404,6 \\
\hline & II & 2 & 1,5305 & 101,107 & 2649,7 & 1649,3 & 373,3 \\
\hline & II & 3 & 1,468 & 90,464 & 2437,9 & 1624,7 & 397,1 \\
\hline & II & 4 & 1,368 & 86,990 & 2457,8 & 1657,8 & 405,4 \\
\hline & II & 5 & 1,5135 & 102,363 & 2702,8 & 1806,6 & 420 \\
\hline & & MW & 1,370 & 90,119 & 2543,7 & 1711,8 & 411,611 \\
\hline & & SD & 0,18 & 10,69 & 126,57 & 66,81 & 20,54 \\
\hline \multirow{12}{*}{ TRP } & I & 1 & 0,8715 & 69,565 & 2668,5 & 2022,3 & 516,5 \\
\hline & I & 2 & Ausfalltier & & & & \\
\hline & I & 3 & Ausfalltier & & & & \\
\hline & I & 4 & Ausreißer & & & & \\
\hline & I & 5 & Ausfalltier & & & & \\
\hline & II & 1 & 1,2525 & 89,683 & 2698,1 & 1820,7 & 426,0 \\
\hline & II & 2 & 1,5710 & 102,947 & 2660,9 & 1906,2 & 466,1 \\
\hline & II & 3 & 1,4980 & 103,095 & 2751,1 & 1981,2 & 482,5 \\
\hline & II & 4 & 1,5840 & 103,168 & 2652,0 & 1772,9 & 415,6 \\
\hline & II & 5 & Ausfalltier & & & & \\
\hline & & MW & 1,3554 & 93,692 & 2686,1 & 1900,7 & 461,3 \\
\hline & & SD & $\mathbf{0 , 3 0}$ & 14,69 & 40,12 & 104,92 & 41,40 \\
\hline
\end{tabular}

$* \mathrm{SP}=$ Sammelperiode 


\begin{tabular}{|c|c|c|c|c|c|c|c|}
\hline Diät & SP* & $\begin{array}{c}\text { Tier- } \\
\text { nr. }\end{array}$ & $\begin{array}{l}\text { Mittlere } \\
\text { LM (kg) }\end{array}$ & $\begin{array}{c}\text { TS-Aufnahme } \\
\text { (g/Tag) }\end{array}$ & 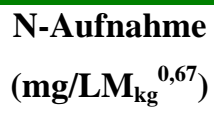 & $\begin{array}{c}\text { ND } \\
\left(\mathrm{mg} / \mathrm{LM}_{\mathrm{kg}}{ }^{0,67}\right)\end{array}$ & $\begin{array}{c}\text { b } \\
\left(b^{*} 10^{6}\right)\end{array}$ \\
\hline \multirow[t]{12}{*}{ ARG } & I & 1 & 0,8310 & 71,654 & 2773,2 & 1858,7 & 428,7 \\
\hline & I & 2 & 1,0385 & 64,967 & 2165,6 & 1735,9 & 492,6 \\
\hline & I & 3 & Ausreißer & & & & \\
\hline & I & 4 & 0,9005 & 70,625 & 2590,2 & 1659,6 & 385,3 \\
\hline & I & 5 & 1,2500 & 89,072 & 2622,3 & 1753,6 & 413,2 \\
\hline & II & 1 & Ausreißer & & & & \\
\hline & II & 2 & 1,2890 & 87,014 & 2509,5 & 1852,2 & 471,0 \\
\hline & II & 3 & 1,1545 & 74,815 & 2323,0 & 1571,6 & 397,8 \\
\hline & II & 4 & 1,1560 & 77,387 & 2400,8 & 1568,8 & 383,9 \\
\hline & II & 5 & 1,5580 & 102,300 & 2598,5 & 1544,6 & 347,3 \\
\hline & & MW & 1,1472 & 79,73 & 2497,9 & 1693,1 & 415,0 \\
\hline & & SD & 0,23 & 12,22 & 192,91 & 126,28 & 47,93 \\
\hline \multirow[t]{12}{*}{ ILE } & I & 1 & 1,1395 & 88,042 & 2812,6 & 1986,4 & 474,2 \\
\hline & I & 2 & Ausreißer & & & & \\
\hline & I & 3 & 1,1885 & 87,821 & 2727,5 & 1964,6 & 479,3 \\
\hline & I & 4 & 1,2345 & 89,515 & 2710,3 & 2013,0 & 504,2 \\
\hline & I & 5 & 1,2625 & 89,736 & 2676,4 & 1824,3 & 430,8 \\
\hline & II & 1 & 1,4905 & 102,482 & 2734,8 & 1790,7 & 409,3 \\
\hline & II & 2 & 1,4515 & 102,998 & 2797,9 & 1822,2 & 411,4 \\
\hline & II & 3 & 1,5335 & 102,703 & 2689,0 & 1804,5 & 421,4 \\
\hline & II & 4 & 1,5735 & 103,071 & 2652,5 & 1814,7 & 431 \\
\hline & II & 5 & 1,5600 & 103,071 & 2667,8 & 1817,7 & 429,7 \\
\hline & & MW & 1,3816 & 96,604 & 2718,7 & 1870,9 & 443,48 \\
\hline & & SD & 0,17 & 7,451 & 56,04 & 89,22 & 33,73 \\
\hline \multirow[t]{12}{*}{ VAL } & I & 1 & 1,1445 & 78,817 & 2505,7 & 1740,7 & 427,6 \\
\hline & I & 2 & Ausreißer & & & & \\
\hline & I & 3 & 1,1910 & 75,505 & 2337,3 & 1508,4 & 374 \\
\hline & I & 4 & 1,1995 & 76,683 & 2362,4 & 1664,7 & 424,4 \\
\hline & I & 5 & 1,4855 & 98,466 & 2628,6 & 1768,3 & 417,6 \\
\hline & II & 1 & Ausreißer & & & & \\
\hline & II & 2 & 1,5895 & 102,734 & 2621,0 & 1722,2 & 402,2 \\
\hline & II & 3 & 1,5615 & 101,998 & 2633,4 & 1797,8 & 427,8 \\
\hline & II & 4 & 1,5460 & 96,994 & 2521,0 & 1684,5 & 404,6 \\
\hline & II & 5 & 1,6095 & 102,440 & 2591,7 & 1726,9 & 408,4 \\
\hline & & MW & 1,4159 & 91,704 & 2525,1 & 1701,7 & 410,81 \\
\hline & & SD & 0,20 & 12,37 & 118,43 & 88,87 & 18,01 \\
\hline
\end{tabular}

$* \mathrm{SP}=$ Sammelperiode 
Tabelle A 24: Ganzkörperanalyse, Versuch 7 (1. LT)

\begin{tabular}{cccccc}
\hline Null-Tiere & \% TS & $\begin{array}{c}\text { \% XA } \\
\text { in TS }\end{array}$ & $\begin{array}{c}\text { \% N } \\
\text { in TS }\end{array}$ & $\begin{array}{c}\text { \% XP } \\
\text { in TS }\end{array}$ & $\begin{array}{c}\text { \% XL } \\
\text { in TS }\end{array}$ \\
\hline 1 & 21,54 & 8,53 & 10,57 & 66,05 & 25,43 \\
2 & 19,84 & 8,43 & 10,80 & 67,53 & 24,04 \\
3 & 19,90 & 8,56 & 10,85 & 67,82 & 23,62 \\
MW & $\mathbf{2 0 , 4 2}$ & $\mathbf{8 , 5 1}$ & $\mathbf{1 0 , 7 4}$ & $\mathbf{6 7 , 1 3}$ & $\mathbf{2 4 , 3 6}$ \\
SD & $\mathbf{0 , 9 7}$ & $\mathbf{0 , 0 7}$ & $\mathbf{0 , 1 5}$ & $\mathbf{0 , 9 5}$ & $\mathbf{0 , 9 5}$ \\
\hline
\end{tabular}

Tabelle A 25: Ganzkörperanalyse, Versuch 7 (21. LT)

\begin{tabular}{|c|c|c|c|c|c|c|}
\hline Diät & Tiernummer & $\%$ TS & $\begin{array}{l}\% \mathrm{XA} \\
\text { in TS }\end{array}$ & $\begin{array}{c}\% \mathrm{~N} \\
\text { in TS }\end{array}$ & $\begin{array}{l}\% \mathrm{XP} \\
\text { in TS }\end{array}$ & $\begin{array}{l}\% \text { XL } \\
\text { in TS }\end{array}$ \\
\hline \multirow[t]{6}{*}{$\mathrm{BC}$} & 1 & 33,94 & 7,78 & 8,71 & 54,46 & 37,76 \\
\hline & 2 & 33,28 & 8,10 & 8,71 & 54,42 & 37,48 \\
\hline & 3 & 33,87 & 7,86 & 8,92 & 55,75 & 36,39 \\
\hline & 4 & 33,37 & 8,05 & 8,66 & 54,15 & 37,80 \\
\hline & MW & 33,61 & 7,95 & 8,75 & 54,70 & 37,36 \\
\hline & SD & 0,34 & 0,15 & 0,11 & 0,72 & 0,66 \\
\hline \multirow[t]{6}{*}{ LYS } & 1 & 32,29 & 8,76 & 8,92 & 55,73 & 35,51 \\
\hline & 2 & 32,58 & 8,21 & 8,64 & 53,98 & 37,81 \\
\hline & 3 & 32,83 & 9,07 & 8,91 & 55,67 & 35,26 \\
\hline & 4 & 32,08 & 10,11 & 9,14 & 57,11 & 32,79 \\
\hline & MW & 32,45 & 9,04 & 8,90 & 55,62 & 35,34 \\
\hline & SD & 0,33 & $\mathbf{0 , 8 0}$ & 0,20 & 1,28 & 2,06 \\
\hline \multirow[t]{6}{*}{ TRP } & 1 & 31,03 & 9,46 & 9,25 & 57,80 & 32,74 \\
\hline & 2 & 32,74 & 8,39 & 9,03 & 56,47 & 35,14 \\
\hline & 3 & 31,57 & 8,10 & 9,12 & 56,97 & 34,93 \\
\hline & 4 & 31,99 & 8,83 & 8,82 & 55,15 & 36,02 \\
\hline & MW & 31,84 & 8,69 & 9,06 & 56,60 & 34,71 \\
\hline & SD & 0,72 & 0,59 & 0,18 & 1,11 & 1,39 \\
\hline \multirow[t]{6}{*}{ ARG } & 1 & 35,03 & 7,74 & 7,93 & 49,55 & 42,71 \\
\hline & 2 & 34,83 & 7,65 & 8,14 & 50,90 & 41,44 \\
\hline & 3 & 33,78 & 7,90 & 8,75 & 54,70 & 37,40 \\
\hline & 4 & 39,02 & 7,02 & 8,14 & 50,89 & 42,09 \\
\hline & MW & 35,66 & 7,58 & 8,24 & 51,51 & 40,91 \\
\hline & SD & 2,30 & 0,38 & 0,36 & 2,22 & 2,40 \\
\hline \multirow[t]{6}{*}{ ILE } & 1 & 34,71 & 8,10 & 8,41 & 52,55 & 39,34 \\
\hline & 2 & 34,02 & 8,04 & 8,63 & 53,91 & 38,05 \\
\hline & 3 & 34,30 & 7,72 & 8,64 & 53,98 & 38,30 \\
\hline & 4 & 32,59 & 8,04 & 8,93 & 55,82 & 36,14 \\
\hline & MW & 33,91 & 7,98 & 8,65 & 54,07 & 37,96 \\
\hline & SD & 0,92 & 0,17 & 0,21 & 1,34 & 1,33 \\
\hline \multirow{6}{*}{ VAL } & 1 & 33,13 & 7,73 & 8,56 & 53,50 & 38,77 \\
\hline & 2 & 34,02 & 7,51 & 8,70 & 54,36 & 38,13 \\
\hline & 3 & 33,08 & 7,95 & 8,78 & 54,88 & 37,16 \\
\hline & 4 & 33,67 & 7,95 & 8,62 & 53,90 & 38,15 \\
\hline & MW & 33,48 & 7,78 & 8,67 & 54,16 & 38,06 \\
\hline & SD & 0,45 & 0,21 & 0,10 & 0,59 & 0,66 \\
\hline
\end{tabular}


Tabelle A 26: Ganzkörperanalyse, Versuch 7 (Beginn Growerperiode, 21. LT)

\begin{tabular}{cccccc}
\hline Null-Tiere & \% TS & $\begin{array}{c}\text { \% XA } \\
\text { in TS }\end{array}$ & $\begin{array}{c}\text { \% N } \\
\text { in TS }\end{array}$ & $\begin{array}{c}\text { \% XP } \\
\text { in TS }\end{array}$ & $\begin{array}{c}\text { \% XL } \\
\text { in TS }\end{array}$ \\
\hline 1 & 31,47 & 7,78 & 9,04 & 56,53 & 35,69 \\
2 & 31,39 & 7,68 & 9,41 & 58,79 & 33,53 \\
3 & 32,40 & 7,69 & 9,22 & 57,65 & 34,66 \\
MW & $\mathbf{3 1 , 7 5}$ & $\mathbf{7 , 7 2}$ & $\mathbf{9 , 2 3}$ & $\mathbf{5 7 , 6 6}$ & $\mathbf{3 4 , 6 3}$ \\
SD & $\mathbf{0 , 5 6}$ & $\mathbf{0 , 0 5}$ & $\mathbf{0 , 1 8}$ & $\mathbf{1 , 1 3}$ & $\mathbf{1 , 0 8}$ \\
\hline
\end{tabular}

Tabelle A 27: Ganzkörperanalyse, Versuch 7 (35 LT)

\begin{tabular}{|c|c|c|c|c|c|c|}
\hline Diät & Tiernummer & $\%$ TS & $\begin{array}{l}\text { \% XA } \\
\text { in TS }\end{array}$ & $\begin{array}{c}\% \mathrm{~N} \\
\text { in TS }\end{array}$ & $\begin{array}{l}\% \text { XP } \\
\text { in TS }\end{array}$ & $\begin{array}{l}\% \mathrm{XL} \\
\text { in TS }\end{array}$ \\
\hline \multirow[t]{6}{*}{$\mathrm{BC}$} & 1 & 36,33 & 6,78 & 8,34 & 52,12 & 41,10 \\
\hline & 2 & 36,64 & 6,48 & 8,01 & 50,03 & 43,48 \\
\hline & 3 & 35,34 & 7,13 & 8,06 & 50,37 & 42,50 \\
\hline & 4 & 37,10 & 6,63 & 7,88 & 49,22 & 44,15 \\
\hline & MW & 36,35 & 6,76 & $\mathbf{8 , 0 7}$ & 50,44 & 42,81 \\
\hline & SD & 0,74 & 0,28 & 0,20 & 1,22 & 1,32 \\
\hline \multirow[t]{6}{*}{ LYS } & 1 & 45,43 & 6,84 & 7,60 & 47,48 & 45,68 \\
\hline & 2 & 35,02 & 7,39 & 8,25 & 51,59 & 41,02 \\
\hline & 3 & 44,23 & 7,91 & 8,67 & 54,21 & 37,88 \\
\hline & 4 & 36,66 & 6,65 & 7,94 & 49,64 & 43,71 \\
\hline & MW & 40,33 & 7,20 & 8,12 & 50,73 & 42,07 \\
\hline & SD & 5,26 & 0,57 & 0,46 & 2,86 & 3,39 \\
\hline \multirow[t]{6}{*}{ TRP } & 1 & 36,10 & 7,50 & 8,52 & 53,22 & 39,28 \\
\hline & 2 & 36,67 & 7,11 & 8,10 & 50,65 & 42,24 \\
\hline & 3 & 36,57 & 7,34 & 8,22 & 51,41 & 41,25 \\
\hline & 4 & 36,77 & 7,10 & 8,26 & 51,60 & 41,30 \\
\hline & MW & 36,53 & 7,26 & 8,28 & 51,72 & 41,02 \\
\hline & SD & $\mathbf{0 , 3 0}$ & 0,19 & $\mathbf{0 , 1 7}$ & 1,08 & 1,25 \\
\hline \multirow[t]{6}{*}{ ARG } & 1 & 36,79 & 6,91 & 8,21 & 51,31 & 41,78 \\
\hline & 2 & 36,45 & 7,17 & 7,88 & 49,27 & 43,56 \\
\hline & 3 & 37,54 & 7,56 & 8,33 & 52,07 & 40,37 \\
\hline & 4 & 38,41 & 6,41 & 7,63 & 47,66 & 45,93 \\
\hline & MW & 37,29 & 7,01 & 8,01 & 50,08 & 42,91 \\
\hline & SD & 0,87 & 0,48 & 0,32 & 2,00 & 2,40 \\
\hline \multirow[t]{6}{*}{ ILE } & 1 & 37,56 & 8,16 & 8,14 & 50,85 & 40,99 \\
\hline & 2 & 36,49 & 6,85 & 8,14 & 50,91 & 42,25 \\
\hline & 3 & 35,30 & 7,36 & 8,36 & 52,22 & 40,41 \\
\hline & 4 & 35,41 & 7,63 & 8,48 & 52,98 & 39,39 \\
\hline & MW & 36,19 & 7,50 & 8,28 & 51,74 & 40,76 \\
\hline & SD & 1,06 & 0,54 & $\mathbf{0 , 1 7}$ & 1,04 & 1,19 \\
\hline \multirow[t]{6}{*}{ VAL } & 1 & 36,30 & 7,13 & 8,36 & 52,24 & 40,64 \\
\hline & 2 & 36,16 & 7,04 & 7,99 & 49,97 & 42,99 \\
\hline & 3 & 35,53 & 7,09 & 8,50 & 53,15 & 39,76 \\
\hline & 4 & 33,94 & 7,25 & 8,77 & 54,81 & 37,93 \\
\hline & MW & 35,49 & 7,13 & 8,41 & 52,54 & 40,33 \\
\hline & SD & 1,08 & 0,09 & 0,32 & 2,02 & 2,10 \\
\hline
\end{tabular}


Tabelle A 28: Anfangs- und Endmasse, Futteraufnahme, Lebendmassezunahme (LMZ) und Futteraufwand, Versuch 7

\begin{tabular}{|c|c|c|c|c|c|c|}
\hline Diät & Box & $\begin{array}{l}\text { Anfangs- } \\
\text { masse (g) }\end{array}$ & $\begin{array}{c}\text { Endmasse } \\
\text { (g) }\end{array}$ & $\begin{array}{c}\text { Futterauf- } \\
\text { nahme (g/d) }\end{array}$ & $\begin{array}{l}\text { LMZ } \\
\text { (g/d) }\end{array}$ & $\begin{array}{c}\text { Futterver- } \\
\text { wertung (g/g) }\end{array}$ \\
\hline \multicolumn{7}{|c|}{ Starterperiode (1. - 3. Woche) } \\
\hline \multirow[t]{8}{*}{$\mathrm{BC}$} & 1 & 50,00 & 1048,80 & 65,15 & 47,56 & 1,37 \\
\hline & 2 & 50,00 & 1067,00 & 64,74 & 48,43 & 1,34 \\
\hline & 3 & 49,95 & 1074,80 & 66,40 & 48,80 & 1,36 \\
\hline & 4 & 49,90 & 1076,40 & 47,86 & 48,88 & 0,98 \\
\hline & 5 & 50,20 & 1157,40 & 66,67 & 52,72 & 1,26 \\
\hline & 6 & 50,30 & 1109,20 & 66,31 & 50,42 & 1,32 \\
\hline & MW & 50,06 & 1088,93 & 62,86 & 49,47 & 1,27 \\
\hline & SD & 0,16 & 38,85 & 7,38 & 1,84 & 0,15 \\
\hline \multirow[t]{8}{*}{ LYS } & 1 & 50,30 & 440,7 & 55,74 & 18,59 & 3,00 \\
\hline & 2 & 50,10 & 525,0 & 51,29 & 22,61 & 2,27 \\
\hline & 3 & 50,15 & 539,2 & 53,56 & 23,29 & 2,30 \\
\hline & 4 & 50,10 & 485,3 & 53,38 & 20,72 & 2,58 \\
\hline & 5 & 49,95 & 486,4 & 37,76 & 20,78 & 1,82 \\
\hline & 6 & 49,70 & 504,9 & 63,25 & 21,68 & 2,92 \\
\hline & MW & 50,05 & 496,92 & 52,50 & 21,28 & 2,48 \\
\hline & SD & 0,20 & 34,77 & 8,33 & 1,66 & 0,44 \\
\hline \multirow[t]{8}{*}{ TRP } & 1 & 50,10 & 785,00 & 49,86 & 35,00 & 1,42 \\
\hline & 2 & 50,05 & 826,20 & 58,80 & 36,96 & 1,59 \\
\hline & 3 & 50,05 & 838,10 & 57,64 & 37,53 & 1,54 \\
\hline & 4 & 49,95 & 833,80 & 56,28 & 37,33 & 1,51 \\
\hline & 5 & 50,15 & 931,50 & 58,17 & 41,97 & 1,39 \\
\hline & 6 & 50,10 & 896,60 & 56,79 & 40,31 & 1,41 \\
\hline & MW & 50,07 & 851,87 & 56,26 & 38,18 & 1,48 \\
\hline & SD & $\mathbf{0 , 0 7}$ & 52,89 & 3,26 & 2,52 & 0,08 \\
\hline \multirow[t]{8}{*}{ ARG } & 1 & 50,15 & 955,10 & 59,39 & 43,09 & 1,38 \\
\hline & 2 & 50,00 & 1024,70 & 64,26 & 46,41 & 1,38 \\
\hline & 3 & 50,10 & 926,13 & 55,79 & 41,72 & 1,34 \\
\hline & 4 & 49,85 & 1035,10 & 62,17 & 46,92 & 1,33 \\
\hline & 5 & 50,10 & 1113,33 & 64,76 & 50,63 & 1,28 \\
\hline & 6 & 50,30 & 1130,30 & 69,47 & 51,43 & 1,35 \\
\hline & MW & 50,08 & 1030,78 & 62,64 & 46,70 & 1,34 \\
\hline & SD & 0,15 & 81,80 & 4,72 & 3,89 & 0,04 \\
\hline \multirow[t]{8}{*}{ ILE } & 1 & 50,05 & 1104,30 & 65,18 & 50,20 & 1,30 \\
\hline & 2 & 50,15 & 1105,80 & 64,97 & 50,27 & 1,29 \\
\hline & 3 & 49,90 & 1133,22 & 66,82 & 51,59 & 1,30 \\
\hline & 4 & 50,20 & 1055,60 & 66,82 & 47,88 & 1,40 \\
\hline & 5 & 50,05 & 1103,10 & 65,47 & 50,15 & 1,31 \\
\hline & 6 & 50,10 & 1084,70 & 65,39 & 49,27 & 1,33 \\
\hline & MW & 50,08 & 1097,79 & 65,77 & 49,89 & 1,32 \\
\hline & SD & 0,10 & 25,85 & 0,83 & 1,24 & 0,04 \\
\hline \multirow[t]{8}{*}{ VAL } & 1 & 49,95 & 969,60 & 56,50 & 43,79 & 1,29 \\
\hline & 2 & 50,00 & 1006,00 & 57,32 & 45,52 & 1,38 \\
\hline & 3 & 50,10 & 1090,56 & 62,60 & 49,55 & 1,22 \\
\hline & 4 & 50,10 & 1018,20 & 60,29 & 46,10 & 1,31 \\
\hline & 5 & 49,95 & 1014,89 & 58,71 & 45,95 & 1,28 \\
\hline & 6 & 50,50 & 1101,25 & 67,47 & 50,04 & 1,35 \\
\hline & MW & 50,10 & 1033,42 & 60,48 & 46,82 & 1,30 \\
\hline & SD & 0,21 & 51,51 & 4,06 & 2,44 & 0,06 \\
\hline
\end{tabular}




\begin{tabular}{|c|c|c|c|c|c|c|}
\hline Diät & Box & $\begin{array}{l}\text { Anfangs- } \\
\text { masse (g) }\end{array}$ & $\begin{array}{c}\text { Endmasse } \\
\text { (g) }\end{array}$ & $\begin{array}{c}\text { Futterauf- } \\
\text { nahme (g/d) }\end{array}$ & $\begin{array}{l}\text { LMZ } \\
\text { (g/d) }\end{array}$ & $\begin{array}{c}\begin{array}{c}\text { Futterver- } \\
\text { wertung }(\mathrm{g} / \mathrm{g})\end{array} \\
\end{array}$ \\
\hline \multicolumn{7}{|c|}{ Growerperiode (3. - 5. Woche) } \\
\hline \multirow[t]{8}{*}{$\mathrm{BC}$} & 1 & 1194,20 & 2782,20 & 185,54 & 113,429 & 1,64 \\
\hline & 2 & 1168,40 & 2765,88 & 173,14 & 114,105 & 1,52 \\
\hline & 3 & 1189,90 & 2786,80 & 184,31 & 114,064 & 1,62 \\
\hline & 4 & 1196,90 & 2721,90 & 179,36 & 108,929 & 1,65 \\
\hline & 5 & 1253,70 & 2602,70 & 173,37 & 96,357 & 1,80 \\
\hline & 6 & 1193,90 & 2709,30 & 175,41 & 108,243 & 1,62 \\
\hline & MW & 1199,50 & 2728,13 & 178,52 & 109,19 & 1,64 \\
\hline & $\mathrm{SD}$ & 28,51 & 69,16 & 5,45 & 6,80 & 0,09 \\
\hline \multirow[t]{8}{*}{ LYS } & 1 & 1174,40 & 2594,9 & 174,55 & 101,464 & 1,72 \\
\hline & 2 & 1179,70 & 2514,9 & 164,71 & 95,371 & 1,73 \\
\hline & 3 & 1153,70 & 2440,1 & 165,44 & 91,886 & 1,80 \\
\hline & 4 & 1225,80 & 2563,6 & 163,54 & 85,830 & 1,91 \\
\hline & 5 & 1254,00 & 2552,3 & 160,11 & 92,738 & 1,73 \\
\hline & 6 & 1217,60 & 2572,3 & 169,58 & 96,764 & 1,75 \\
\hline & MW & 1200,87 & 2539,69 & 166,32 & 94,01 & 1,77 \\
\hline & $\mathrm{SD}$ & 37,68 & 55,46 & 5,06 & 5,25 & 0,07 \\
\hline \multirow[t]{8}{*}{ TRP } & 1 & 1190,30 & 2718,00 & 176,34 & 109,121 & 1,62 \\
\hline & 2 & 1174,90 & 2737,10 & 177,38 & 111,586 & 1,59 \\
\hline & 3 & 1187,60 & 2649,20 & 171,34 & 104,400 & 1,64 \\
\hline & 4 & 1172,30 & 2704,10 & 176,57 & 109,414 & 1,61 \\
\hline & 5 & 1247,60 & 2705,50 & 180,57 & 104,136 & 1,73 \\
\hline & 6 & 1218,30 & 2732,11 & 175,51 & 108,129 & 1,62 \\
\hline & MW & 1198,50 & 2707,67 & 176,29 & 107,80 & 1,64 \\
\hline & $\mathrm{SD}$ & 29,09 & 31,64 & 2,99 & 2,96 & 0,05 \\
\hline \multirow[t]{8}{*}{$\mathrm{ARG}$} & 1 & 1214,00 & 2656,80 & 169,68 & 103,057 & 1,68 \\
\hline & 2 & 1192,20 & 2715,50 & 171,41 & 108,807 & 1,71 \\
\hline & 3 & 1173,10 & 2513,80 & 164,48 & 95,764 & 1,79 \\
\hline & 4 & 1183,20 & 2540,40 & 159,44 & 96,943 & 1,76 \\
\hline & 5 & 1189,40 & 2611,40 & 163,02 & 101,571 & 1,76 \\
\hline & 6 & 1236,30 & 2719,33 & 163,99 & 105,931 & 1,68 \\
\hline & MW & 1198,03 & 2626,21 & 165,34 & 102,01 & 1,73 \\
\hline & $\mathrm{SD}$ & 23,11 & 86,95 & 4,44 & 5,05 & 0,05 \\
\hline \multirow[t]{8}{*}{ ILE } & 1 & 1188,30 & 2798,5 & 169,68 & 115,014 & 1,48 \\
\hline & 2 & 1199,40 & 2706,6 & 171,41 & 107,657 & 1,59 \\
\hline & 3 & 1171,60 & 2675,6 & 164,48 & 107,429 & 1,53 \\
\hline & 4 & 1150,70 & 2572,5 & 159,44 & 101,557 & 1,57 \\
\hline & 5 & 1248,30 & 2679,5 & 163,02 & 102,229 & 1,59 \\
\hline & 6 & 1238,30 & 2749,0 & 163,99 & 107,907 & 1,52 \\
\hline & MW & 1199,43 & 2696,95 & 165,34 & 106,97 & 1,55 \\
\hline & $\mathrm{SD}$ & 37,87 & 76,63 & 4,44 & 4,86 & 0,05 \\
\hline \multirow[t]{8}{*}{ VAL } & 1 & 1199,80 & 2634,1 & 169,51 & 102,451 & 1,65 \\
\hline & 2 & 1205,30 & 2598,3 & 169,44 & 99,500 & 1,70 \\
\hline & 3 & 1182,80 & 2570,4 & 164,10 & 99,117 & 1,66 \\
\hline & 4 & 1177,90 & 2426,3 & 166,40 & 89,174 & 1,87 \\
\hline & 5 & 1178,20 & 2564,8 & 158,51 & 99,041 & 1,60 \\
\hline & 6 & 1244,70 & 2667,9 & 169,85 & 101,656 & 1,67 \\
\hline & MW & 1198,12 & 2576,98 & 166,30 & 98,49 & 1,69 \\
\hline & $\mathrm{SD}$ & 25,55 & 83,51 & 4,43 & 4,78 & 0,09 \\
\hline
\end{tabular}


Tabelle A 29: Mittlere Lebendmasse, TS-Aufnahme, N-Aufnahme, N-Deposition (ND) und Proteinqualität (b), Versuch 8, Starterperiode

\begin{tabular}{|c|c|c|c|c|c|c|c|}
\hline Diät & $\mathbf{S P}^{*}$ & Tiernr. & $\begin{array}{l}\text { Mittlere } \\
\text { LM (kg) }\end{array}$ & $\begin{array}{c}\text { TS-Aufnahme } \\
\text { (g/Tag) }\end{array}$ & $\begin{array}{l}\text { N-Aufnahme } \\
\left(\mathrm{mg}^{2} \mathbf{L M}_{\mathrm{kg}}{ }^{0,67}\right)\end{array}$ & $\begin{array}{c}\mathrm{ND} \\
\left(\mathrm{mg} / \mathrm{LM}_{\mathrm{kg}}{ }^{0,67}\right)\end{array}$ & $\begin{array}{c}\mathbf{b} \\
\left(\mathbf{b}^{*} 10^{6}\right)\end{array}$ \\
\hline \multirow[t]{12}{*}{$\mathrm{BC}$} & I & 1 & 0,4835 & 55,464 & 3868,7 & 2614,3 & 339,6 \\
\hline & I & 2 & 0,5105 & 58,375 & 3926,2 & 2655,7 & 344,7 \\
\hline & I & 3 & 0,4685 & 52,844 & 3764,6 & 2492,6 & 320,5 \\
\hline & I & 4 & 0,5085 & 57,065 & 3848,2 & 2482,3 & 311,3 \\
\hline & I & 5 & 0,4775 & 55,027 & 3870,5 & 2561,4 & 327 \\
\hline & II & 1 & 0,7795 & 70,603 & 3576,1 & 2427,2 & 322,4 \\
\hline & II & 2 & 0,8075 & 70,022 & 3463,8 & 2352,9 & 316,4 \\
\hline & II & 3 & Ausreißer & & & & \\
\hline & II & 4 & 0,809 & 70,458 & 3481,0 & 2419,0 & 329,4 \\
\hline & II & 5 & 0,7685 & 70,312 & 3595,5 & 2491,0 & 335,2 \\
\hline & & MW & 0,624 & 62,241 & 3710,5 & 2499,6 & 327,4 \\
\hline & & SD & 0,16 & 7,84 & 181,61 & 96,84 & 10,99 \\
\hline \multirow[t]{12}{*}{ LYS } & I & 1 & 0,5090 & 57,862 & 3549,7 & 2184,8 & 275,3 \\
\hline & I & 2 & 0,4670 & 51,204 & 3327,8 & 1904,4 & 242,2 \\
\hline & I & 3 & 0,4735 & 54,375 & 3501,3 & 1971,7 & 241,2 \\
\hline & I & 4 & 0,4890 & 54,057 & 3406,6 & 2067,3 & 264,7 \\
\hline & I & 5 & 0,5065 & 59,131 & 3639,5 & 2053,5 & 245,4 \\
\hline & II & 1 & 0,7780 & 75,617 & 3491,1 & 2069,5 & 258,7 \\
\hline & II & 2 & 0,7285 & 65,471 & 3158,8 & 1870,4 & 249,2 \\
\hline & II & 3 & 0,7535 & 77,044 & 3634,1 & 1998,8 & 236,7 \\
\hline & II & 4 & 0,7700 & 73,240 & 3404,8 & 2071,2 & 265,6 \\
\hline & II & 5 & 0,7740 & 75,617 & 3503,2 & 2078,1 & 259,3 \\
\hline & & MW & 0,6249 & 64,362 & 3461,7 & 2027,0 & 253,8 \\
\hline & & SD & 0,14 & 10,24 & 144,98 & 92,624 & 12,69 \\
\hline \multirow[t]{12}{*}{ THR } & I & 1 & 0,5490 & 62,025 & 3649,5 & 2401,7 & 310,5 \\
\hline & I & 2 & 0,5335 & 61,866 & 3710,7 & 2439,6 & 313,4 \\
\hline & I & 3 & 0,5455 & 63,929 & 3777,6 & 2498,6 & 320,7 \\
\hline & I & 4 & 0,5285 & 59,487 & 3590,5 & 2413,5 & 318,1 \\
\hline & I & 5 & 0,5465 & 61,232 & 3613,8 & 2412,8 & 315,9 \\
\hline & II & 1 & 0,8400 & 74,557 & 3299,1 & 2206,9 & 300,7 \\
\hline & II & 2 & 0,8300 & 75,191 & 3354,0 & 2087,7 & 272,6 \\
\hline & II & 3 & 0,8600 & 76,936 & 3351,1 & 2169,9 & 288,6 \\
\hline & II & 4 & 0,8280 & 76,302 & 3409,0 & 2247,2 & 299,1 \\
\hline & II & 5 & 0,8140 & 74,716 & 3376,5 & 2289,2 & 310,7 \\
\hline & & MW & 0,6875 & 68,624 & 3513,2 & 2316,7 & 305,0 \\
\hline & & SD & 0,155 & 7,40 & 173,39 & 135,705 & 15,05 \\
\hline \multirow[t]{12}{*}{ TRP } & I & 1 & 0,4905 & 51,065 & 3253 & 1963 & 258,1 \\
\hline & I & 2 & 0,5295 & 58,223 & 3523 & 2183 & 276,9 \\
\hline & I & 3 & 0,4935 & 56,474 & 3583 & 2189 & 273,6 \\
\hline & I & 4 & 0,529 & 64,109 & 3882 & 2379 & 287,3 \\
\hline & I & 5 & 0,541 & 61,087 & 3644 & 2279 & 285,9 \\
\hline & II & 1 & 0,778 & 69,518 & 3251 & 2107 & 285 \\
\hline & II & 2 & 0,8385 & 73,654 & 3276 & 2244 & 310,6 \\
\hline & II & 3 & 0,764 & 61,246 & 2899 & 1797 & 257,9 \\
\hline & II & 4 & 0,7995 & 65,22 & 2995 & 2007 & 288,9 \\
\hline & II & 5 & Ausfalltier & & & & \\
\hline & & MW & 0,640 & 62,288 & 3367,333 & 2127,556 & 280,467 \\
\hline & & SD & 0,149 & 6,821 & 317,231 & 179,538 & 16,376 \\
\hline
\end{tabular}

$* \mathrm{SP}=$ Sammelperiode 


\begin{tabular}{|c|c|c|c|c|c|c|c|}
\hline Diät & $\mathbf{S P}^{*}$ & Tiernr. & $\begin{array}{l}\text { Mittlere } \\
\text { LM (kg) }\end{array}$ & $\begin{array}{c}\text { TS-Aufnahme } \\
\text { (g/Tag) }\end{array}$ & $\begin{array}{l}\text { N-Aufnahme } \\
\left(\mathbf{m g} / \mathbf{L M}_{\mathbf{k g}}{ }^{0,67}\right)\end{array}$ & $\begin{array}{c}\mathrm{ND} \\
\left(\mathrm{mg} / \mathrm{LM}_{\mathrm{kg}}{ }^{0,67}\right)\end{array}$ & $\begin{array}{c}b \\
\left(b^{*} 10^{6}\right)\end{array}$ \\
\hline \multirow[t]{12}{*}{ ARG } & I & 1 & 0,546 & 62,127 & 3599 & 2245 & 282,9 \\
\hline & I & 2 & 0,5045 & 59,902 & 3659 & 2237 & 276,7 \\
\hline & I & 3 & 0,5235 & 57,042 & 3399 & 2168 & 284,2 \\
\hline & I & 4 & 0,534 & 62,921 & 3700 & 2271 & 280 \\
\hline & I & 5 & 0,524 & 61,491 & 3662 & 2428 & 315,1 \\
\hline & II & 1 & 0,84 & 74,997 & 3255 & 2000 & 264,5 \\
\hline & II & 2 & 0,7955 & 75,474 & 3398 & 2056 & 263,3 \\
\hline & II & 3 & 0,8165 & 74,997 & 3318 & 2100 & 278 \\
\hline & II & 4 & 0,8155 & 75,95 & 3363 & 1989 & 254,2 \\
\hline & II & 5 & 0,8275 & 76,268 & 3344 & 2210 & 297,2 \\
\hline & & MW & 0,673 & 68,117 & 3469,700 & 2170,400 & 279,610 \\
\hline & & SD & 0,155 & 7,983 & 166,334 & 136,642 & 17,487 \\
\hline \multirow[t]{12}{*}{ ILE } & I & 1 & 0,5305 & 61,953 & 3731 & 2676 & 368,1 \\
\hline & I & 2 & 0,4925 & 52,875 & 3347 & 2251 & 305,4 \\
\hline & I & 3 & 0,518 & 61,794 & 3781 & 2427 & 304,8 \\
\hline & I & 4 & 0,5315 & 59,086 & 3554 & 2396 & 317,6 \\
\hline & I & 5 & 0,508 & 52,875 & 3278 & 2242 & 309,9 \\
\hline & II & 1 & 0,8455 & 76,924 & 3390 & 2306 & 313,2 \\
\hline & II & 2 & 0,8075 & 74,694 & 3394 & 2437 & 342,1 \\
\hline & II & 3 & 0,827 & 75,968 & 3398 & 2274 & 305,7 \\
\hline & II & 4 & 0,8625 & 75,172 & 3269 & 2214 & 305 \\
\hline & II & 5 & 0,799 & 74,694 & 3419 & 2521 & 359,9 \\
\hline & & MW & 0,672 & 66,604 & 3456,100 & 2374,400 & 323,170 \\
\hline & & SD & 0,166 & 9,870 & 177,113 & 146,382 & 24,316 \\
\hline \multirow[t]{12}{*}{ VAL } & I & 1 & 0,5225 & 57,919 & 3518,9 & 2705,6 & 398,6 \\
\hline & I & 2 & 0,5350 & 63,328 & 3787,0 & 2429,3 & 304,9 \\
\hline & I & 3 & 0,5410 & 61,737 & 3664,4 & 2620,1 & 360 \\
\hline & I & 4 & 0,5055 & 57,919 & 3597,7 & 2473,6 & 330,9 \\
\hline & I & 5 & 0,5305 & 63,965 & 3846,8 & 2710,5 & 366 \\
\hline & II & 1 & 0,7875 & 60,464 & 2790,7 & 1838,0 & 275,7 \\
\hline & II & 2 & 0,8485 & 75,580 & 3318,3 & 2238,5 & 305,4 \\
\hline & II & 3 & 0,8560 & 76,694 & 3347,4 & 2254,3 & 306 \\
\hline & II & 4 & 0,7770 & 72,397 & 3371,7 & 2178,1 & 288,5 \\
\hline & II & 5 & 0,8380 & 76,376 & 3381,3 & 2404,7 & 335,8 \\
\hline & & MW & 0,6742 & 66,638 & 3462,4 & 2385,3 & 327,2 \\
\hline & & SD & 0,16 & 7,76 & 301,02 & 269,74 & 38,50 \\
\hline
\end{tabular}

*SP = Sammelperiode 
Tabelle A 30: Mittlere Lebendmasse, TS-Aufnahme, N-Aufnahme, N-Deposition (ND) und Proteinqualität (b), Versuch 8, Growerperiode

\begin{tabular}{|c|c|c|c|c|c|c|c|}
\hline Diät & SP* & Tiernr. & $\begin{array}{l}\text { Mittlere } \\
\text { LM (kg) }\end{array}$ & $\begin{array}{c}\text { TS-Aufnahme } \\
\text { (g/Tag) }\end{array}$ & $\begin{array}{l}\text { N-Aufnahme } \\
\left(\mathrm{mg}^{2} \mathbf{L M}_{\mathrm{kg}}{ }^{0,67}\right)\end{array}$ & $\begin{array}{c}\mathrm{ND} \\
\left(\mathrm{mg} / \mathrm{LM}_{\mathrm{kg}}{ }^{0,67}\right) \\
\end{array}$ & $\begin{array}{c}\text { b } \\
\left(b^{*} 10^{6}\right)\end{array}$ \\
\hline \multirow[t]{12}{*}{$\mathrm{BC}$} & I & 1 & 1,6025 & 114,191 & 3289,7 & 2120,9 & 459,9 \\
\hline & I & 2 & 1,5560 & 111,955 & 3289,6 & 2124,9 & 461,7 \\
\hline & I & 3 & 1,6455 & 108,526 & 3071,5 & 2075,1 & 471,5 \\
\hline & I & 4 & 1,6290 & 116,875 & 3330,2 & 2209,5 & 495,8 \\
\hline & I & 5 & 1,5425 & 115,831 & 3423,4 & 2229,6 & 492,4 \\
\hline & II & 1 & 2,0435 & 127,161 & 3112,7 & 1985,9 & 428,2 \\
\hline & II & 2 & 1,9955 & 126,267 & 3140,5 & 1993,8 & 427,5 \\
\hline & II & 3 & 2,0840 & 124,328 & 3003,6 & 1995,9 & 447,9 \\
\hline & II & 4 & 2,1055 & 129,248 & 3101,1 & 2085,0 & 471,4 \\
\hline & II & 5 & 2,0040 & 133,273 & 3305,3 & 2065,4 & 434,1 \\
\hline & & MW & 1,8208 & 120,766 & 3206,8 & 2088,6 & 459,0 \\
\hline & & SD & 0,24 & 8,32 & 137,26 & 85,45 & 24,65 \\
\hline \multirow[t]{12}{*}{ LYS } & I & 1 & 1,6010 & 118,396 & 3104,8 & 1794,0 & 361,6 \\
\hline & I & 2 & 1,5160 & 110,968 & 3018,4 & 1800,7 & 374,2 \\
\hline & I & 3 & 1,5595 & 117,357 & 3132,2 & 1820,3 & 366,9 \\
\hline & I & 4 & 1,6185 & 119,733 & 3117,1 & 1953,4 & 415,2 \\
\hline & I & 5 & 1,5590 & 116,613 & 3113,0 & 1912,3 & 400,6 \\
\hline & II & 1 & 2,0280 & 134,291 & 3005,7 & 1606,5 & 317,0 \\
\hline & II & 2 & 1,9370 & 129,835 & 2996,8 & 1704,2 & 346,3 \\
\hline & II & 3 & 1,9910 & 133,102 & 3016,1 & 1667,0 & 333,0 \\
\hline & II & 4 & 2,0720 & 135,925 & 2998,9 & 1861,2 & 397,3 \\
\hline & II & 5 & 1,9710 & 131,914 & 3009,5 & 1803,7 & 376,3 \\
\hline & & MW & 1,7853 & 124,814 & 3051,2 & 1792,4 & 368,8 \\
\hline & & SD & 0,23 & 9,06 & 57,16 & 107,54 & 30,89 \\
\hline \multirow[t]{12}{*}{ THR } & I & 1 & 1,5760 & 119,096 & 3186,2 & 1968,5 & 411,8 \\
\hline & I & 2 & 1,5745 & 119,836 & 3208,0 & 1921,7 & 392,0 \\
\hline & I & 3 & 1,5870 & 117,912 & 3139,9 & 1848,1 & 375,1 \\
\hline & I & 4 & 1,6220 & 118,652 & 3113,7 & 1950,7 & 414,6 \\
\hline & I & 5 & 1,5890 & 120,131 & 3196,3 & 1797,6 & 352,4 \\
\hline & II & 1 & 2,0235 & 135,074 & 3056,5 & 1865,8 & 391,4 \\
\hline & II & 2 & 2,0020 & 136,257 & 3105,4 & 1821,9 & 370,5 \\
\hline & II & 3 & Ausreißer & & & & \\
\hline & II & 4 & 2,1005 & 134,334 & 2964,6 & 1790,7 & 377,6 \\
\hline & II & 5 & 2,0190 & 135,665 & 3074,4 & 1713,6 & 340,3 \\
\hline & & MW & 1,7882 & 126,329 & 3116,1 & 1853,2 & 380,6 \\
\hline & & SD & 0,24 & 8,58 & 78,03 & 83,02 & 24,84 \\
\hline
\end{tabular}

$* \mathrm{SP}=$ Sammelperiode 


\begin{tabular}{|c|c|c|c|c|c|c|c|}
\hline Diät & SP* & Tiernr. & $\begin{array}{l}\text { Mittlere } \\
\text { LM (kg) }\end{array}$ & $\begin{array}{c}\text { TS-Aufnahme } \\
\text { (g/Tag) }\end{array}$ & $\begin{array}{l}\text { N-Aufnahme } \\
\left(\mathrm{mg} / \mathrm{LM}_{\mathrm{kg}}{ }^{0,67}\right)\end{array}$ & $\begin{array}{c}\text { ND } \\
\left(\mathrm{mg} / \mathrm{LM}_{\mathrm{kg}}{ }^{0,67}\right)\end{array}$ & $\begin{array}{c}\text { b } \\
\left(b^{*} 10^{6}\right)\end{array}$ \\
\hline \multirow[t]{12}{*}{ TRP } & I & 1 & 1,6270 & 119,841 & 3154,5 & 1960,4 & 412,9 \\
\hline & I & 2 & 1,6880 & 119,245 & 3062,3 & 1995,6 & 439,2 \\
\hline & I & 3 & 1,5310 & 118,798 & 3257,0 & 2047,3 & 433,1 \\
\hline & I & 4 & 1,6630 & 119,245 & 3093,1 & 1892,7 & 396,1 \\
\hline & I & 5 & Ausreißer & & & & \\
\hline & II & 1 & 2,0625 & 134,896 & 3029,0 & 1811,2 & 376,3 \\
\hline & II & 2 & 2,1640 & 135,195 & 2939,6 & 1799,7 & 383,8 \\
\hline & II & 3 & 2,0050 & 135,492 & 3100,6 & 1839,8 & 377,0 \\
\hline & II & 4 & Ausreißer & & & & \\
\hline & II & 5 & 2,0345 & 134,449 & 3046,8 & 1969,1 & 430,9 \\
\hline & & MW & 1,8469 & 127,145 & 3085,4 & 1914,5 & 406,2 \\
\hline & & SD & 0,24 & 8,42 & 93,34 & 91,99 & 26,22 \\
\hline \multirow[t]{12}{*}{$\mathrm{ARG}$} & I & 1 & 1,6170 & 119,194 & 3076,6 & 1796,8 & 365,8 \\
\hline & I & 2 & 1,5090 & 119,343 & 3226,5 & 2048,8 & 437,9 \\
\hline & I & 3 & 1,6205 & 117,705 & 3033,8 & 1755,0 & 357,6 \\
\hline & I & 4 & 1,4985 & 116,661 & 3168,8 & 1920,6 & 396,5 \\
\hline & I & 5 & 1,5580 & 100,719 & 2665,3 & 1789,0 & 419,4 \\
\hline & II & 1 & 2,0450 & 136,031 & 3000,1 & 1682,9 & 339,5 \\
\hline & II & 2 & 1,9545 & 135,732 & 3085,6 & 1775,8 & 358,1 \\
\hline & II & 3 & 2,0420 & 135,285 & 2986,6 & 1717,2 & 351,4 \\
\hline & II & 4 & 1,9705 & 133,200 & 3011,6 & 1724,9 & 350,9 \\
\hline & II & 5 & 1,9575 & 115,320 & 2618,9 & 1766,0 & 418,2 \\
\hline & & MW & 1,7773 & 122,919 & 2987,4 & 1797,7 & 379,5 \\
\hline & & SD & 0,23 & 11,73 & 197,23 & 108,80 & 35,15 \\
\hline \multirow[t]{12}{*}{ ILE } & I & 1 & 1,5340 & 119,433 & 3254,0 & 1911,4 & 382,9 \\
\hline & I & 2 & 1,6590 & 120,621 & 3118,3 & 1814,3 & 366,5 \\
\hline & I & 3 & 1,5890 & 119,878 & 3190,0 & 1922,8 & 394,6 \\
\hline & I & 4 & 1,6095 & 118,245 & 3119,6 & 1887,6 & 391,0 \\
\hline & I & 5 & & & & & \\
\hline & II & 1 & 1,9970 & 135,476 & 3093,2 & 1738,6 & 345,7 \\
\hline & II & 2 & & & & & \\
\hline & II & 3 & 2,0530 & 136,516 & 3059,7 & 1789,0 & 365,3 \\
\hline & II & 4 & 2,0465 & 135,327 & 3039,5 & 1793,7 & 369,3 \\
\hline & II & 5 & 2,1335 & 135,625 & 2962,4 & 1832,3 & 392,0 \\
\hline & & MW & 1,828 & 127,640 & 3104,6 & 1836,2 & 375,9 \\
\hline & & SD & 0,25 & 8,69 & 89,94 & 65,31 & 17,08 \\
\hline \multirow[t]{12}{*}{ VAL } & I & 1 & 1,5845 & 120,952 & 3220,4 & 1797,8 & 349,8 \\
\hline & I & 2 & 1,6830 & 120,060 & 3070,1 & 1936,3 & 415,0 \\
\hline & I & 3 & 1,6310 & 119,317 & 3115,9 & 1860,0 & 382,0 \\
\hline & I & 4 & 1,5960 & 119,763 & 3173,3 & 2002,6 & 426,5 \\
\hline & I & 5 & 1,6130 & 120,506 & 3170,4 & 1699,7 & 326,0 \\
\hline & II & 1 & 2,0220 & 136,851 & 3094,6 & 1718,1 & 339,4 \\
\hline & II & 2 & 2,1240 & 134,027 & 2932,4 & 1623,1 & 329,7 \\
\hline & II & 3 & 2,0825 & 134,473 & 2981,3 & 1806,8 & 380,8 \\
\hline & II & 4 & 2,0680 & 137,000 & 3051,6 & 1706,4 & 340,7 \\
\hline & II & 5 & 2,0500 & 135,662 & 3039,5 & 1790,4 & 368,2 \\
\hline & & MW & 1,8454 & 127,861 & 3084,9 & 1794,1 & 365,8 \\
\hline & & SD & 0,24 & 8,22 & 89,39 & 115,39 & 35,08 \\
\hline
\end{tabular}

$* \mathrm{SP}=$ Sammelperiode 
Tabelle A 31: Mittlere Lebendmasse, TS-Aufnahme, N-Aufnahme, N-Deposition (ND) und Proteinqualität (b) im Versuchs 9, Starterperiode

\begin{tabular}{|c|c|c|c|c|c|c|c|}
\hline Diät & SP* & $\begin{array}{c}\text { Tier- } \\
\text { nr. }\end{array}$ & $\begin{array}{l}\text { Mittlere } \\
\text { LM (kg) }\end{array}$ & $\begin{array}{c}\text { TS-Aufnahme } \\
\text { (g/Tag) }\end{array}$ & $\begin{array}{l}\text { N-Aufnahme } \\
\left(\text { mg/LM }_{\text {kg }}{ }^{0,67}\right)\end{array}$ & $\begin{array}{c}\mathrm{ND} \\
\left(\mathrm{mg} / \mathrm{LM}_{\mathrm{kg}}{ }^{0,67}\right)\end{array}$ & $\begin{array}{c}\text { b } \\
\left(b^{*} 10^{6}\right)\end{array}$ \\
\hline \multirow[t]{18}{*}{$\mathrm{BC}$} & I & 1 & 0,4068 & 52,586 & 4124,2 & 2745 & 350,2 \\
\hline & I & 2 & 0,4218 & 52,281 & 4001,9 & 2910 & 409,0 \\
\hline & I & 3 & 0,3653 & 49,529 & 4174,8 & 2853 & 375,0 \\
\hline & I & 4 & 0,4330 & 55,185 & 4150,4 & 2864 & 380,4 \\
\hline & I & 5 & 0,3945 & 53,198 & 4258,5 & 2942 & 394,2 \\
\hline & I & 6 & 0,3798 & 51,975 & 4268,2 & 2892 & 377,9 \\
\hline & I & 7 & 0,3393 & 46,778 & 4142,8 & 2821 & 368,7 \\
\hline & I & 8 & 0,4228 & 52,892 & 4042,3 & 2806 & 373,6 \\
\hline & II & 1 & 0,6845 & 74,752 & 4136,5 & 2831 & 372,2 \\
\hline & II & 2 & 0,6995 & 72,459 & 3951,8 & 2847 & 394,4 \\
\hline & II & 3 & 0,6925 & 74,752 & 4104,4 & 2778 & 360,5 \\
\hline & II & 4 & 0,7205 & 74,294 & 3972,4 & 2730 & 359,4 \\
\hline & II & 5 & 0,6800 & 75,364 & 4188,8 & 2923 & 394,8 \\
\hline & II & 6 & 0,6575 & 75,975 & 4319,1 & 2659 & 314,1 \\
\hline & II & 7 & 0,6165 & 74,447 & 4418,8 & 2923 & 374,0 \\
\hline & II & 8 & 0,6900 & 73,529 & 4047,1 & 2631 & 328,5 \\
\hline & & MW & 0,5378 & 63,125 & 4143,9 & 2822 & 370,4 \\
\hline & & SD & 0,15 & 11,85 & 128,07 & 93,30 & 24,48 \\
\hline \multirow{16}{*}{ LYS } & I & 1 & 0,2380 & 27,855 & 3073,5 & 1596 & 210,3 \\
\hline & I & 2 & 0,3728 & 50,260 & 4105,9 & 2793 & 364,3 \\
\hline & I & 3 & 0,2578 & 31,185 & 3262,0 & 2106 & 283,8 \\
\hline & I & 4 & 0,2548 & 25,433 & 2681,2 & 1669 & 254,3 \\
\hline & I & 5 & 0,3825 & 40,571 & 3257,5 & 2172 & 297,3 \\
\hline & I & 6 & 0,2745 & 34,970 & 3506,8 & 2330 & 307,6 \\
\hline & I & 7 & 0,3010 & 36,484 & 3439,5 & 2029 & 255,5 \\
\hline & II & 1 & 0,3665 & 40,874 & 3377,2 & 2126 & 278,0 \\
\hline & II & 2 & 0,6345 & 74,936 & 4286,4 & 2450 & 273,2 \\
\hline & II & 3 & 0,3950 & 53,591 & 4211,1 & 2949 & 400,8 \\
\hline & II & 4 & 0,3620 & 34,970 & 2913,4 & 1909 & 277,5 \\
\hline & II & 5 & 0,5950 & 61,311 & 3661,4 & 2095 & 251,1 \\
\hline & II & 6 & 0,4020 & 47,838 & 3715,1 & 2339 & 292,2 \\
\hline & II & 7 & 0,4830 & 53,591 & 3680,2 & 2189 & 266,3 \\
\hline & & MW & 0,3799 & 43,848 & 3512,2 & 2197 & 286,6 \\
\hline & & SD & 0,121 & 13,88 & 474,32 & 371,88 & 47,65 \\
\hline \multirow{16}{*}{ THR } & I & 1 & 0,2678 & 31,121 & 3174,5 & 2259,4 & 323,9 \\
\hline & I & 2 & 0,3438 & 44,240 & 3817,1 & 2786,3 & 390,0 \\
\hline & I & 3 & 0,3450 & 43,783 & 3768,4 & 2529,4 & 328,4 \\
\hline & I & 4 & 0,3925 & 49,885 & 3938,2 & 2605,4 & 331,5 \\
\hline & I & 5 & 0,3908 & 50,037 & 3962,0 & 2472,5 & 300,3 \\
\hline & I & 6 & 0,3955 & 50,342 & 3954,1 & 2846,4 & 394,0 \\
\hline & I & 7 & 0,2570 & 31,884 & 3342,8 & 2358,0 & 328,9 \\
\hline & II & 1 & 0,4435 & 49,732 & 3617,6 & 2411,7 & 315,4 \\
\hline & II & 2 & 0,6225 & 57,970 & 3359,9 & 2041,3 & 263,7 \\
\hline & II & 3 & 0,6165 & 70,022 & 4084,8 & 2576,7 & 313,2 \\
\hline & II & 4 & 0,6825 & 74,751 & 4073,5 & 2603,9 & 320,2 \\
\hline & II & 5 & 0,6540 & 71,852 & 4029,0 & 2335,9 & 268,8 \\
\hline & II & 6 & 0,6740 & 73,683 & 4049,1 & 2885,1 & 396,3 \\
\hline & II & 7 & 0,4715 & 59,343 & 4143,2 & 2841,2 & 374,5 \\
\hline & & MW & 0,4683 & 54,189 & 3808,2 & 2539,5 & 332,1 \\
\hline & & SD & 0,15 & 14,45 & 314,40 & 247,67 & 42,67 \\
\hline
\end{tabular}

*SP $=$ Sammelperiode 


\begin{tabular}{|c|c|c|c|c|c|c|c|}
\hline Diät & SP* & $\begin{array}{c}\text { Tier- } \\
\text { nr. }\end{array}$ & $\begin{array}{l}\text { Mittlere } \\
\text { LM (kg) }\end{array}$ & $\begin{array}{c}\text { TS-Aufnahme } \\
\text { (g/Tag) }\end{array}$ & $\begin{array}{l}\text { N-Aufnahme } \\
\left(\text { mg/LM }_{\text {kg }}{ }^{6,67}\right)\end{array}$ & $\begin{array}{c}\mathrm{ND} \\
\left(\mathrm{mg} / \mathrm{LM}_{\mathrm{kg}}{ }^{0,67}\right)\end{array}$ & $\begin{array}{c}\text { b } \\
\left(b^{*} 10^{6}\right)\end{array}$ \\
\hline \multirow{16}{*}{ ILE } & I & 1 & 0,3918 & 48,181 & 3773,9 & 2357,8 & 291,3 \\
\hline & I & 2 & 0,3425 & 42,235 & 3619,7 & 2484,5 & 331,4 \\
\hline & I & 3 & 0,3330 & 42,235 & 3688,6 & 2621,6 & 358,0 \\
\hline & I & 4 & 0,2905 & 41,930 & 4012,7 & 2587,5 & 321,3 \\
\hline & I & 5 & 0,2538 & 31,104 & 3259,1 & 2077,8 & 278,7 \\
\hline & I & 6 & 0,2850 & 30,647 & 2970,8 & 2001,8 & 290,2 \\
\hline & I & 7 & 0,3990 & 52,603 & 4069,9 & 2408,1 & 279,6 \\
\hline & II & 1 & 0,6560 & 71,662 & 3973,6 & 2452,5 & 295,3 \\
\hline & II & 2 & 0,5700 & 62,819 & 3827,2 & 2500,5 & 317,0 \\
\hline & II & 3 & 0,5800 & 68,003 & 4095,0 & 2753,1 & 354,7 \\
\hline & II & 4 & 0,4995 & 55,042 & 3663,6 & 2359,7 & 300,5 \\
\hline & II & 5 & 0,4345 & 51,078 & 3732,6 & 2359,0 & 294,8 \\
\hline & II & 6 & 0,4775 & 53,518 & 3671,2 & 2370,3 & 302,1 \\
\hline & II & 7 & 0,6655 & 76,084 & 4178,4 & 2406,3 & 272,0 \\
\hline & & MW & 0,4413 & 51,939 & 3752,6 & 2410,0 & 306,2 \\
\hline & & SD & 0,137 & 14,01 & 329,72 & 195,33 & 26,92 \\
\hline \multirow[t]{16}{*}{ VAL } & I & 1 & 0,3355 & 42,296 & 3675,6 & 2462,5 & 321,5 \\
\hline & I & 2 & 0,2250 & 24,213 & 2749,9 & 2054,2 & 325,0 \\
\hline & I & 3 & 0,2578 & 28,197 & 2923,8 & 2245,7 & 348,3 \\
\hline & I & 4 & 0,2858 & 29,576 & 2862,0 & 1964,6 & 293,6 \\
\hline & I & 5 & 0,3283 & 39,691 & 3500,0 & 2490,5 & 344,2 \\
\hline & I & 6 & 0,3738 & 43,522 & 3518,2 & 2492,3 & 342,8 \\
\hline & I & 7 & 0,3018 & 36,932 & 3445,7 & 2087,5 & 265,4 \\
\hline & II & 1 & 0,6055 & 70,799 & 4142,4 & 2823,2 & 369,5 \\
\hline & II & 2 & 0,3445 & 36,013 & 3074,5 & 2075,1 & 294,9 \\
\hline & II & 3 & 0,4170 & 49,345 & 3706,8 & 2660,3 & 366,3 \\
\hline & II & 4 & 0,4700 & 51,797 & 3591,2 & 2541,9 & 347,7 \\
\hline & II & 5 & 0,5735 & 66,815 & 4054,1 & 2720,5 & 349,8 \\
\hline & II & 6 & Ausreißer & & & & \\
\hline & II & 7 & 0,5165 & 60,838 & 3959,7 & 2314,6 & 269,6 \\
\hline & & MW & 0,3873 & 44,618 & 3477,2 & 2379,5 & 326,0 \\
\hline & & SD & 0,131 & 14,70 & 455,72 & 278,14 & 34,83 \\
\hline
\end{tabular}

*SP = Sammelperiode 
Tabelle A 32: Mittlere Lebendmasse, TS-Aufnahme, N-Aufnahme, N-Deposition (ND) und Proteinqualität (b) im Versuchs 9, Growerperiode

\begin{tabular}{|c|c|c|c|c|c|c|c|}
\hline Diät & SP* & Tiernr. & $\begin{array}{l}\text { Mittlere } \\
\text { LM (kg) }\end{array}$ & $\begin{array}{c}\begin{array}{c}\text { TS-Aufnahme } \\
\text { (g/Tag) }\end{array} \\
\end{array}$ & $\begin{array}{l}\text { N-Aufnahme } \\
\left(\mathrm{mg}^{2} \mathbf{L M}_{\mathrm{kg}}{ }^{0,67}\right)\end{array}$ & $\begin{array}{c}\mathrm{ND} \\
\left(\mathrm{mg} / \mathrm{LM}_{\mathrm{kg}}{ }^{0,67}\right)\end{array}$ & $\begin{array}{c}\text { b } \\
\left(b^{*} 10^{6}\right)\end{array}$ \\
\hline \multirow[t]{18}{*}{$\mathrm{BC}$} & I & 1 & 1,373 & 114,075 & 3657,0 & 2365,1 & 534,2 \\
\hline & I & 2 & 1,385 & 114,521 & 3649,1 & 2282,4 & 488,2 \\
\hline & I & 3 & 1,370 & 113,183 & 3632,8 & 2393,9 & 556,4 \\
\hline & I & 4 & 1,271 & 114,819 & 3875,3 & 2569,2 & 664,5 \\
\hline & I & 5 & 1,311 & 114,224 & 3777,0 & 2372,1 & 521,5 \\
\hline & I & 6 & 1,326 & 115,116 & 3777,5 & 2309,6 & 485,7 \\
\hline & I & 7 & 1,280 & 115,414 & 3877,0 & 2401,4 & 526,0 \\
\hline & I & 8 & 1,365 & 114,373 & 3680,0 & 2084,9 & 397,2 \\
\hline & II & 1 & 1,796 & 126,866 & 3396,5 & 1976,7 & 389,2 \\
\hline & II & 2 & 1,814 & 127,312 & 3385,7 & 1923,1 & 371,9 \\
\hline & II & 3 & 1,832 & 125,825 & 3324,1 & 2124,3 & 456,6 \\
\hline & II & 4 & 1,719 & 126,717 & 3494,2 & 2260,5 & 498,2 \\
\hline & II & 5 & 1,726 & 124,932 & 3435,0 & 1999,2 & 392,8 \\
\hline & II & 6 & 1,758 & 126,717 & 3442,1 & 2066,1 & 417,2 \\
\hline & II & 7 & 1,724 & 127,015 & 3495,6 & 2076,3 & 414,7 \\
\hline & II & 8 & 1,776 & 124,040 & 3345,8 & 1982,8 & 397,3 \\
\hline & & MW & 1,551 & 120,322 & 3577,8 & 2199,2 & 469,5 \\
\hline & & SD & 0,23 & 6,12 & 186,71 & 193,22 & 79,70 \\
\hline \multirow[t]{16}{*}{ LYS } & I & 1 & 1,1870 & 110,586 & 3853,3 & 1921,7 & 326,4 \\
\hline & I & 2 & 1,3635 & 111,025 & 3525,4 & 1963,9 & 370,6 \\
\hline & I & 3 & 1,3140 & 109,268 & 3556,7 & 2049,8 & 397,6 \\
\hline & I & 4 & 1,3525 & 106,631 & 3404,3 & 1942,7 & 376,5 \\
\hline & I & 5 & Ausalltier & & & & \\
\hline & I & 6 & 1,1945 & 107,217 & 3720,1 & 2158,6 & 421,9 \\
\hline & I & 7 & 1,3555 & 110,293 & 3516,0 & 1848,0 & 334,9 \\
\hline & II & 1 & 1,5425 & 106,338 & 3108,8 & 1666,2 & 322,9 \\
\hline & II & 2 & 1,7615 & 117,177 & 3134,1 & 1633,2 & 311,2 \\
\hline & II & 3 & 1,6645 & 113,808 & 3161,7 & 1708,2 & 329,4 \\
\hline & II & 4 & 1,7050 & 108,096 & 2955,0 & 1451,4 & 281,3 \\
\hline & II & 5 & Ausfalltier & & & & \\
\hline & II & 6 & 1,5290 & 103,848 & 3053,9 & 1654,7 & 325,4 \\
\hline & II & 7 & 1,7270 & 116,445 & 3156,1 & 1667,5 & 318,4 \\
\hline & & MW & 1,4747 & 110,061 & 3345,5 & 1805,5 & 343,0 \\
\hline & & SD & 0,21 & 4,08 & 206,54 & 206,54 & 40,17 \\
\hline \multirow[t]{16}{*}{ THR } & I & 1 & 1,2820 & 98,864 & 3271,1 & 1879,4 & 370,2 \\
\hline & I & 2 & 1,2145 & 100,196 & 3437,5 & 2097,4 & 430,3 \\
\hline & I & 3 & 1,2360 & 110,112 & 3733,6 & 2247,5 & 459,9 \\
\hline & I & 4 & 1,3585 & 111,000 & 3532,8 & 2139,8 & 436,1 \\
\hline & I & 5 & 1,2895 & 112,036 & 3692,5 & 2129,7 & 413,2 \\
\hline & I & 6 & 1,2620 & 99,456 & 3325,6 & 1919,7 & 377,5 \\
\hline & I & 7 & 1,1060 & 103,008 & 3762,7 & 2083,3 & 387,8 \\
\hline & II & 1 & 1,6280 & 107,300 & 3025,1 & 1903,0 & 408,8 \\
\hline & II & 2 & 1,5525 & 110,408 & 3213,3 & 1806,4 & 353,2 \\
\hline & II & 3 & 1,6175 & 117,068 & 3314,8 & 1956,7 & 391,6 \\
\hline & II & 4 & 1,7485 & 117,068 & 3146,3 & 1867,7 & 380,9 \\
\hline & II & 5 & 1,6670 & 118,252 & 3281,4 & 1807,3 & 346,2 \\
\hline & II & 6 & 1,5730 & 103,896 & 2997,3 & 1642,1 & 327,9 \\
\hline & II & 7 & 1,4565 & 116,772 & 3547,0 & 2034,7 & 393,1 \\
\hline & & MW & 1,4280 & 108,960 & 3377,2 & 1965,3 & 391,2 \\
\hline & & SD & 0,20 & 6,95 & 249,18 & 164,31 & 36,47 \\
\hline
\end{tabular}

$* \mathrm{SP}=$ Sammelperiode 


\begin{tabular}{|c|c|c|c|c|c|c|c|}
\hline Diät & SP* & Tiernr. & $\begin{array}{l}\text { Mittlere } \\
\text { LM (kg) }\end{array}$ & $\begin{array}{c}\text { TS-Aufnahme } \\
\text { (g/Tag) }\end{array}$ & $\begin{array}{l}\text { N-Aufnahme } \\
\text { (mg/LM }_{k \mathbf{0 , 6 7}} \text { ) }\end{array}$ & $\begin{array}{c}\text { ND } \\
\left(\mathrm{mg} / \mathrm{LM}_{\mathrm{kg}}{ }^{0,67}\right)\end{array}$ & $\begin{array}{c}b \\
\left(b^{*} 10^{6}\right)\end{array}$ \\
\hline \multirow[t]{16}{*}{ ILE } & I & 1 & 1,3175 & 112,157 & 3619 & 2153,7 & 431,6 \\
\hline & I & 2 & 1,2300 & 91,711 & 3099 & 1984,3 & 429,5 \\
\hline & I & 3 & 1,2745 & 104,453 & 3446 & 1980,7 & 385,0 \\
\hline & I & 4 & 1,3660 & 111,565 & 3514 & 1776,7 & 314,7 \\
\hline & I & 5 & 1,2280 & 107,861 & 3648 & 2076,3 & 397,4 \\
\hline & I & 6 & 1,3205 & 107,861 & 3475 & 1652,8 & 285,5 \\
\hline & I & 7 & 1,2965 & 106,675 & 3479 & 1992,1 & 385,3 \\
\hline & II & 1 & 1,6915 & 115,565 & 3154 & 1728,9 & 336,2 \\
\hline & II & 2 & 1,5105 & 86,674 & 2552 & 1552,3 & 356,0 \\
\hline & II & 3 & 1,6450 & 105,194 & 2925 & 1502,0 & 297,2 \\
\hline & II & 4 & 1,7415 & 114,972 & 3077 & 1503,4 & 282,8 \\
\hline & II & 5 & 1,5740 & 114,380 & 3276 & 1916,3 & 382,0 \\
\hline & II & 6 & 1,6680 & 114,380 & 3151 & 1656,2 & 315,8 \\
\hline & II & 7 & 1,6970 & 108,305 & 2949 & 1613,0 & 324,9 \\
\hline & & MW & 1,4686 & 107,268 & 3240,286 & 1792,0 & 351,7 \\
\hline & & SD & 0,20 & 8,56 & 311,359 & 221,65 & 50,71 \\
\hline \multirow[t]{16}{*}{ VAL } & I & 1 & 1,2025 & 93,593 & 3210,4 & 1738,9 & 333,2 \\
\hline & I & 2 & 1,0700 & 58,087 & 2154,6 & 858,1 & 217,2 \\
\hline & I & 3 & 0,9875 & 35,209 & 1378,1 & 546,7 & 231,9 \\
\hline & I & 4 & 1,1755 & 62,693 & 2183,5 & 1184,5 & 298,3 \\
\hline & I & 5 & 0,9515 & 63,733 & 2557,4 & 1451,4 & 325,0 \\
\hline & I & 6 & 1,0675 & 75,618 & 2809,3 & 1548,6 & 322,4 \\
\hline & I & 7 & 1,5215 & 99,239 & 2907,6 & 1575,2 & 318,8 \\
\hline & II & 1 & 1,3850 & 101,467 & 3166,1 & 1864,3 & 377,3 \\
\hline & II & 2 & 1,2675 & 71,606 & 2371,1 & 1726,5 & 446,3 \\
\hline & II & 3 & 1,4935 & 117,066 & 3472,9 & 2362,6 & 560,9 \\
\hline & II & 4 & 1,2945 & 106,518 & 3477,7 & 2120,6 & 434,9 \\
\hline & II & 5 & 1,3330 & 95,525 & 3058,1 & 1729,4 & 346,9 \\
\hline & II & 6 & 1,7525 & 84,807 & 2260,3 & 1106,1 & 267,3 \\
\hline & II & 7 & 1,8260 & 81,114 & 2103,1 & 1080,9 & 280,2 \\
\hline & & MW & 1,3091 & $\mathbf{8 1 , 8 7 7}$ & 2650,7 & 1492,4 & 340,0 \\
\hline & & SD & 0,27 & 22,27 & 608,85 & 494,87 & 91,54 \\
\hline
\end{tabular}

*SP $=$ Sammelperiode

Tabelle A 33: Ganzkörperanalyse, Versuch 10 (1. LT)

\begin{tabular}{cccccc}
\hline Null-Tiere & \% TS & $\begin{array}{c}\text { \% XA } \\
\text { in TS }\end{array}$ & $\begin{array}{c}\text { \% N } \\
\text { in TS }\end{array}$ & $\begin{array}{c}\text { \% XP } \\
\text { in TS }\end{array}$ & $\begin{array}{c}\text { \% XL } \\
\text { in TS }\end{array}$ \\
\hline 1 & 21,21 & 8,95 & 11,38 & 71,11 & 19,94 \\
2 & 21,33 & 8,96 & 11,53 & 72,07 & 18,97 \\
3 & 21,68 & 8,91 & 11,36 & 71,01 & 20,08 \\
MW & $\mathbf{2 1 , 4 1}$ & $\mathbf{8 , 9 4}$ & $\mathbf{1 1 , 4 2}$ & $\mathbf{7 1 , 4 0}$ & $\mathbf{1 9 , 6 7}$ \\
SD & $\mathbf{0 , 2 4}$ & $\mathbf{0 , 0 3}$ & $\mathbf{0 , 0 9}$ & $\mathbf{0 , 5 8}$ & $\mathbf{0 , 6 0}$ \\
\hline
\end{tabular}

Tabelle A 34: Ganzkörperanalyse, Versuch 10 (Beginn Growerperiode, 21. LT)

\begin{tabular}{cccccc}
\hline Null-Tiere & \% TS & $\begin{array}{c}\text { \% XA } \\
\text { in TS }\end{array}$ & $\begin{array}{c}\text { \% N } \\
\text { in TS }\end{array}$ & $\begin{array}{c}\text { \% XP } \\
\text { in TS }\end{array}$ & $\begin{array}{c}\text { \% XL } \\
\text { in TS }\end{array}$ \\
\hline 1 & & 7,78 & 9,04 & 56,53 & 35,69 \\
2 & 31,47 & 7,68 & 9,41 & 58,79 & 33,53 \\
3 & 31,39 & 7,69 & 9,22 & 57,65 & 34,66 \\
MW & $\mathbf{3 1 , 4 5}$ & $\mathbf{7 , 7 2}$ & $\mathbf{9 , 2 3}$ & $\mathbf{5 7 , 6 6}$ & $\mathbf{3 4 , 6 3}$ \\
SD & $\mathbf{0 , 5 6}$ & $\mathbf{0 , 0 5}$ & $\mathbf{0 , 1 8}$ & $\mathbf{1 , 1 3}$ & $\mathbf{1 , 0 8}$ \\
\hline
\end{tabular}


Tabelle A 35: Ganzkörperanalyse, Versuch 10 (21. LT)

\begin{tabular}{|c|c|c|c|c|c|c|}
\hline Diät & Tiernummer & $\%$ TS & $\begin{array}{l}\% \mathrm{XA} \\
\text { in TS }\end{array}$ & $\begin{array}{c}\% \mathrm{~N} \\
\text { in } \mathrm{TS}\end{array}$ & $\begin{array}{l}\% \mathrm{XP} \\
\text { in TS }\end{array}$ & $\begin{array}{l}\% \mathrm{XL} \\
\text { in TS }\end{array}$ \\
\hline \multirow[t]{8}{*}{$\mathrm{BC}$} & 1 & 30,3247 & 8,4936 & 9,5856 & 59,9102 & 31,5963 \\
\hline & 2 & 31,2445 & 8,3942 & 9,2463 & 57,7896 & 33,8162 \\
\hline & 3 & 32,3850 & 8,0323 & 8,7730 & 54,8310 & 37,1368 \\
\hline & 4 & 32,9522 & 8,1958 & 8,7973 & 54,9834 & 36,8208 \\
\hline & 5 & 31,8013 & 8,2065 & 9,3509 & 58,4434 & 33,3501 \\
\hline & 6 & 30,2082 & 9,0537 & 9,4746 & 59,2165 & 31,7298 \\
\hline & MW & 31,4860 & 8,3960 & 9,2046 & 57,5290 & 34,0750 \\
\hline & SD & 1,1043 & 0,3606 & 0,3445 & 2,1532 & 2,4145 \\
\hline \multirow[t]{8}{*}{ LYS } & 1 & 30,5540 & 8,9721 & 9,1497 & 57,1857 & 33,8422 \\
\hline & 2 & 31,9576 & 9,6062 & 8,6810 & 54,2563 & 36,1374 \\
\hline & 3 & 32,1975 & 9,3510 & 8,5055 & 53,1595 & 37,4896 \\
\hline & 4 & 30,8176 & 8,9713 & 9,7653 & 61,0332 & 29,9955 \\
\hline & 5 & 31,7098 & 8,9579 & 8,9695 & 56,0595 & 34,9826 \\
\hline & 6 & 31,0988 & 9,5280 & 9,2709 & 57,9431 & 32,5289 \\
\hline & MW & 31,3892 & 9,2311 & 9,0570 & 56,6062 & 34,1627 \\
\hline & SD & 0,6615 & 0,3008 & 0,4493 & 2,8079 & 2,6750 \\
\hline \multirow[t]{7}{*}{ THR } & 1 & 31,8530 & 8,0740 & 8,5138 & 53,2114 & 38,7146 \\
\hline & 2 & 32,4630 & 8,6297 & 8,9069 & 55,6679 & 35,7025 \\
\hline & 3 & 31,0739 & 8,5877 & 9,1080 & 56,9252 & 34,4871 \\
\hline & 4 & 31,1873 & 9,3747 & 9,1120 & 56,9498 & 33,6755 \\
\hline & 5 & 32,7843 & 8,0843 & 8,6730 & 54,2065 & 37,7092 \\
\hline & MW & 26,6705 & 7,1752 & 7,4605 & 46,6281 & 30,4940 \\
\hline & SD & 12,7597 & 3,4012 & 3,4430 & 21,5187 & 13,7603 \\
\hline \multirow{8}{*}{$\mathrm{TRP}$} & 1 & 30,6836 & 9,0015 & 9,2819 & 58,0118 & 32,9866 \\
\hline & 2 & 32,7056 & 8,3058 & 8,8578 & 55,3611 & 36,3331 \\
\hline & 3 & 33,1174 & 8,1461 & 8,5617 & 53,5104 & 38,3435 \\
\hline & 4 & 34,0575 & 7,4136 & 8,2639 & 51,6496 & 40,9368 \\
\hline & 5 & Ausreißer & & & & \\
\hline & 6 & 31,0209 & 8,9052 & 9,0778 & 56,7361 & 34,3587 \\
\hline & MW & 32,3170 & 8,3544 & 8,8086 & 55,0538 & 36,5917 \\
\hline & SD & 1,4291 & 0,6429 & 0,4051 & 2,5321 & 3,1622 \\
\hline \multirow{8}{*}{$\mathrm{ARG}$} & 1 & 34,1442 & 7,5571 & 8,4511 & 52,8197 & 39,6232 \\
\hline & 2 & 34,2896 & 8,2762 & 8,3725 & 52,3283 & 39,3954 \\
\hline & 3 & 34,4381 & 7,7519 & 8,1601 & 51,0008 & 41,2473 \\
\hline & 4 & 32,9632 & 7,7858 & 8,4235 & 52,6469 & 39,5672 \\
\hline & 5 & 35,3596 & 7,5571 & 7,8940 & 49,3376 & 43,1053 \\
\hline & 6 & 33,1997 & 8,3609 & 8,1443 & 50,9021 & 40,7370 \\
\hline & MW & 34,0657 & 7,8815 & 8,2409 & 51,5059 & 40,6126 \\
\hline & SD & $\mathbf{0 , 8 7 5 7}$ & 0,3527 & 0,2150 & 1,3435 & 1,4273 \\
\hline \multirow[t]{8}{*}{ ILE } & 1 & 32,3530 & 7,8384 & 8,5712 & 53,5700 & 38,5916 \\
\hline & 2 & 32,4766 & 8,3724 & 8,7125 & 54,4532 & 37,1743 \\
\hline & 3 & 34,5425 & 7,5472 & 8,0083 & 50,0521 & 42,4007 \\
\hline & 4 & 33,2830 & 8,8995 & 8,1984 & 51,2397 & 39,8608 \\
\hline & 5 & 31,9668 & 8,5858 & 8,6588 & 54,1172 & 37,2970 \\
\hline & 6 & 32,5057 & 8,5971 & 8,7508 & 54,6924 & 36,7106 \\
\hline & MW & 32,8546 & 8,3067 & 8,4833 & 53,0208 & 38,6725 \\
\hline & SD & 0,9314 & 0,5126 & 0,3064 & 1,9150 & 2,1589 \\
\hline \multirow[t]{7}{*}{ VAL } & 1 & 33,7077 & 8,8487 & 8,5401 & 53,3753 & 37,7760 \\
\hline & 2 & 32,0567 & 8,4984 & 8,1015 & 50,6345 & 40,8671 \\
\hline & 3 & 32,3974 & 8,7978 & 8,4475 & 52,7967 & 38,4056 \\
\hline & 4 & 33,7068 & 8,9186 & 8,1488 & 50,9300 & 40,1513 \\
\hline & 5 & 31,5432 & 9,2926 & 8,8492 & 55,3077 & 35,3997 \\
\hline & MW & 32,6824 & 8,8712 & 8,4174 & 52,6089 & 38,5199 \\
\hline & SD & 0,9838 & 0,2849 & 0,3059 & 1,9120 & 2,1490 \\
\hline
\end{tabular}


Tabellenanhang

Tabelle A 36: Ganzkörperanalyse, Versuch 10 (35. LT)

\begin{tabular}{|c|c|c|c|c|c|c|}
\hline Diät & Tiernummer & $\%$ TS & $\begin{array}{l}\text { \% XA } \\
\text { in TS }\end{array}$ & $\begin{array}{c}\% \mathrm{~N} \\
\text { in TS }\end{array}$ & $\begin{array}{l}\% \mathrm{XP} \\
\text { in TS }\end{array}$ & $\begin{array}{l}\% \mathrm{XL} \\
\text { In TS }\end{array}$ \\
\hline \multirow[t]{8}{*}{$\mathrm{BC}$} & 1 & 34,3897 & 7,2370 & 9,0144 & 56,3403 & 36,4228 \\
\hline & 2 & 35,0196 & 6,8264 & 8,7475 & 54,6718 & 38,5017 \\
\hline & 3 & 36,0038 & 6,9835 & 8,5329 & 53,3304 & 39,6860 \\
\hline & 4 & 34,1903 & 7,5917 & 8,7762 & 54,8510 & 37,5573 \\
\hline & 5 & 35,6774 & 6,5891 & 8,4604 & 52,8775 & 40,5334 \\
\hline & 6 & 33,4301 & 7,8471 & 8,7423 & 54,6395 & 37,5134 \\
\hline & MW & 34,7852 & 7,1791 & 8,7123 & 54,4518 & 38,3691 \\
\hline & SD & 0,9677 & 0,4755 & 0,1965 & 1,2284 & 1,5242 \\
\hline \multirow[t]{8}{*}{ LYS } & 1 & 33,5978 & 7,5528 & 8,6038 & 53,7739 & 38,6733 \\
\hline & 2 & 35,6949 & 7,0318 & 8,1760 & 51,0997 & 41,8685 \\
\hline & 3 & 33,3492 & 7,2916 & 7,7429 & 48,3933 & 44,3151 \\
\hline & 4 & 35,8177 & 7,1440 & 7,9092 & 49,4326 & 43,4235 \\
\hline & 5 & 31,5969 & 7,8579 & 8,8534 & 55,3337 & 36,8083 \\
\hline & 6 & 36,6003 & 7,2943 & 8,1374 & 50,8586 & 41,8471 \\
\hline & MW & 34,4428 & 7,3621 & 8,2371 & 51,4820 & 41,1560 \\
\hline & SD & 1,9038 & 0,2995 & 0,4195 & 2,6216 & 2,8696 \\
\hline \multirow[t]{8}{*}{ THR } & 1 & 35,2992 & 7,5774 & 8,6061 & 53,7883 & 38,6343 \\
\hline & 2 & 36,1408 & 6,7104 & 8,0576 & 50,3603 & 42,9293 \\
\hline & 3 & 35,4856 & 7,4076 & 8,2529 & 51,5807 & 41,0116 \\
\hline & 4 & 35,0930 & 7,1849 & 8,4772 & 52,9824 & 39,8327 \\
\hline & 5 & 34,5894 & 7,6983 & 8,4425 & 52,7655 & 39,5363 \\
\hline & 6 & Ausreißer & & & & \\
\hline & MW & 35,3216 & 7,3157 & 8,3673 & 52,2954 & 40,3888 \\
\hline & SD & 0,5672 & 0,3895 & 0,2143 & 1,3395 & 1,6550 \\
\hline \multirow[t]{8}{*}{ TRP } & 1 & 33,8467 & 7,7143 & 8,7069 & 54,4181 & 37,8675 \\
\hline & 2 & 36,2726 & 7,1535 & 8,2903 & 51,8142 & 41,0324 \\
\hline & 3 & 35,1254 & 8,1570 & 8,7091 & 54,4317 & 37,4112 \\
\hline & 4 & 33,3826 & 7,8509 & 8,9391 & 55,8692 & 36,2799 \\
\hline & 5 & 34,6536 & 7,1183 & 8,3709 & 52,3179 & 40,5638 \\
\hline & 6 & 35,4544 & 6,8217 & 8,3050 & 51,9065 & 41,2718 \\
\hline & MW & 35,8948 & 7,0175 & 8,1760 & 51,1002 & 41,8822 \\
\hline & SD & 0,9145 & 0,5350 & 0,2834 & 1,7712 & 2,1882 \\
\hline \multirow[t]{8}{*}{$\mathrm{ARG}$} & 1 & 36,9636 & 7,0676 & 7,8477 & 49,0482 & 43,8841 \\
\hline & 2 & 37,2477 & 6,5121 & 7,7162 & 48,2262 & 45,2618 \\
\hline & 3 & 36,1062 & 7,3297 & 8,2811 & 51,7571 & 40,9132 \\
\hline & 4 & 34,8140 & 7,6758 & 8,3446 & 52,1539 & 40,1703 \\
\hline & 5 & 35,8292 & 7,1991 & 8,3052 & 51,9077 & 40,8933 \\
\hline & 6 & 38,5997 & 6,8247 & 7,6324 & 47,7028 & 45,4725 \\
\hline & MW & 36,5934 & 7,1015 & 8,0212 & 50,1326 & 42,7659 \\
\hline & SD & 1,3098 & 0,4041 & 0,3247 & 2,0293 & 2,3867 \\
\hline \multirow[t]{8}{*}{ ILE } & 1 & 35,0638 & 8,0606 & 8,3350 & 52,0938 & 39,8456 \\
\hline & 2 & 36,0726 & 7,1837 & 7,9333 & 49,5830 & 43,2332 \\
\hline & 3 & 34,4667 & 7,9261 & 8,5956 & 53,7224 & 38,3516 \\
\hline & 4 & 34,3747 & 7,5618 & 8,6709 & 54,1931 & 38,2451 \\
\hline & 5 & 35,1826 & 7,5254 & 8,4048 & 52,5298 & 39,9447 \\
\hline & 6 & 36,0036 & 7,6118 & 8,2794 & 51,7463 & 40,6419 \\
\hline & MW & 35,1940 & 7,6449 & 8,3698 & 52,3114 & 40,0437 \\
\hline & SD & $\mathbf{0 , 7 2 7 3}$ & 0,3120 & 0,2618 & 1,6365 & 1,8264 \\
\hline \multirow[t]{8}{*}{ VAL } & 1 & 37,1382 & 6,5032 & 8,1411 & 50,8819 & 42,6149 \\
\hline & 2 & 36,2943 & 6,7075 & 7,8447 & 49,0294 & 44,2632 \\
\hline & 3 & 35,0413 & 7,7801 & 8,4466 & 52,7912 & 39,4287 \\
\hline & 4 & 34,7322 & 7,1493 & 8,5323 & 53,3268 & 39,5240 \\
\hline & 5 & 36,4849 & 6,4983 & 7,8777 & 49,2356 & 44,2662 \\
\hline & 6 & 35,6779 & 7,4669 & 8,2138 & 51,3365 & 41,1966 \\
\hline & MW & 35,8948 & 7,0175 & 8,1760 & 51,1002 & 41,8822 \\
\hline & SD & 0,9145 & 0,5350 & 0,2834 & 1,7712 & 2,1882 \\
\hline
\end{tabular}


Tabelle A 37: Anfangs- und Endmasse, Futteraufnahme, Zuwachs und Futteraufwand, Versuch 10

\begin{tabular}{|c|c|c|c|c|c|c|}
\hline Diät & $\begin{array}{c}\text { Tiernum } \\
\text { mer }\end{array}$ & $\begin{array}{l}\text { Anfangs- } \\
\text { masse (g) }\end{array}$ & $\begin{array}{c}\text { End- } \\
\text { masse (g) }\end{array}$ & $\begin{array}{c}\text { Futteraufnahme } \\
(\mathrm{g} / \mathrm{d})\end{array}$ & $\begin{array}{c}\text { Zuwachs } \\
\text { (g/d) }\end{array}$ & $\begin{array}{c}\begin{array}{c}\text { Futteraufwan } \\
\text { d (g/g) }\end{array} \\
\end{array}$ \\
\hline \multicolumn{7}{|c|}{ Starterperiode (1 - 3 Woche) } \\
\hline \multirow[t]{8}{*}{$\mathrm{BC}$} & 1 & 44,70 & 1244,67 & 66,99 & 57,14 & 1,17 \\
\hline & 2 & 45,00 & 1176,90 & 67,58 & 53,90 & 1,25 \\
\hline & 3 & 45,20 & 1167,70 & 66,00 & 53,45 & 1,23 \\
\hline & 4 & 45,20 & 1189,50 & 69,37 & 54,49 & 1,27 \\
\hline & 5 & 45,10 & 1117,90 & 64,33 & 51,09 & 1,26 \\
\hline & 6 & 45,00 & 1172,50 & 64,79 & 53,69 & 1,21 \\
\hline & MW & 45,03 & 1178,2 & 66,51 & 53,96 & 1,23 \\
\hline & $\mathrm{SD}$ & 0,19 & 40,82 & 1,87 & 1,95 & 0,04 \\
\hline \multirow{8}{*}{ LYS } & 1 & 45,10 & 550,00 & 41,56 & 24,04 & 1,73 \\
\hline & 2 & 45,10 & 629,30 & 44,27 & 27,82 & 1,59 \\
\hline & 3 & 45,00 & 575,10 & 43,11 & 25,24 & 1,71 \\
\hline & 4 & 45,10 & 483,89 & 52,20 & 20,89 & 2,50 \\
\hline & 5 & 44,90 & 562,30 & 45,77 & 24,64 & 1,86 \\
\hline & 6 & 44,80 & 575,30 & 49,15 & 25,26 & 1,95 \\
\hline & MW & 45,00 & 562,65 & 46,02 & 24,65 & 1,89 \\
\hline & $\mathrm{SD}$ & 0,13 & 47,16 & 3,97 & 2,25 & 0,32 \\
\hline \multirow{8}{*}{ TRP } & 1 & 45,00 & 807,50 & 47,56 & 36,31 & 1,31 \\
\hline & 2 & 45,00 & 863,10 & 49,36 & 38,96 & 1,27 \\
\hline & 3 & 45,00 & 740,00 & 43,20 & 33,10 & 1,31 \\
\hline & 4 & 45,00 & 859,20 & 54,06 & 38,77 & 1,39 \\
\hline & 5 & 44,90 & 734,40 & 48,29 & 32,83 & 1,47 \\
\hline & & 45,30 & 890,60 & 52,13 & 40,25 & 1,30 \\
\hline & MW & 45,03 & $\mathbf{8 1 5 , 8 0}$ & 49,12 & 36,70 & 1,34 \\
\hline & SD & 0,14 & 66,57 & 3,79 & 3,14 & 0,08 \\
\hline \multirow{8}{*}{ ARG } & 1 & 45,40 & 781,00 & 45,78 & 35,03 & 1,31 \\
\hline & 2 & 45,00 & 807,30 & 48,22 & 36,30 & 1,33 \\
\hline & 3 & 44,90 & 825,00 & 48,39 & 37,15 & 1,30 \\
\hline & 4 & 44,90 & 823,90 & 51,04 & 37,10 & 1,38 \\
\hline & 5 & 45,00 & 806,70 & 52,53 & 36,27 & 1,45 \\
\hline & & 44,60 & 875,25 & 53,73 & 39,55 & 1,36 \\
\hline & MW & 44,97 & $\mathbf{8 1 9 , 8 7}$ & 49,93 & 36,90 & 1,35 \\
\hline & SD & 0,26 & 31,49 & 2,98 & 1,72 & 0,05 \\
\hline \multirow[t]{8}{*}{ ILE } & 1 & 45,70 & 660,30 & 37,51 & 29,27 & 1,28 \\
\hline & 2 & 45,00 & 702,90 & 42,63 & 31,33 & 1,36 \\
\hline & 3 & 44,80 & 802,30 & 46,43 & 36,07 & 1,29 \\
\hline & 4 & 45,00 & 815,60 & 48,11 & 36,70 & 1,31 \\
\hline & 5 & 44,80 & 783,40 & 46,47 & 35,17 & 1,32 \\
\hline & 6 & 44,70 & 702,80 & 50,42 & 31,34 & 1,61 \\
\hline & MW & 45,00 & 744,55 & 45,25 & 33,31 & 1,36 \\
\hline & SD & 0,36 & 63,98 & 4,57 & 3,25 & 0,12 \\
\hline \multirow{8}{*}{ VAL } & 1 & 44,90 & 700,10 & 42,19 & 31,20 & 1,35 \\
\hline & 2 & 45,20 & 887,20 & 47,32 & 40,10 & 1,18 \\
\hline & 3 & 45,10 & 737,00 & 41,47 & 32,95 & 1,26 \\
\hline & 4 & 45,00 & 776,80 & 44,96 & 34,85 & 1,29 \\
\hline & 5 & 45,00 & 588,30 & 40,61 & 25,87 & 1,57 \\
\hline & 6 & 44,80 & 934,22 & 51,74 & 42,35 & 1,22 \\
\hline & MW & 45,00 & 770,60 & 44,72 & 34,55 & 1,31 \\
\hline & SD & 0,14 & 126,28 & 4,22 & 5,89 & 0,14 \\
\hline
\end{tabular}




\begin{tabular}{|c|c|c|c|c|c|c|}
\hline Diät & $\begin{array}{c}\text { Tiernum } \\
\text { mer }\end{array}$ & $\begin{array}{l}\text { Anfangs- } \\
\text { masse (g) }\end{array}$ & $\begin{array}{c}\text { End- } \\
\text { masse (g) }\end{array}$ & $\begin{array}{c}\text { Futteraufnahme } \\
\text { (g/d) }\end{array}$ & $\begin{array}{c}\text { Zuwachs } \\
\text { (g/d) }\end{array}$ & $\begin{array}{c}\text { Futteraufwan } \\
\text { d (g/g) }\end{array}$ \\
\hline \multicolumn{7}{|c|}{ Growerperiode (3 - 5 Woche) } \\
\hline \multirow[t]{8}{*}{$\mathrm{BC}$} & 1 & 1129,13 & 2569,75 & 161,47 & 102,90 & 1,57 \\
\hline & 2 & 1130,75 & 2731,13 & 173,67 & 114,31 & 1,52 \\
\hline & 3 & 1137,50 & 2743,25 & 178,34 & 114,70 & 1,55 \\
\hline & 4 & 1141,75 & 2545,88 & 182,09 & 100,29 & 1,82 \\
\hline & 5 & 1110,63 & 2628,38 & 170,50 & 108,41 & 1,57 \\
\hline & 6 & 1130,25 & 2756,50 & 172,32 & 116,16 & 1,48 \\
\hline & MW & 1178,20 & 2662,50 & 173,07 & 109,47 & 1,59 \\
\hline & SD & 40,82 & 93,19 & 7,08 & 6,70 & 0,12 \\
\hline \multirow{8}{*}{ LYS } & 1 & 1138,50 & 2525,29 & 169,27 & 99,06 & 1,71 \\
\hline & 2 & 1118,13 & 2397,25 & 154,40 & 91,37 & 1,69 \\
\hline & 3 & 1118,50 & 2567,38 & 173,96 & 103,49 & 1,68 \\
\hline & 4 & 1130,63 & 2479,75 & 165,47 & 96,37 & 1,72 \\
\hline & 5 & 1140,63 & 2477,50 & 161,09 & 95,49 & 1,69 \\
\hline & 6 & 1129,38 & 2545,50 & 172,13 & 101,15 & 1,70 \\
\hline & MW & 562,65 & 2498,80 & 166,07 & 97,85 & 1,70 \\
\hline & $\mathrm{SD}$ & 47,16 & 61,17 & 7,36 & 4,33 & 0,01 \\
\hline \multirow[t]{8}{*}{ THR } & 1 & 1130,00 & 2499,00 & 163,53 & 97,79 & 1,67 \\
\hline & 2 & 1129,50 & 2425,63 & 162,91 & 92,58 & 1,76 \\
\hline & 3 & 1131,00 & 2525,63 & 168,76 & 99,62 & 1,69 \\
\hline & 4 & 1129,38 & 2600,43 & 171,77 & 105,08 & 1,63 \\
\hline & 5 & 1130,00 & 2627,75 & 174,91 & 106,98 & 1,63 \\
\hline & 6 & 1145,63 & 2492,63 & 164,50 & 96,21 & 1,71 \\
\hline & MW & 777,28 & 2528,50 & 167,73 & 99,72 & 1,68 \\
\hline & SD & 109,61 & 74,55 & 4,91 & 5,45 & 0,05 \\
\hline \multirow[t]{8}{*}{ TRP } & 1 & 1131,63 & 2607,00 & 166,98 & 105,38 & 1,58 \\
\hline & 2 & 1118,88 & 2492,71 & 160,33 & 98,13 & 1,63 \\
\hline & 3 & 1129,13 & 2669,75 & 174,28 & 110,04 & 1,58 \\
\hline & 4 & 1159,38 & 2520,43 & 165,64 & 97,22 & 1,70 \\
\hline & 5 & 1130,00 & 2702,57 & 176,29 & 112,33 & 1,57 \\
\hline & 6 & 1130,50 & 2570,14 & 166,82 & 102,83 & 1,62 \\
\hline & MW & 815,80 & 2593,77 & 168,38 & 104,30 & 1,61 \\
\hline & SD & 66,57 & 82,41 & 5,92 & 6,14 & 0,05 \\
\hline \multirow[t]{8}{*}{ ARG } & 1 & 1127,50 & 2594,38 & 171,58 & 104,78 & 1,64 \\
\hline & 2 & 1140,00 & 2677,14 & 177,62 & 109,80 & 1,62 \\
\hline & 3 & 1123,50 & 2529,83 & 167,16 & 100,45 & 1,66 \\
\hline & 4 & 1133,43 & 2513,29 & 169,37 & 98,56 & 1,72 \\
\hline & 5 & 1143,75 & 2540,13 & 168,56 & 99,74 & 1,69 \\
\hline & & 1138,38 & 2542,50 & 169,27 & 100,29 & 1,69 \\
\hline & MW & 819,87 & 2566,20 & 170,62 & 102,28 & 1,67 \\
\hline & SD & 31,49 & 60,76 & 3,71 & 4,25 & 0,04 \\
\hline \multirow[t]{8}{*}{ ILE } & 1 & 1133,14 & 2389,83 & 158,46 & 89,76 & 1,77 \\
\hline & 2 & 1141,88 & 2469,14 & 154,10 & 94,80 & 1,63 \\
\hline & 3 & 1124,25 & 2298,50 & 152,49 & 83,88 & 1,82 \\
\hline & 4 & 1144,25 & 2341,29 & 156,98 & 85,50 & 1,84 \\
\hline & 5 & 1130,00 & 2231,00 & 144,02 & 78,64 & 1,83 \\
\hline & 6 & 1134,13 & 2192,71 & 144,05 & 75,61 & 1,91 \\
\hline & MW & 744,55 & 2320,40 & 151,70 & 84,70 & 1,80 \\
\hline & SD & 63,98 & 102,12 & 6,29 & 7,06 & 0,09 \\
\hline \multirow[t]{8}{*}{ VAL } & 1 & 1128,57 & 2257,29 & 164,65 & 80,62 & 2,04 \\
\hline & 2 & 1129,63 & 2386,63 & 160,90 & 89,79 & 1,79 \\
\hline & 3 & 1141,63 & 2262,00 & 155,99 & 80,03 & 1,95 \\
\hline & 4 & 1126,43 & 2286,29 & 162,26 & 82,85 & 1,96 \\
\hline & 5 & 1130,25 & 2358,50 & 157,78 & 87,73 & 1,80 \\
\hline & 6 & 1137,71 & 2402,00 & 167,84 & 90,31 & 1,86 \\
\hline & MW & 770,60 & 2325,45 & 161,58 & 85,20 & 1,90 \\
\hline & SD & 126,28 & 64,64 & 4,35 & 4,63 & 0,10 \\
\hline
\end{tabular}




\section{Danksagung}

An dieser Stelle möchte ich Herrn Prof. Dr. F. Liebert für die Überlassung des Themas sowie für die wissenschaftliche Betreuung im Verlauf der Promotionsarbeit danken.

Frau Prof. Dr. E. Pawelzik vom Institut für Agrikulturchemie danke ich herzlich für die Übernahme des Korreferates.

Besonders möchte ich mich bei Herrn Dr. habil. Wecke für seine freundliche Unterstützung bei der Durchführung der Tierversuche sowie bei der Korrektur der vorliegenden Arbeit bedanken.

Ich danke auch Frau Marbell für ihre vielfältige Hilfe während der ganzen Promotionszeit.

Allen Mitarbeiterinnen und Mitarbeitern des Institutes für Tierphysiologie und Tierernährung gilt mein herzlicher Dank für die tatkräftige Unterstützung bei der Durchführung der Versuche und Laborarbeiten, ohne deren Unterstützung und Hilfe diese Arbeit nicht zustande gekommen wäre.

Vielen Dank allen Freunden und Mitdoktoranden für ihre Unterstützung und aufmunternden Worte und Gesten. 